\title{
Cognitive dynamics of fluent reading and spelling development
}

Citation for published version (APA):

Vaessen, A. A. (2010). Cognitive dynamics of fluent reading and spelling development. [Doctoral Thesis, Maastricht University]. Datawyse / Universitaire Pers Maastricht. https://doi.org/10.26481/dis.20100423av

Document status and date:

Published: 01/01/2010

DOI:

10.26481/dis.20100423av

Document Version:

Publisher's PDF, also known as Version of record

\section{Please check the document version of this publication:}

- A submitted manuscript is the version of the article upon submission and before peer-review. There can be important differences between the submitted version and the official published version of record.

People interested in the research are advised to contact the author for the final version of the publication, or visit the DOI to the publisher's website.

- The final author version and the galley proof are versions of the publication after peer review.

- The final published version features the final layout of the paper including the volume, issue and page numbers.

Link to publication

\footnotetext{
General rights rights.

- You may freely distribute the URL identifying the publication in the public portal. please follow below link for the End User Agreement:

www.umlib.nl/taverne-license

Take down policy

If you believe that this document breaches copyright please contact us at:

repository@maastrichtuniversity.nl

providing details and we will investigate your claim.
}

Copyright and moral rights for the publications made accessible in the public portal are retained by the authors and/or other copyright owners and it is a condition of accessing publications that users recognise and abide by the legal requirements associated with these

- Users may download and print one copy of any publication from the public portal for the purpose of private study or research.

- You may not further distribute the material or use it for any profit-making activity or commercial gain

If the publication is distributed under the terms of Article $25 \mathrm{fa}$ of the Dutch Copyright Act, indicated by the "Taverne" license above, 


\title{
Cognitive dynamics of fluent reading and spelling development
}

\author{
Annieke Angelina Vaessen
}


(C) A. Vaessen, Maastricht 2010

ISBN 978-90-5278-933-0

Cover picture: Pietro Magni's marble statue of 'the reading girl', National Gallery of Art in Washington D.C. (picture retrieved from flickr).

Production: Datawyse | Universitaire Pers Maastricht 


\title{
Cognitive dynamics of fluent reading and spelling development
}

\author{
Proefschrift \\ Ter verkrijging van de graad van doctor aan de Universiteit Maastricht, \\ op gezag van de Rector Magnificus, Prof. mr. G. P. M. F. Mols, \\ volgens het besluit van het College van Decanen, \\ in het openbaar te verdedigen op vrijdag 23 april om 14.00 uur \\ door
}

Annieke Angelina Vaessen

Geboren op 30 September 1979 te Hoensbroek

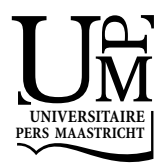




\section{Promotor}

Prof. dr. L. Blomert

Beoordelingscommissie

Prof. dr. B. Jansma (voorzitter)

Dr. L. Jonkman

Prof. dr. G. Schülte-Korne

Prof. dr. H. Wimmer 


\section{Table of contents}

$\begin{array}{ll}\text { Chapter 1: General Introduction } & 7\end{array}$

Chapter 2: Cognitive development of reading fluency 29

Chapter 3: Impact of orthographic consistency on the cognitive predictors of 61 reading skill in grade 2

Chapter 4: Impact of orthographic consistency on cognitive development of reading fluency

Chapter 5: Cognitive development of spelling skills

Chapter 6: Cognitive deficits underlying dyslexia: the double deficit hypothesis

Chapter 7: Summary and Discussion

Dankwoord

Curriculum Vitae 

Chapter 1

General Introduction 


\subsection{Overview}

In contrast to spoken language, written language is a recent cultural invention which did not exist until 5500 years ago (Rayner \& Pollatsek, 1989). Only a few centuries ago, the ability to read and write was a privilege of only a small percentage of the world population. Yet, nowadays the ability to decode, produce and understand written language is crucial for successful participation in our modern technologybased society (National Reading Counsil, 1998; Snowling, 2000). Literacy skills are not only important in educational settings but are used in almost every aspect of daily live. Insufficient literacy levels might lead to drop out at school, problems attaining and retaining a job, and consequently economic disadvantages and emotional distress. Therefore, it's essential to understand how literacy skills emerge, and why some people show persistent difficulties acquiring written language skills despite adequate education, sufficient intelligence and normal sensory functioning (i.e. developmental dyslexia).

Since the ability to encode and decode written language is an evolutionary 'new' human ability, requiring explicit instruction to emerge, it is improbable that the human brain contains a specialized 'literacy module'. Rather, during the acquisition of literacy skills, existing cognitive brain mechanisms in the visual and language domain will be recruited and specialized to serve as a network for reading and writing. Therefore, a prominent body of literacy research has focused on the basic cognitive processes underlying literacy skills. Many of these studies have concentrated on the initial phases of literacy acquisition in order to get more insight in which cognitive abilities are a prerequisite for learning to read and spell. However, the development of literacy involves a continuous progressive reorganization and specialization of relevant behavioral and brain systems into adulthood (Schlaggar \& McCandliss, 2007). Hence, to get a full picture of the development of fluent and effortless reading and spelling skills, it is highly relevant to investigate literacy acquisition in a wider developmental framework. Therefore, the main aim of this thesis is to investigate the cognitive development of reading and spelling skills in a sample ranging from beginning to experienced readers (chapter 2, 4 and 5). Moreover, since languages differ in their consistency of letter-speech sound mappings, and this orthographic consistency might modulate the organization of the reading system (Frost, 2005; Ziegler \& Goswami, 2005), we investigated the cognitive dynamics of reading in several languages varying in orthographic consistency (chapter 3 and 4). Finally, in chapter 6 , we focused on children with developmental dyslexia to investigate the impact of deficits in cognitive processing on literacy development. Before turning to the results of these studies, the themes that are relevant for this thesis will be shortly introduced in the current chapter. 


\subsection{Theories on reading development}

Although some languages like Chinese use symbols to represent complete words (logographic scripts), most modern languages use alphabetic scripts, in which individual speech sounds (phonemes) are represented by written symbols (graphemes). Each language consists of a limited number of these letter-speech sound units, which can be combined to create an indefinite amount of words (Perfetti \& Marron, 1998). The first crucial step when learning to read an alphabetic script is therefore to acquire basic understanding of the system that maps symbols and sounds (Ziegler \& Goswami, 2005).

At initial phases of reading acquisition, each grapheme of a written word has to be sequentially decoded into its corresponding phoneme. This phonological decoding process takes much time and effort in beginning readers. To achieve the high level of automatization which is the key characteristic of skilled reading, complete words and morphemes have to be linked directly to their phonological or semantic counterpart (Perfetti, 1985). Thus, the development of fluent reading involves a developmental shift from slow phonological decoding to automatic recognition of whole word forms (see Ehri, 2005 for an overview). This transition from slow, sequential performance to fast, automatized performance is not specific to reading but common to learning in all domains (Share, 2008). There are several theories on how this developmental shift in reading strategies works.

Stage-like theories of learning to read assume that children move through a sequence of stages (Ehri, 1995; Frith, 1985; Marsh, Friedman, Welsh, \& Desberg, 1981). For instance, (Frith, 1985) defines three stages: a logographic stage, in which words are recognized based on certain visual cues, an alphabetic stage, in which grapheme-phoneme rules are used to read words and non-words, and an orthographic stage, in which words are recognized as one unit. Ehri (1995; 2005) used a slightly different classification and preferred the term phases instead of stages because this lays less emphasis on how discrete the boundary is between stages. She proposes five stages: a pre-alphabetic stage, in which children only recognize some words based on visual cues, a partial alphabetic phase in which children know some letter-speech sound correspondences and may recognize words partially by phonetic cues and partially by contextual guessing, a full alphabetic phase, when children's knowledge of the alphabetic principle is complete and they are able to decipher new words, and a consolidates alphabetic phase, in which full connections are formed between morphographic units (e.g. words, morphemes, onsets) and their phonological and semantic counterparts. However, what these theories have in common is that they assume that children move from one phase/stage to a succeeding stage, and in each stage one reading strategy dominates.

In contrast, Share $(1999 ; 2008)$ proposes a more transitional, item-based perspective. According to the "self-teaching" model of Share (Jorm \& Share, 1983; 
Share, 1995) the development of efficient automatic word recognition skills crucially depends on successful phonological recoding of words. Consequently, the question whether a child uses phonological decoding or automatic word recognition to read a word does not so much depend on which stage a child is in, but more on whether an item is familiar. Every time a word is successfully decoded, an opportunity is provided to build up a word-specific orthographic representation (Ehri \& Saltmarsh, 1995; Reitsma, 1983), thus with increasing reading experience, a growing amount of words will transit from unfamiliar to familiar. Since children are more exposed to words that have a high frequency of occurrence, this transition probably takes place earlier in time for high-frequency than for low-frequency words. Skilled readers will probably recognize most existing words by sight, but very rare and new words will still require phonological decoding. Thus, rather than interpreting reading development as moving from a phonological stage to an 'orthographic' stage (e.g. Frith, 1985), reading development is placed in a continuous 'unfamiliar-tofamiliar/beginner-to-expert' framework (Share, 2008, p. 592). Therefore, in chapter 2 and 4 we investigate fluent reading development in a sample of children ranging from beginner to experienced reader, including words that vary in familiarity (pseudowords, low-frequency words, high-frequency words).

\subsection{Cognitive functions underlying literacy skills}

As previously mentioned, the brain probably does not contain an innate 'module' for reading and spelling, but builds upon existing language and visual cognitive processes. In this paragraph, three of these basic cognitive processes will be described; phonological processing, letter-speech sound processing and speeded naming of visual items.

Phonological processing - One of the most important and most extensively investigated cognitive reading-related processes is phonological awareness (PA), the ability to recognize, identify and manipulate speech sounds within a word (Goswami \& Bryant, 1990). Many studies have confirmed the strong connection between reading tasks and tasks that tap phonological processes (e.g. Bradley \& Bryant., 1983; Cardoso-Martins \& Pennington, 2004; Torgesen, Wagner, \& Rashotte, 1994; Torgesen, Wagner, Rashotte, Burgess, \& Hecht, 1997; Wagner, Torgesen, \& Rashotte, 1994). Yet, the direction of this relationship is disputed.

To start reading in an alphabetic script, a certain understanding of the sound structure of language seems crucial (Ziegler \& Goswami, 2005). However, the perception of phonemes (the smallest contrastive sound unit) does not appear to be an integral part of the human language system; preliterate levels of phonemic awareness are usually very low (e.g. Liberman, Shankweiler, Fischer, \& Carter, 1974), and adults that have never learned to read show great difficulties when executing pho- 
nemic awareness tasks (Morais, Bertelson, Cary, \& Alegria, 1986; Morais, Cary, Alegria, \& Bertelson, 1979). Thus, the awareness of phonemes, in contrast to the awareness of larger sound units, seems to arise only at the moment reading skill starts to emerge (Ziegler \& Goswami, 2005).

Thus, a certain level of phonological awareness (either at the phoneme level or at syllable/rime level) seems critical for the initial understanding of the written language system (e.g. Hulme, Snowling, Caravolas, \& Caroll, 2005; Lundberg, Frost, \& Peterson, 1991). At the same time, learning to read facilitates the understanding of the sound structure of words, resulting in a strong, reciprocal relationship between phonological awareness and reading (Perfetti, Beck, Bell, \& Hughes, 1987; Wagner \& Torgesen, 1987; Wimmer, Landerl, Linortner, \& Hummer, 1991; Ziegler \& Goswami, 2005). When investigating the cognitive dynamics of reading and spelling it is therefore indispensable to include measures of phonological awareness.

Letter-speech sound processing - Knowing which letter corresponds to which speech sound is the first crucial step in learning to read and spell in alphabetic languages (Ehri, 1998), and successful letter-speech sound decoding forms a basis for subsequent fluent reading skills (see paragraph 1.2). Several studies have shown a strong predictive relationship between preschool letter knowledge and reading performance in grade 1 (Lyytinen et al., 2001; Lyytinen et al., 2004; Pennington \& Lefly, 2001; Scarborough, 1990; Willems \& Blomert, submitted; Wimmer \& Hummer, 1990). Yet, the influence of letter-speech sound knowledge on successful reading at later developmental phases is less extensively investigated, probably because children are assumed to know which letter belongs to which sound after a relatively short period of reading instruction (Aarnoutse, van Leeuwe, \& Verhoeven, 2000; Hardy, Smythe, Stennet, \& Wilson, 1972; Siegel \& Faux, 1989). However, knowing the relationship between letters and sounds is not necessarily equivalent to the efficient use of this knowledge during reading. Evidence for this claim stems mainly from electrophysiological brain studies. For instance, Froyen et al. (Froyen, Van Atteveldt, Bonte, \& Blomert, 2008; Froyen, Bonte, van Atteveldt, \& Blomert, 2009) used a mismatch negativity paradigm (MMN) to examine the modulating influence of letters on speech sound processing. In adults, it was shown that the presence of a letter modulated the auditory MMN evoked by speech sounds in an early time window, which was interpreted as automatic integration of letters and speech sounds (Froyen et al., 2008). In contrast, beginning readers did not show any signs of early letter-speech sound integration even though they received one year of reading instruction and generally knew which letter belonged to which speech sound (Froyen et al., 2009). Moreover, even after four years of reading instruction, children did not show fully 'adult-like' letter-speech sound integration, indicating an ongoing development of letter-speech sound integration far beyond the initial stages of reading acquisition. In addition, a recent brain imaging study has found deviant brain activation in areas associated with the processing of letter-speech 
sound pairs in dyslexic children (Blau et al., in revision) and even in dyslexic adult readers (Blau, Atteveldt, Ekkebus, Goebel, \& Blomert, in press), suggesting that abnormal letter-speech sound integration might be a persistent manifestation of poor reading into adulthood. Therefore, even when examining cognitive reading development after the initial phases of reading acquisition, it seems highly relevant to include measures of efficiency of letter-speech sound processing (chapter 4 and 5 of this thesis).

Rapid automatized naming (RAN) - a third cognitive skill that has frequently been associated with reading skill is the fast, automatic naming of well known visual items such as letters, digits, objects and colors (RAN). Several studies have demonstrated RAN (especially alphanumeric RAN) to contribute to reading ability, over and above the influence of phonological awareness (Bowers \& Swanson, 1991; Felton \& Brown, 1990; Manis, Doi, \& Bhadha, 2000; Manis, Seidenberg, \& Doi, 1999; Wolf, 1986). Moreover, many dyslexic readers perform poorly on RAN tasks (for an overview see Wolf, Bowers, \& Biddle, 2000). Rapid naming seems to be related to slightly different aspects of literacy than phonological awareness. While phonological awareness is most strongly related to reading tasks requiring phonological decoding, such as pseudoword reading (Bowers, Sunseth, \& Golden, 1999; Cornwall, 1992; Manis et al., 2000; Manis et al., 1999; Torgesen et al., 1997) , RAN is mainly related to tasks that are thought to depend on visual word recognition, such as exception word reading (Bowers \& Swanson, 1991; Clarke, Hulme, \& Snowling, 2005; Wile \& Borowsky, 2004). The exact nature of the RAN-reading relationship is still under debate, as is the question whether RAN can be seen as independent from phonological processing (see paragraph 1.7 and chapter 6 of this thesis). The explanations of the RAN-reading relationship are numerous, and can be roughly divided into language-specific and domain-general explanations.

Domain general explanations assume that RAN problems are an index of broader cognitive deficits that affect both reading and non-language processes. For instance, Kail and Hall, (1994) have proposed that RAN links to reading speed as both tasks involve a general speed component. An alternative domain-general explanation has been offered in early work from Bowers and colleagues, who hypothesized that naming speed reflects the functioning of a general timing mechanism, and a disruption of this mechanism would cause a disturbance of temporal integration of visual and phonological information as well as timing-related deficits outside the language domain (Bowers \& Wolf, 1993; Wolf, 1991, 1997).

However, most research up to date is more in accordance with languagespecific interpretations of RAN (Savage, 2004). Some researchers have claimed that RAN reflects the retrieval of phonological codes from memory and in that sense is a phonological skill. Others have claimed that RAN is an index of orthographic skill (Bowers, Golden, Kennedy, \& Young, 1994; Levy, Bourassa, \& Horn, 1999; Savage, Pillay, \& Melidona, 2008), thus the ability to store and retrieve visual orthographic 
patterns. Again others have put emphasize on the fact that RAN, like reading, requires the matching of print and sound, and that the performance on RAN tasks is a manifestation of the ability to efficiently match visual/orthographic to phonological information (Berninger, Abbott, Billingsley, \& Nagy, 2001; Bowers \& Ishaik, 2003; Wimmer, Mayringer, \& Landerl, 1998) or the ability to form arbitrary associations between print and sound (Manis et al., 1999).

Despite the ongoing discussion about the exact nature of the RAN-reading relationship, RAN is a skill that contributes strongly and uniquely to reading performance and should therefore be included when investigating the cognitive development of fluent reading (chapter 2-6).

\subsection{Cognitive development of reading}

As described in detail in paragraph 1.2, the development of fluent reading skills is assumed to involve a gradual shift from slow sequential phonological decoding to fast, automatic word recognition (Ehri, 1995, 2005; Share, 1999, 2008). Since phonological awareness (PA) is thought to be more strongly associated with reading tasks requiring phonological decoding and RAN more strongly to reading tasks requiring orthographic word recognition (see paragraph 1.3), a concomitant shift in the relative importance of these cognitive skills might be expected. That is, cognitive skills underlying the ability to decode words letter-by-letter (e.g. PA) might be more important in the beginning stages of reading acquisition, when most written words are still unfamiliar, while cognitive skills associated with the ability to automatically recognize orthographic word patterns (like RAN) might only become relevant at later stages of reading acquisition. The results of several developmental studies in transparent orthographies and some English-language studies indeed suggest that the influence of PA decreases over time, while the influence of RAN is consistent or increases (e.g. Badian, 2001; Bast \& Reitsma, 1998; De Jong \& Van der Leij, 1999; Landerl \& Wimmer, 2008; Lervåg, Bråten, \& Hulme, 2009; Van den Bos, Zijlstra, \& lutje Spelberg, 2002). However, the declining relationship between PA and reading might also be a (partial) consequence of methodological factors. First, children learning to read in an transparent orthography often reach high levels of accuracy on phonological tasks after a short time of reading instruction, thus the statistical power of such tasks might be reduced (Patel, Snowling, \& de Jong, 2004) and correlations between PA and reading might be attenuated. Second, PA is traditionally measured with accuracy measures, while reading is always based on speeded measures in transparent orthographies, which might have caused an underestimation of the effect of PA (Georgiou, Parrila, Kirby, \& Stephenson, 2008; Share, 2008). Third, most studies that found a declining relationship between PA and reading examined the additional effect of (kindergarten) PA on subsequent 
reading level after prior reading level was taken into account. However, a failure to find an additional effect of PA does not necessarily mean that there is no association between PA and reading (De Jong \& Van der Leij, 2002; Lervåg et al., 2009). The autoregressive effect of reading is very powerful, so little variance is left to be explained by individual differences in cognitive skills (Stoolmiller \& Bank, 1995). To clarify this issue we therefore investigated the concurrent contributions of RAN and PA to fluent word reading in a large Dutch-speaking sample from grade 1 to grade 6 , including speeded measures for all variables (chapter 2). Furthermore, the reading task used in this study contained three types of words: high-frequency, lowfrequency and pseudowords, providing the possibility to study the cognitive development of fluent word reading in an unfamiliar-to-familiar/beginner-to-expert framework (see paragraph 1.2).

\subsection{Modulating influence of orthographic consistency}

Alphabetic languages strongly differ in their degree of consistency how letters map onto their corresponding speech sounds. In completely transparent orthographies, each letter corresponds to one phoneme and each phoneme corresponds to one grapheme. English, on the other hand, has extremely ambiguous letter-speech sound correspondences. The same letter can be pronounced in several ways (e.g., "a" in cat, saw, made, and car) and vise versa. English has been considered to be an 'outlier' orthography (Share, 2008), since most alphabetic orthographies have a much more consistent relationships between orthography and phonology. However, the relative transparency does vary between European languages; orthographies such as French and Portuguese are considered relatively opaque while for instance Hungarian and Finnish have a very consistent orthography (Borgwaldt, Hellwig, \& De Groot, 2005; Seymour, Aro, \& Erskine, 2003). Dutch is considered to be relatively transparent, comparable to for instance German ((Patel et al., 2004).

Orthographic consistency is thought to strongly influence the rate at which reading is acquired in a specific language (Seymour et al., 2003). In transparent orthographies, the correspondences between letters and sounds are easy to learn, and therefore, words can usually be correctly decoded after only a short period of reading instruction. However, when the orthographic system of a language is very complex and letters can be represented by multiple speech sounds, the acquisition of the basic principles of reading might take much more time and effort. A widescaled EU-research project comparing reading acquisition in 14 European countries has demonstrated that most children learning to read in a transparent orthography (e.g., Italian, German, Greek, Spanish, Finnish) reached ceiling levels on reading accuracy after one year of reading instruction (Seymour et al., 2003). In contrast, reading accuracy levels were lower (around $80 \%$ words were read correctly after 
the first grade) in less transparent languages (e.g., Portuguese, French, Danish). In English, the most extreme opaque orthography, children could read less than $40 \%$ of the words correct at end of grade 1 and reading accuracy performance was not even at ceiling after two years of reading instruction. Comparable effects have been found in other cross-linguistic comparisons (e.g. Bruck, Genesee, \& Caravolas, 1997; Ellis \& Large, 1987; Frith, Wimmer, \& Landerl, 1998; Goswami, Gombert, \& De Barrera, 1998; Goswami, Ziegler, \& Richardson, 2005).

It has been hypothesized that the orthographic consistency of a language not only influences the rate at which reading develops but also fundamentally affects the organization of the reading system. For instance, the orthographic depth hypothesis (Frost, 2005; Katz \& Frost, 1992) assumes that in opaque orthographies, in which many words cannot be read correctly using grapheme-phoneme decoding strategies, skilled readers have to rely heavily on orthographic word recognition, while skilled readers in transparent orthographies more heavily rely on phonological decoding. This would implicate that the relative importance of underlying cognitive skills is also modulated by orthographic consistency. The fact that (in contrast to what was found in more transparent orthographies, par 1.4.) several studies with English language learners found a strong, consistent influence of PA over time, and only a minor influence of RAN (e.g. Cardoso-Martins \& Pennington, 2004; Wagner et al., 1994) seems to support the assumption that the cognitive dynamics of reading is influenced by orthographic consistency. However, direct comparison of Englishlanguage studies with those conducted in transparent orthographies is complicated by the fact that most English-language studies have based reading performance on accuracy measures while studies in transparent languages use fluency measures. For the same reason that the role of accuracy based PA might be underestimated in transparent orthographies because speeded measures of reading are used (see par. 1.4), the role of (speeded) RAN in reading might be underestimated when using reading accuracy measures (Georgiou, Parrila et al., 2008; Share, 2008). Thus, in order to directly evaluate the modulating influence of orthographic consistency on the cognitive dynamics of reading acquisition, it is essential to directly compare languages with varying orthographic consistency using comparable measurement parameters.

Previous cross-linguistic comparisons have shown contrasting results. Mann and Wimmer (2002) and Georgiou, Parrila, and Papadopoulos (Georgiou, Parilla, \& Papadopoulos, 2008) reported that PA was more important when learning to read in English, while RAN was more important learning to read in Greek or German. However, Patel et al. (2004) and Caravolas, Volin and Hulme (2005) found equally important roles for PA and/or RAN in transparent and opaque orthographies. In chapter 3, we aimed to shed more light on this debate by examining the modulating influence of orthographic consistency on the cognitive dynamics of reading in 5 European writing systems lying on a continuum from transparent to less transpar- 
ent (Finnish, Hungarian, Dutch, Portuguese, French). Orthographic transparency was quantified using entropy computations for the initial letter-sound mappings in each language (Borgwaldt et al., 2005). In addition, in chapter 4 we more closely investigated the influence of onset entropy on the cognitive development of reading in grade 1 to 4 in three of the previously mentioned languages (Hungarian, Dutch, Portuguese) to test whether the assumed shift in the cognitive contributions to reading fluency (see par 1.4) is modulated by orthographic consistency.

\subsection{Cognitive development of spelling}

One of the most important literacy skills, next to reading, is spelling. With spelling, we refer to the ability to apply one's knowledge of phoneme-grapheme mappings, spelling rules, morphological rules or word-specific knowledge in order to correctly produce the correct spelling of a word. The acquisition of accurate spelling skills is assumed to be even a bigger challenge than the acquisition of reading skills. While reading 'only' requires the recognition of words or letter-patterns, spelling requires the active production of letters and words. Moreover, most alphabetic languages are more consistent in the script-to-speed sound direction than in the speech sound to script direction, thus there are more phonetically correct ways to spell than to read a word (Bosman \& Van Orden, 1997; Ehri, 1997).

Since reading and spelling both require the mapping of verbal language to written script and vise versa, it is likely that these skills at least partly build upon shared cognitive mechanisms. Some researchers have even suggested that reading and spelling are 'two sides of the same coin' (Ehri, 1997, 2000; Perfetti, 1997). However, others have postulated that spelling and reading, even though they will partly rely on common cognitive processes, will additionally build upon unique cognitive skills (e.g. Berninger, Cartwright, Yates, \& Swanson, 1994; Nikolopoulos, Goulandris, Hulme, \& Snowling, 2006; Shanahan, 1984).

In initial phases of literacy acquisition, spelling as well as reading is thought to heavily rely on phonological decoding and recoding skills (Ehri, 1997). In accordance with this view, several studies show that PA and letter-speech sound (LSS) knowledge predict spelling performance at least as well as it predicts reading performance at initial phases of literacy acquisition (Borzone de Manrique \& Signorini, 1994; Landerl \& Wimmer, 2008; Leppanen, Niemi, Aunola, \& Nurmi, 2006; Nikolopoulos et al., 2006; Stage \& Wagner, 1992; Strattman \& Hodson, 2005; Wimmer \& Hummer, 1990). However, the impact of these cognitive skills on reading and/or spelling performance might change developmentally. As stated before, theories of reading development assume children to increasingly rely on automatic visual word recognition thereby reducing the importance of phonological decoding skills for skilled reading (see par. 1.2 and 1.4). Similarly, stage-based models of spelling (Ehri, 1992; 
Frith, 1980; Marsh, Friedman, Welch, \& Desberg, 1980) assume that experienced predominately rely on word-specific knowledge or morphemic knowledge when spelling a word, possibly implying that individual differences in phonological recoding skills have little impact on spelling performance at later stages of spelling acquisition. In contrast, more interactive theories of spelling assume that children use a wide range of spelling strategies from early phases of spelling acquisition on and continue to adaptively use these strategies throughout development (Keuning \& Verhoeven, 2008; Snowling, 1994; Varnhagen, McCallum, \& Burstow, 1997). These models thus might imply that cognitive skills like PA and LSS knowledge, which are important at beginning phases of spelling acquisition, continue to exert an influence on spelling skills at later phases of spelling acquisition. Some developmental spelling studies have found a diminishing relationship between PA and spelling performance (Jongejan, Verhoeven, \& Siegel, 2007) but most studies found a stable influence of PA to spelling performance over years (e.g. Caravolas, Hulme, \& Snowling, 2001; Landerl \& Wimmer, 2008; Maki, Voeten, Vauras, \& Poskiparta, 2001; Stuart \& Masterson, 1992). To our knowledge, only one study investigated the impact of LSS knowledge on spelling after the first stages of spelling acquisition (Caravolas et al., 2001). This study showed that kindergarten LSS predicts spelling performance at least until grade 3 .

In contrast to the rather straightforward theoretical link between phonological awareness, letter-speech sound knowledge and spelling, the theoretical link between RAN and spelling is less apparent. Some researchers have claimed that RAN reflects the ability to build up orthographic representations (Bowers et al., 1994; Levy et al., 1999; Savage et al., 2008), implying that RAN should be related to spelling as well as reading. Others have claimed that RAN reflects a process that is mainly important for fluent word reading, e.g. the efficient mapping of orthographic word forms to phonological codes (e.g. Berninger et al., 2001; Bowers \& Ishaik, 2003). Studies focusing on the involvement of RAN in spelling show contrasting results; while some studies found a significant contribution of RAN to spelling performance (e.g. Plaza \& Cohen, 2004; Savage et al., 2008), others have failed to find any contribution of RAN to spelling performance (e.g. Cornwall, 1992; Landerl \& Wimmer, 2008; Nikolopoulos et al., 2006). A methodological factor that might complicate the comparison of the role of RAN in spelling and reading is the fact that reading is measured with speeded measures (at least in transparent orthographies) while spelling is always measured with accuracy measures in all orthographies. Since RAN is always a speeded measure, the role of RAN in reading might be accentuated and the role of RAN in spelling attenuated. In chapter 5 we therefore focused on the cognitive development of spelling in grade 1 to 6 , using speeded measures for all variables. Moreover, to shed more light on the relationship between the cognitive processes underlying spelling and the cognitive processes un- 
derlying reading, we examined which cognitive skills are shared and which are unique to spelling and reading at different levels of spelling expertise.

\subsection{Abnormal development of reading and spelling skills: dyslexia}

Even though understanding and producing written language is not an innate ability, most children manage to become fluent readers and spellers within a few years of reading instruction. Nevertheless, some readers show persistent difficulties in attaining adequate reading and spelling levels, despite normal intelligence, adequate educational instruction and normal sensory functioning (Lyon, Shaywitz, \& Shaywitz, 2003). These children, referred to as developmental dyslexics, are characterized by slow, inaccurate word reading and/or inadequate spelling skills. In a recent epidemiological study, the prevalence of dyslexia in the Netherlands was estimated at approximately $4 \%$ (Blomert, 2005).

Numerous studies have focused on the question which cognitive deficits underlie the reading and spelling problems in dyslexia. Initially, it was believed that developmental dyslexia was a result of visual perception deficits (which explains the original term 'congenital word blindness', Morgan, 1896). However, nowadays dyslexia is considered to be a verbal language disorder, originating from problems in phonological processing (Vellutino, 1979; Vellutino, Fletcher, Snowling, \& Scanlon, 2004). Instable or degraded phonological representations are thought to affect the establishment of letter-speech sound associations, which in turn lead to problems with reading and writing. A wealth of evidence supports this 'phonological deficit' hypothesis; First, dyslexics show low performance on a variety of phonological tasks (Beaton, 2004; Brady, 1997; Ramus et al., 2003), even in comparison to readingmatched controls (e.g. Sunseth \& Bowers, 2002) and non-dyslexic poor readers (Badian, 1994). In addition, early phonological deficiencies predict later reading and spelling disability (Bradley \& Bryant., 1983; Gathercole, Willis, \& Baddeley, 1991; Wagner \& Torgesen, 1987). Moreover, training focusing on improving phonological awareness has beneficial effects on reading and spelling abilities, especially when combined with training in letter-sound knowledge (Bus \& van IJzendoorn, 1999; Byrne \& Fielding-Barnsley, 1993, 1995; Hatcher, Hulme, \& Snowling, 2004).

However, dyslexics are not only characterized by impaired performance on phonological awareness tasks; many dyslexics also show problems with speeded naming of visual items (for an overview, see Wolf et al., 2000). It has proposed that impaired performance on RAN tasks is just another manifestation of a phonological processing deficit. That is, naming problems are supposed to reflect difficulties with the retrieval of phonological codes from memory. However, Wolf \& Bowers (Bowers 
\& Wolf, 1993; Wolf \& Bowers, 1999) have questioned the 'monopoly position' of phonological deficits as an explanatory construct for dyslexia; their 'double deficit' hypothesis acknowledges the existence of phonological deficits but postulates that impaired RAN performance might reflect a second, independent core deficit in dyslexia. In their view, reading problems in dyslexia might thus either be a consequence of a phonological deficit, a consequence of a naming deficit, or a combination of these two. The double deficit hypothesis has several important implications, not only for theories on dyslexia and reading development, but also at a practical level. If different subtypes of dyslexia exist, resulting from distinct underlying cognitive deficits and characterized by different reading and spelling patterns, it might not be sufficient to use one and the same therapy for all dyslexics. In other words, single naming deficit subtypes might require a different type of remediation than do single phonological subtypes.

The claim that naming problems represent a second core deficit independent from a phonological deficit brings about several predictions or assumptions (Vukovic \& Siegel, 2006). First, naming problems should contribute uniquely to literacy problems even when controlling for phonological problems. Second, a substantial amount of dyslexics should show naming problems in the absence of phonological problems. Third, performance on phonological awareness tasks and naming tasks ought to be relatively unrelated. And finally, since rapid naming and phonological awareness are thought to be related to different aspects of reading (see par. 1.3) children with a single naming deficit are supposed to show a different pattern of literacy problems than do children with a single phonological deficit. Children with a combined deficit (double deficit) are assumed to have most severe literacy problems because the consequences of the two deficits are additive. Previous studies showed inconsistent results regarding these double deficit assumptions. In chapter 6 , we therefore investigated the four assumptions of the double deficit hypothesis within-subject in a large sample of well-diagnosed dyslexics.

\subsection{Specific aims of the thesis}

In chapter 2, the cognitive development of reading fluency is investigated in a large Dutch school population ranging from beginning to experienced readers. Theories on reading development assume a shift from slow, sequential phonological decoding to fast automatic word recognition, and we hypothesized that this shift will be reflected in a concomitant shift in the contributions of PA and RAN to reading. Moreover, we included words that vary in frequency of occurrence (high-frequency, low-frequency and pseudo-words) since the acquisition of word-specific orthographic knowledge strongly depends on the frequency of exposure to a specific word. 
In chapter 3, we tested the modulating influence of orthographic consistency on the cognitive predictors of reading ability. In this study, second graders from five European countries with languages lying on a continuum from (almost) completely transparent to relatively opaque are included (Finnish, Hungarian, Dutch, Portuguese and French).

In chapter 4, the influence of orthographic consistency on cognitive reading development is investigated in more detail in three of the five languages (Hungarian, Dutch, and Portuguese). In this study, we examined whether the cognitive shift found in Dutch readers (chapter 2) could also be observed in other orthographies, and whether orthographic consistency influenced the rate at which this cognitive shift occurred.

Chapter 5 focused on the cognitive development of spelling. We examined whether the cognitive dynamics of spelling followed the same developmental course as was found for reading (chapter 2 ) and which cognitive skills underlie the relationship between reading and spelling.

Finally, in chapter 6 we investigated the cognitive deficits associated with developmental dyslexia. More specifically, we investigated whether naming problems represent a second core deficit in dyslexia, independent of phonological deficits. 


\section{References}

Aarnoutse, C., van Leeuwe, J., \& Verhoeven, L. (2000). Ontwikkeling van beginnende geletterdheid [development of beginning literacy]. Pedagogische Studiën, 77, 307 - 325.

Badian, N. A. (1994). Do dyslexic and other poor readers differ in reading related cognitive skills? Reading and Writing: An Interdisciplinary Journal, 6(45-63).

Badian, N. A. (2001). Phonological and orthographic processing: Their roles in reading prediction. Annals of Dyslexia, 51, 179-202.

Bast, J., \& Reitsma, P. (1998). Analyzing the development of individual differences in terms of Matthew effects in reading: Results from a Dutch longitudinal study. Developmental Psychology, 34(6), 13731399.

Beaton, A. A. (2004). Dyslexia, reading and the brain: A sourcebook of psychological and biological research. New York: Psychology Press.

Berninger, V. W., Abbott, R. D., Billingsley, F., \& Nagy, W. (2001). Processes underlying timing and fluency: efficiency, automaticity, coordination and morphological awareness. In M. Wolf (Ed.), Dyslexia, fluency and the brain (pp. 383-414). Timonium, MD: York Press.

Berninger, V. W., Cartwright, A. C., Yates, C. M., \& Swanson, H. L. (1994). Developmental skills related to writing and reading acquisition in the intermediate grades: Shared and unique functional systems. Reading and Writing, 6(2), 161-196.

Blau, V., Atteveldt, N., Ekkebus, M., Goebel, R., \& Blomert, L. (in press). Reduced neural integration of letters and speech sounds links phonological and reading deficits in adult dyslexia. Current Biology.

Blau, V., Reitler, J., Van Atteveldt, N., Gerretsen, P., Seitz, J., Goebel, R., et al. (in revision). deviant processing of letters and speech sounds as proximate cause of reading failure: an fMRI study of dyslexic children.

Blomert, L. (2005). Dyslexie in Nederland - theorie, praktijk en beleid [Dyslexia in The Netherlands - theory, practice and policy]. Amsterdam: Nieuwezijds Publishers.

Borgwaldt, S. R., Hellwig, F. M., \& De Groot, A. M. B. (2005). Onset entropy matters - Letter-to-phoneme mappings in seven languages. Reading and Writing, 18, 211-229.

Borzone de Manrique, A. M., \& Signorini, A. (1994). Phonological awareness, spelling and reading abilities in Spanish-speaking children. British Journal of Educational Psychology, 64(3), 429-439.

Bosman, A. M. T., \& Van Orden, G. C. (1997). Why spelling is more difficult than reading. In C. A. Perfetti, L. Rieben \& M. Fayol (Eds.), Learning to spell: Research, theory, and practice across languages. (pp. 173-194). Mahwah, NJ, US: Lawrence Erlbaum Associates Publishers.

Bowers, P. G., Golden, J., Kennedy, A., \& Young, A. (1994). Limits upon orthographic knowledge due to processes indexed by naming speed. In V. W. Berninger (Ed.), The varieties of orthographic knowledge I: Theoretical and developmental issues. Dordrecht, The Netherlands: Kluwer Academic Publishers.

Bowers, P. G., \& Ishaik, G. (2003). RAN's contribution to understanding reading disabilities. In S. Graham, H. Swanson \& K. R. Lee Harris (Eds.), Handbook of learning disabilities (pp. 140-157). New York, US: Guilford Press.

Bowers, P. G., Sunseth, K., \& Golden, J. (1999). The route between rapid naming and reading progress. Scientific Studies of Reading, 3(1), 31-53. 
Bowers, P. G., \& Swanson, L. B. (1991). Naming speed deficits in reading disability: Multiple measures of a singular process. Journal of Experimental Child Psychology, 51(2), 195-219.

Bowers, P. G., \& Wolf, M. (1993). Theoretical links among naming speed, precise timing mechanisms and orthographic skill in dyslexia. Reading and Writing, 5(1), 69-85.

Bradley, L., \& Bryant., P. E. (1983). Categorizing sounds and learning to read - a causal connection. Nature, 301, 419-421.

Brady, S. A. (1997). Ability to encode phonological representations: and underlying difficulty of poor readers. . In B. A. Blachman (Ed.), Foundations of reading acquisition and dyslexia: Implications for early intervention (pp. 21-47). Mahwah, NJ: Lawrence Erlbaum Associates.

Bruck, M., Genesee, F., \& Caravolas, M. (1997). A cross-linguistic study of early literacy acquisition. In B. A. Blachman (Ed.), Foundations of reading acquisition and dyslexia: Implications for early intervention. Mahwah, NJ: Lawrence Erlbaum Associates.

Bus, A. G., \& van IJzendoorn, M. H. (1999). Phonological awareness and early reading: A meta-analysis of experimental training studies. Journal of Educational Psychology, 91(3), 403-414.

Byrne, B., \& Fielding-Barnsley, R. (1993). Evaluation of a program to teach phonemic awareness to young children: A 1-year follow-up. Journal of Educational Psychology, 85(1), 104-111.

Byrne, B., \& Fielding-Barnsley, R. (1995). Evaluation of a program to teach phonemic awareness to young children: A 2- and 3-year follow-up and a new preschool trial. Journal of Educational Psychology, $87(3), 488-503$.

Caravolas, M., Hulme, C., \& Snowling, M. J. (2001). The foundations of spelling ability: Evidence from a 3year longitudinal study. Journal of Memory and Language, 45(4), 751-774.

Caravolas, M., Volin, J., \& Hulme, C. (2005). Phoneme awareness is a key component of alphabetic literacy skills in consistent and inconsistent orthographies: evidence from Czech and English children. Journal of Experimental Child Psychology, 92, 107-139.

Cardoso-Martins, C., \& Pennington, B. F. (2004). The relationship between phoneme awareness and rapid serial naming skills and literacy acquisition: The role of developmental period and reading ability. Scientific Studies of Reading, 8(1), 27-52.

Clarke, P., Hulme, C., \& Snowling, M. (2005). Individual differences in RAN and reading: A response timing analysis. Journal of Research in Reading, 28(2), 73-86.

Cornwall, A. (1992). The relationship of phonological awareness, rapid naming, and verbal memory to severe reading and spelling disability. Journal of Learning Disabilities, 25(8), 532-538.

De Jong, P. F., \& Van der Leij, A. (1999). Specific Contributions of Phonological Abilities to Early Reading Acquisition: Results From a Dutch Latent Variable Longitudinal Study. Journal of Educational Psychology, 91(3), 450-476.

De Jong, P. F., \& Van der Leij, A. (2002). Effects of phonological abilities and linguistic comprehension on the development of reading. Scientific Studies of Reading, 6(1), 51-77.

Ehri, L. C. (1992). Review and commentary: Stages of spelling development. In S. Templeton \& D. Bear (Eds.), Development of Orthographic Knowledge and the Foundations of Literacy: A Memorial Festschrift for Edmund H. Henderson (pp. 307-332). Hillsdale, N.J.: Erlbaum.

Ehri, L. C. (1995). Phases of development in learning to read words by sight. Journal of Research in Reading, 18, 116-125. 
Ehri, L. C. (1997). Learning to read and learning to spell are one and the same, almost. In C. A. Perfetti, L. Rieben \& M. Fayol (Eds.), Learning to spell: research, theory, and practice across languages (pp. 237269). Mahwah, NJ, US: Lawrence Erlbaum Associates.

Ehri, L. C. (1998). Grapheme-phoneme knowledge is essential to learning to read words in English. In J. L. Metsala \& L. C. Ehri (Eds.), Word recognition in beginning literacy (pp. 3-40). Mahwah, NJ, US: Lawrence Erlbaum Associates Publishers.

Ehri, L. C. (2000). Learning to read and learning to spell: Two sides of a coin. Topics in Language Disorders, 20 (3)(19-36).

Ehri, L. C. (2005). Development of sight word reading: Phases and findings. In M. J. Snowling \& C. Hulme (Eds.), The Science of Reading: A Handbook (pp. 135-154). Oxford: Blackwell publishing.

Ehri, L. C., \& Saltmarsh, J. (1995). Beginning readers ourperform older disabled readers in learning to read words by sight. Reading and Writing, 7, 295-326.

Ellis, N., \& Large, B. (1987). The development of reading: as you seek so shall you find. British Journal of Psychology, 78, 1-28.

Felton, R. H., \& Brown, I. S. (1990). Phonological processes as predictors of specific reading skills in children at risk for reading failure. Reading and Writing: An Interdisciplinary Journal, 2(1), 39-59.

Frith, U. (1980). Unexpected spelling problems. In U. Frith (Ed.), Cognitive Processes in Spelling (pp. 495515). London: Academic Press.

Frith, U. (1985). Beneath the surface of developmental dyslexia. . In K. E. Patterson, J. C. Marshhall \& M. Coltheart (Eds.), Surface Dyslexia (pp. 301-322). London: Erlbaum.

Frith, U., Wimmer, H., \& Landerl, K. (1998). Differences in phonological recoding in German- and Englishspeaking children. Scientific Studies of Reading, 2, 31-54.

Frost, R. (2005). Orthographic systems and skilled word recognition processes in reading. In M. J. Snowling \& C. Hulme (Eds.), The science of reading (pp. 272-295).

Froyen, D., Van Atteveldt, N., Bonte, M., \& Blomert, L. (2008). Cross-modal enhancement of the MMN to speech-sounds indicates early and automatic integration of letters and speech-sounds. Neuroscience Letters, 430(1), 23-28.

Froyen, D. J., Bonte, M. L., van Atteveldt, N., \& Blomert, L. (2009). The long road to automation: neurocognitive development of letter-speech sound processing. Journal of Cognitive Neuroscience, 21(3), 567-580.

Gathercole, S. E., Willis, C., \& Baddeley, A. D. (1991). Differentiating phonological memory and awareness of rhyme: Reading and vocabulary development in children. Britisch journal of Pscyhology, 82, 387406.

Georgiou, G. K., Parilla, R., \& Papadopoulos, T. C. (2008). Predictors of word decoding and reading fluency across languages varying in orthographic consistency. Journal of Educational Psychology, 100, 566-580.

Georgiou, G. K., Parrila, R., Kirby, J. R., \& Stephenson, K. (2008). Rapid naming components and their relationship with phonological awareness, orthographic knowledge, speed of processing, and different reading outcomes. Scientific Studies of Reading, 12(4), 325-350.

Goswami, U., \& Bryant, P. (1990). Phonological skills and learning to read. Hove, UK: Lawrence Erlbaum. 
Goswami, U., Gombert, J. E., \& De Barrera, L. F. (1998). Children's orthographic representations and linguistic transparency: Nonsense word reading in English, French, and Spanish. Applied Psycholinguistics, 19, 19-52.

Goswami, U., Ziegler, J. C., \& Richardson, U. (2005). The effects of spelling consistency on phonological awareness: A comparison of English and German. Journal of Experimental Child Psychology, 92, 345365.

Hardy, M. H., Smythe, P. C., Stennet, R. G., \& Wilson, H. R. (1972). Developmental patterns in elemental reading skills: phoneme-grapheme and grapheme-phoneme correspondences. Journal of Educational Psychology, 63, 433-436.

Hatcher, P. J., Hulme, C., \& Snowling, M. J. (2004). Explicit phoneme training combined with phonic reading instruction helps young children at risk of reading failure. Journal of Child Psychology and Psychiatry, 45(2), 338-358.

Hulme, C., Snowling, M., Caravolas, M., \& Caroll, J. (2005). Phonological skills are (probably) one cause of succes in learning to read: a commont on Castles and Coltheart. Scientific Studies of Reading, 9, 351365.

Jongejan, W., Verhoeven, L., \& Siegel, L. S. (2007). Predictors of reading and spelling abilities in first- and second-language learners. Journal of Educational Psychology, 99(4), 835-851.

Jorm, A. F., \& Share, D. L. (1983). Phonological recoding and reading acquisition. Applied Psycholinguistics, 4, 103-147.

Kail, R., \& Hall, L. K. (1994). Processing speed, naming speed, and reading. Developmental Psychology, 30(6), 949-954.

Katz, L., \& Frost, R. (1992). The reading process is different for different orthographies: the orthographic depth hypothesis. In L. Katz \& R. Frost (Eds.), Orthography, phonology, morphology and meaning. Oxford, England:: North-Holland.

Keuning, J., \& Verhoeven, L. (2008). Spelling development throughout the elementary grades: The Dutch case. Learning and Individual Differences, 18(4), 459-470.

Landerl, K., \& Wimmer, H. (2008). Development of word reading fluency and spelling in a consistent orthography: an 8-year follow-up. Journal of Educational Psychology, 100(1), 150-161.

Leppanen, U., Niemi, P., Aunola, K., \& Nurmi, J. (2006). Development of Reading and Spelling Finnish From Preschool to Grade 1 and Grade 2. Scientific Studies of Reading, 10(1), 3-30.

Lervåg, A., Bråten, I., \& Hulme, C. (2009). The cognitive and linguistic foundations of early reading development: A Norwegian latent variable longitudinal study. Developmental Psychology, 45(3), 764.

Levy, B. A., Bourassa, D. C., \& Horn, C. (1999). Fast and slow namers: benefits of segmentation and whole word training. Journal of Experimental Child Psychology, 73(2), 115-138.

Liberman, I. Y., Shankweiler, D. P., Fischer, F. W., \& Carter, B. (1974). Explicit syllable and phoneme segmentation in the young child. Journal of Experimental Child Psychology, 18, 201-212.

Lundberg, I., Frost, J., \& Peterson, O. P. (1991). Phonemic awareness can be developed without reading instruction. In S. A. Brady \& D. P. Shankweiler (Eds.), Phonological processes in literacy: a tribute to Isabelle Liberman (pp. 150-165). Hillsdale, NJ: Erlbaum Publishers.

Lyon, G. R., Shaywitz, S. E., \& Shaywitz, B. A. (2003). A definition of dyslexia. Annals of Dyslexia, 53, 1-14. 
Lyytinen, H., Ahonen, T., Eklund, K., Guttorm, T. K., Laakso, M. L., Leinonen, S., et al. (2001). Developmental pathways of children with and without familial risk for dyslexia during the first years of life. Developmental Neuropsychology, 20(2), 535-554.

Lyytinen, H., T. , Ahonen, K., Eklund, T., Guttorm, P., Kulju, M. L., Laakso, M., et al. (2004). Early Development of Children at Familial Risk for Dyslexia: Follow-up from Birth to School Age. Dyslexia, 10(3), 146-178.

Maki, H. S., Voeten, M. J. M., Vauras, M. M. S., \& Poskiparta, E. H. (2001). Predicting writing skill development with word recognition and preschool readiness skills. Reading and Writing, 14(7), 643-672.

Manis, F. R., Doi, L. M., \& Bhadha, B. (2000). Naming speed, phonological awareness, and orthographic knowledge in second graders. Journal of Learning Disabilities, 33(4), 325-333, 374.

Manis, F. R., Seidenberg, M. S., \& Doi, L. M. (1999). See Dick RAN: Rapid naming and the longitudinal prediction of reading subskills in first and second graders. Scientific Studies of Reading, 3(2), 129157.

Mann, V., \& Wimmer, H. (2002). Phoneme awareness and pathways into literacy: A comparison of German and American children. Reading and Writing: An Interdisciplinary Journal, 15, 653-682.

Marsh, G., Friedman, M., Welch, V., \& Desberg, P. (1980). The development of strategies in spelling. In U. Frith (Ed.), Cognitive processes in spelling (pp. 339-353). London: Academic Press.

Marsh, G., Friedman, M., Welsh, V., \& Desberg, P. (1981). A cognitive developmental theory of reading acquisition. . In G. MacKinnon \& T. Walker (Eds.), Reading research: advances in theory and practice (pp. 199-211). New York: Academic Press.

Morais, J., Bertelson, P., Cary, L., \& Alegria, J. (1986). Literacy training and speech segmentation. Cognition, 24, 45-64.

Morais, J., Cary, L., Alegria, J., \& Bertelson, P. (1979). Does awareness of speech as a sequence of phones arise spontaneously? Cognition, 7, 323-331.

Morgan, W. P. (1896). A Case of Congenital Word Blindness. British Medical Journal, ii, 178.

National Reading Counsil. (1998). Preventing reading difficulties in young children. Washington, D.C.: National Academy Press.

Nikolopoulos, D., Goulandris, N., Hulme, C., \& Snowling, M. J. (2006). The cognitive bases of learning to read and spell in Greek: Evidence from a longitudinal study. Journal of Experimental Child Psychology, 94(1), 1-17.

Patel, T. K., Snowling, M. J., \& de Jong, P. F. (2004). A cross-linguistic comparison of children learning to read in English and Dutch. Journal of Educational Psychology, 96(4), 785-797.

Pennington, B. F., \& Lefly, D. L. (2001). Early reading development in children at family risk for dyslexia. Child Development, 72(3), 816-833.

Perfetti, C. A. (1985). Reading ability. New York: Oxford City Press.

Perfetti, C. A. (1997). The psycholinguistics of spelling and reading. In C. A. Perfetti, L. Rieben \& M. Fayol (Eds.), Learning to spell: Research, theory, and practice across languages. (pp. 21-38). Mahwah, NJ, US: Lawrence Erlbaum Associates.

Perfetti, C. A., Beck, I., Bell, L. C., \& Hughes, C. (1987). phonemic knowledge and learning to read are reciprocal: a longitudinal study of first grade children. Merill-Palmer Quarterly, 33(3), 283-319. 
Perfetti, C. A., \& Marron, M. A. (1998). Learning to Read: Literacy Acquisition by Children and Adults. In D. A. Wagner (Ed.), Advances in adult literacy research and development. Cresskill: Hampton Press.

Plaza, M., \& Cohen, H. (2004). Predictive influence of phonological processing, morphological/syntactic skill, and naming speed on spelling performance. Brain and Cognition, 55(2), 368-373.

Ramus, F., Rosen, S., Dakin, S. C., Day, B. L., Castellote, J. M., White, S., et al. (2003). Theories of developmental dyslexia: Insights from a multiple case study of dyslexic adults. Brain: A Journal of Neurology, 126(4), 841-865.

Rayner, K., \& Pollatsek, A. (1989). The Psychology of Reading. New Jersey: Prentice-Hall.

Reitsma, P. (1983). Printed word learning in beginning readers. Journal of Experimental Child Psychology, 36, 321-339.

Savage, R. (2004). Motor skills, automaticity and developmental dyslexia: A review of the research literature. Reading and Writing: An Interdisciplinary Journal, 17, 301-324.

Savage, R., Pillay, V., \& Melidona, S. (2008). Rapid serial naming is a unique predictor of spelling in children. Journal of Learning Disabilities, 41(3), 235-250.

Scarborough, H. S. (1990). Very early language deficits in dyslexic children. Child Development, 61(6), 1728-1743.

Schlaggar, B. L., \& McCandliss, B. D. (2007). Development of neural systems for reading. Annual Review of Neuroscience, 30, 475-503.

Seymour, P., Aro, M., \& Erskine, J. (2003). Foundation literacy acquisition in European orthographies. British Journal of Psychology, 94(2), 143-174.

Shanahan, T. (1984). Nature of the reading-writing relation: An exploratory multivariate analysis. Journal of Educational Psychology, 76(3), 466-477.

Share, D. L. (1995). Phonological recoding and self-teaching: sine qua non of reading acquisition. Cognition, 55, 151-218.

Share, D. L. (1999). Phonological recoding and orthographic learning: A direct test of the self-teaching hypothesis. Journal of Experimental Child Psychology, 72(2), 95-129.

Share, D. L. (2008). On the Anglocentricities of current reading research and practice: The perils of overreliance on an 'outlier' orthography. Psychological Bulletin, 134(4), 584-615.

Siegel, L. S., \& Faux, D. (1989). Acquisition of certain grapheme-phoneme correspondences in normally achieving and diabled readers. Reading and Writing, an interdisciplinary journal, 1, 37-52.

Snowling, M. (2000). Dyslexia. Oxford: Blackwell Publishers.

Snowling, M. J. (1994). Towards a model of spelling acquisition: the development of some component skills. In G. D. A. Brown \& N. C. Ellis (Eds.), Handbook of spelling: Theory, Process and Intervention. Chichester: John Wiley \& Sons Ltd.

Stage, S. A., \& Wagner, R. K. (1992). Development of young children's phonological and orthographic knowledge as revealed by their spellings. Developmental Psychology, 28(2), 287-296.

Stoolmiller, M., \& Bank, L. (1995). Autoregressive effects in structural equation models: we see some problems. In J. Gottman (Ed.), The analysis of change. Mahwah, NJ: Lawrence Erlbaum Associates.

Strattman, K., \& Hodson, B. W. (2005). Variables that influence decoding and spelling in beginning readers. Child Language Teaching \& Therapy, 21(2), 165-190. 
Stuart, M., \& Masterson, J. (1992). Patterns of reading and spelling in 10-year-old children related to prereading phonological abilities. Journal of Experimental Child Psychology, 54(2), 168-187.

Sunseth, K., \& Bowers, P. G. (2002). Rapid naming and phonemic awareness: Contributions to reading, spelling, and orthographic knowledge. Scientific Studies of Reading, 6(4), 401-429.

Torgesen, J. K., Wagner, R. K., \& Rashotte, C. A. (1994). Longitudinal studies of phonological processing and reading. Journal of Learning Disabilities, 27(5), 276-291.

Torgesen, J. K., Wagner, R. K., Rashotte, C. A., Burgess, S. R., \& Hecht, S. A. (1997). Contributions of phonological awareness and rapid automatic naming ability to the growth of word-reading skills in second- to fifth-grade children. Scientific Studies of Reading, 1(2), 161-185.

Van den Bos, K. P., Zijlstra, B. J. H., \& lutje Spelberg, H. C. (2002). Life-span data on continuous-naming speeds of numbers, letters, colors, and pictured objects, and word-reading speed. Scientific Studies of Reading, 6(1), 25-49.

Varnhagen, C. K., McCallum, M., \& Burstow, M. (1997). Is children's spelling naturally stage-like? Reading and Writing, 9(5), 451-481.

Vellutino, F. R. (1979). Dyslexia: Theory and research. Cambridge, MA: MIT Press.

Vellutino, F. R., Fletcher, J. M., Snowling, M. J., \& Scanlon, D. M. (2004). Specific reading disability (dyslexia): what have we learned in the past four decades? Journal of Child Psychology and Psychiatry, 45(1), 2-40.

Vukovic, R. K., \& Siegel, L. S. (2006). The double-deficit hypothesis: A comprehensive analysis of the evidence. Journal of Learning Disabilities, 39(1), 25-47.

Wagner, R. K., \& Torgesen, J. K. (1987). The nature of phonological processing and its causal role in the acquisition of reading skills. Psychological Bulletin, 101(2), 192-212.

Wagner, R. K., Torgesen, J. K., \& Rashotte, C. A. (1994). Development of reading-related phonological processing abilities: New evidence of bidirectional causality from a latent variable longitudinal study. Developmental Psychology, 30(1), 73-87.

Wile, L. T., \& Borowsky, R. (2004). What does rapid automatized naming measure? A new RAN task compared to naming and lexical decision. Brain and Language, 90, 47-62.

Willems, G., \& Blomert, L. (submitted). The reciprocal relationship between phonological processing and reading: new evidence from Dutch children at-risk and not at-risk for dyslexia.

Wimmer, H., \& Hummer, P. (1990). How German-speaking first graders read and spell: Doubts on the importance of the logographic stage. Applied Psycholinguistics, 11, 349-368.

Wimmer, H., Landerl, K., Linortner, R., \& Hummer, P. (1991). The relationship of phonemic awareness to reading acquisition: more consequence than precondition but still important. Cognition, 40(3), 219249.

Wimmer, H., Mayringer, H., \& Landerl, K. (1998). Poor reading:b a deficit in skill-automatization or a phonological deficit? Scientific Studies of Reading, 2, 321-340.

Wolf, M. (1986). Rapid alternating stimulus naming in the developmental dyslexias. Brain and Language, $27(2), 360-379$.

Wolf, M. (1991). The word-retrieval deficit hypothesis and developmental dyslexia. Learning and Individual Differences, 3(3), 205-223. 
Wolf, M. (1997). A provisional, integrative account of phonological and naming-speed deficits in dyslexia: Implications for diagnosis and intervention. In B. A. Blachman \& A. Benita (Eds.), Foundations of reading acquisition and dyslexia: Implications for early intervention (pp. 67-92). Mahwah, NY: Lawrence Erlbaum Associates.

Wolf, M., \& Bowers, P. G. (1999). The double-deficit hypothesis for the developmental dyslexias. Journal of Educational Psychology, 91(3), 415-438.

Wolf, M., Bowers, P. G., \& Biddle, K. (2000). Naming-speed processes, timing, and reading: A conceptual review. Journal of Learning Disabilities, 33(4), 387-407.

Ziegler, J. C., \& Goswami, U. (2005). Reading acquisition, developmental dyslexia, and skilled reading across languages: a psycholinguistic grain size theory. Psychological Bulletin, 131(1), 3-29. 


\section{Chapter 2}

\section{Cognitive development of reading fluency}

This chapter is based on:

Vaessen, A.A. \& Blomert, L. (2010). Long-term cognitive dynamics of fluent reading development. Journal of experimental child psychology, 105, 213-231 


\begin{abstract}
Most theories of reading development assume a shift from slow sequential subword decoding to automatic processing of orthographic word forms. We hypothesized that this shift should be reflected in a concomitant shift in reading-related cognitive functions. The present study investigated the cognitive dynamics underlying reading development in a large school sample ranging from beginning to experienced readers. The results showed that phonological awareness (PA) and RAN substantially contributed to reading fluency over all six primary school grades. However, the relationship between PA and word (but not pseudoword) reading fluency decreased as a function of reading experience, while the relationship between RAN and word reading fluency gradually increased. Moreover, this cognitive shift was most pronounced for high-frequency words. The results seem to point to the development of one and only one reading network for all types of words, in which processing load or type of processing depends on word familiarity and amount of reading experience.
\end{abstract}




\subsection{Introduction}

Most developmental reading models suggest a shift from slow sequential letter-tosound decoding to fast, effortless recognition of whole word forms during reading acquisition (e.g., Backman, Bruck, Hebert, \& Seidenberg, 1984; Doctor \& Coltheart, 1980; Ehri, 2005; Frith, 1986; Morton, 1989; Sprenger-Charolles, Siegel, Bechennec, \& Serniclaes, 2003). According to the self-teaching hypothesis of Share (Jorm \& Share, 1983; Share, 1995, 1999), phonological recoding (letter-to-sound processing) is crucial for the acquisition of visual word recognition skills. This phonological recoding serves as a self-teaching function enabling children to learn detailed orthographic representations necessary for fluent effortless reading. The shift from phonological decoding to automatic word-recognition is probably not all-or-none (Share, 2008). Rather, there might be a gradual transition from a predominant use of phonological recoding strategies to a predominant use of automatic word recognition. Brain studies indicate that this gradual specialization of the word recognition process continues to develop for years (Brem et al., 2006; Mauer, Brem, Bucher, \& Brandeis, 2005; Posner \& McCandliss, 1999; Schlaggar \& McCandliss, 2007). Moreover, since the acquisition of word-specific orthographic knowledge is thought to strongly depend on frequent exposure to a specific word (Share, 1999), the recognition of words based on word-specific knowledge is thought to partly depend on frequency of occurrence of a specific word. Thus, to get full insight in the development of the reading network, reading should be investigated in a broad developmental framework including readers ranging from beginners to experts and including words of varying frequency of occurrence (Share, 2008).

\section{Cognitive functions underlying reading development}

Since it is expected that fluent reading acquisition involves a shift in reading strategies, one might assume that the relative involvement of underlying cognitive processes also shift during the acquisition of fluent reading skills. That is, cognitive skills crucial for learning to read in beginning readers might have little or a different impact on reading performance at later stages of reading acquisition.

Two basic cognitive skills frequently and uniquely associated with reading acquisition are phonological awareness (PA) and rapid automatized naming of visual items (RAN). PA, the ability to perceive and manipulate speech sounds within a word, shows a strong, reciprocal connection with reading acquisition (e.g., Adams, 1995; Goswami \& Bryant, 1990). A certain level of awareness of the sound structure of words seems necessary to understand the basic principles of reading in an alphabetic script, while on the other hand learning to read strongly facilitates awareness of phonemes (Castles \& Coltheart, 2004; Ehri, 2005; Perfetti, Beck, Bell, \& Hughes, 1987; Torgesen, Wagner, \& Rashotte, 1994; Wagner \& Torgesen, 1987; Ziegler \& 
Goswami, 2005). Although PA seems to be related to a wide variety of reading tasks, it has been claimed that PA is most strongly associated with reading tasks requiring phonological decoding, such as pseudoword reading (Bowers, 1995; Bowers, Sunseth, \& Golden, 1999; Cornwall, 1992; Manis, Doi, \& Bhadha, 2000; Manis, Seidenberg, \& Doi, 1999; Savage \& Frederickson, 2005; Sunseth \& Bowers, 2002; Torgesen, Wagner, Rashotte, Burgess, \& Hecht, 1997). RAN, on the other hand, seems to be most strongly involved in reading tasks requiring the recognition of word-specific orthographic patterns, such as exception word reading and orthographic choice tasks (Bowers \& Swanson, 1991; Clarke, Hulme, \& Snowling, 2005; Compton, DeFries, \& Olson, 2001; Georgiou, Parrila, Kirby, \& Stephenson, 2008; Manis et al., 2000; Manis et al., 1999; Savage \& Frederickson, 2005; Sunseth \& Bowers, 2002; Wile \& Borowsky, 2004). There might be several explanations why RAN is strongly related to automatic word recognition skills. It has been claimed that RAN reflects the ability to store or build-up orthographic word patterns (Georgiou, Parrila et al., 2008; Levy, Bourassa, \& Horn, 1999; Savage, Pillay, \& Melidona, 2008; Wolf \& Bowers, 1999). Others have claimed that RAN reflects the ability to efficiently match visual/orthographic information to phonological codes (e.g., Berninger, Abbott, Billingsley, \& Nagy, 2001; Bowers \& Ishaik, 2003; Vaessen, Gerretsen, \& Blomert, 2009) or the fast retrieval of phonological codes from memory (e.g., Chiappe, Stringer, Siegel, \& Stanovich, 2002; Clarke et al., 2005; Katz \& Shankweiler, 1985; Pennington, Cardoso-Martins, Green, \& Lefly, 2001; Torgesen et al., 1997; Wagner, Torgesen, \& Rashotte, 1994).

If RAN reflects processes important for automatic visual word recognition and PA is more important for phonological decoding, we hypothesize that individual differences in PA might impact reading fluency most strongly in beginning readers who use phonological decoding strategies, while individual differences in RAN levels might exert a stronger influence on reading fluency in experienced readers.

\section{Development of the cognitive dynamics of reading fluency}

During the past few decades, many researchers have focused on the role of PA and RAN in reading acquisition. However, since we are specifically interested in developmental changes in the strength of the cognitive contributions of PA and RAN to reading performance, only the results of studies including at least two different levels of reading expertise will be reviewed. These studies can be divided into two types of study design: cross-sectional studies that investigate the concurrent relationship between PA and RAN at different points in time, and longitudinal studies that investigate the influence of PA and RAN on subsequent reading performance in two or more different periods.

Longitudinal studies that are conducted in transparent orthographies mostly report modifications in the (additional) contributions of PA and/or RAN over time. 
For instance, de Jong and van der Leij (1999) found in Dutch children that PA when measured at the start of first grade was predictive for word reading fluency at the end grade 1, even when prior reading achievement was taken into account. In contrast, grade 1 PA was not predictive for reading performance in grade 2 , while RAN significantly added variance to reading fluency at both time points. In a follow-up study including children from grade 1 to grade 3 (de Jong \& van der Leij, 2002), neither PA nor RAN (when tested in grade 1 ) did exert an additional effect on reading fluency after the second grade when prior reading level was taken into account. Landerl and Wimmer (2008) examined the influence of pre-literacy PA and RAN performance on word reading fluency in Austrian children tested in grade 1, 4 and 6 and found no significant contribution of PA on reading level after grade 1 when preliteracy letter knowledge was taken into account. The contribution of RAN to reading fluency was significant in all grades, but the strength of the contribution of RAN did not change developmentally. In line with these results, Bast and Reitsma (1998) only found a significant influence of pre-literacy PA skills on reading performance at the start of grade 1 in Dutch children (RAN was not tested). In grade 2 and 3, PA did not exert an additional effect on reading after prior reading level was taken into account. In a Norwegian study, Lervåg, Bråten and Hulme (2009) found that grade 1 PA performance significantly affected grade 1 , but not grade 2 or 3 , reading performance after prior reading level was controlled for. In contrast, RAN continued to be a significant predictor until grade 3. In a Finnish study (Leppanen, Aunola, Niemi, \& Nurmi, 2008) preschool PA did not predict subsequent reading skills in grade 1 and 2 when preschool reading level was controlled for (RAN was not tested).

The results of two cross-sectional studies seem to support a change in contributions of PA and RAN over time in transparent orthographies: In a cross-sectional Finnish study (Muller \& Brady, 2001) PA strongly contributed to reading comprehension and pseudoword decoding speed in the first grade in normal as well as poor readers, but only in poor readers in fourth grade. RAN was a significant predictor of reading performance in poor as well as normal readers in both grades. Van den Bos, Zijlstra, and Lutje Spelberg (2002) did not include a measure of PA, but found an increasing contribution of (alphanumeric) RAN to word reading fluency in a crosssectional study with Dutch children from grade 2, 4, 6, and 7, and in 16 and 46-year old readers.

Some studies with English-speaking children also report a change in PA and RAN contributions: in a longitudinal Canadian study including children from grade 1 to 5 (Kirby, Parrila, \& Pfeiffer, 2003), the influence of kindergarten PA on word and pseudoword reading accuracy declined while the influence of kindergarten RAN on word and pseudoword reading accuracy increased (analyses were controlled for preschool letter-recognition). Similarly, Badian (2001) showed that kindergarten PA performance significantly affected reading performance in grade 1 after prior reading level was taken into account, but not in grade 3 or 7 . RAN was not tested, but 
the influence of kindergarten orthographic skills on subsequent reading level was strong and increased over years. In a study of Wagner et al. (1997), PA was a strong predictor even when prior reading level was taken into account in all test periods (kindergarten to 2 nd grade, 1 st to 3 th grade, 2 nd to 4 th grade) but the strength of the contributions decreased. RAN exerted additional effects on reading performance in the first two test periods, but not in the last one. In contrast, Torgesen and colleagues (1997) found that the contributions of grade 2 RAN and PA performance to grade 4 reading performance were similar to the contributions of grade 3 RAN and PA performance to grade 5 reading performance: In both periods RAN was relatively stronger related to word reading speed and PA to non-word and word reading accuracy. Similarly, Bowers (1995) showed that PA contributed most strongly to text reading accuracy and RAN to reading speed, but the relationships did not substantially change from grade 2 to grade 4 .

To summarize, several longitudinal predictor studies in transparent orthographies and some longitudinal predictor studies with English-speaking children report a decrease in the additional effect of PA on subsequent reading performance. This provides some support for the hypothesis that the impact of PA on reading performance diminishes over time as a consequence of a reduced use of phonological decoding strategies. However, conclusions should be drawn carefully. First, most studies that report a declining PA-reading relationship were conducted in transparent orthographies. Performance on phonological tasks often reaches ceiling, reducing the statistical power of these tasks (Patel, Snowling, \& de Jong, 2004). Moreover, PA is traditionally tested with accuracy measures while reading performance is mostly investigated with speeded measures in studies in orthographically transparent languages, since reading accuracy tasks quickly reach ceiling levels. This incompatibility in measurement parameters might have led to an underestimation of the role of PA in reading in transparent orthographies (Georgiou, Parilla, \& Papadopoulos, 2008; Share, 2008). A solution for this measurement-incompatibility problem might be to use speeded measures for all variables, including PA. In the current study we therefore included a sensitive, speeded measure of PA to investigate the role of PA in a transparent orthography. As far as we are aware of, only three previous studies included a speeded measure of PA (Moll, Fussenegger, Willburger, \& Landerl, 2009; Patel et al., 2004; Vaessen et al., 2009).

A second reason for precaution when interpreting the results of above mentioned studies is that most of these studies are longitudinal, and measured PA and RAN only at one occasion while reading was tested at several occasions. Therefore, it cannot be ruled out that a decreasing relationship between PA and reading performance is simply a consequence of the fact that the time between the measurement points increased. Moreover, several of the above mentioned studies report the additional influence of PA and RAN after prior reading level is taken into account. If the purpose of a study is to investigate the causality of the relationship 
between cognitive predictors and reading, this study design is preferred. However, when investigating developmental changes in the relationship between cognitive skills and reading this method might have some disadvantages. That is, the autoregressive effect of reading is very powerful, so little variance is left to be explained by individual differences in cognitive skills (Stoolmiller \& Bank, 1995). Consequently, the absence of an additional effect of PA and RAN in longitudinal designs does not necessarily imply that these skills are no longer associated with reading (de Jong \& van der Leij, 2002; Lervåg et al., 2009). Indeed, Lervåg and colleagues (2009) found strong concurrent correlations between PA and reading performance, even though contributions of PA were not significant when prior reading level was taken into account. Moreover, some cross-language investigations found strong concurrent correlations between PA and reading performance in transparent as well as opaque orthographies even in more advanced readers (Caravolas, Volin, \& Hulme, 2005; Patel et al., 2004). Therefore, when investigating the hypothesis that the assumed shift in reading strategy is accompanied by a shift in the cognitive functions associated with reading, it is important to examine whether the concurrent relationships between cognitive skills and reading skills change as a function of reading expertise.

\section{The present study}

Reading theories assume a shift from slow phonological decoding to fast automatic visual word recognition. The aim of the present study is to investigate whether this shift is reflected in a concomitant shift in the strength of the concurrent contributions of two basic cognitive processes (RAN and PA) to reading fluency. Therefore, we investigated the cognitive development of reading fluency in a large sample covering all primary school grades, using speeded measures for all variables to avoid possible speed-accuracy problems. For PA, a difficult pseudoword phoneme deletion task was used to avoid ceiling performance. Alphanumeric measures of RAN were used, since alphanumeric RAN is found to be a stronger, more consistent predictor than non-alphanumeric RAN (e.g., Bowey \& Miller, 2007; Compton, 2003; van den Bos et al., 2002; van den Bos, Zijlstra, \& van den Broeck, 2003).

We examined the contributions PA and RAN for three different word types (high-frequency, low-frequency and pseudowords). If the assumption that PA is strongly related to phonological recoding and RAN is specifically strongly related to automatic word recognition is correct, and if familiarity of a word indeed influences the acquisition of word-specific orthographic knowledge (Share, 1999, 2008), it is expected that the shift in the contributions of PA and RAN to reading fluency is influenced by word frequency. More specifically, we expect that a cognitive shift would occur earlier in time for words with a high frequency of occurrence, since children are confronted with these words more often and consequently many of these words might be recognized by sight from early on, while it takes longer to 
form word-specific orthographic representations for words with a low frequency of occurrence.

To ensure the possibility of direct comparisons between the contributions of PA and RAN to reading fluency in different grades we used dominance analysis (Azen \& Budescu, 2003; Budescu, 1993) to determine which predictor is most important at a certain point in time. Dominance analysis allows a direct comparison of the contributions of each variable, since it measures the relative importance of a predictor in the context of all possible models which contain some subset of predictors. Moreover, the use of this method also allows to estimate the statistical relevance of an observed difference between the contributions of two variables (Alf \& Graf, 1999). The present study was thus explicitly designed to investigate the cognitive dynamics of fluent reading development.

\subsection{Methods}

\section{Participants}

1423 children from 17 Dutch primary schools in 5 regions in the Netherlands participated in this study. The sample was unselected in the sense that all children within one classroom participated, regardless of their reading and spelling performance level (grade $1 n=210$, grade $2 n=285$, grade $3 n=259$, grade $4, n=263$, grade 5 $n=226$, grade $6 n=180$ ).

Mean age and mean standard score on vocabulary and non-verbal IQ as well as mean raw scores on the reading and cognitive tasks for each grade are presented in table 2.1 .

\section{Procedure}

The tasks were administered individually outside the classroom (only the non-verbal IQ task was administered in the classroom). The reading-tasks, the PA task, the speeded naming tasks and the baseline RT task were computer-administered, using a specialized response-box to precisely measure response times in milliseconds (Dyslexia Differential Diagnosis; 3DM, Blomert \& Vaessen, 2009). The Vocabulary task (RAKIT; Bleichrodt, Drenth, Zaal, \& Resing, 1988) and the non-verbal IQ task (RAVEN CPM; Raven, Court, \& Raven, 1995) were paper-and-pencil tasks.

\section{Tasks}

Reading- The word reading task includes three subtasks: high-frequency words (HF), low-frequency words (LF) and pseudowords (PW). Mean frequency of HF words ranged between 790 and 45810 (CELEX-database; Baayen, Piepenbrock, \& 
Gulikers, 1995), mean frequency of LF words ranged between 6 and 342. Each level consisted of 75 words (5 screens of 15 items). The difficulty level of each screen systematically increased: the first screen contained monosyllabic words without consonant clusters, the second screen monosyllabic words with consonant clusters, the third screen bi-syllabic words without consonant clusters, the fourth screen bisyllabic words with consonant clusters and the fifth screen 3- or 4 syllabic words with consonant clusters. Participants were instructed to accurately read as many words as possible. When the participant finished reading the items on one screen, the experimenter pressed a button to continue with the next screen until the time limit was reached (half a minute for each reading subtask). Reading fluency is expressed in a combined score for accuracy and speed (correct words/halve a minute). Reading accuracy is proportion of correctly read words (correct words/total amount of words read $x$ 100). Test-retest reliability coefficients of the three reading fluency subtasks are respectively .91, .93 and .92 (reported in the test manual of 3DM).

Phonological awareness (PA)- The phoneme deletion task contained 23 pseudowords and measured accuracy as well as response time. The pseudowords had a CVC or a CCVCC structure. The participant was instructed to delete a consonant positioned either at the beginning of a word, at the end of a word or within a consonant cluster. Response time was time between stimulus offset and the button press by the tester as soon as the participant responded. The task has an internal consistency of .85 for accuracy (reported in the test manual of 3DM). To calculate the reliabilities of the speed scores, the test was split in two halves (odd and even items) and for each grade correlations were calculated between the two halves (corrected for test-length with spearman-brown correction). Reliability coefficients of the speed scores were on average .93.

Rapid naming (RAN)- The rapid naming task consisted of three subtasks: letters, digits and objects. For each subtask, 5 items were repeated 6 times (15 items per screen, two screens per subtask). The participant was instructed to name the items as fast and accurate as possible. The correlation (with Spearman-Brown correction to correct for test-length) between the speed scores on the first and the second screen were respectively $.80, .83$ and .73 for letters, digits and objects (reported in the test manual of 3DM).

Baseline response time- A row of 4 empty squares was presented and in one of the squares appeared an animation figure. The participant had to respond as fast as possible by pressing the corresponding button. The correlation between the two test halves was .94 (with spearman-brown correction).

Vocabulary- Vocabulary was tested by matching one of 4 pictures to an orally presented word and the accuracy of performance was expressed in the number of correct responses. The test has an internal consistency of .81 (reported in the test manual RAKIT). 
Non-verbal IQ- Non-verbal IQ was measured using the RAVEN-CPM. For the Dutch version of this task, Van Bon (1986) reported reliabilities of .80 and higher.

\subsection{Results}

Means and standard deviations for cognitive and reading measures for each grade are presented in table 2.1. The main aim of the present study was to investigate the cognitive development of fluent word reading of different word types (HF words, LF words and PW). We therefore first investigated how reading fluency of these three word types develops by examining the effect of grade and word-type on reading fluency. Next, we investigated the cognitive contributions of PA and RAN to reading fluency and whether they changed developmentally. For the regression and correlation analyses we used standardized scores (based on national standardization) instead of raw scores. This has two advantages: First, these standardized T-scores are normalized, thus reducing effects of outliers or non-normally distributed data. Second, the standardization method is based on test period (amount of months of formal reading instruction), so all analyses are automatically controlled for effects

of months of reading instruction. 


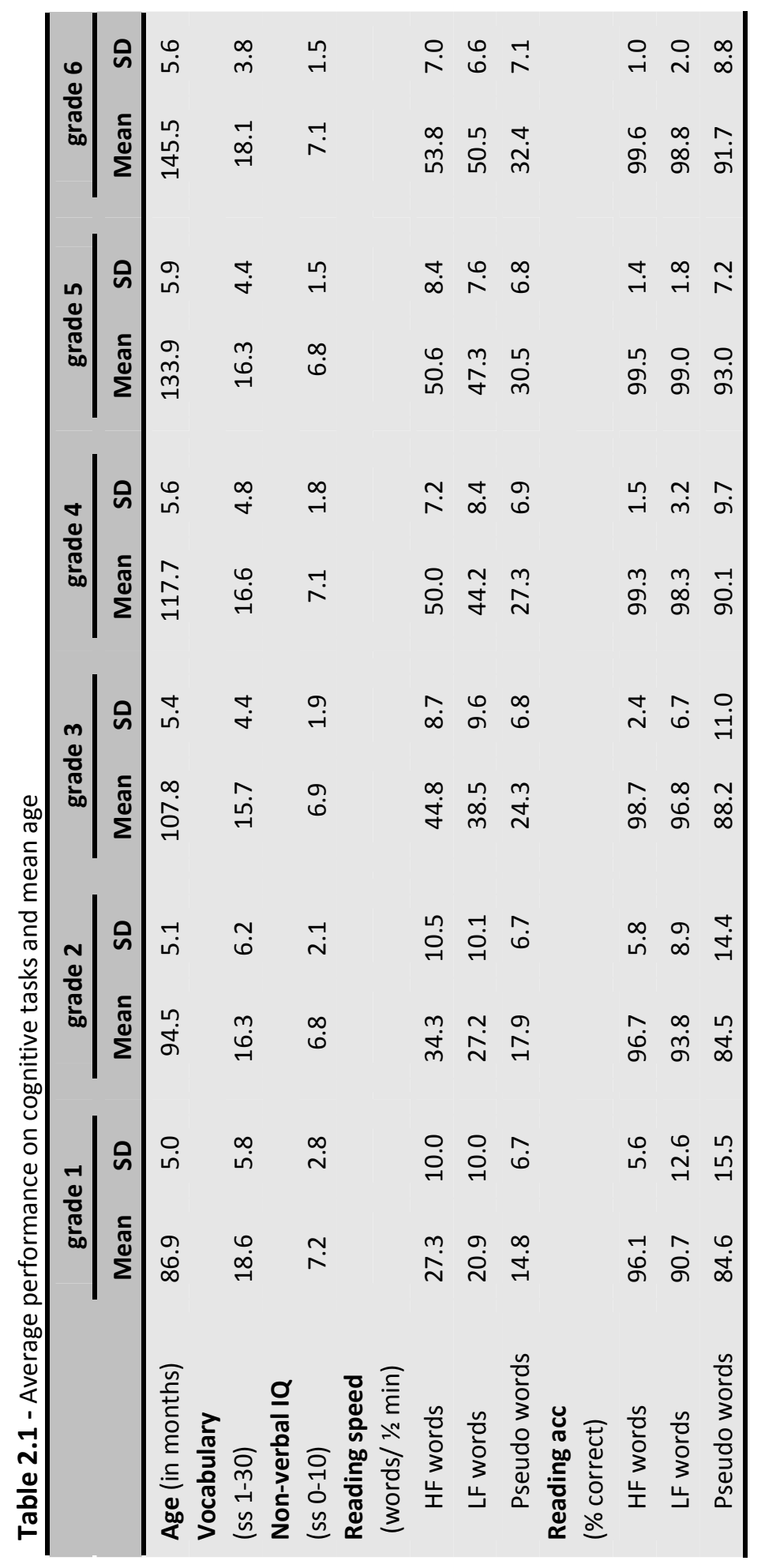




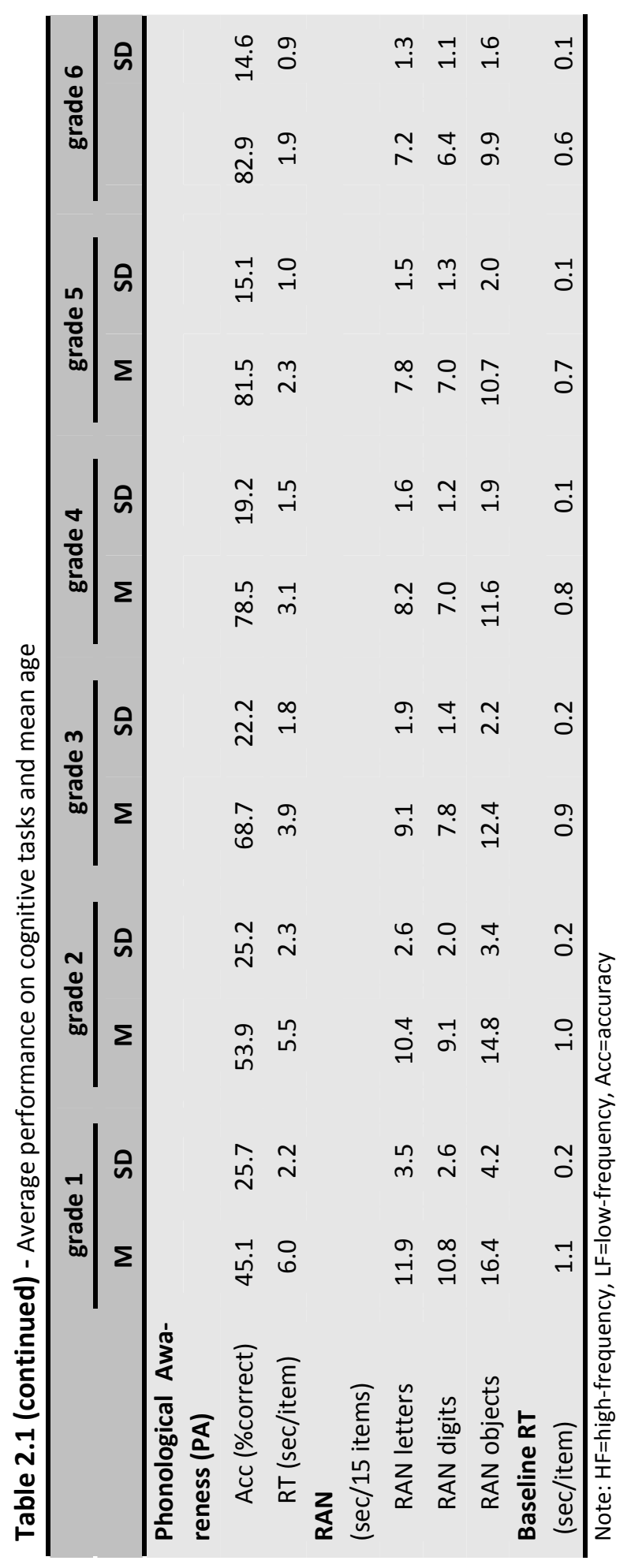




\section{Development of reading fluency}

The results in table 2.1 show that reading accuracy for all word types is high in all grades. Even in grade 1, more than $90 \%$ of existing words and around $85 \%$ of pseudowords are read correctly. However, reading fluency levels strongly increase over years. A factorial repeated-measures ANOVA with Word-type as within-subject factor (3 levels: HF high-frequency, LF low-frequency and PW pseudowords) and Grade as between-subject factor ( 6 levels) revealed a significant interaction between Grade and Word-type $(F(10,2834)=107.56, p<.000, r=.52)$, indicating that the effect of word-type on reading fluency varies per grade.

Planned contrasts revealed that in all grades, high-frequency words were read more quickly than low-frequency words, grade1 $F(1,209)=632.5, p<.001, r=.87$; grade $2 \mathrm{~F}(1,284)=923.8, \mathrm{p}<.001, \mathrm{r}=.87$; grade $3 \mathrm{~F}(1,258)=417.7, \mathrm{p}<.001, \mathrm{r}=.79$; grade $4 F(1,262)=410.3, p<.001, r=.78$; grade $5 F(1,225)=101.8, p<.001, r=.56$; grade 6 $F(1,179)=70.0, p<.001, r=.53$, and that low-frequency words were read more quickly than pseudowords, grade1 $F(1,209)=361.3, p<.001, r=.80$; grade $2 F(1,284)=853.9$, $\mathrm{p}<.001, \mathrm{r}=.87$; grade $3 \mathrm{~F}(1,258)=1722.3, \mathrm{p}<.001, \mathrm{r}=.93$; grade $4 \mathrm{~F}(1,262)=2975.9$, $p<.001, r=.96$; grade $5 \mathrm{~F}(1,225)=2676.7, p<.001, r=.96$; grade $6 \mathrm{~F}(1,179)=2407.6$, $p<.001, r=.93$. The pattern of the effect sizes suggests that differrences between HF and LF words decreased (in grade $1 r=.87$, in grade $6 r=.53$ ), while differences between LF words and PW tended to increase over the years (effect sizes in grade 1 $r=.80$, in grade $6 r=.93$ ).

To investigate whether the strength of the relationship between reading fluency level of each word type changed over time, correlations between standardized scores on HF reading fluency, LF reading fluency and PW reading fluency were calculated for each grade. Correlations between reading fluency of the different word types were high in each grade (between .55 and .93; see appendix for a full correlation matrix per grade), but the strength of the relationship between reading fluency of different word types seemed to decline over years (in grade 1, $r$ between .89 and .93 , in grade $6 r$ between .55 and .74). To investigate whether this developmental trend is statistically significant, hierarchical regressions were conducted with standardized scores on reading fluency of one word-type (e.g., HF-words) as dependent variable and standardized scores on reading fluency of the other word-type (e.g., LF words), Grade and the interaction term between reading fluency and grade as independent variables (all variables were centered before calculating interaction terms to avoid collinearity). Three sets of hierarchical regression analyses were conducted, one with HF fluency as dependent variable and LF fluency, grade and LF fluency $x$ Grade as independent variables, one with HF fluency as dependent variable and PW fluency, grade and PW fluency $x$ Grade as independent variables and a third one with LF fluency as dependent variable and PW fluency, grade and the PW fluency $x$ Grade as independent variables. Results are presented in table 2.2. The most inter- 
esting results for the purpose of this analysis are the interaction terms between reading fluency and grade. The relationship between HF and LF words significantly decreased as a function of grade, $\beta=-.08, p<.0001$, as did the relationship between HF words and PW, $\beta=-.11, p<.0001$ and the relationship between LF words and PW, $\beta=-.05, p<.01$.

\section{The cognitive dynamics of reading development}

Dominance analysis: To determine the relative importance of the contribution of RAN and PA to reading fluency, we conducted a set of dominance analyses. Dominance analysis (DA; Azen \& Budescu, 2003; Budescu, 1993) estimates the average increase in R2 over all possible models, accounting for the variable's direct effect (the effect of a variable irrespective of the effect of other predictors), total effect (the full model when all other predictors are controlled) and partial effect (conditional on all subsets of predictors). In this way, the importance of PA as a predictor for reading fluency can be directly compared to that of RAN, without making strong inferences about the hierarchical ordering of these variables.

Table 2.2 - Relationship between reading fluency levels of different word types and interaction with grade

\begin{tabular}{lccccc}
\hline \multicolumn{2}{c}{ HF fluency } & \multicolumn{2}{c}{ HF fluency } & \multicolumn{2}{c}{ LW fluency } \\
\multicolumn{1}{c}{ Variable } & stand. $\boldsymbol{\beta}$ & \multicolumn{1}{c}{ Variable } & stand. $\boldsymbol{\beta}$ & Variable & stand. $\boldsymbol{\beta}$ \\
\hline LW fluency & $.84^{* * *}$ & PW fluency & $.72^{* * *}$ & PW fluency & $.82^{* * *}$ \\
Grade & .00 & Grade & .01 & Grade & .01 \\
LwxGrade & $-.08^{* * *}$ & PwxGrade & $-.11^{* * *}$ & PWxGrade & $-.05^{* *}$ \\
& & & & & \\
Adj. $\mathrm{R}^{2}$ & $.750^{* * *}$ & adj. $\mathrm{R}^{2}$ & $.566^{* * *}$ & adj. $\mathrm{R}^{2}$ & $.715^{* * *}$ \\
\hline
\end{tabular}

Note: $\mathrm{HF}=$ high-frequency word, $\mathrm{LF}=\mathrm{low}$-frequency word, $\mathrm{PW}=$ pseudoword.

$* * p<.01 * * p<.0001$.

Since the inclusion of each additional variable exponentially increases the number of calculations and DA tables, it is important to reduce the number of possible predictors to theoretically meaningful subsets of cognitive variables. For the purpose of the present study we were mainly interested in the contributions of PA and RAN, while we merely wanted to control for general cognitive influences from non-verbal $I Q$, vocabulary and baseline-RT. Therefore, we included these control variables always together at the first step of the regression equations (constrained dominance analysis, Azen \& Budescu, 2003). To further reduce the number of predictor variables, we conducted an exploratory factor analysis (with oblimin rotation) on the standardized scores of the theoretically relevant cognitive measures (phoneme deletion accuracy, phoneme deletion speed, RAN letters and RAN digits). RAN objects showed low correlations with reading fluency (see appendix) and was there- 
fore not included in these analyses. The results clearly showed a two-factor solution: RAN letters and digits loaded on the first factor (Eigen value 2.07, factor loadings respectively .88 and .89), PA accuracy and PA speed loaded on the second factor (Eigen value 1.06, factor loadings respectively .91 and .85). Together these two factors explained $78.2 \%$ of the variance. All commonalities were well above .70 . Moreover, a 3-factor solution would result in a third factor with an Eigen value below .50 , suggesting that the two-factor solution is the most parsimonious one.

Dominance analyses were conducted for each Word Type (HF, LF and PW) and for each Grade (grade 1-2, grade 3-4, grade 5-6) with the control variables at the first step and the factor scores of PA and RAN at the second or the third step. The results are shown in table 2.3 and 2.4 .

The first column of table 2.3 and 2.4 describes the amount of variance explained by either the control variables alone (model $k=1$ ) or the control variables plus PA or RAN (model $k=2$ ). The second and third columns show the unique contributions of PA or RAN when added to the original model. The average contributions of PA and RAN are shown in the last row of each column. Figure 2.1 visualizes the developmental pattern of the average contributions to reading fluency by showing the average contributions of the PA and the RAN factors per grade (average $R^{2} \times 100$ to indicate percentage of explained variance). Moreover, since for theoretical purposes it might be interesting to know how much variance is explained by PA when PA is measured with accuracy measures only, we conducted additional analyses with the RAN factor and PA accuracy. The average contributions of PA accuracy to reading fluency are visualized in figure 2.1 (dashed grey bars). The results of this analysis show that the contributions of PA when based on accuracy scores only are substantially lower than when a combined speed-accuracy PA measure is used.

Difference between contribution RAN and PA: Alf and Graf (1999) simplified the method to determine the asymptotic confidence limits for the difference between two R2 coefficients (developed by Olkin \& Finn, 1995). A difference is considered significant if the $95 \%$-confidence limit of this difference does not contain 0 . In effect, we compared the average contribution of RAN with the average contribution of PA at each grade. We calculated the 95\%-confidence limits for the difference between the average $R^{2}$ of PA and the average $R^{2}$ of RAN. Table 2.5 shows the difference in $R^{2}$, the standard error and the confidence upper and lower limit for each Grade and each Word-type.

The overall results of the dominance analysis not only revealed a substantial contribution of PA and RAN to reading fluency of all word-types in all grades (with the sole exception of the PA contribution to high-frequency word reading fluency in grade 5), but also a change in the relative weight of the contributions as a function of word-type and reading experience.

In grade 1 and 2 PA contributed significantly stronger than RAN to reading fluency of all word types. In grade 3 RAN was the dominant contributor to reading 
fluency of high-frequency words, whereas PA was dominant for pseudowords. The contributions of PA and RAN to low-frequency word reading fluency were of similar strength. In grade 4, RAN dominated PA for high-frequency words, while RAN and PA contributed equally strong to reading fluency of low-frequency words and pseudowords. In grade 5 RAN was the dominant contributor to reading fluency of all existing words (HF and LF), while RAN and PA contributed equally strong to reading fluency of pseudowords. In grade 6, again RAN was the strongest predictor to HF and LF word reading fluency, while PA was the strongest predictor of pseudoword reading fluency.

Developmental changes in contribution RAN and PA: To test whether changes in RAN and PA contributions over grades were significant, we conducted hierarchical regression analyses with $\mathrm{PA}, \mathrm{RAN}$, grade and the interaction terms between the cognitive variables and grade as predictor variables (all variables were centered to avoid collinearity problems). The results are listed in table 2.6.

The contribution of PA to HF and LW word reading fluency significantly decreased as a function of grade (interaction between PA and grade resp. $\beta=-.16$, $p<.0001$ and $\beta=-.09, p<.0001)$. In contrast, the contribution of RAN to HF and LF word reading fluency significantly increased as a function of grade (interaction between RAN and grade resp. $\beta=.13, p<.001$ and $\beta=.11, p<.0001)$. The contributions of RAN and PA to PW reading fluency did not significantly change as a function of grade, although the interaction term between RAN and grade was marginally significant, $\beta=.042, p=.058$. It should be noted that the contributions of RAN to reading fluency in grade 1 and 2 (see table 2.3 and figure 2.1) are a bit lower than usually reported in studies in transparent orthographies (de Jong \& van der Leij, 2002; van den Bos et al., 2002). Moreover, in grade 6 we found an unexpected drop in the contribution of RAN to reading fluency compared to grade 5 (see figure 2.1). Therefore, it is possible that the significant modulation of grade on the contribution of RAN is a statistical artifact rather than a genuine developmental effect. To test this, we conducted a new set of hierarchical regression analyses for grade 3 to 5 only (with HF, LF and PW fluency as dependent variables and PA, RAN, grade and the interaction terms between PA and grade and RAN and grade as predictor variables). The results show that grade significantly modulated the effect of PA and RAN on HF fluency (RANxgrade $\beta=.09, p<.01$, PAxgrade $\beta=-.13, p<.0001$ ) and LF fluency (RANxgrade $\beta=.11, p<.01$, PAxgrade $\beta=-.09, p<.01$ ), but not on PW fluency. In other words, the modulating effect of grade on the cognitive contributions to word reading fluency can also be observed in a smaller grade-range and cannot be attributed to statistical or methodological artifacts. 
Table 2.3 - Results of dominance analyses for grade 1, 2 and 3

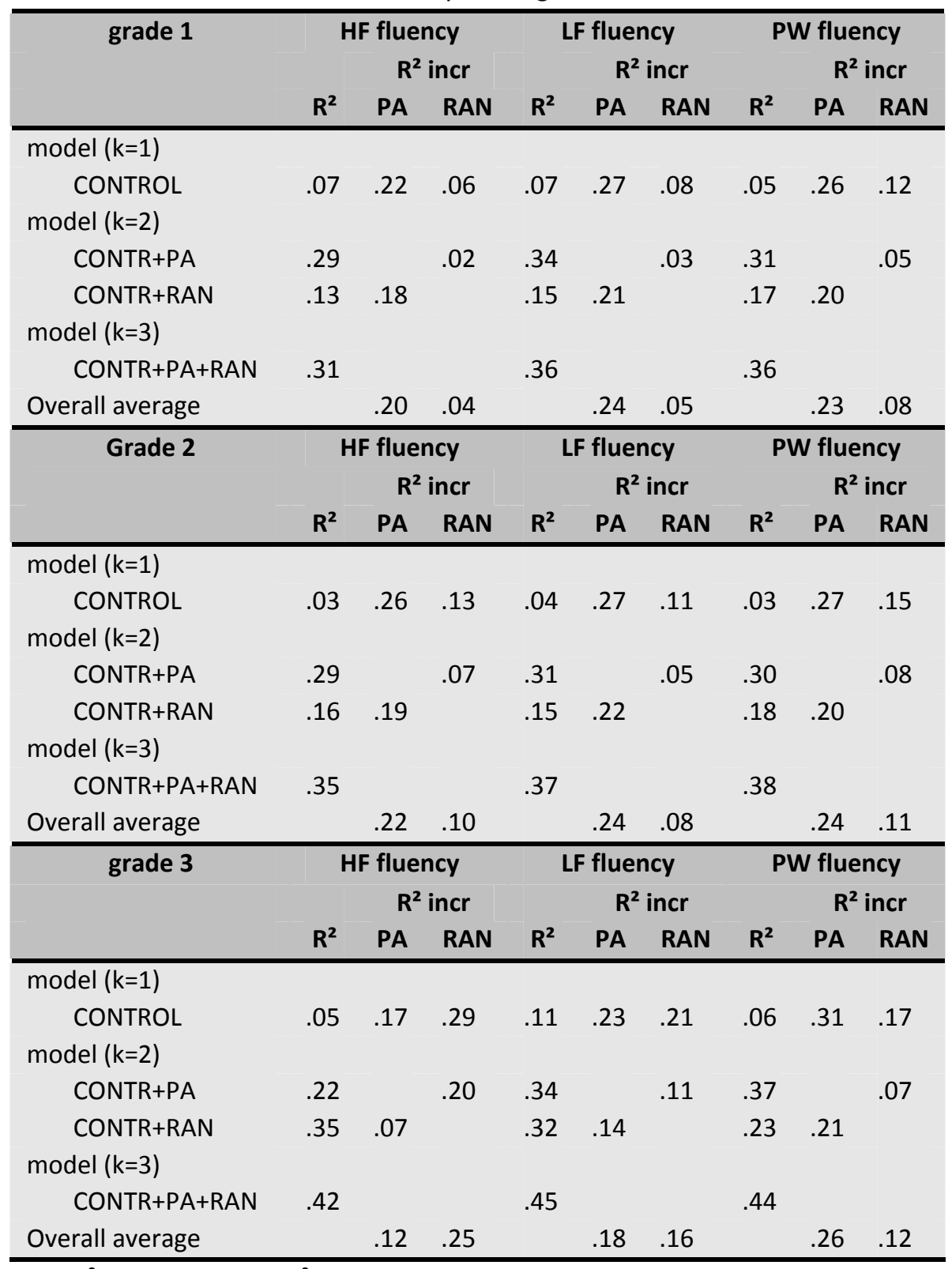

Note: $R^{2}$ incr= increase in $R^{2}$ when variable is added. CONTR= Vocabulary, non-verbal $I Q$, baseline RT, HF=high-frequency word, $\mathrm{LF}=$ low-frequency word, $\mathrm{PW}=$ pseudoword. 
Table 2.4 - Results of dominance analyses for grade 4, 5 and 6

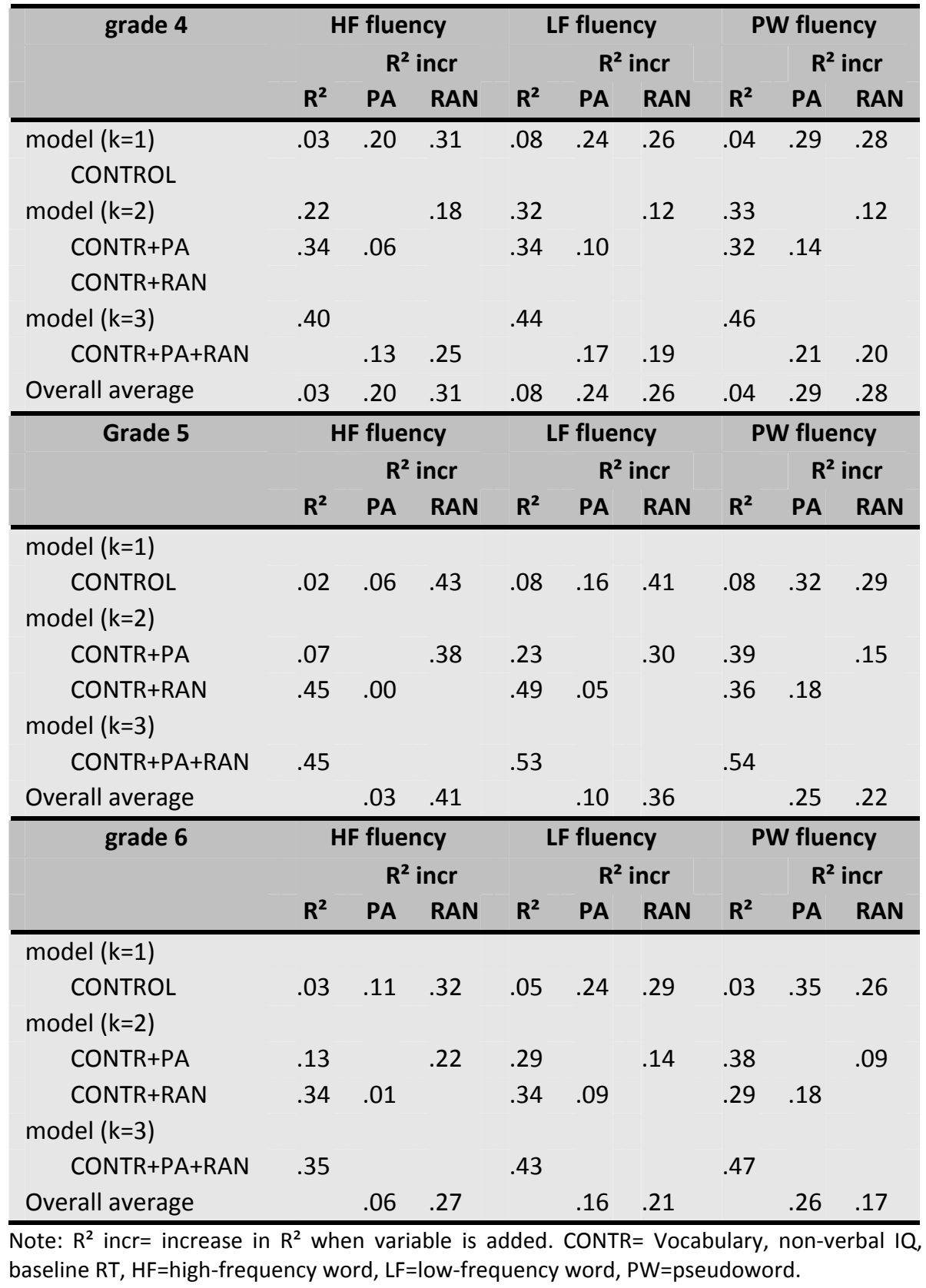


HF words

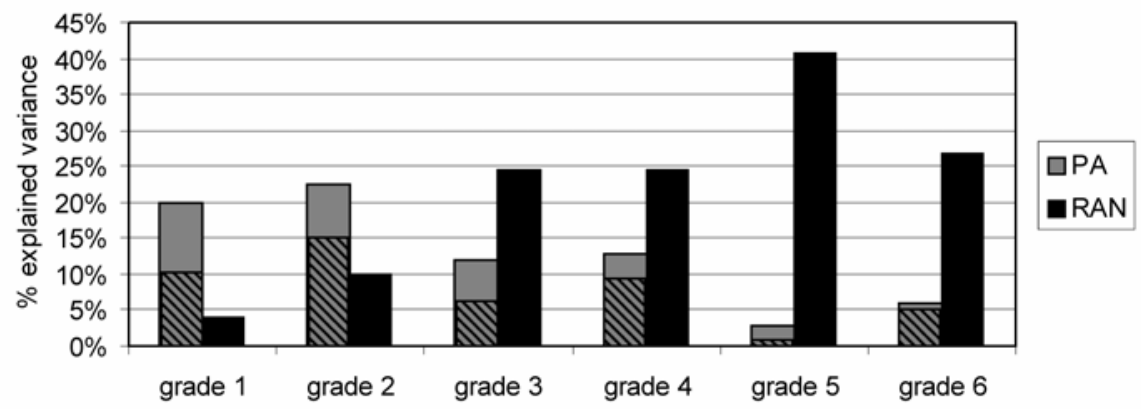

LF words

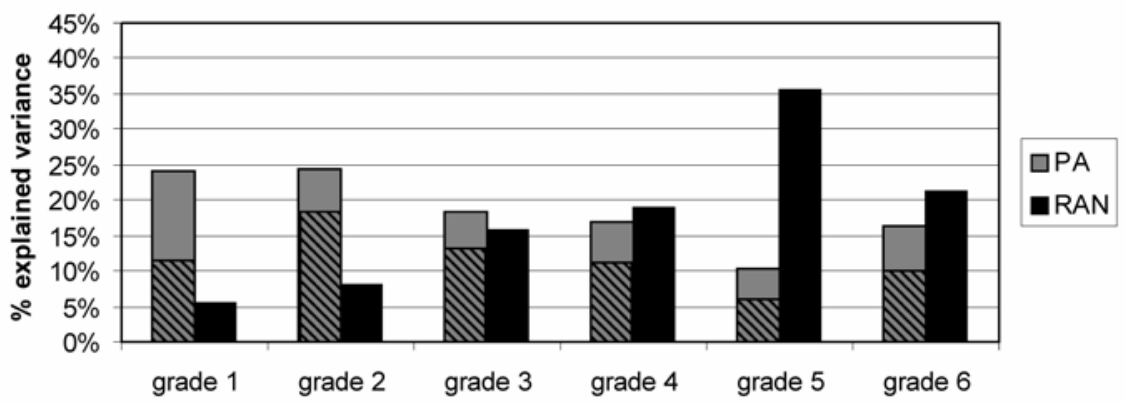

Pseudowords

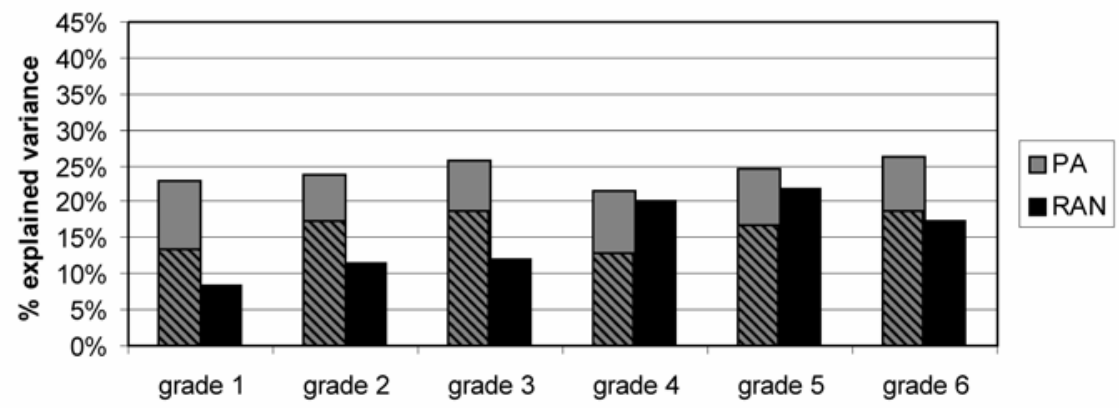

Figure 2.1 - Average contributions of RAN and PA to reading speed of different word types (dashed grey bars represent contributions of PA when measured with accuracy measures only) 
Table 2.5 - Asymptotic 95\% confidence intervals for differences between the contribution of PA and the contribution of RAN

\begin{tabular}{|c|c|c|c|c|c|c|c|c|}
\hline \multirow[b]{2}{*}{ word type } & \multirow[b]{2}{*}{ grade } & \multirow[b]{2}{*}{ PA } & \multirow[b]{2}{*}{ RAN } & \multirow{2}{*}{$\begin{array}{l}\text { diff } \\
\text { PA- } \\
\text { RAN }\end{array}$} & \multirow[b]{2}{*}{ SE } & \multicolumn{2}{|c|}{$\begin{array}{c}\text { Confidence } \\
\text { Interval }\end{array}$} & \multirow{2}{*}{$\begin{array}{c}\text { Compa- } \\
\text { rison } \\
\text { PA-RAN }\end{array}$} \\
\hline & & & & & & lower & Upper & \\
\hline \multirow[t]{6}{*}{ HF fluency } & Grade 1 & .20 & .04 & $.16^{*}$ & .05 & .07 & .25 & PA $>$ RAN \\
\hline & Grade 2 & .22 & .10 & $.13^{*}$ & .03 & .06 & .19 & $P A>R A N$ \\
\hline & Grade 3 & .12 & .25 & $-.13^{*}$ & .04 & -.20 & -.05 & $\mathrm{PA}<\mathrm{RAN}$ \\
\hline & Grade 4 & .13 & .25 & $-.12^{*}$ & .03 & -.18 & -.05 & $\mathrm{PA}<\mathrm{RAN}$ \\
\hline & Grade 5 & .03 & .41 & $-.38 *$ & .05 & -.48 & -.28 & $\mathrm{PA}<\mathrm{RAN}$ \\
\hline & Grade 6 & .06 & .27 & $-.21^{*}$ & .05 & -.31 & -.11 & $\mathrm{PA}<\mathrm{RAN}$ \\
\hline \multirow[t]{6}{*}{ LF fluency } & Grade 1 & .24 & .05 & $.19 *$ & .05 & .09 & .28 & $\mathrm{PA}>\mathrm{RAN}$ \\
\hline & Grade 2 & .24 & .08 & $.16^{*}$ & .04 & .09 & .24 & $\mathrm{PA}>\mathrm{RAN}$ \\
\hline & Grade 3 & .18 & .16 & .03 & .02 & -.01 & .06 & $P A=R A N$ \\
\hline & Grade 4 & .17 & .19 & -.02 & .02 & -.05 & .01 & $P A=R A N$ \\
\hline & Grade 5 & .10 & .36 & $-.25^{*}$ & .05 & -.35 & -.16 & $\mathrm{PA}<\mathrm{RAN}$ \\
\hline & Grade 6 & .16 & .21 & $-.05 *$ & .03 & -.10 & -.01 & $\mathrm{PA}<\mathrm{RAN}$ \\
\hline \multirow[t]{6}{*}{ PW fluency } & Grade 1 & .23 & .08 & $.14^{*}$ & .04 & .06 & .23 & PA $>$ RAN \\
\hline & Grade 2 & .24 & .11 & $.12 *$ & .03 & .06 & .19 & PA>RAN \\
\hline & Grade 3 & .26 & .12 & $.14^{*}$ & .04 & .06 & .21 & PA>RAN \\
\hline & Grade 4 & .21 & .20 & .01 & .01 & -.01 & .04 & $P A=R A N$ \\
\hline & Grade 5 & .25 & .22 & .03 & .02 & -.01 & .06 & $P A=R A N$ \\
\hline & Grade 6 & .26 & .17 & $.09 *$ & .04 & .02 & .16 & $P A>R A N$ \\
\hline
\end{tabular}

Note: $\mathrm{HF}=$ high-frequency word, $\mathrm{LF}=$ low-frequency word, $\mathrm{PW}=$ pseudoword. *difference is significant $(p<.05)$

Table 2.6 - Developmental effects on the contribution of RAN and PA to reading fluency

\begin{tabular}{lccc}
\hline & HF fluency & LF fluency & PW fluency \\
\hline RAN & $.43^{* *}$ & $.36^{* *}$ & $.32^{* *}$ \\
PA & $.29^{* *}$ & $.42^{* *}$ & $.48^{* *}$ \\
Grade & -.00 & .01 & .00 \\
RAN x Grade & $.13^{* *}$ & $.11^{* *}$ & .04 \\
PA x Grade & $-.16^{* *}$ & $-.09^{* *}$ & -.03 \\
& & & $.430^{* * *}$ \\
adj. $\mathrm{R}^{2}$ & $.378^{* * *}$ & $.419^{* * *}$ & .01
\end{tabular}

$* * p<.0001$. 


\subsection{Discussion}

Most theories of reading development assume a shift from slow sequential processing on sub word levels to automatic processing of whole word forms during the acquisition of fluent reading skills. We hypothesized that this shift implies a concomitant shift in the cognitive functions associated with reading. The present study therefore focused on an analysis of the cognitive dynamics of reading fluency in a large sample varying from beginning to experienced readers, using speeded measures for all variables.

Our results revealed that both PA and RAN uniquely and substantially contributed to word reading fluency from the first to the sixth grade of primary school. In addition, we found a gradual change in the contribution of PA and RAN to word, but not pseudoword, reading fluency. PA was most important in beginning readers, while RAN was more important for fluent word reading in experienced readers. Furthermore, the shift in relative importance of the predictors of word reading fluency occurred earlier for high-frequency (HF) words than for low-frequency (LF) words; RAN was the most important predictor of HF word reading fluency in grade 3-4, whereas RAN became the most important predictor of LF words only in grade 5-6. And in contrast to word reading fluency, pseudoword (PW) reading fluency was best predicted by PA in all grades (except in grade 4 and 5 where the contributions of PA and RAN were equally strong). In closing, it is noteworthy that the relationship between vocabulary and reading fluency was weak, which is in agreement with what was reported in a recent cross-language investigation including five European languages varying in orthographic depth (Ziegler et al., in press).

\section{Implications for role of PA and RAN}

Previous studies in transparent orthographies have indicated that PA contributions to reading performance diminish after grade 1 (e.g., de Jong \& van der Leij, 1999; Landerl \& Wimmer, 2008; Lervåg et al., 2009). However, since most of these studies were kindergarten predictor studies investigating the (additional) effect of early PA performance on subsequent reading performance, the decreasing relationship between PA and reading performance could possibly be a consequence of an increasing time between the cognitive measurement and the reading measurement and/or a result of the strong autoregressive effect of reading (see introduction). Moreover, these studies in transparent orthographies typically measured PA with a nonspeeded measure while reading performance was based on a speeded measure, which might have lead to attenuated correlations between PA and reading performance (see also Share, 2008).

Indeed, the results of the present study show that the concurrent relationships between PA and reading performance remain strong at least until the fourth grade. 
Furthermore, the inclusion of PA speed increases the contribution of phonological awareness to reading fluency in the present study (see figure 2.1), emphasizing the importance of including speeded PA measures in future reading research. However, in the context of the research questions it is even more important to notice that we found a clear decrease in the relationship between PA (both accuracy and speed) and word reading fluency as a function of reading experience, despite the fact that all conditions in the present study were optimal to observe strong correlations between PA and reading fluency (compatible measurement-parameters, PA task without ceiling effect, concurrent relationships). Moreover, the slope of this declining relationship was influenced by word-frequency (i.e., the decrease in the relationship between PA and reading was most pronounced for HF words). This suggests that the decreasing influence of PA is not merely a methodological effect or a 'maturational' effect. Rather, it might reflect the build-up of an orthographic lexicon thereby reducing the need for a fine-grained phonological analysis. A comparable argument may hold for the significantly increased contribution of RAN to word reading fluency.

The fact that RAN is also substantially related to pseudoword reading fluency in the present study might indicate that RAN not so much relates to a content specific property of the reading process such as the ability to store word-specific orthographic patterns (see Moll et al., 2009 for similar conclusions), but rather reflect the automation or efficiency of matching visual/orthographic units to their phonological counterparts (see also Bowers \& Ishaik, 2003; Vaessen et al., 2009) or the efficient retrieval of phonological codes (e.g., Torgesen et al., 1997; Wagner \& Torgesen, 1987). Fluent reading of words as well as pseudowords probably relies on the fast, automatic recognition and matching of letter-strings (i.e., words, syllables, consonant-clusters) to corresponding phonological codes (Kronbichler et al., 2007), which might explain why RAN is also involved in pseudoword reading fluency. It is worth mentioning that a general speed explanation of the RAN-reading fluency relationship as offered by Kail and Hall (1994) is not supported by the present data. First, response time on the baseline RT task did not strongly relate to RAN. Second, RAN showed a strong relationship with reading fluency even though the analyses were controlled for baseline RT. And third, a general speed explanation does not explain the specific developmental pattern found in this study.

\section{Theoretical implications for models of reading acquisition}

Although most models of reading acquisition assume a shift from phonological decoding to visual word recognition (see introduction), models differ in how they describe this shift. Stage-based models of reading acquisition assume that readers move through a sequence of reading stages in which one kind of reading 'strategy' dominates. However, our data do not support a strict stage-based model of reading, 
since both PA and RAN are more or less associated with reading fluency at all levels of reading expertise, and changes in the strength of the contributions are gradual. The current results are more in line with models of reading acquisition that describe the transition from phonological decoding to automatic word recognition as a continuous process, such as Ehri's Phase Theory (Ehri, 1995, 2005) and Share's selfteaching hypothesis (Share, 1995; 1999; 2008). The Phase Theory proposes that, across development, children learn to use different decoding strategies for reading. By frequently decoding words letter-by-letter, they develop increasingly efficient strategies to connect print to speech. The view that children develop more efficient recoding strategies over years fits nicely with the current results showing that children learn to read all types of words, including pseudowords more quickly when they become more proficient readers. Moreover, Share's item-based view that the recognition of words by sight depends on the familiarity with an item rather than the developmental stage a child is in, is consistent with the current results showing that the word frequency modulated the developmental course of the relationship between PA, RAN and reading fluency. Words with a high-frequency of occurrence will become familiar more quickly than words with a low-frequency of occurrence, which is in line with our finding that the observed cognitive shift occurred at a later point in time for LF than it did for HF words.

The results of the current study do not seem to support a strict dichotomy between different word types in terms of distinct routes for pseudo words and known words (as proposed by dual route models of reading, e.g., Coltheart, Rastle, Perry, Langdon, \& Ziegler, 2001). The fact that both PA and RAN are involved in reading fluency of different word types and at different levels of reading expertise and the fact that the correlations between pseudoword fluency and word reading fluency remain substantial even in experienced readers point to the development of one and the same reading network for all types of words, in which processing load or type of processing may differ depending on the stimulus properties and amount of reading experience.

\section{Generalizing to other orthographies}

Since the current study only included Dutch children, it does not allow strong conclusions on the role of PA and RAN in more opaque orthographies like English. However, since our results are closely linked to universal theories of reading development, some remarks about the generalisability of the current results are warranted.

It has been suggested that PA is more strongly involved in reading and for a longer period of time in opaque orthographies, while RAN is a less important predictor (see Share, 2008). However, one should be careful directly comparing English-language studies with those conducted in transparent orthographies. Many English-language studies have used accuracy measures to define reading perform- 
ance, while studies in transparent orthographies have used speeded measures of reading. For the same reason the use of speeded reading measures might lead to an underestimation of the role of PA accuracy in transparent orthographies, the use of reading accuracy measures might lead to an underestimation of the role of speeded naming in English (Georgiou, Parilla et al., 2008; Share, 2008). Indeed, English studies that included both speed and accuracy of reading found stronger contributions of RAN to reading speed as compared to reading accuracy (e.g., Bowers, 1995; Cirino, Israelian, Morris, \& Morris, 2005; Katzir et al., 2006; Savage \& Frederickson, 2005; Schatschneider, Fletcher, Francis, Carlson, \& Foorman, 2004).

From a theoretical point of view, it would be awkward not to expect a change in the cognitive dynamics of reading over time in the English orthography, since in all orthographies the quintessence of reading skill is to read fluently and effortlessly, which depends on the fast, automatic recognition of word forms (e.g., Share, 2008). If (as we hypothesize) this shift from slow phonological decoding to fast automatic word recognition is accompanied by a cognitive shift in the contributions of RAN and PA, this cognitive shift should occur in all orthographies, although not necessarily within the same time frame. More developmental cross-linguistic research is needed to compare the relationship between PA, RAN and reading in orthographies varying in transparency.

The present study has some limitations worth mentioning. First, since the present study investigated the concurrent relationships between PA, RAN and reading fluency and did not include preschoolers, interpretations about the causality of the relationship between these cognitive variables and reading fluency are not indicated. Second, our reading fluency measure is a combined speed-accuracy measure (number of words read correctly within time limit). Since beginning readers might show a higher error percentage than more experienced readers, fluency scores in lower grades might actually express reading speed as well as reading accuracy, while in higher grades reading fluency is a purer expression of reading speed. This in turn might bias the strength of the contribution of PA. However, even in grade 1 accuracy levels were high (above $90 \%$ for word reading and around $85 \%$ on pseudoword reading) so we do not expect a strong bias. At the same time the high reading accuracy levels placed constraints on the present data, since we could only reliably test the cognitive dynamics of reading fluency, thereby leaving open the question whether the same pattern of results would be found for reading accuracy. The results of some English-language studies (Badian, 2001; Kirby et al., 2003) however indicate that the reported declining impact of PA on reading can also be found when reading performance is based on accuracy measures. 


\section{Conclusions}

To the best of our knowledge, this is the first study investigating the cognitive dynamics of fluent reading development in 'an unfamiliar-to-familiar/beginner-toexpert framework' (as suggested by Share, 2008) in a large school sample covering all primary school grades, with speeded measures for all reading and all cognitive tasks. The results revealed that PA and RAN considerably contributed to reading performance in all grades, although the strength of the contribution changed. The assumed shift in the quality of the reading process is reflected in a relative and gradual shift in cognitive functions extending over six grades of reading development. The influence of PA on word reading gradually decreased, while RAN became more important for word reading. PA as well as RAN contributed strongly to pseudoword reading fluency at all grades. These results seem to reflect the development of one and the same reading network for all types of words, in which processing load or type of processing may differ depending on the stimulus properties and reading experience.

\section{Acknowledgements}

The present study was partly supported by a grant (608/001/2005) of the Dutch National Board of Health Care Insurance to L. Blomert 


\section{Appendix - correlation matrices per grade}

\begin{tabular}{|c|c|c|c|c|c|c|c|c|c|c|}
\hline Grade 1 & 1 & 2 & 3 & 4 & 5 & 6 & 7 & 8 & 9 & 10 \\
\hline \multicolumn{11}{|l|}{ 1. HF fluency } \\
\hline 2. LF fluency & .93 & & & & & & & & & \\
\hline 3. PW fluency & .89 & .92 & & & & & & & & \\
\hline 4. PA acc & .51 & .53 & .54 & & & & & & & \\
\hline 5. PA speed & .49 & .53 & .49 & .40 & & & & & & \\
\hline 6. RAN letters & .25 & .26 & .34 & .13 & .17 & & & & & \\
\hline 7. RAN digits & .38 & .39 & .40 & .27 & .19 & .36 & & & & \\
\hline 8. RAN object & .30 & .34 & .33 & .20 & .18 & .33 & .51 & & & \\
\hline 9. Vocabulary & .20 & .22 & .19 & .19 & .25 & .14 & .05 & .06 & & \\
\hline 10. non-verbal IQ & .11 & .11 & .09 & .11 & .18 & -.17 & -.04 & .07 & .12 & \\
\hline 11. Baseline RT & .18 & .10 & .12 & .06 & .06 & .24 & .20 & .24 & .08 & .12 \\
\hline Grade 2 & 1 & 2 & 3 & 4 & 5 & 6 & 7 & 8 & 9 & 10 \\
\hline \multicolumn{11}{|l|}{ 1. HF fluency } \\
\hline 2. LF fluency & .93 & & & & & & & & & \\
\hline 3. PW fluency & .82 & .88 & & & & & & & & \\
\hline 4. PA acc & .46 & .49 & .50 & & & & & & & \\
\hline 5. PA speed & .50 & .50 & .50 & .53 & & & & & & \\
\hline 6. RAN letters & .27 & .26 & .28 & .14 & .18 & & & & & \\
\hline 7. RAN digits & .44 & .39 & .44 & .23 & .25 & .50 & & & & \\
\hline 8. RAN object & .28 & .25 & .21 & .27 & .17 & .34 & .46 & & & \\
\hline 9. Vocabulary & .13 & .16 & .14 & .22 & .08 & .07 & -.07 & -.02 & & \\
\hline 10. non-verbal IQ & .20 & .22 & .19 & .32 & .18 & .10 & .12 & .18 & .15 & \\
\hline 11. Baseline RT & .08 & .05 & .05 & .05 & .09 & .05 & .13 & .14 & -.08 & .21 \\
\hline Grade 3 & 1 & 2 & 3 & 4 & 5 & 6 & 7 & 8 & 9 & 10 \\
\hline \multicolumn{11}{|l|}{ 1. HF fluency } \\
\hline 2. LF fluency & .85 & & & & & & & & & \\
\hline 3. PW fluency & .73 & .83 & & & & & & & & \\
\hline 4. PA acc & .43 & .50 & .56 & & & & & & & \\
\hline 5. PA speed & .48 & .55 & .57 & .64 & & & & & & \\
\hline 6. RAN letters & .49 & .40 & .36 & .28 & .29 & & & & & \\
\hline 7. RAN digits & .52 & .46 & .40 & .17 & .25 & .58 & & & & \\
\hline 8. RAN object & .39 & .35 & .27 & .18 & .28 & .44 & .44 & & & \\
\hline 9. Vocabulary & .20 & .30 & .23 & .27 & .19 & .09 & -.02 & .12 & & \\
\hline 10. non-verbal IQ & .18 & .26 & .22 & .28 & .22 & .03 & -.08 & .22 & .32 & \\
\hline 11. Baseline RT & .14 & .13 & .09 & .15 & .18 & .15 & .07 & .23 & -.01 & .28 \\
\hline
\end{tabular}




\begin{tabular}{|c|c|c|c|c|c|c|c|c|c|c|}
\hline Grade 4 & 1 & 2 & 3 & 4 & 5 & 6 & 7 & 8 & 9 & 10 \\
\hline \multicolumn{11}{|l|}{ 1. HF fluency } \\
\hline 2. LF fluency & .83 & & & & & & & & & \\
\hline 3. PW fluency & .69 & .80 & & & & & & & & \\
\hline 4. PA acc & .43 & .48 & .50 & & & & & & & \\
\hline 5. PA speed & .47 & .56 & .57 & .63 & & & & & & \\
\hline 6. RAN letters & .50 & .45 & .46 & .28 & .32 & & & & & \\
\hline 7. RAN digits & .53 & .49 & .49 & .29 & .34 & .63 & & & & \\
\hline 8. RAN object & .30 & .29 & .23 & .21 & .27 & .40 & .43 & & & \\
\hline 9. Vocabulary & .13 & .26 & .20 & .21 & .26 & .07 & .03 & .09 & & \\
\hline 10. non-verbal IQ & .09 & .16 & .10 & .26 & .17 & .05 & -.01 & .18 & .27 & \\
\hline 11. Baseline RT & .11 & .10 & -.01 & .09 & .21 & .10 & .10 & .22 & .09 & .35 \\
\hline Grade 5 & 1 & 2 & 3 & 4 & 5 & 6 & 7 & 8 & 9 & 10 \\
\hline \multicolumn{11}{|l|}{ 1. HF fluency } \\
\hline 2. LF fluency & .82 & & & & & & & & & \\
\hline 3. PW fluency & .59 & .77 & & & & & & & & \\
\hline 4. PA acc & .18 & .35 & .52 & & & & & & & \\
\hline 5. PA speed & .29 & .47 & .58 & .54 & & & & & & \\
\hline 6. RAN letters & .59 & .62 & .53 & .26 & .34 & & & & & \\
\hline 7. RAN digits & .63 & .61 & .48 & .15 & .26 & .71 & & & & \\
\hline 8. RAN object & .44 & .51 & .45 & .28 & .31 & .48 & .55 & & & \\
\hline 9. Vocabulary & .01 & .17 & .21 & .20 & .20 & .11 & -.05 & .16 & & \\
\hline 10. non-verbal IQ & .03 & .08 & .08 & .22 & .04 & .09 & -.02 & .14 & .28 & \\
\hline 11. Baseline RT & .12 & .25 & .22 & .10 & .20 & .11 & .11 & .23 & .23 & .20 \\
\hline Grade 6 & 1 & 2 & 3 & 4 & 5 & 6 & 7 & 8 & 9 & 10 \\
\hline \multicolumn{11}{|l|}{ 1. HF fluency } \\
\hline 2. LF fluency & .71 & & & & & & & & & \\
\hline 3. PW fluency & .55 & .74 & & & & & & & & \\
\hline 4. PA acc & .28 & .41 & .51 & & & & & & & \\
\hline 5. PA speed & .31 & .52 & .54 & .52 & & & & & & \\
\hline 6. RAN letters & .52 & .52 & .47 & .27 & .38 & & & & & \\
\hline 7. RAN digits & .54 & .52 & .49 & .31 & .41 & .69 & & & & \\
\hline 8. RAN object & .36 & .38 & .31 & .26 & .28 & .50 & .48 & & & \\
\hline 9. Vocabulary & -.02 & .15 & .03 & .18 & .18 & .08 & .04 & .07 & & \\
\hline 10. non-verbal IQ & -.03 & -.09 & -.14 & .05 & -.06 & -.15 & -.07 & .01 & .21 & \\
\hline 11. Baseline RT & .14 & .09 & .02 & .10 & .24 & .08 & .10 & .18 & -.03 & .19 \\
\hline
\end{tabular}




\section{References}

Adams, M. J. (1995). Beginning to read. London: MIT Press.

Alf, E. F., \& Graf, R. G. (1999). Asymptotic Confidence Limits for the difference between two squared multiple correlations: a simplified approach. Psychological Methods, 4, 70-75.

Azen, R., \& Budescu, D. V. (2003). The dominance analysis approach for comparing predictors in multiple regression. Psychological Methods, 8(2), 129-148.

Baayen, R. H., Piepenbrock, R., \& Gulikers, L. (1995). The CELEX lexical database.

(CD-ROM). Philadelphia, PA: Linguistic Data Consortium, University of Pennsylvania.

Backman, J., Bruck, M., Hebert, M., \& Seidenberg, M. S. (1984). Acquisition and use of spelling-sound correspondences in reading. Journal of Experimental Child Psychology, 38, 114-133.

Badian, N. A. (2001). Phonological and orthographic processing: Their roles in reading prediction. Annals of Dyslexia, 51, 179-202.

Bast, J., \& Reitsma, P. (1998). Analyzing the development of individual differences in terms of Matthew effects in reading: Results from a Dutch longitudinal study. Developmental Psychology, 34(6), 13731399.

Berninger, V. W., Abbott, R. D., Billingsley, F., \& Nagy, W. (2001). Processes underlying timing and fluency: efficiency, automaticity, coordination and morphological awareness. In M. Wolf (Ed.), Dyslexia, fluency and the brain (pp. 383-414). Timonium, MD: York Press.

Bleichrodt, N., Drenth, P. D., Zaal, J. N., \& Resing, W. C. M. (1988). RAKIT: Revisie Amsterdamse Kinder Intelligentie Test [revision Amsterdam Children Intelligence Test]. Lisse: Swets \& Zeitlinger.

Blomert, L., \& Vaessen, A. (2009). Differentiaal Diagnostiek van Dyslexie: Cognitieve analyse van lezen en spellen [Dyslexia Differential Diagnosis: Cognitive analysis of reading and spelling]. Amsterdam: Boom test publishers BV.

Bowers, P. G. (1995). Tracing symbol naming speed's unique contributions to reading disabilities over time. Reading and Writing: An Interdisciplinary Journal, 7, 189-216.

Bowers, P. G., \& Ishaik, G. (2003). RAN's contribution to understanding reading disabilities. In S. Graham, H. Swanson \& K. R. Lee Harris (Eds.), Handbook of learning disabilities (pp. 140-157). New York, US: Guilford Press.

Bowers, P. G., Sunseth, K., \& Golden, J. (1999). The route between rapid naming and reading progress. Scientific Studies of Reading, 3(1), 31-53.

Bowers, P. G., \& Swanson, L. B. (1991). Naming speed deficits in reading disability: multiple measures of a singular process. Journal of Experimental Child Psychology, 51(2), 195-219.

Bowey, J. A., \& Miller, R. (2007). Correlates of orthographic learning in third-grade children's silent reading. Journal of Research in Reading, 30(2), 115-128.

Brem, S., Bucher, K., Halder, P., Summers, P., Dietrich, T., Martin, E., et al. (2006). Evidence for developmental changes in the visual word processing network beyond adolescence. Neuroimage, 29(3), 822837.

Budescu, D. V. (1993). Dominance Analysis: a new approach to the problem of relative importance of predictors in multiple regression. Psychological Bulletin, 114, 542-551. 
Caravolas, M., Volin, J., \& Hulme, C. (2005). Phoneme awareness is a key component of alphabetic literacy skills in consistent and inconsistent orthographies: evidence from Czech and English children. Journal of Experimental Child Psychology, 92, 107-139.

Castles, A., \& Coltheart, M. (2004). Is there a causal link from phonological awareness to success in learning to read? Cognition, 91(1), 77-111.

Chiappe, P., Stringer, R., Siegel, L. S., \& Stanovich, K. E. (2002). Why the timing deficit hypothesis does not explain reading disability in adults. Reading and Writing: An Interdisciplinary Journal, 15(1-2), 73107.

Cirino, P., Israelian, M. K., Morris, M. K., \& Morris, R. D. (2005). Evaluation of the Double Deficit Hypothesis in college students referred for learning difficulties. Journal of Learning Disabilities, 38(1), 29-44.

Clarke, P., Hulme, C., \& Snowling, M. (2005). Individual differences in RAN and reading: A response timing analysis. Journal of Research in Reading, 28(2), 73-86.

Coltheart, M., Rastle, K., Perry, C., Langdon, R., \& Ziegler, J. (2001). DRC: a dual route cascaded model of visual word recognition and reading aloud. Psychological Review, 108(1), 204-256.

Compton, D. L. (2003). Modelling the relationship between growth in rapid naming speed and growth in decoding skill in first-grade children. Journal of Educational Psychology, 95(2), 225-239.

Compton, D. L., Defries, J. C., \& Olson, R. K. (2001). Are RAN- and phonological awareness-deficits additive in children with reading disabilities? Dyslexia, 7(3), 125-149.

Cornwall, A. (1992). The relationship of phonological awareness, rapid naming, and verbal memory to severe reading and spelling disability. Journal of Learning Disabilities, 25(8), 532-538.

de Jong, P. F., \& van der Leij, A. (1999). Specific contributions of phonological abilities to early reading acquisition: results from a Dutch latent variable longitudinal study. Journal of Educational Psychology, 91(3), 450-476.

de Jong, P. F., \& van der Leij, A. (2002). Effects of phonological abilities and linguistic comprehension on the development of reading. Scientific Studies of Reading, 6(1), 51-77.

Doctor, E. A., \& Coltheart, M. (1980). Children's use of phonological encoding when reading for meaning. Memory and Cognition, 8(3), 195-209.

Ehri, L. C. (1995). Phases of development in learning to read words by sight. Journal of Research in Reading, 18, 116-125.

Ehri, L. C. (2005). Development of sight word reading: Phases and findings. In M. J. Snowling \& C. Hulme (Eds.), The Science of Reading: A Handbook (pp. 135-154). Oxford: Blackwell publishing.

Frith, U. (1986). A developmental framework for developmental dyslexia. Annals of Dyslexia, 36, 69-81.

Georgiou, G. K., Parilla, R., \& Papadopoulos, T. C. (2008). Predictors of word decoding and reading fluency across languages varying in orthographic consistency. Journal of Educational Psychology, 100, 566-580.

Georgiou, G. K., Parrila, R., Kirby, J. R., \& Stephenson, K. (2008). Rapid naming components and their relationship with phonological awareness, orthographic knowledge, speed of processing, and different reading outcomes. Scientific Studies of Reading, 12(4), 325-350.

Goswami, U., \& Bryant, P. (1990). Phonological skills and learning to read. Hove, UK: Lawrence Erlbaum.

Jorm, A. F., \& Share, D. L. (1983). Phonological recoding and reading acquisition. Applied Psycholinguistics, 4, 103-147. 
Kail, R., \& Hall, L. K. (1994). Processing speed, naming speed, and reading. Developmental Psychology, 30(6), 949-954.

Katz, L., \& Shankweiler, D. (1985). Repetitive naming and the detection of word retrieval deficits in the beginning reader. Cortex, 21(4), 617-625.

Katzir, T., Youngsuk, K., Wolf, M., O'Brien, B., Kennedy, B., Lovett, M., et al. (2006). Reading fluency: the whole is more than the parts. Annals of Dyslexia, 56(1), 51-82.

Kirby, J. R., Parrila, R. K., \& Pfeiffer, S. L. (2003). Naming speed and phonological awareness as predictors of reading development. Journal of Educational Psychology, 95(3), 453-464.

Kronbichler, M., Bergmann, J., Hutzler, F., Staffen, W., Mair, A., Ladurner, G., et al. (2007). Taxi vs. taksi: on orthographic word recognition in the left ventral occipitotemporal cortex. Journal of cognitive neuroscience, 19(10), 1584-1594.

Landerl, K., \& Wimmer, H. (2008). Development of word reading fluency and spelling in a consistent orthography: an 8-year follow-up. Journal of Educational Psychology, 100(1), 150-161.

Leppanen, U., Aunola, K., Niemi, P., \& Nurmi, J. (2008). Letter knowledge predicts grade 4 reading fluency and reading comprehension. Learning and Instruction, 18(6), 548-564.

Lervåg, A., Bråten, I., \& Hulme, C. (2009). The cognitive and linguistic foundations of early reading development: A Norwegian latent variable longitudinal study. Developmental Psychology, 45(3), 764.

Levy, B. A., Bourassa, D. C., \& Horn, C. (1999). Fast and slow namers: benefits of segmentation and whole word training. Journal of Experimental Child Psychology, 73(2), 115-138.

Manis, F. R., Doi, L. M., \& Bhadha, B. (2000). Naming speed, phonological awareness, and orthographic knowledge in second graders. Journal of Learning Disabilities, 33(4), 325-333, 374.

Manis, F. R., Seidenberg, M. S., \& Doi, L. M. (1999). See Dick RAN: Rapid naming and the longitudinal prediction of reading subskills in first and second graders. Scientific Studies of Reading, 3(2), 129157.

Mauer, U., Brem, S., Bucher, K., \& Brandeis, D. (2005). Emerging neurophysiological specialization for letter strings. Journal of Cognitive Neuroscience, 17, 1532-1552.

Moll, K., Fussenegger, B., Willburger, E., \& Landerl, K. (2009). RAN is not a measure of orthographic processing: evidence from the asymmetric German orthography. Scientific Studies of Reading, 13, 125.

Morton, J. (1989). An information-processing account of reading acquisition. In A. M. Galaburda (Ed.), From reading to neurons (pp. 43-66). Cambridge, MA: MIT Press.

Muller, K., \& Brady, S. (2001). Correlates of early reading performance in a transparent orthography. Reading and Writing, 14(7-8), 757-799.

Olkin, I., \& Finn, J. D. (1995). correlations redux. Psychological Bulletin, 118, 155-164.

Patel, T. K., Snowling, M. J., \& de Jong, P. F. (2004). A cross-linguistic comparison of children learning to read in English and Dutch. Journal of Educational Psychology, 96(4), 785-797.

Pennington, B. F., Cardoso-Martins, C., Green, P. A., \& Lefly, D. L. (2001). Comparing the phonological and double deficit hypotheses for developmental dyslexia. Reading and Writing: An Interdisciplinary Journal, 14(7-8), 707-755.

Perfetti, C. A., Beck, I., Bell, L. C., \& Hughes, C. (1987). Phonemic knowledge and learning to read are reciprocal: a longitudinal study of first grade children. Merill-Palmer Quarterly, 33(3), 283-319. 
Posner, M., \& McCandliss, B. D. (1999). Brain circuity during reading. In R. M. Klein \& P. A. McMullen (Eds.), Converging Methods for Understanding Reading and Dyslexia (pp. 305-337): MIT Press.

Raven, J., Court, J. H., \& Raven, J. C. (1995). Coloured Progressive Matrices. Oxford: Oxford Psychologists Press Ltd.

Savage, R., \& Frederickson, N. (2005). Evidence of a highly specific relationship between rapid automatic naming of digits and text-reading speed. Brain and language, 93(2), 152-159.

Savage, R., Pillay, V., \& Melidona, S. (2008). Rapid serial naming is a unique predictor of spelling in children. Journal of Learning Disabilities, 41(3), 235-250.

Schatschneider, C., Fletcher, J. M., Francis, D. J., Carlson, C. D., \& Foorman, B. R. (2004). Kindergarten Prediction of Reading skills: a longitudinal comparative analysis. Journal of Educational Psychology, 96(2), 265-282.

Schlaggar, B. L., \& McCandliss, B. D. (2007). Development of neural systems for reading. Annual Review of Neuroscience, 30, 475-503.

Share, D. L. (1995). Phonological recoding and self-teaching: sine qua non of reading acquisition. Cognition, 55, 151-218.

Share, D. L. (1999). Phonological recoding and orthographic learning: A direct test of the self-teaching hypothesis. Journal of Experimental Child Psychology, 72(2), 95-129.

Share, D. L. (2008). On the Anglocentricities of current reading research and practice: The perils of overreliance on an 'outlier' orthography. Psychological Bulletin, 134(4), 584-615.

Sprenger-Charolles, L., Siegel, L. S., Bechennec, D., \& Serniclaes, W. (2003). Development of phonological and orthographic processing in reading aloud, in silent reading, and in spelling: A four-year longitudinal study. Journal of Experimental Child Psychology, 84, 194-217.

Stoolmiller, M., \& Bank, L. (1995). Autoregressive effects in structural equation models: we see some problems. In J. Gottman (Ed.), The analysis of change. Mahwah, NJ: Lawrence Erlbaum Associates, Inc.

Sunseth, K., \& Bowers, P. G. (2002). Rapid naming and phonemic awareness: Contributions to reading, spelling, and orthographic knowledge. Scientific Studies of Reading, 6(4), 401-429.

Torgesen, J. K., Wagner, R. K., \& Rashotte, C. A. (1994). Longitudinal studies of phonological processing and reading. Journal of Learning Disabilities, 27(5), 276-286; discussion 287-291.

Torgesen, J. K., Wagner, R. K., Rashotte, C. A., Burgess, S. R., \& Hecht, S. A. (1997). Contributions of phonological awareness and rapid automatic naming ability to the growth of word-reading skills in second- to fifth-grade children. Scientific Studies of Reading, 1(2), 161-185.

Vaessen, A. A., Gerretsen, P., \& Blomert, L. (2009). Naming problems do not reflect a second, independent core deficit in dyslexia: 'Double deficits' explored. Journal of Experimental Child Psychology, 103, 202-221.

Van Bon, W. H. J. (1986). Raven's coloured progressive matrices. Nederlandse normen en enige andere uitkomsten van onderzoek. Lisse, NL: Swets \& Zeitlinger.

van den Bos, K. P., Zijlstra, B. J. H., \& lutje Spelberg, H. C. (2002). Life-span data on continuous-naming speeds of numbers, letters, colors, and pictured objects, and word-reading speed. Scientific Studies of Reading, 6(1), 25-49. 
van den Bos, K. P., Zijlstra, B. J. H., \& van den Broeck, W. (2003). Specific relations between alphanumeric-naming speed and reading speeds of monosyllabic and multisyllabic words. Applied Psycholinguistics, 24, 407-430.

Wagner, R. K., \& Torgesen, J. K. (1987). The nature of phonological processing and its causal role in the acquisition of reading skills. Psychological Bulletin, 101(2), 192-212.

Wagner, R. K., Torgesen, J. K., \& Rashotte, C. A. (1994). Development of reading-related phonological processing abilities: New evidence of bidirectional causality from a latent variable longitudinal study. Developmental Psychology, 30(1), 73-87.

Wagner, R. K., Torgesen, J. K., Rashotte, C. A., Hecht, S. A., Barker, T. A., Burgess, S. R., et al. (1997). Changing relations between phonological processing abilities and word-level reading as children develop from beginning to skilled readers: a 5-year longitudinal study. Developmental Psychology, $33(3), 468-479$.

Wile, L. T., \& Borowsky, R. (2004). What does rapid automatized naming measure? A new RAN task compared to naming and lexical decision. Brain and Language, 90, 47-62.

Wolf, M., \& Bowers, P. G. (1999). The double-deficit hypothesis for the developmental dyslexias. Journal of Educational Psychology, 91(3), 415-438.

Ziegler, J. C., Bertrand, D., Toth, D., Csepe, V., Reis, A., Faisca, L., et al. (in press). Orthographic Depth and its impact on universal predictors of reading: a cross-language investigation. Psychological Science.

Ziegler, J. C., \& Goswami, U. (2005). Reading acquisition, developmental dyslexia, and skilled reading across languages: a psycholinguistic grain size theory. Psychological Bulletin, 131(1), 3-29. 


\section{Chapter 3}

\section{Impact of orthographic consistency on the cognitive predictors of reading skills in grade 2}

This chapter is based on:

Ziegler, J.C., Bertrand, D. Tóth, D., Csépe, V. Reis, R. Faísca , L., Saine, N., Lyytinen, H., Vaessen , A. \& Blomert, L. (in press). Orthographic Depth And Its Impact On Universal Predictors Of Reading: A Cross-language Investigation. Psychological Science. 


\begin{abstract}
Alphabetic orthographies differ in the transparency of their letter-sound mappings, with English orthography being less transparent than other alphabetic scripts. The outlier status of English has led scientists to question the generality of findings based on English-language studies. We investigated the role of phonological awareness, memory, vocabulary, rapid naming, and nonverbal intelligence in reading performance across five languages lying at differing positions along a transparency continuum (Finnish, Hungarian, Dutch, Portuguese, and French). Results from a sample of 1,265 children in Grade 2 showed that phonological awareness was the main factor associated with reading performance in each language. However, its impact was modulated by the transparency of the orthography, being stronger in less transparent orthographies. The influence of rapid naming was rather weak and limited to reading and decoding speed. Most predictors of reading performance were relatively universal across these alphabetic languages, although their precise weight varied systematically as a function of script transparency.
\end{abstract}




\subsection{Introduction}

Alphabetic orthographies differ with respect to how consistently letters map onto sounds. For example, in Finnish, Italian or Greek, the same letter is almost always pronounced the same in different words. These writing systems are referred to as consistent or transparent. In contrast, in English and to a lesser degree in French, the same letter is often pronounced differently in different words (e.g., "a" in cat, was, saw, made, and car). These writing systems are referred to as inconsistent or opaque. The orthographic consistency of a writing system has been shown to influence skilled reading (Frost, Katz, \& Bentin, 1987; Ziegler, Perry, Jacobs, \& Braun, 2001).

Most importantly, however, it has become clear over the past decade that orthographic consistency is the key factor determining the rate of reading acquisition across different languages (for review, see Ziegler \& Goswami, 2005). One of the most striking demonstrations comes from a cross-language investigation, in which reading performance was measured at the end of grade 1 in 14 European countries (Seymour, Aro, \& Erskine, 2003b). While reading accuracy in most transparent languages (e.g., Italian, German, Greek, Spanish, Finnish) reached ceiling after the first year, reading performance in less transparent languages (e.g., Portuguese, French, Danish) was lower, around 80\%. However, reading performance in English, the least transparent of the above orthographies, was only $34 \%$. This basic finding has been replicated in a number of small-scale experiments (Bruck, Genesee, \& Caravolas, 1997; Ellis \& Large, 1987; Frith, Wimmer, \& Landerl, 1998; Goswami, Gombert, \& de Barrera, 1998; Goswami, Ziegler, Dalton, \& Schneider, 2001).

The outlier position of English has led some scientists to question the very foundations of our knowledge on skilled reading, reading development and dyslexia. For example, Share (2008) recently argued that "the extreme ambiguity of English spelling-sound correspondence has confined reading science to an insular, anglocentric research agenda addressing theoretical and applied issues with limited relevance for a universal science of reading" (p. 584). The most worrisome concern is that English-based research might have over-estimated the importance of phonological awareness in reading development (Landerl \& Wimmer, 2000; Share, 2008). This is an important concern because phonological awareness has been argued to be the most important predictor of reading development in English (e.g., Schatschneider et al., 2004; Share, Jorm, Maclean, \& Matthews, 1984).

Phonological awareness typically refers to our ability to identify and manipulate units of sound (e.g., deleting the initial phoneme of a spoken word). Phonological awareness does not only predict reading level of normally developing children but also poor reading and dyslexia (e.g., Bradley \& Bryant, 1983). Phonological awareness has been shown to predict reading outcomes even before reading instruction 
(Puolakanaho et al., 2007). Moreover, training phonological awareness skills significantly improves children's ability to read and spell (Ehri et al., 2001).

Why would English-based research have exaggerated the effects of phonological awareness? It is well known that the link between phonological awareness and reading is bidirectional. High levels of phonological awareness facilitate reading development - at the same time, successful reading development boosts phonological awareness skills (Perfetti, Beck, Bell, \& Hughes, 1987). Phonological awareness of the smallest units of sounds, namely phonemes, might actually only develop through learning to read and write (Castles \& Coltheart, 2004). If so, transparent orthographies with a one-to-one mapping between letters and sounds should naturally promote high levels of phonological awareness. As a consequence, phonological awareness might be a weaker predictor of reading development in transparent than in opaque orthographies. In contrast, rapid automatized naming (RAN) has been argued to be more important in transparent than opaque orthographies (e.g., de Jong \& van der Leij, 2003; Wimmer, Mayringer, \& Landerl, 2000).

These predictions have been tested in a number of cross-language studies that typically compared English with one other language. However, the results are rather mixed. While some studies found that phonological awareness was only important in English but not than in other languages, such as Greek or German (Georgiou, Parrila, \& Papadopoulos, 2008; Mann \& Wimmer, 2002), others found that phonological awareness was equally important both in English and other languages, such as Dutch and Czech (Caravolas, Volin, \& Hulme, 2005; Patel et al., 2004). Similarly, while some have shown that RAN was more important in transparent languages than in English (Georgiou, Parrila, \& Papadopoulos, 2008; Mann \& Wimmer, 2002), others reported equal influences across languages (Patel et al., 2004).

\section{The present study}

The goal of the present study was to shed new light on whether orthographic transparency influences predictors of reading development. The novelty of our approach was to compare a number of languages with scripts ranging from transparent (Finnish) to less transparent (French). With regard to phonological awareness, three distinct claims can be distinguished. The first is that phonological awareness should be the most important factor in each language ("strong claim"). The second is that phonological awareness should be important in all languages but its impact might vary across languages ("weak claim"). Finally, the third is that phonological awareness should be equally important in all languages. Apart from phonological awareness, we were interested in other commonly studied factors, such as short term memory (PSTM), RAN, vocabulary knowledge (VOCAB) and nonverbal intelligence (NVIQ). 
Orthographic transparency was quantified using entropy computations for the initial letter-sound mapping in each language (Borgwaldt et al., 2005). The advantage of using word onsets is that one can meaningfully compare languages with different orthographic and phonological structures because all of them have word onsets. Thus, onset entropy provides a fairly objective and assumption-free index of the transparency of a writing system (see also below). The mean entropy values for the five languages used in the present study are presented in Table 3.1 along with English as a comparison.

Table 3.1 - Onset entropy measures for English and the 5 languages used in the present study.

\begin{tabular}{lccc}
\hline Language & $\begin{array}{c}\text { Number } \\
\text { of Letters }\end{array}$ & $\begin{array}{c}\text { Number of } \\
\text { Phonemes }\end{array}$ & $\begin{array}{c}\text { Entropy } \\
\text { value* }\end{array}$ \\
\hline Finnish & 24 & 24 & 0.00 \\
Hungarian & 33 & 62 & 0.17 \\
Dutch & 30 & 41 & 0.23 \\
Portuguese & 41 & 31 & 0.42 \\
French & 33 & 36 & 0.46 \\
English & 27 & 46 & 0.83 \\
\hline
\end{tabular}

Note: ${ }^{*}$ the higher the entropy value, the more inconsistent the writing system

The basic design of the study is summarized in Figure 3.1. In short, we were interested in how five major cognitive components relate to reading and decoding across five different languages. The general approach was to use a multi-level analysis with Level 1 representing the individual subject level and Level 2 representing entropy.

Within each country, we targeted a grade 2 school population. A total of 1263 children participated in the study. For each country, a test battery was developed that measured reading and decoding along with the five predictor variables. Note that one of the trickiest issues in cross-language research is to devise parallel tests that can be compared across different countries in a meaningful way. One strategy is to use literally identical material across languages (Frith et al., 1998; Landerl, Wimmer, \& Frith, 1997; Ziegler et al., 2001). However, this strategy only works for languages that are fairly similar with respect to orthographic and phonological structure, such as German and English. When languages differ on too many dimensions, this strategy does no longer work. In this case, creating parallel tests by simply translating a "common" test into different languages is likely to produce insensitive and artificial tests that are often subject to ceiling effects (e.g., Seymour et al., 2003). Thus, a more appropriate strategy consists of using language-specific tests 
that are maximally sensitive for measuring a particular component in a given language. Performance on these language-specific tests can then be compared by standardizing performance within each country before comparing it across different countries. Thus, rather than comparing absolute performance levels across countries, the present approach consisted of comparing z-score distributions across countries, thus creating a common meaningful scale for the cross-language comparison.

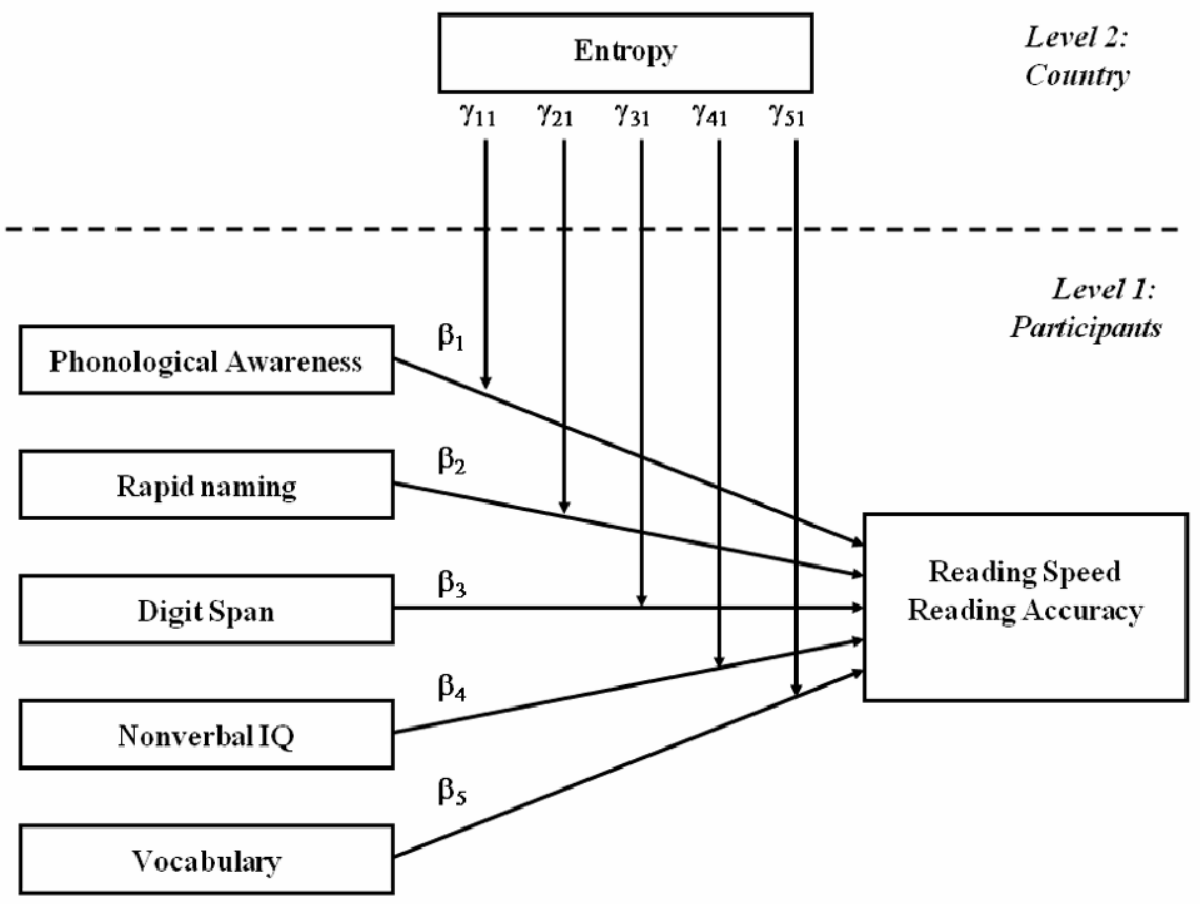

Figure 3.1 - Basic design of the study displaying the five factors that influence reading at the individual level (Level 1) and their potential modulation by script entropy (Level 2). 


\subsection{Methods}

\section{Entropy Measure}

Entropy for initial letter-sound mappings was calculated as

$$
H=\sum p_{i} \log _{2} 1 / p_{i}(1),
$$

where $\mathrm{p} 1$ is the probability of the first pronunciation of a given letter, $\mathrm{p} 2$ is the probability of the second pronunciation of the letter (if a second pronunciation exists), and so on for all $\mathrm{n}$ possible pronunciations of that letter. If a letter always corresponds to one phoneme, then its entropy value is zero (e.g., Finland). The greater the number of pronunciations of a letter, the higher its entropy value. The values for Hungarian, Dutch, Portuguese, French and English were taken from Borgwaldt et al. (2005). The values for Finnish were calculated using the Finnish Text Collection (FTC) corpus. One concern is to what extent the onset measure is comparable to measures that have been used in previous studies, such as rhyme consistency (Ziegler, Stone \& Jacobs, 1997). Perry and Ziegler (2002, Table 3.1) compared spelling-to-sound entropy for onsets and rhymes in German and English and found fairly similar values for onsets and rhymes. Moreover, if one compares onset and rhyme consistency in languages with many monosyllabic words (e.g., German, English, French, Dutch), for which both onset and rhyme entropy can be computed, one finds exactly the same entropy rank order regardless of whether the onset or the rhyme was used for the computation.

\section{Participants}

The study was conducted in five different European countries: Finland, France, Hungary, Netherlands, and Portugal. Each partner selected a sample of children in grade $2(\mathrm{~N}=1263$ ) that was thought to be typical of the country's grade 2 students in terms of socio-economic makeup, ethnic composition, level of reading achievement and overall cognitive performance. They were tested in the second half of the school year (between January and June) ${ }^{1}$. The sample consisted of 166 Finnish children (aged $107.6 \pm 4.2$ months), 181 French children (aged $92.4 \pm 6.2$ months), 139 Hungarian children (aged $105.9 \pm 6.4$ months), 597 Dutch children (aged $93.3 \pm 5.3$ months), and 182 Portuguese children (aged $92.4 \pm 5.7$ months). Percentage of boys per country is presented in table 3.2 .

\footnotetext{
${ }^{1}$ In Finland, phonological awareness and rapid naming were tested at the end of first grade.
} 


\section{Tasks}

Word Reading - Reading speed and accuracy was measured in each country with a language-specific version of the One-Minute-Reading test. This choice was ideal for the present purpose because a standardized version of this test was available in each country. In this test, children were asked to read during 1 minute as many words as possible from word list ordered in terms of word difficulty. Reading speed was taken as the number of words read per second; reading accuracy the percentage of words read aloud correctly amongst the words read.

Phonological Decoding - Each partner devised a list of legal pronounceable pseudowords that were representative for each language and writing system. Pseudowords were created such that they were maximally similar to the real words by replacing a single letter or letter cluster either at the beginning, middle or end of a real word. All plausible pronunciations were taken as correct. Decoding speed was defined as the number of pseudowords read correctly by second; decoding accuracy was the percentage of words read aloud correctly amongst the words read.

Phonological Awareness (PA) - PA was assessed by a classic phoneme deletion task in words and pseudowords. Because classic phoneme deletion tasks tend to be at ceiling in the fully transparent Finnish orthography, a more complex PA task focusing on the comparison of final phonemes was used in Finland. All tests were again language-specific in the sense that each partner selected the phonological structures that were the most typical for the respective language (e.g., CVCVCV in Finland; CVCVC in France, etc.). The dependent variable was the percentage of correct responses.

Rapid Automatized Naming (RAN) - The object version of the original RAN task was used in each country (Denckla \& Rudel, 1974). That is, a child was presented with an object matrix that contained the line drawings of 5 objects that were randomly repeated. Children had to name the objects as rapidly as possible. The dependent variable was the number of correctly named items per second.

Phonological Short Term Memory (PSTM) - PSTM was assessed using the forward digit span task from the Wechsler Intelligence Scale for Children (WISC). In this test, children were asked to repeat a sequence of digits in the exact same order (2 trials per sequence length, sequence lengths going from 2 to 9 digits). The task stopped when the child failed both trials of a given length. The dependent variable was memory span, which corresponds to the largest sequence that a child could report correctly.

Nonverbal IQ (NVIQ) - NVIQ was assessed with one of two standardized tests. Finland and France used the non verbal subtests (Picture completion, Block design, Object assembly and Coding) from the WISC-III. Hungary used Block design from the WISC IV. Netherlands and Portugal used Raven's Progressive Matrices. 
Vocabulary - The vocabulary subtest of the WISC was used in all countries except for the Netherlands where a passive vocabulary test was used.

\subsection{Results}

Absolute performance on reading and decoding across the five countries is shown in table 3.2. Below, we will focus on simultaneous regressions for each country and multi-level analyses of reading speed and accuracy.

Table 3.2 - Percentage boys and means and (standard deviations) on reading tasks within each country

\begin{tabular}{lccccc}
\hline & $\begin{array}{c}\text { Finland } \\
(\mathbf{N}=166)\end{array}$ & $\begin{array}{c}\text { Hungary } \\
(\mathbf{N}=139)\end{array}$ & $\begin{array}{c}\text { Netherlands } \\
(\mathbf{N}=597)\end{array}$ & $\begin{array}{c}\text { Portugal } \\
(\mathbf{N}=182)\end{array}$ & $\begin{array}{c}\text { France } \\
(\mathbf{N}=181)\end{array}$ \\
\hline \% of boys & $47 \%$ & $56 \%$ & $50 \%$ & $45 \%$ & $58 \%$ \\
Reading & .51 & .84 & 1.06 & .58 & .51 \\
speed & $(0.11)$ & $(0.30)$ & $(0.33)$ & $(0.27)$ & $(0.26)$ \\
Decoding & .60 & .74 & .71 & .53 & .61 \\
speed & $(0.17)$ & $(0.24)$ & $(0.22)$ & $(0.22)$ & $(0.16)$ \\
& & & & & \\
Reading & 91.90 & 93.53 & 95.02 & 82.42 & 68.06 \\
accuracy & $(11.36)$ & $(7.72)$ & $(7.15)$ & $(16.90)$ & $(18.69)$ \\
Decoding & 80.26 & 86.92 & 85.19 & 82.67 & 76.17 \\
accuracy & $(23.21)$ & $(14.20)$ & $(13.77)$ & $(19.12)$ & $(20.71)$ \\
\hline
\end{tabular}

\section{Regression Analyses by Country}

The raw data of each variable were transformed into z-scores for each country. Simultaneous regression analyses were conducted separately for each country for reading (accuracy and speed) and decoding (accuracy and speed). The standardized beta weights and the amount of variance accounted for are presented in Table 3.3 for each country.

Inspection of Table 3.3 shows that the regression structure was fairly similar across countries (for the full correlation matrix, see appendices). 
Table 3.3 - Standardized regression coefficients resulting from simultaneous regression analyses using the five factors as predictors for reading skills within each country.

\begin{tabular}{|c|c|c|c|c|c|}
\hline & $\begin{array}{l}\text { Finland } \\
(\mathrm{N}=166)\end{array}$ & $\begin{array}{l}\text { Hungary } \\
(\mathrm{N}=139)\end{array}$ & $\begin{array}{c}\text { Netherlands } \\
(\mathrm{N}=597)\end{array}$ & $\begin{array}{l}\text { Portugal } \\
(\mathrm{N}=182)\end{array}$ & $\begin{array}{c}\text { France } \\
(\mathrm{N}=181)\end{array}$ \\
\hline \multicolumn{6}{|c|}{ Reading Speed } \\
\hline PA & $.31 * * *$ & $.49 * * *$ & $.41 * * *$ & $.54 * * *$ & $.53 * * *$ \\
\hline RAN & .08 & $.30 * * *$ & $.12 * *$ & $.15 *$ & .11 \\
\hline PSTM & .03 & .04 & .04 & -.01 & .05 \\
\hline VOC & $.32 * * *$ & -.12 & .06 & -.01 & $.14^{*}$ \\
\hline NVIQ & -.05 & -.10 & .03 & .09 & .03 \\
\hline $\mathrm{R}_{\mathrm{adj}}{ }^{2}$ & .25 & .34 & .23 & .41 & .38 \\
\hline \multicolumn{6}{|c|}{ Reading Accuracy } \\
\hline PA & $.27 * * *$ & $.45 * * *$ & $.39 * * *$ & $.49 * * *$ & $.52 * * *$ \\
\hline RAN & .05 & .11 & .05 & .12 & .05 \\
\hline PSTM & $-.26 *$ & $.22 *$ & .05 & .07 & .08 \\
\hline VOC & $.41 * * *$ & -.10 & .00 & -.02 & .06 \\
\hline NVIQ & .05 & -.14 & .05 & -.03 & .03 \\
\hline$R_{\mathrm{adj}}{ }^{2}$ & .21 & .28 & .19 & .31 & .32 \\
\hline \multicolumn{6}{|c|}{ Decoding Speed } \\
\hline PA & $.18 *$ & $.44 * * *$ & $.33 * * *$ & $.55 * * *$ & $.40 * * *$ \\
\hline RAN & .06 & $.29 * *$ & $.10^{* *}$ & $.13 *$ & $.16^{*}$ \\
\hline PSTM & .19 & -.07 & .06 & .01 & .02 \\
\hline VOC & .09 & -.11 & .00 & -.01 & .12 \\
\hline NVIQ & -.17 & -.13 & -.00 & .11 & .00 \\
\hline $\mathrm{R}_{\mathrm{adj}}{ }^{2}$ & .05 & .24 & .15 & .43 & .24 \\
\hline \multicolumn{6}{|c|}{ Decoding Accuracy } \\
\hline PA & $.38 * * *$ & $.38 * * *$ & $.40 * * *$ & $.43 * * *$ & $.55 * * *$ \\
\hline RAN & .08 & .01 & -.06 & .02 & .12 \\
\hline PSTM & .11 & $.32 * * *$ & $.10 * *$ & $.15^{*}$ & -.01 \\
\hline VOC & $.36 * * *$ & -.14 & .06 & .02 & .06 \\
\hline NVIQ & .01 & -.04 & .08 & -.03 & -.02 \\
\hline $\mathrm{R}_{\mathrm{adj}}{ }^{2}$ & .33 & .26 & .22 & .24 & .34 \\
\hline
\end{tabular}

Note: PA, Phonological Awareness; RAN, Rapid Automatized Naming; PSTM, Phonological Short Term Memory; VOCAB, Vocabulary; NVIQ, Nonverbal Intelligence; $R_{a d j}{ }^{2}$, adjusted variance accounted for; ${ }^{*}, \mathrm{p} \leq .05 ;{ }^{* *}, \mathrm{p} \leq .01 ; * *, \mathrm{p} \leq .001$ 
Most notably, PA was the strongest correlate of reading (speed and accuracy) in all countries but Finland. For pseudoword decoding, PA was the strongest correlate in all countries. RAN was a significant correlate of reading and decoding speed but not accuracy in most countries (the exceptions were Finland both for reading and decoding speed and France for reading speed). However, the influence of RAN was much weaker than that of PA. PSTM had a significant influence on reading and decoding accuracy but not speed in a few countries, most notably Hungary. VOCAB predicted reading and decoding in Finland and reading speed in France. Finally, NVIQ had no significant influence on reading or decoding.

\section{Multi-level Regression Analysis}

Multi-level regressions were conducted to investigate the impact of script entropy on the various components of reading and decoding using a two level hierarchical linear model with the effects of script entropy being represented at Level 2 and the effects the five components on reading being represented at Level 1 (see Figure 3.1). The analyses were performed using the HLM procedure (Proc Mixed) of SAS 9.1. Maximum likelihood estimation with robust standard errors was used to estimate the parameters, and the overall fit of the models was evaluated on the basis of examination of the likelihood ratio test. The results for the reading outcomes are presented in Table 3.4.

The Level 1 correlations showed that PA, RAN, PSTM and VOCAB were all positively regressed onto reading speed and accuracy. According to the regression coefficients $(\beta)$, PA was the most important factor in predicting reading speed and accuracy. On Level 2, entropy had a statistically significant positive influence on the relationship between $P A$ and reading and a significantly negative influence on the relationship between VOCAB and reading. This suggests that the impact of PA on reading was more important when entropy was high (i.e., inconsistent scripts) than when entropy was low (i.e., consistent scripts). On the contrary, the impact of VO$\mathrm{CAB}$ on reading was stronger when entropy was low. To check whether this result was mainly due to the Finnish sample, the HLM analysis was repeated without the Finnish sample. The results showed that the effects of entropy on VOCAB were no longer significant thus confirming that they were largely due to the Finnish sample. 
Table 3.4 - Regression coefficients from the HLM analyses using Participants at level 1 and Entropy at level 2

\begin{tabular}{|c|c|c|c|c|}
\hline & $\begin{array}{l}\text { Reading } \\
\text { speed }\end{array}$ & $\begin{array}{l}\text { Reading } \\
\text { acc }\end{array}$ & $\begin{array}{l}\text { Decoding } \\
\text { speed }\end{array}$ & $\begin{array}{c}\text { Decoding } \\
\text { acc }\end{array}$ \\
\hline \multicolumn{5}{|c|}{ Level 1: individuals } \\
\hline Intercept & $-.900 * *$ & $-.761 *$ & $-.399(*)$ & $-.856\left(^{*}\right)$ \\
\hline $\mathrm{x}_{1}: \mathrm{PA}$ & $.381 * * *$ & $.604 * * *$ & $.182 * * *$ & $.718 * * *$ \\
\hline $\mathrm{x}_{2}:$ RAN & $.164 *$ & .081 & .082 & .016 \\
\hline$x_{3}:$ PSTM & $.146\left(^{*}\right)$ & .063 & $.157 *$ & $.293 * * *$ \\
\hline $\mathrm{x}_{4}: \mathrm{NVIQ}$ & -.030 & -.011 & -.095 & .014 \\
\hline$x_{5}:$ VOC & $.244 * * *$ & $.381 * *$ & -.053 & $.397 * * *$ \\
\hline \multicolumn{5}{|c|}{ Level 2: entropy } \\
\hline Intercept & .903 & .623 & .105 & 1.278 \\
\hline $\mathrm{x}_{1}: \mathrm{PA}$ & $.445 *$ & $.689 *$ & $.687 * * *$ & -.351 \\
\hline$x_{2}:$ RAN & .091 & .230 & .341 & .087 \\
\hline$x_{3}:$ PSTM & -.325 & .224 & $-.385(*)$ & -.471 \\
\hline $\mathrm{x}_{4}: \mathrm{NVIQ}$ & .192 & .084 & $.303 *$ & -.079 \\
\hline$x_{5}: \mathrm{VOC}$ & -.422 & $-1.047 *$ & .359 & $-.980 * *$ \\
\hline$\Delta-2 \mathrm{LL}$ & $11.6\left(^{*}\right)$ & $10.7\left(^{*}\right)$ & $38.6 * * *$ & $26.5^{* * *}$ \\
\hline$\Delta$ Parameters & 6 & 6 & 6 & 6 \\
\hline
\end{tabular}

Note. Level 1, Individuals; Level 2, Language/Entropy; PA, Phonological Awareness; RAN, Rapid Automatized Naming; PSTM, Phonological Short Term Memory; VOC, Vocabulary; NVIQ, Nonverbal Intelligence; -2LL, -2Log-Likelihood; *, $\mathrm{p} \leq .05 ;{ }^{* *}, \mathrm{p} \leq .01 ;{ }^{* *}, \mathrm{p} \leq .001$.

The decoding data yielded similar results. Entropy had a statistically significant positive influence on the relationship between PA and decoding and a significantly negative influence on the relationship between VOCAB and decoding. Thus, as for reading, the influence of $P A$ and $V O C A B$ were modulated such that $P A$ was a more important component in opaque orthographies while VOCAB was a more important component in transparent orthographies. Again, the effects of VOCAB disappeared when Finnish was excluded from the analysis. 


\subsection{Discussion}

The main goal of this study was to investigate the major components of reading across five languages that vary systematically in script transparency. The most important question concerned the importance of PA as a universal predictor for reading development. With respect to the three claims presented in the introduction, the "strong claim" that phonological awareness should be the most important factor in each language was only confirmed in four of the five languages. The claim that PA should be equally important in all languages (e.g.,Caravolas, Kessler, Hulme, \& Snowling, 2005; Patel et al., 2004) was not supported because the impact of PA on reading and decoding was systematically modulated by script entropy with PA being more important in less transparent languages. Together then, the results strongly supported the "weak claim" according to which PA is important in all languages but its impact is modulated by script entropy, a finding that is in line with the main conclusions of the National Reading Panel (see also Ehri et al., 2001). The significant influence of PA in all languages counters previous claims that PA plays little or no role in transparent languages (Georgiou, Parrila, \& Papadopoulos, 2008; Landerl \& Wimmer, 2008; Mann \& Wimmer, 2002).

The modulation of PA by transparency is certainly a direct consequence of the reciprocal influence of PA on reading. The higher PA is at the beginning of reading, the better the expected reading level of a child. At the same time, the easier it is for children to learn about letters and their sounds, the quicker children develop phoneme size representations which support phonological decoding. That is, the oneto-one mapping between letters and sounds in a transparent orthography promotes access to phonemes thus boosting basic PA skills and helping to set of phonemesized representations (see Goswami, Ziegler, \& Richardson, 2005). This orthography-dependent refinement process should even work in children with initially poor phonological skills (dyslexics). Potential differences in pre-literate PA skills of readers in transparent languages should become homogenized more quickly during learning to read, which would automatically lead to weaker correlations between $\mathrm{PA}$ and reading in transparent orthographies.

This scenario makes a number of predictions: First, effects of PA in transparent orthographies should be more transient. That is, the impact of PA on reading should be more important prior to reading or in early grades. Such a developmental trend has indeed been observed in a number of studies (de Jong \& van der Leij, 2003; Landerl \& Wimmer, 2000; Landerl \& Wimmer, 2008; Leppanen, Niemi, Aunola, \& Nurmi, 2006). Note that our study was probably favorable to detecting strong PA effects as PA was assessed fairly early (grade 2). Second, measures of PA in transparent orthographies should be more easily subject to ceiling effects. This point has been made most clearly by Caravolas et al. (2005b) who showed that identical effects of PA on reading can be found in transparent and nontransparent orthogra- 
phies as long as PA tasks were rendered sufficiently difficult in the transparent orthography. Ceiling effects and/or lack of power might indeed explain why some of the previous studies failed to find robust PA effects in transparent orthographies (e.g.,Harris \& Giannouli, 1999; Holopainen, Ahonen, \& Lyytinen, 2001; \{but see Puolakanaho et al., 2007). Finally, reading accuracy reaches ceiling very quickly in transparent orthographies (Seymour et al., 2003) leaving reading speed as the primary dependent variable. Thus, a PA measure capable of predicting reading speed must probably include a speed component that is sensitive to how quickly children can access phonemes (see Vaessen, Gerretsen, \& Blomert, 2009).

In contrast to our expectations, RAN was only a weak component; it was limited to reading and decoding speed and its influence was not significantly modulated by script transparency. This finding stands in contrast to previous studies showing that RAN was more important than PA in predicting reading in transparent orthographies, such as Dutch and German (e.g., de Jong \& van der Leij, 1999; Wimmer et al., 2000). How can this discrepancy be explained? First, the present study used object RAN rather than alphanumerical RAN. Although we believe that object RAN is a purer measure of naming speed deficits (because not confounded by letter recognition), it has to be acknowledged that object RAN tends to have lower correlations with reading than alphanumerical RAN (Vaessen et al., 2009). Second, it is probably misleading to think of RAN as an independent nonphonological component (for review see Vaessen et al., 2009). Indeed, Chiappe, Stringer, Siegel and Stanovitch (2002) showed that $25 \%$ of the variance in reading explained by naming speed is unique; the other $75 \%$ is shared with PA. Therefore, even if the rather modest correlation between naming speed and PA suggests that RAN tasks only incorporate a relatively small phonological component (e.g., Swanson, Trainin, Necoechea, \& Hammill, 2003), it appears to be just this phonological component that predicts reading performance the best (see Vaessen et al., 2009). If so, whenever PA measures are not sufficiently sensitive and/or reach ceiling, the lion part of the shared variance is left to RAN, which will become the dominant predictor. Given the sensitivity of PA in our study, it is not surprising that RAN was somewhat retrograded to explaining smaller amounts of variance in reading and decoding speed. This explanation seems also consistent with the cross-language results obtained by Patel et al. (2004) for Dutch and English. They included a speed measure of PA, which is less subject to ceiling effects, and reported almost identical results for English and Dutch with strong effects for PA (both accuracy and speed) but no effects for RAN.

Interestingly, the data from the fully transparent Finnish orthography seem to deviate in several important ways. First, Finnish was the only script for which PA was not the most important predictor. Second, only Finnish showed strong correlations with VOCAB. Strong correlations between VOCAB and reading are somewhat at odds with the literature suggesting that readers of transparent orthographies rely less on lexical, supralexical and contextual variables than readers of opaque orthog- 
raphies or less skilled readers (for review see Share, 2008). However, correlations go in both directions and it is likely that the proficient reading level of Finnish children in grade 2 allowed the good Finnish readers to considerably boost their vocabulary knowledge through reading.

One limitation of the present study is its focus on alphabetic scripts. One might argue that the present findings do not apply to non-alphabetic scripts, such as Chinese, which is spoken/read by at least $20 \%$ of the world's population. However, a number of cross-cultural studies comparing English and Chinese reported strikingly similar results. For example, McBride and Kail (2002) measured PA, speeded naming, visual-spatial skills and processing speed in Chinese and English and found that PA was the strongest predictor of reading in both languages (see alsoHo \& Bryant, 1997). Despite these striking similarities, there might be some important differences between alphabetic and nonalphabetic scripts in terms of orthographic and morphological awareness (McBride-Chang, Shu, Zhou, Wat, \& Wagner, 2003; Tan, Spinks, Eden, Perfetti, \& Siok, 2005). Such potential differences would deserve systematic cross-script exploration.

In conclusion, PA is a key component of reading acquisition and decoding in all countries although its influence is weaker in transparent than in opaque writing systems thus highlighting the importance of PA not as a pure phonological variable but as variable that is itself influenced by learning to read and the transparency of a language (Castles \& Coltheart, 2004). Comparatively, RAN had a much weaker influence and was limited to reading speed (Vaessen et al., 2009). Thus, the bottom line is that the predictors of reading performance, at least in alphabetic languages, are relatively universal although their precise weight varies systematically as a function of a language's transparency.

\section{Acknowledgements}

The present study was supported by grant 2006-2798/001-001 SO2 61OBGE of the EU-SOCRATES program Action 6.1.2 \& 6.2 to Leo Blomert. We thank the schools, children, parents, and teachers for their enthusiastic participation. 


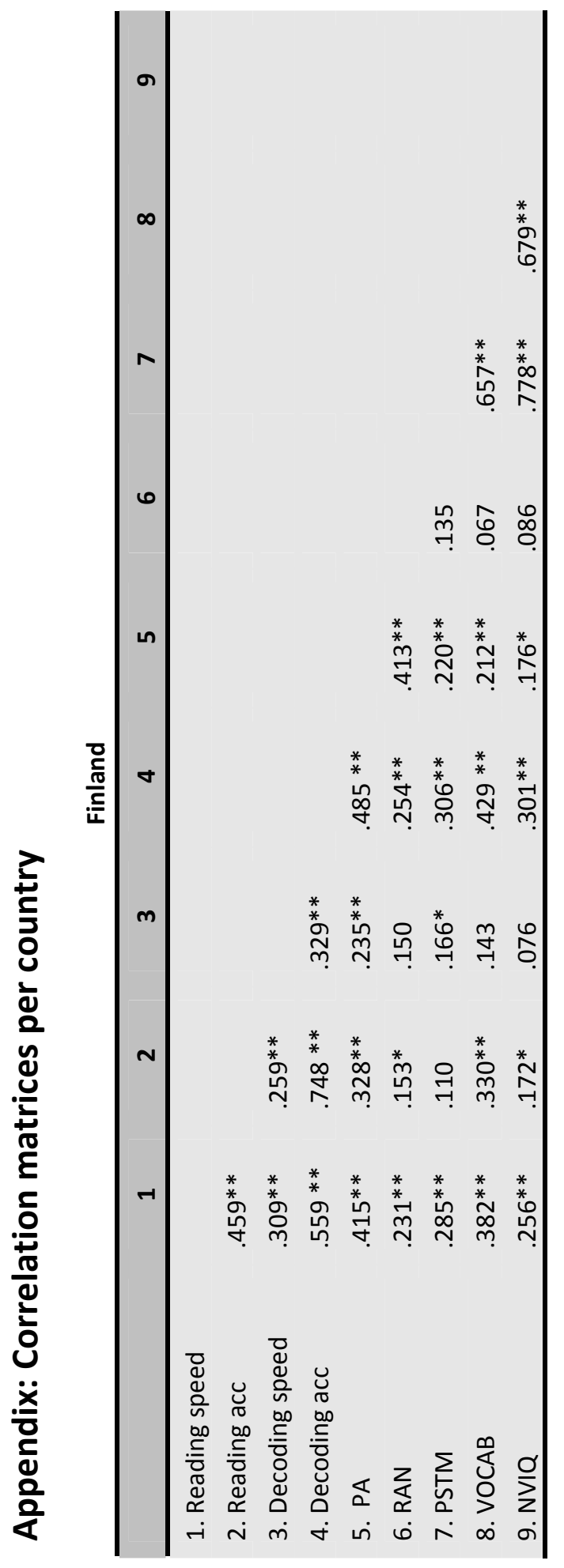




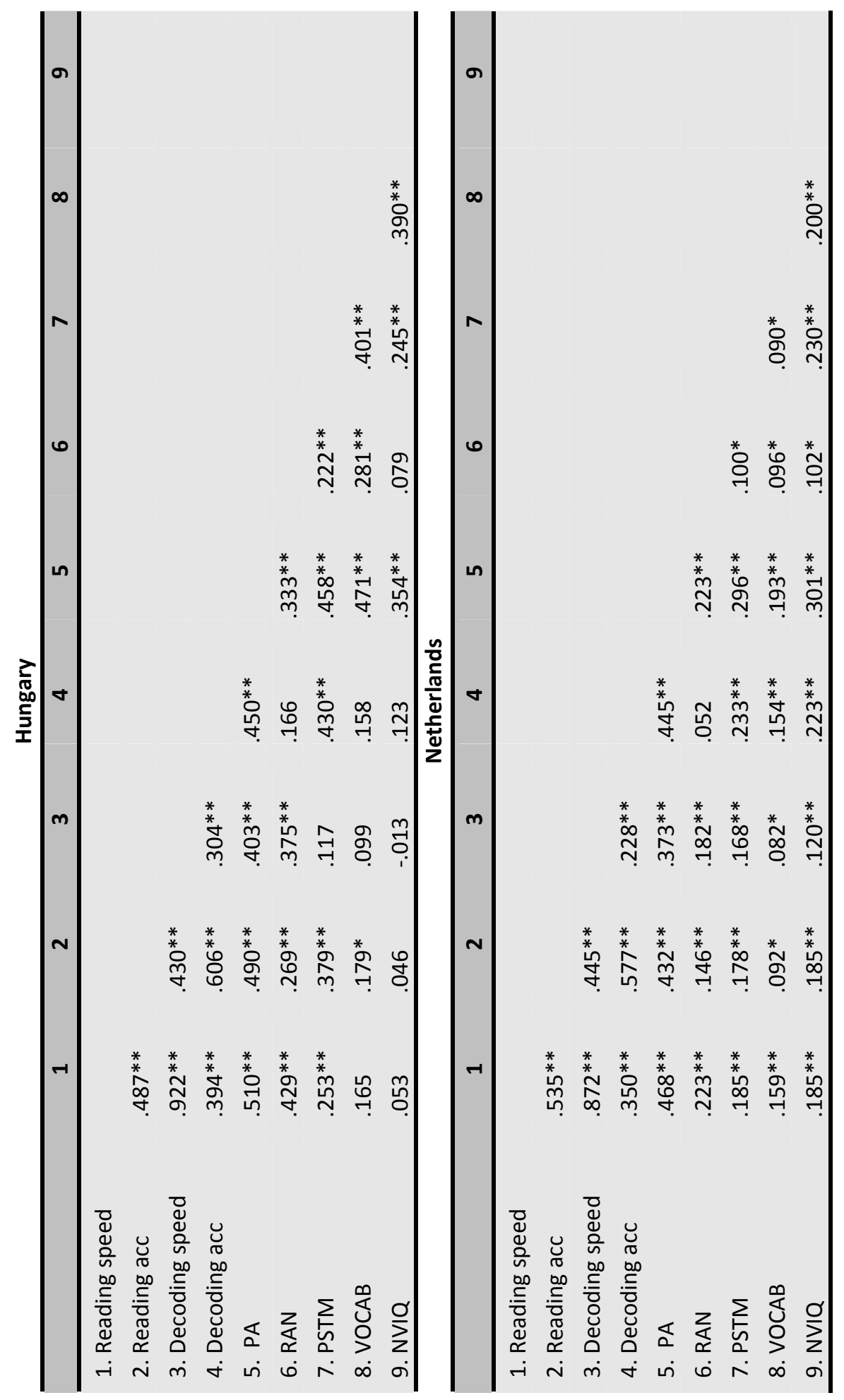




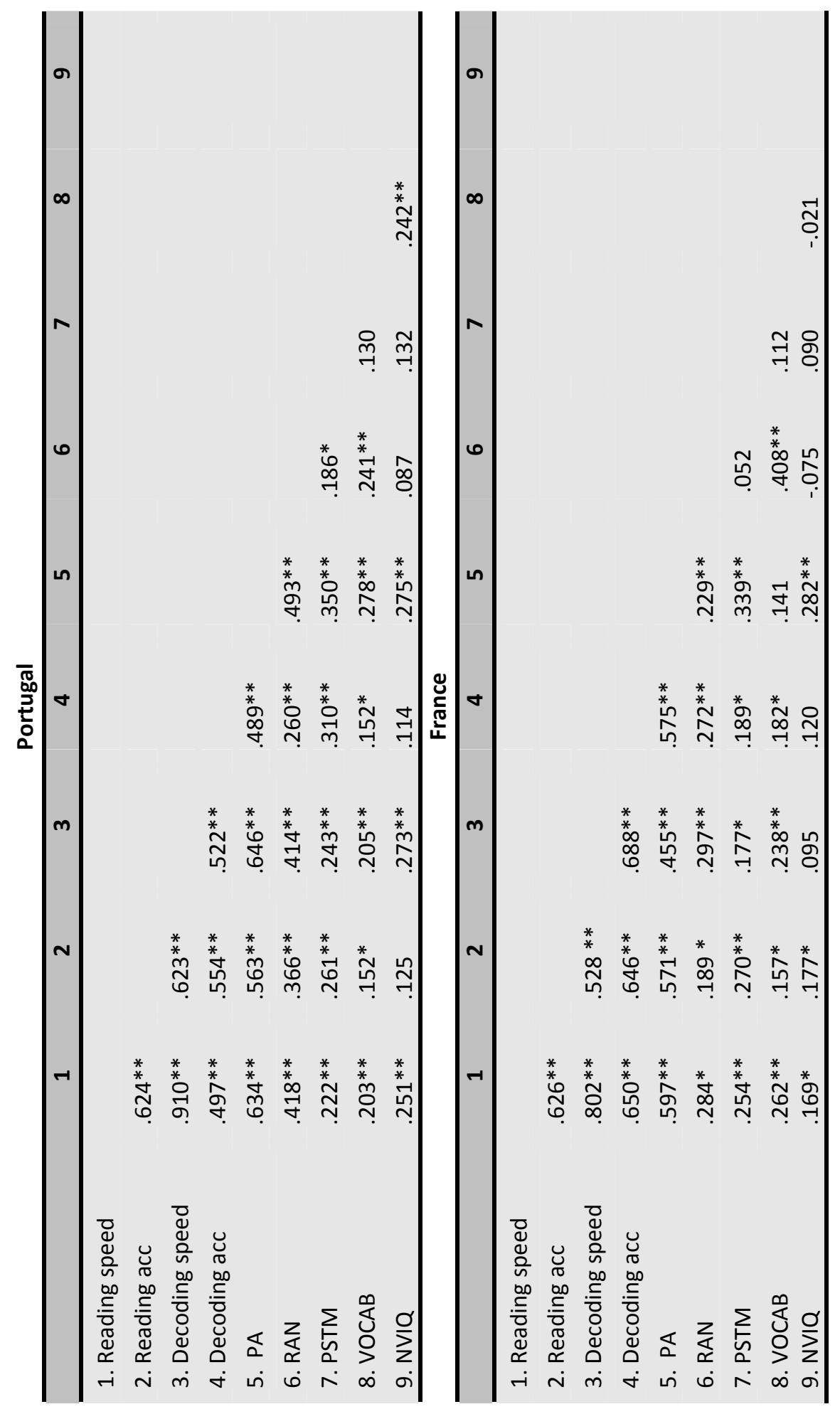




\section{References}

Borgwaldt, S. R., Hellwig, F. M., \& De Groot, A. M. B. (2005). Onset entropy matters - letter-to-phoneme mappings in seven languages. Reading and Writing 18, 211-229.

Bradley, L., \& Bryant, P. E. (1983). Categorizing sounds and learning to read: A causal connection. Nature, 301, 419-421.

Bruck, M., Genesee, F., \& Caravolas, M. (1997). A cross-linguistic study of early literacy acquisition. In B. A. Blachman (Ed.), Foundations of reading acquisition and dyslexia: Implications for early intervention (pp. 145-162). Mahwah, NJ: Lawrence Erlbaum Associates.

Caravolas, M., Volin, J., \& Hulme, C. (2005). Phoneme awareness is a key component of alphabetic literacy skills in consistent and inconsistent orthographies: Evidence from Czech and English children. Journal of Experimental Child Psychology, 92, 107-139.

Castles, A., \& Coltheart, M. (2004). Is there a causal link from phonological awareness to success in learning to read? Cognition, 91, 77-111.

Chiappe, P., Stringer, R., Siegel, L. S., \& Stanovich, K. E. (2002). Why the timing deficit hypothesis does not explain reading disability in adults. Reading and Writing, 15, 73-107.

de Jong, P. F., \& van der Leij, A. (1999). Specific contributions of phonological abilities to early reading acquisition: Results from a Dutch latent variable longitudinal study. Journal of Educational Psychology, 91, 450-476.

de Jong, P. F., \& van der Leij, A. (2003). Developmental changes in the manifestation of a phonological deficit in dyslexic children learning to read a regular orthography. Journal of Educational Psychology, 95, 22-40.

Denckla, M. B., \& Rudel, R. (1974). Rapid "automatized" naming of pictured objects, colors, letters and numbers by normal children. Cortex, 10, 186-202.

Ehri, L. C., Nunes, S. R., Willows, D. M., Schuster, B. V., Yaghoub-Zadeh, Z., \& Shanahan, T. (2001). Phonemic awareness instruction helps children learn to read: Evidence from the National Reading Panel's meta-analysis. Reading Research Quarterly, 36, 250-287.

Ellis, N., \& Large, B. (1987). The development of reading: as you seek so shall you find. British Journal of Psychology, 78, 1-28.

Frith, U., Wimmer, H., \& Landerl, K. (1998). Differences in phonological recoding in German- and Englishspeaking children. Scientific Studies of Reading, 2, 31-54.

Frost, R., Katz, L., \& Bentin, S. (1987). Strategies for visual word recognition and orthographical depth: A multilingual comparison. Journal of Experimental Psychology: Human Perception \& Performance, 13, 104-115.

Georgiou, G. K., Parrila, R., \& Papadopoulos, T. C. (2008). Predictors of word decoding and reading fluency across languages varying in orthographic consistency. Journal of Educational Psychology, 100, 566-580.

Goswami, U., Gombert, J. E., \& de Barrera, L. F. (1998). Children's orthographic representations and linguistic transparency: Nonsense word reading in English, French, and Spanish. Applied Psycholinguistics, 19, 19-52.

Goswami, U., Ziegler, J. C., Dalton, L., \& Schneider, W. (2001). Pseudohomophone effects and phonological recoding procedures in reading development in English and German. Journal of Memory \& Language, 45, 648-664. 
Goswami, U., Ziegler, J. C., \& Richardson, U. (2005). The effects of spelling consistency on phonological awareness: A comparison of English and German. Journal of Experimental Child Psychology, 92, 345365.

Harris, M., \& Giannouli, V. (1999). Learning to read and spell in Greek: the importance of letter knowledge and morphological awareness. In M. Harris \& G. Hatano (Eds.), Learning to Read and Write: $A$ Cross-Linguistic Perspective (pp. 51 - 70). Cambridge: Cambridge University Press.

Ho, C. S.-H., \& Bryant, P. (1997). Phonological skills are important in learning to read Chinese. Developmental Psychology, 33, 946-951.

Holopainen, L., Ahonen, T., \& Lyytinen, H. (2001). Predicting delay in reading achievement in a highly transparent language. Journal of Learning Disabilities, 34, 401-413.

Landerl, K., \& Wimmer, H. (2000). Deficits in phoneme segmentation are not the core problem of dyslexia: Evidence from German and English children. Applied Psycholinguistics, 21, 243-262.

Landerl, K., \& Wimmer, H. (2008). Development of word reading fluency and spelling in a consistent orthography: An 8-year follow-up. Journal of Educational Psychology, 100, 150-161.

Leppanen, U., Niemi, P., Aunola, K., \& Nurmi, J. E. (2006). Development of reading and spelling Finnish from preschool to Grade 1 and Grade 2. Scientific Studies of Reading, 10, 3-30.

Mann, V., \& Wimmer, H. (2002). Phoneme awareness and pathways into literacy: A comparison of German and American children. Reading \& Writing, 15(7-8), 653-682.

McBride-Chang, C., Shu, H., Zhou, A. B., Wat, C. P., \& Wagner, R. K. (2003). Morphological awareness uniquely predicts young children's Chinese character recognition. Journal of Educational Psychology, 95, 743-751.

Patel, T. K., Snowling, M. J., \& de Jong, P. F. (2004). A cross-linguistic comparison of children learning to read in English and Dutch. Journal of Educational Psychology, 96, 785-797.

Perfetti, C. A., Beck, I., Bell, L. C., \& Hughes, C. (1987). Phonemic Knowledge and Learning to Read Are Reciprocal - a Longitudinal-Study of 1st-Grade Children. Merrill-Palmer Quarterly-Journal of Developmental Psychology, 33, 283-319.

Perry, C., \& Ziegler, J. C. (2002). Cross-language computational investigation of the length effect in reading aloud. Journal of Experimental Psychology: Human Perception \& Performance, 28, 990-1001.

Puolakanaho, A., Ahonen, T., Aro, M., Eklund, K., Leppanen, P. H., Poikkeus, A. M., et al. (2007). Very early phonological and language skills: estimating individual risk of reading disability. Journal of Child Psychology and Psychiatry, 48, 923-931.

Schatschneider, C., Fletcher, J. M., Francis, D. J., Carlson, C. D., \& Foorman, B. R. (2004). Kindergarten prediction of reading skills: A longitudinal comparative analysis. Journal of Educational Psychology, 96, 265-282.

Seymour, P. H. K., Aro, M., \& Erskine, J. M. (2003). Foundation literacy acquisition in European orthographies. British Journal of Psychology, 94, 143-174.

Share, D. L. (2008). On the anglocentricities of current reading research and practice: The perils of overreliance on an "Outlier" orthography. Psychological Bulletin, 134, 584-615.

Share, D. L., Jorm, A. F., Maclean, R., \& Matthews, R. (1984). Sources of Individual-Differences in Reading Acquisition. Journal of Educational Psychology, 76, 1309-1324. 
Swanson, H. L., Trainin, G., Necoechea, D. M., \& Hammill, D. D. (2003). Rapid naming, phonological awareness, and reading: A meta-analysis of the correlation evidence. Review of Educational Research, 73, 407-440.

Tan, L. H., Spinks, J. A., Eden, G. F., Perfetti, C. A., \& Siok, W. T. (2005). Reading depends on writing, in Chinese. Proceedings of the National Academy of Sciences U S A, 102, 8781-8785.

Vaessen, A., Gerretsen, P., \& Blomert, L. (2009). Naming problems do not reflect a second independent core deficit in dyslexia: Double deficits explored. Journal of Experimental Child Psychology, 103, 202221.

Wimmer, H., Mayringer, H., \& Landerl, K. (2000). The double-deficit hypothesis and difficulties in learning to read a regular orthography. Journal of Educational Psychology, 92, 668-680.

Ziegler, J. C., \& Goswami, U. (2005). Reading acquisition, developmental dyslexia, and skilled reading across languages: a psycholinguistic grain size theory. Psychological Bulletin, 131, 3-29.

Ziegler, J. C., Perry, C., Jacobs, A. M., \& Braun, M. (2001). Identical words are read differently in different languages. Psychological Science, 12, 379-384.

Ziegler, J. C., Stone, G. O., \& Jacobs, A. M. (1997). What is the pronunciation for -ough and the spelling for $\mathrm{u} /$ ? A database for computing feedforward and feedback consistency in English. Behavior Research Methods, Instruments \& Computers, 29, 600-618. 



\section{Chapter 4}

\section{Impact of orthographic consistency on cognitive development of reading fluency}

This chapter is based on:

Vaessen, A., Bertrand, D., Tóth, D., Csépe, C., Faísca, L., Reis, A., \& Blomert, L. (accepted). Cognitive function underlying reading development do not differ between transparent and opaque orthographies. Journal of Educational Psychology. 


\begin{abstract}
Although the transparency of a writing system is hypothesized to systematically influence the cognitive skills associated with reading development, results of crosslanguage investigations are inconsistent and usually do not address this issue in a developmental context. We therefore investigated the cognitive dynamics of reading fluency of different word types in grade 1-4 in three orthographies differing in degree of transparency (Hungarian, Dutch and Portuguese). The overall results showed that the relative strength of the contributions of phonological awareness (PA) and rapid naming (RAN) to word reading fluency shifted as a function of reading expertise: the contribution of PA remained significant in all grades but decreased as a function of grade, while the contribution of RAN increased. Orthographic depth systematically modulated the strength of the cognitive contributions to reading, but not the overall developmental pattern. Together, these results indicate that the cognitive development of reading skill is fairly universal (at least for alphabetic scripts) and differences in orthographic depth will not recruit different cognitive processes, but will mainly be expressed in rate of reading development.
\end{abstract}




\subsection{Introduction}

At initial stages of learning to read an alphabetic script, children typically decode words by mapping each letter onto its corresponding speech sound. This phonological decoding process initially costs much time and effort. However, to achieve the high level of automatization which is the key characteristic of skilled reading, complete words and morphemes have to be linked directly to their phonological or semantic counterparts (Perfetti, 1985). Therefore most models of reading development describe a developmental shift from slow phonological decoding to automatic recognition of whole word forms (e.g. Ehri, 1995, 2005; Frith, 1985; Marsh, Friedman, Welsh, \& Desberg, 1981; Share, 1995, 1999). Some of these models have suggested that this shift occurs in a stage-like manner, in the sense that children move through a series of stages dominated by one strategy (Frith, 1985; Marsh et al., 1981). The phase theory of Ehri $(1995 ; 2005)$ also suggests that children proceed through a number of phases during the development of fluent reading skills: a prealphabetic phase in which words are recognized based on visual cues, a partial alphabetic phase, in which children know some but not all letter-speech sound correspondences and may recognize words partially by phonetic cues and partially by contextual guessing, a full alphabetic phase, when children's knowledge of the alphabetic principle is complete and they are able to decipher new words, and a consolidated alphabetic phase, in which full connections are formed between morphographic units (e.g. words, morphemes, onsets, rhymes) and their phonological and semantic counterparts. However, in contrast to traditional stage-models of reading, this theory assumes that the shift from one phase to another is rather transitional and boundaries between phases are less sharp. The self-teaching hypothesis of Share (Share, 1995; 1999; 2008) also argues for a more transitional, item-based instead of stage-based view, in the sense that the ability to recognize a word by sight depends more on the familiarity of a word than on the dominant strategy assumedly typical for a given developmental reading stage. Every word is unfamiliar at one point in reading development and hence has to be deciphered by phonological decoding. This phonological decoding of words lies at the basis of forming connections between orthographic (word-specific) patterns and phonological codes (Ehri, 2005; Share, 1995). Since children are more exposed to words that have a high frequency of occurrence, orthographic representations will be established more quickly for high-frequency than for low-frequency words. Share therefore recommends to investigate reading development in "the context of an unfamiliar-to-familiar/novice-to-expert framework" (Share, 2008, p.592).

A recent study of Vaessen \& Blomert (in revision) demonstrated that the shift from phonological decoding to automatic word recognition is accompanied by a concomitant gradual shift in the relative importance of the cognitive skills underlying reading. Phonological awareness was related to word reading fluency until the 
sixth grade, but its contribution to reading fluency was much stronger in beginning phases of reading development, when children rely heavily on phonological decoding strategies. In contrast, the contribution of rapid automatized naming (RAN) was modest in beginning readers but gradually increased as a function of reading experience. In line with the item-based view on reading development proposed by Share (1999; 2008), the shift in the relative importance of PA and RAN occurred earlier for HF than for LF words; RAN was the strongest contributor to HF word reading fluency from the third grade on, but its contribution to LF word reading fluency only dominated that of PA in grade 5 . As might be expected, PA remained the dominant contributor to pseudoword reading fluency, although RAN also substantially contributed.

Several other studies in transparent orthographies have reported a declining influence of PA and a strong influence of RAN on reading fluency (e.g. de Jong \& van der Leij, 1999, 2002; Landerl \& Wimmer, 2008; Lervåg, Bråten, \& Hulme, 2009; Nikolopoulos, Goulandris, Hulme, \& Snowling, 2006). In contrast, English language studies usually report a stronger and longer-lasting influence of PA (e.g. Swanson, Trainin, Necoechea, \& Hammil, 2003; Torgesen, Wagner, Rashotte, Burgess, \& Hecht, 1997; Wagner, Torgesen, \& Rashotte, 1994), and only a modest influence of RAN on reading (Parrila, Kirby, \& McQuarrie, 2004; Powell, Stainthorp, Stuart, Garwood, \& Quinlan, 2007; Wagner et al., 1994). This discrepancy between transparent and opaque orthographies might indicate that the cognitive dynamics of reading vary as a function of the orthographic consistency of a language. However, it should be noted that reading performance in transparent orthographies is typically based on fluency measures, while most English language studies focused on reading accuracy. Since PA is generally measured with accuracy measures in all types of orthographies, the influence of PA on reading fluency in transparent orthographies might thus be attenuated. Similarly, the influence of (speeded) RAN in opaque orthographies might be underestimated due to the use of reading accuracy measures (Georgiou, Parrila, Kirby, \& Stephenson, 2008; Share, 2008; Vaessen \& Blomert, in revision). To illustrate the effect of this measurement-parameter incompatibility, Vaessen and Blomert (in revision) showed a stronger and longer-lasting influence of PA on reading fluency when a speeded PA measure was included. Similarly, Englishlanguage studies including speeded reading measures usually found strong contributions of RAN (e.g. Bowers, 1993; Cirino, Israelian, Morris, \& Morris, 2005; Schatschneider, Fletcher, Francis, Carlson, \& Foorman, 2004), indicating that differences between transparent and opaque orthographies might be less pronounced than often assumed.

Nevertheless, orthographic consistency might impact the cognitive dynamics of reading development. For instance, the Orthographic Depth Hypothesis (ODH; Katz \& Frost, 1992) holds that the consistent, one-to-one relationship between letters and speech sounds in transparent orthographies strongly encourages the use of 
phonological decoding processes. In contrast, opaque orthographies support the recognition of words via their visual orthographic structure, because graphemephoneme decoding might often lead to erroneous results. A weak version of the $\mathrm{ODH}$ (Frost, 2005) proposes relative, rather than qualitative, differences between transparent and opaque orthographies, but both versions of the ODH assume a stronger involvement of phonological decoding strategies in transparent than in opaque orthographies. An alternative interpretation (Psycholinguistic Grain Size Theory (PGST), Ziegler \& Goswami, 2005) emphasized that children in all alphabetic orthographies use phonological decoding strategies, but children learning to read in more opaque orthographies are required to develop more flexible decoding strategies not only aimed at the grapheme-phoneme level, but also at larger units like syllables, onset, rhymes and/or morphemes. Although this interpretation has many features in common with the $\mathrm{ODH}$, its predictions regarding the role of phonological processing in transparent and opaque orthographies differ since it assumes equal or even stronger involvement of phonological processing in opaque compared to transparent orthographies (Georgiou, Parilla, \& Papadopoulos, 2008; Ziegler \& Goswami, 2005).

Empirical investigations of the impact of orthographic consistency on the cognitive predictors of reading show rather contrasting results. Some studies (Georgiou, Parilla et al., 2008; Mann \& Wimmer, 2002) reported PA as the strongest predictor of reading accuracy and fluency in English and RAN as the stronger predictor of reading accuracy and fluency in transparent orthographies (resp. Greek and German). Others found strong influences of PA on reading performance in both transparent (resp. Czech and Dutch) and English orthographies (Caravolas, Volin, \& Hulme, 2005; Patel, Snowling, \& de Jong, 2004).

It should be noted that the above mentioned cross-linguistic studies compared English with one other, more transparent, orthography. However, in a recent review, Share (2008) argues that the English orthography has an outlier position in terms of its extreme ambiguous letter-speech sound correspondences. Nevertheless, results from non-Anglophone studies are usually interpreted in the light of theories based on Anglophone research, although "the outcomes of nonAnglophone investigations are likely to offer a better approximation to the global norm" (Share, 2008, p. 604). Therefore, a recent cross-language investigation of Ziegler et al (in press) included five languages (Finnish, Hungarian, Dutch, Portuguese and French) lying on a continuum of orthographic consistency, to systematically investigate the impact of orthographic consistency on the cognitive skills underlying reading. Orthographic consistency was expressed in a script entropy measure for each language (Borgwaldt, Hellwig, \& De Groot, 2005; see also methods of the current paper). The advantage of using word onset entropy measures is that the orthographic consistency of languages with varying orthographic structures can be meaningfully compared because all of them have word onsets (Ziegler et al., in 
press). Ziegler and colleagues showed that PA was the important predictor of reading accuracy and speed in all orthographies, although the strength of the contribution of PA to reading performance systematically varied with the degree of entropy, that is, the role of PA was relatively stronger in more opaque orthographies.

The results of Ziegler and colleagues as well as the results of Georgiou et al. (2008) and Mann and Wimmer (2002) thus indicate that orthographic consistency does have an impact on the strength of the contributions of PA, but none of these studies specifically addressed the question how orthographic consistency influences the time course of the cognitive development of reading. The results of Vaessen and Blomert (in revision) indicate a shift in the relative importance of the cognitive skills underlying reading fluency as a function of both reading experience and word type, but this study was restricted to Dutch readers only. Therefore, the purpose of the present study is to investigate how orthographic consistency modulates the developmental course of the cognitive skills underlying reading fluency.

Next to measures of PA and RAN we included additional measures for two cognitive skills that are thought to play a role in reading acquisition and skilled reading: letter-speech sound (LSS) knowledge and verbal working memory (VWM). Although verbal working memory is strongly tied to phonological processes (Baddeley, 1995), and phonological awareness problems and verbal working memory problems seem to stem from the same underlying phonological deficit (e.g. Tijms, 2004), others have reported that verbal working memory contributed uniquely to word reading even when controlling for phonological awareness levels (Georgiou, Das, \& Hayward, 2008; McCallum et al., 2006) and therefore we included a measure of VWM.

Kindergarten LSS knowledge is reported to be strongly related to early reading performance (Puolakanaho et al., 2007; Scarborough, 1990; Share, Jorm, Maclean, \& Matthews, 1984; Wagner et al., 1994; Wimmer \& Hummer, 1990). However, because children are supposed to know which letter belongs to which speech sound after a relatively short period of reading instruction even in opaque orthographies (Hardy, Smythe, Stennet, \& Wilson, 1972; Seymour, Aro, \& Erskine, 2003; Wentink \& Verhoeven, 2003), only a few studies have focused on the relationship between LSS and reading after the initial phases of reading acquisition. One of these studies (Leppanen, Niemi, Aunola, \& Nurmi, 2006) showed that LSS and reading were strongly correlated at least until grade 4 . One recent cross-language investigation has indicated that LSS knowledge might have a stronger relationship with reading fluency in English than in a transparent orthography like Greek (Manolitsis, Georgiou, Stephenson, \& Parrila, in press). Moreover, recent brain research has shown that automation of letter-speech sound correspondences takes years to develop even in normal readers and even though children perfectly knew which letter belonged to which speech sound after the first grade (Froyen, van Atteveldt, Bonte, \& Blomert, 2008; Froyen, Bonte, van Atteveldt, \& Blomert, 2009). Thus, including measures of efficiency of the processing of letter-speech sound correspondences 
might shed more light on the role of grapheme-phoneme integration in fluent reading development and the potentially modulating influence of orthographic consistency on this relationship.

\section{The present study}

The present study investigates the impact of orthographic consistency on the relative importance of four cognitive skills (PA, RAN, LSS knowledge and VWM) for word reading fluency in a developmental context. The large unselected school sample (n $=2244$ ) consisted of first to fourth graders from three different European countries with languages varying in orthographic consistency (Hungarian, Dutch, Portuguese). The degree of orthographic consistency was based on word onset entropy (see methods).

The reading task included three different word types (high-frequency, lowfrequency and pseudowords) because it was previously shown that the relative importance of the cognitive contributors to reading fluency was influenced by both reading experience and word familiarity (Vaessen \& Blomert, in revision). Moreover, all cognitive tasks (except verbal working memory tasks) measured speed as well as accuracy, thereby avoiding speed-accuracy confounds in their relation with reading fluency. The task designs used in the different languages were the same, as they are adaptations of the same test battery (Blomert \& Vaessen, 2009; Csépe, Tóth, Vaessen \& Blomert, in prep; Reis, Faísca, Vaessen, \& Blomert, in prep), but test items were adapted to the specifics of each language. Creating completely parallel tasks by simply translating a "common test" into different languages would have been impossible for most cognitive skills because of the large differences in orthographic and phonological structure between the languages. This would have lead to insensitive tests that are often subject to ceiling effects (Seymour et al., 2003).

\subsection{Methods}

\section{Participants}

The sample consisted of 674 Hungarian, 954 Dutch and 616 Portuguese primary school children from grade 1 to grade 4 . The sample sizes, mean age and average number of months of formal reading instruction per grade are presented in table 4.1. All first graders were tested at the end of the school year. In all countries, a small group of second graders was tested in September or October (Hungary $n=15$, Netherlands $n=20$, Portugal $n=44$ ), while the rest of the second graders were tested middle or end of the school year. Since reading performance of the beginning sec- 
ond graders resembled that of the first graders, they were included in the first grade sample.

The results in table 4.1 show that at least in the first two grades average number of months of formal reading instruction is comparable. Furthermore, it is noticeable that Hungarian children enter primary school when they are seven years old, while Dutch and Portuguese children enter school when they turn six years old. However, correlations between age and reading level were low ( $r$ between .01 and .04), suggesting that the influence of age at school onset on reading performance was negligible once amount of reading instruction is taken into account.

For a part of the children (HUN $n=607, N L n=462$, PRT $n=242$ ) data were available on educational levels of the mother and father (three levels: I primary school or less, II secondary school or Vocational Education, III college or university). In the Hungarian sample, $4-7 \%$ of the parents (first percentage corresponds to father's educational level, second percentage corresponds to mother's educational level) had an educational level of I, 63\%-57\% had an educational level of II, and 33-36\% had an educational level of III. In the Dutch sample, only $2-1 \%$ of the parents had an educational level of I, 54\%-61\% had an educational level of II, and $44-38 \%$ had an educational level of III. In the Portuguese sample these proportions were respectively $14 \%-9 \%, 73-72 \%$, and $13-19 \%$. Correlations between educational level and reading fluency level were rather low: in HUN $r=.10-.20$, in NL $r=.07-.12$ and in PRT $r=.12-20$.

In all three countries, formal reading instruction started at school entrance. No formal instruction on letter-speech sound relations or phonological training was provided in kindergarten. In the Netherlands all official reading instruction methods are phonics based and in Hungary, all official reading instruction methods are at least partly phonics based. In Portugal teaching methods can be more variable. From a large part of the Portuguese sample $(n=570)$ individual information on teaching method was available: $67 \%$ of these children learned to read with a (partly) phonics-based method, $27 \%$ received syllabic-based training and $7 \%$ received whole-word based training. In a previous study with Portuguese students it was shown that there was no significant influence of teaching method on reading performance (Mendonça et al., 2008). 
Table 4.1 - Sample sizes, average months of formal reading instruction and mean

\begin{tabular}{|c|c|c|c|c|c|c|}
\hline & & \multirow[b]{2}{*}{$\mathbf{N}$} & \multicolumn{2}{|c|}{$\begin{array}{l}\text { Months of formal } \\
\text { reading instruction }\end{array}$} & \multicolumn{2}{|c|}{ Age (in months) } \\
\hline & & & Mean & SD & Mean & SD \\
\hline \multirow[t]{3}{*}{ grade 1} & HUN & 81 & 9.2 & 0.7 & 93.3 & 4.9 \\
\hline & NL & 236 & 9.8 & 0.8 & 87.3 & 5.1 \\
\hline & PRT & 91 & 10.1 & 1.6 & 86.4 & 5.3 \\
\hline \multirow[t]{3}{*}{ grade 2} & HUN & 205 & 17.3 & 1.3 & 103.6 & 5.4 \\
\hline & NL & 214 & 15.1 & 0.8 & 94.4 & 5.1 \\
\hline & PRT & 131 & 16.4 & 3.0 & 93.5 & 5.7 \\
\hline \multirow[t]{3}{*}{ grade 3} & HUN & 203 & 26.5 & 1.7 & 114.9 & 4.6 \\
\hline & NL & 245 & 25.5 & 1.0 & 108.0 & 5.4 \\
\hline & PRT & 194 & 25.0 & 3.3 & 104.1 & 6.5 \\
\hline \multirow[t]{3}{*}{ grade 4} & HUN & 185 & 36.9 & 1.9 & 127.0 & 5.7 \\
\hline & NL & 259 & 33.7 & 0.8 & 117.6 & 5.6 \\
\hline & PRT & 200 & 34.7 & 3.4 & 117.1 & 8.5 \\
\hline
\end{tabular}

Note: HUN=Hungary, NL=Netherlands, PRT=Portugal

\section{Procedure}

The samples were all part of national standardization studies of a reading test battery. In the Dutch sample, 17 schools in 5 different regions of the country participated. In the Portuguese sample, 31 schools were included, all from the Algarve region. In the Hungarian sample, 10 schools participated, all from the Budapest region. Schools in this region were selected in such way that both low and high SES neighborhoods were represented. First, the schools were approached for participation. When the schools were willing to participate, parents were asked for permission by letter. All children that got permission to participate were tested, regardless of their reading and spelling level.

Tasks were individually administered at school by a trained project coworker outside the classroom. All tasks were administered in either one or two sessions. The first and the second test session always fell within one week.

\section{Measure of orthographic consistency}

The degree of orthographic consistency was estimated by using script entropy computations for the initial letter-speech sound mapping in each language (Borgwaldt et al., 2005; Treiman, Berch, Tincoff, \& Weatherson, 1993). Script entropy values 
were adopted from Borgwaldt et al (see also Ziegler et al., in press) and were defined as follows:

$$
H=\sum \text { pi } \log 21 / p i
$$

where $\mathrm{p} 1$ is the probability of the first pronunciation of a given letter, $\mathrm{p} 2$ is the probability of the second pronunciation of the letter (if a second pronunciation exists), and so on for all $\mathrm{n}$ possible pronunciations of that letter. If a letter always corresponds to one phoneme, its entropy value is zero. So the higher the entropy value is, the larger the number of pronunciations of one letter and the more inconsistent the letter-speech sound correspondences. The entropy values for the Hungarian, Dutch and Portuguese language were respectively; $0.17,0.23$, and 0.42 . Since onset entropy was used as a general measure of orthographic consistency in the current study, it is important to know in how far this measure is comparable to other measures of orthographic consistency, such as rhyme consistency. A study of Perry and Ziegler (2002) has shown that onset entropy and rhyme entropy values of German and English were comparable. Moreover, Ziegler et al (in press) showed that the ranking order of languages with many monosyllabic words (German, English, French and Dutch) remains the same regardless of whether the onset or the rhyme was used. Finally, Borgwaldt et al. (2005) showed that the onset entropy ranking order of the included languages was in line with the descriptions of the languages' orthography and phonology. Onset entropy thus seems a reliable measure of the orthographic consistency of a language.

\section{Tasks}

The tasks used for this study were all part of a computerized cognitive reading test (3DM: Differential Diagnosis of Dyslexia; Blomert \& Vaessen, 2009) and the Portuguese and the Hungarian version of this test (respectively Reis et al., in prep; Csépe et al, in prep). The task designs were very similar, but items were adapted to the specific characteristics of each language.

Word reading - The word reading task contained three different subtasks: highfrequency words, low-frequency words and pseudowords. For each subtask, participants were instructed to accurately read as many words as possible in half a minute. 15 words per screen were presented (with a maximum of 75 words for each subtask). Words and pseudowords increased in length and syllabic structure. In the Netherlands and Hungary, the first screen of 15 items contained monomorphemic words without consonant clusters, the second screen monomorphemic words with consonant clusters, the third screen two-syllabic words without consonant clusters, the fourth screen two-syllabic words with consonant clusters and the last screen 3 or 4-syllabic words. In Portugal, the task design was the same, except that in the 
first two screens two-syllabic words were used (in Portuguese most words have at least 2 syllables). The task resulted in a fluency score (correct words/ half a minute) for each subtask. Test-retest reliabilities were .91 in the Hungarian sample, .95 in the Dutch sample (reported in the test manual). For the Portuguese sample, testretest reliabilities were not yet available.

Phonological awareness - Pseudowords were presented aurally (over headphones). The child was instructed to delete a speech sound (the beginning consonant, the end consonant, or a consonant within a consonant cluster) and provide the remaining pseudoword. In all three countries, the task contained three levels that varied in difficulty: the first level contained CVC words from which the first $\mathrm{C}$ had to be deleted, the second level contained CCVCC words or CVCVC words from which the first or second consonant had to be deleted, and the third level contained CCVCC words from which the consonant within the cluster had to be deleted. The administrator pressed a button as soon as the participant gave an answer to indicate response time. Response time was time between stimulus offset and the button press. Accuracy score was percentage correct items. Internal consistency indices of the accuracy scores were respectively .94 (PRT) and .87 (NL and HUN). Internal consistency of speed scores was respectively .96 (PRT), .93 (NL) and .95 (HUN).

Rapid naming - The child was instructed to name visually presented letters, digits or objects as fast as possible. Sheets with 15 items (5 letters, digits or objects repeated 3 times) were presented on the screen. Each set of 15 items was presented two times, with a different order of items. The letter and digit names were mono-syllabic in each country, the object names were either mono- or bi-syllabic (one item in Portuguese had 3 syllables). Response time was calculated as the mean reaction time of the two presentations. The naming tasks had a reliability of respectively .82 (PRT), .80 (NL) and .86 (HUN).

Letter-speech sound association (LSS) tasks - Two tasks were used to measure accuracy and automation of letter-speech sound knowledge; a LSS identification task and a LSS discrimination task. In the LSS identification task, a phoneme was presented over the headphones and at the same time four letter(combination)s were presented on the screen e.g. /b/ and ' $b$ ' ' $d$ ' ' $t$ ' ' $p$ '). The child had to choose which letter(combination) belonged to the phoneme by pressing the corresponding button. In the LSS discrimination task, a visual letter (combination) and a auditory presented speech sound were presented at the same time, and the child had judge whether the letter and the speech sound were same or different (e.g. /o/ and ' $a$ '). Accuracy (\% correct) as well as response time (sec/item) was measured. Each country used the letter-speech sound combinations that were specific for their language. The accuracy scores of the LSS identification and LSS discrimination task had an internal consistency of respectively .69 and .84 (PRT), .70 and .80 (NL) and .76 and .89 (HUN). The speed scores on the LSS identification task and the LSS discrimina- 
tions task had an internal consistency of respectively .88 and .93 (PRT), .90 and .95 (NL) and .92 and .97 (HUN).

Verbal working memory - Two tasks were used: a phoneme span task and a syllable span task. In both tasks, a sequence of phonemes/syllables was aurally presented and the child was instructed to repeat this sequence in the same order. The phoneme span task only contained consonants. The syllable span contained monosyllabic syllables with a CVC or CCV structure. The syllables or the combination of syllables did not form existing words. The sequences ranged from two to six items. Accuracy score was total number of correctly repeated items within each sequence. Reliability coefficients for the phoneme span task were respectively .73 (PRT), .63 (NL) and .53 (HUN) and for the syllable span task respectively .75 (PRT), .71 (NL) and .68 (HUN).

Baseline response time - A row of four empty squares was presented on the screen. Each stimulus consisted of an animation figure that appeared in one of the four squares. The participant had to respond as fast as possible by pressing the corresponding button. Mean reaction time was measured over 20 items. This task was the same in all countries. The task had an internal consistency of respectively. .94 (PRT), .93 (NL) and .95 (HUN).

\section{Data preparation}

Because reading fluency was treated as dependent variable, subjects with missing values on these variables were not included in the sample. Also, participants with more than 2 missing values were excluded from analyses. For the other subjects, missing values were imputed using a version of expectation maximization (EM) an imputation method described by Schneider (2001) and implemented in MatLab (Schneider, 2008). All variables had less than 3\% missing values. Random simulations of the imputation method showed that it could accurately predict actual values (mean correlation: 0.70, mean root-mean-square relative imputation error: 0.07 ), and did not distort the distribution of the variables.

Because the letter-speech sound tasks required a motor response, and response time measures were based on this motor response, we used the baseline response time task to control for effects of individual differences in motor response time. We first regressed the baseline RT on the LSS identification and discrimination response times. Subsequently, we computed the residuals, which were used as corrected response time scores for the LSS tasks.

For the regression analyses, standardized T-scores (calculated separately for each country) instead of raw scores were used. This has several advantages: first, intrinsic differences between countries in difficulty level of tasks due to differences in task construction are leveled out, equalizing results over countries. Second, these standardized T-scores are normalized, thus reducing effects of outliers or non- 
normally distributed data. Third, the standardization method is based on months of formal reading instruction, so all analyses are automatically controlled for mediating effects of amount of reading instruction.

Table 4.2 - Tasks, labels and variables

\begin{tabular}{|c|c|c|}
\hline Tasks & task label & $\begin{array}{c}\text { Variable } \\
\text { name }\end{array}$ \\
\hline high-frequency word reading fluency & HF fluency & \\
\hline Low frequency word reading fluency & LF fluency & \\
\hline Pseudoword reading fluency & PW fluency & \\
\hline hig-frequency word reading accuracy & $\mathrm{HF}$ acc & \\
\hline Low frequency word reading accuracy & LF acc & \\
\hline Pseudoword reading accuracy & PW acc & \\
\hline phoneme deletion accuracy & PD acc & PA-A \\
\hline phoneme deletion speed & PD RT & PA-RT \\
\hline RAN letters & RAN letters & \\
\hline RAN digits & RAN digits & - RAN \\
\hline RAN objects & RAN objects & \\
\hline Letter-speech sound identification accuracy & LSS-id acc & \\
\hline Letter-speech sound discrimination accuracy & LSS-disc acc & \\
\hline Letter-speech sound identification speed & LSS-id RT & LSS-RT \\
\hline Letter-speech sound discrimination speed & LSS-disc RT & \\
\hline phoneme span & Phoneme span & \\
\hline Syllable span & Syllable span & \\
\hline Baseline response time task & Baseline RT & \\
\hline
\end{tabular}

\subsection{Results}

\section{Descriptives}

Since this study includes many cognitive variables (manifest as well as latent), we provided an overview of the names and labels of the tasks and the label of the cognitive variable used in the analysis (table 4.2). 
Table 4.3 - Raw scores (mean's and standard deviations) on reading measures

\begin{tabular}{llllllllll}
\hline & & \multicolumn{3}{c}{ grade 1 } & \multicolumn{2}{c}{ grade 2 } & \multicolumn{2}{c}{ grade 3 } & \multicolumn{2}{c}{ Grade 4 } \\
& & Mean & (SD) & Mean & (SD) & Mean & (SD) & Mean & (SD) \\
\hline HF fluency & HUN & 21.0 & $(8.4)$ & 32.0 & $(9.2)$ & 37.7 & $(9.8)$ & 43.9 & $(9.0)$ \\
& NL & 27.7 & $(10.2)$ & 35.0 & $(9.8)$ & 44.9 & $(8.3)$ & 50.1 & $(7.2)$ \\
& PRT & 11.3 & $(10.7)$ & 17.6 & $(9.6)$ & 28.6 & $(10.8)$ & 33.5 & $(9.6)$ \\
\hline \multirow{4}{*}{ LF fluency } & HUN & 17.0 & $(7.4)$ & 24.8 & $(7.5)$ & 29.3 & $(8.5)$ & 35.5 & $(8.8)$ \\
& NL & 21.3 & $(10.2)$ & 27.8 & $(9.9)$ & 38.4 & $(9.4)$ & 44.2 & $(8.4)$ \\
& PRT & 8.9 & $(8.0)$ & 12.6 & $(7.2)$ & 21.2 & $(9.2)$ & 24.9 & $(8.8)$ \\
\hline PW fluency & HUN & 15.5 & $(6.1)$ & 22.8 & $(6.4)$ & 26.6 & $(7.5)$ & 30.3 & $(6.9)$ \\
& NL & 14.9 & $(6.6)$ & 18.3 & $(6.6)$ & 24.2 & $(6.5)$ & 27.2 & $(6.9)$ \\
& PRT & 9.3 & $(7.7)$ & 14.0 & $(6.8)$ & 20.1 & $(7.3)$ & 22.7 & $(7.0)$ \\
\hline HF acc & HUN & 97.0 & $(5.1)$ & 98.1 & $(3.7)$ & 98.7 & $(2.9)$ & 99.2 & $(1.9)$ \\
& NL & 95.9 & $(5.8)$ & 97.2 & $(4.8)$ & 98.8 & $(2.3)$ & 99.2 & $(1.5)$ \\
& PRT & 72.7 & $(31.0)$ & 88.8 & $(14.9)$ & 93.9 & $(11.4)$ & 96.3 & $(8.1)$ \\
\hline \multirow{6}{*}{ LF acc } & HUN & 92.9 & $(9.6)$ & 93.9 & $(7.2)$ & 95.6 & $(5.4)$ & 96.9 & $(3.8)$ \\
& NL & 90.5 & $(12.7)$ & 94.7 & $(7.0)$ & 96.9 & $(6.7)$ & 98.3 & $(3.2)$ \\
& PRT & 61.6 & $(32.0)$ & 76.6 & $(18.8)$ & 86.2 & $(15.8)$ & 88.9 & $(10.4)$ \\
\hline PW acc & HUN & 86.9 & $(11.7)$ & 90.6 & $(8.9)$ & 92.5 & $(8.9)$ & 93.2 & $(6.8)$ \\
& NL & 84.1 & $(15.4)$ & 85.5 & $(13.3)$ & 88.4 & $(10.9)$ & 89.9 & $(9.6)$ \\
& PRT & 66.7 & $(34.4)$ & 84.1 & $(15.9)$ & 88.6 & $(12.8)$ & 89.4 & $(11.3)$ \\
\hline
\end{tabular}

Note: HUN=Hungary, NL=Netherlands, PRT=Portugal, HF=High-frequency, LF=low-frequency, $\mathrm{PW}=$ pseudoword, acc=accuracy

Table 4.3 and 4.4 show the means and standard deviations for the reading and cognitive measures for each grade and country. Direct statistical comparison of raw scores is not useful since items of the tasks are adapted to the specific characteristics of each language. Nevertheless it is worth noticing that Portuguese readers performed relatively poor on all reading tasks. In the appendix, the correlations between the reading and cognitive tasks for each country are shown. The overall correlational pattern was remarkably similar between countries, although the relationship between PD accuracy and reading fluency was strongest in Portuguese and weakest in Hungarian (PRT: .58-.66, NL .46-52, HUN .38-.41), as was the relationship between accuracy on the LSS tasks and reading fluency (PRT .42-.48, NL .32-.39, HUN .25-.30). 
Table 4.4 - Raw scores (mean's and standard deviations) on cognitive measures

\begin{tabular}{|c|c|c|c|c|c|c|c|c|c|}
\hline & & \multicolumn{2}{|c|}{ grade 1} & \multicolumn{2}{|c|}{ Grade 2} & \multicolumn{2}{|c|}{ Grade 3} & \multicolumn{2}{|c|}{ grade 4} \\
\hline & & $M$ & (SD) & $M$ & (SD) & $\mathbf{M}$ & (SD) & $M$ & (SD) \\
\hline \multirow{3}{*}{$\begin{array}{l}\text { Phon Del acc } \\
\text { (\% cor) }\end{array}$} & HUN & 57.9 & $(22.4)$ & 72.5 & $(18.2)$ & 78.0 & $(16.6)$ & 83.9 & (13.7) \\
\hline & $\mathrm{NL}$ & 45.3 & $(25.4)$ & 55.4 & (25.3) & 69.0 & (21.5) & 78.3 & (19.3) \\
\hline & PRT & 33.8 & $(28.2)$ & 43.8 & $(24.6)$ & 59.6 & $(24.6)$ & 66.8 & (20.3) \\
\hline \multirow{3}{*}{$\begin{array}{l}\text { Phon Del RT } \\
\text { (sec/item) }\end{array}$} & HUN & 6.0 & $(2.6)$ & 4.9 & (1.9) & 3.7 & $(1.2)$ & 3.5 & (1.0) \\
\hline & $\mathrm{NL}$ & 6.1 & $(2.2)$ & 5.5 & (2.3) & 3.9 & (1.8) & 3.1 & (1.5) \\
\hline & PRT & 6.6 & $(2.5)$ & 6.9 & (2.3) & 5.3 & (2.3) & 4.6 & (2.0) \\
\hline \multirow{3}{*}{$\begin{array}{l}\text { RAN letters } \\
\text { (item/sec) }\end{array}$} & HUN & 1.5 & $(0.3)$ & 1.6 & $(0.3)$ & 1.8 & $(0.3)$ & 1.9 & $(0.3)$ \\
\hline & $\mathrm{NL}$ & 1.4 & $(0.3)$ & 1.5 & $(0.3)$ & 1.7 & $(0.3)$ & 1.9 & $(0.3)$ \\
\hline & PRT & 1.1 & $(0.4)$ & 1.3 & $(0.3)$ & 1.5 & $(0.4)$ & 1.6 & $(0.4)$ \\
\hline \multirow{3}{*}{$\begin{array}{l}\text { RAN digits } \\
\text { (item/sec) }\end{array}$} & HUN & 1.5 & $(0.2)$ & 1.8 & $(0.3)$ & 1.9 & $(0.3)$ & 2.1 & $(0.4)$ \\
\hline & $\mathrm{NL}$ & 1.5 & $(0.3)$ & 1.7 & $(0.3)$ & 2.0 & $(0.3)$ & 2.2 & $(0.3)$ \\
\hline & PRT & 1.3 & $(0.3)$ & 1.5 & $(0.3)$ & 1.7 & $(0.3)$ & 1.8 & $(0.3)$ \\
\hline \multirow{3}{*}{$\begin{array}{l}\text { RAN objects } \\
\text { (item/sec) }\end{array}$} & HUN & 1.0 & $(0.2)$ & 1.2 & $(0.2)$ & 1.2 & $(0.2)$ & 1.3 & $(0.2)$ \\
\hline & NL & 1.0 & $(0.2)$ & 1.1 & $(0.2)$ & 1.2 & $(0.2)$ & 1.3 & $(0.2)$ \\
\hline & PRT & 0.9 & $(0.2)$ & 0.9 & $(0.2)$ & 1.0 & $(0.2)$ & 1.1 & $(0.2)$ \\
\hline \multirow{3}{*}{$\begin{array}{l}\text { LSS-id Acc } \\
\text { (\% cor) }\end{array}$} & HUN & 88.1 & (7.9) & 89.9 & (10.3) & 91.2 & $(7.3)$ & 91.8 & (6.0) \\
\hline & $\mathrm{NL}$ & 90.7 & (8.6) & 92.8 & (6.1) & 94.5 & $(5.2)$ & 95.6 & (4.1) \\
\hline & PRT & 77.7 & (18.7) & 84.0 & (9.6) & 89.3 & (8.8) & 90.3 & (6.4) \\
\hline \multirow{3}{*}{$\begin{array}{l}\text { LSS-disc acc } \\
\text { (\% cor) }\end{array}$} & HUN & 80.1 & (15.7) & 85.0 & $(14.2)$ & 86.6 & (12.7) & 88.8 & (11.0) \\
\hline & $\mathrm{NL}$ & 81.8 & (12.6) & 86.2 & (9.6) & 89.2 & (6.9) & 91.2 & (6.8) \\
\hline & PRT & 74.5 & (16.8) & 77.8 & (13.4) & 86.3 & (8.4) & 88.2 & (8.3) \\
\hline \multirow{3}{*}{$\begin{array}{l}\text { LSS-id RT } \\
\text { (sec/item) }\end{array}$} & HUN & 2.2 & $(0.4)$ & 2.0 & $(0.4)$ & 1.7 & $(0.3)$ & 1.6 & $(0.3)$ \\
\hline & $\mathrm{NL}$ & 2.8 & $(0.6)$ & 2.6 & $(0.5)$ & 2.1 & $(0.4)$ & 2.0 & (0.4) \\
\hline & PRT & 3.7 & (1.0) & 3.4 & (0.7) & 2.9 & $(0.7)$ & 2.6 & $(0.5)$ \\
\hline \multirow{3}{*}{$\begin{array}{l}\text { LSS-disc RT } \\
\text { (sec/item) }\end{array}$} & HUN & 1.7 & $(0.4)$ & 1.5 & $(0.4)$ & 1.3 & $(0.4)$ & 1.2 & $(0.3)$ \\
\hline & $\mathrm{NL}$ & 2.1 & $(0.6)$ & 1.9 & $(0.5)$ & 1.6 & $(0.3)$ & 1.5 & (0.4) \\
\hline & PRT & 2.4 & $(0.7)$ & 2.2 & (0.6) & 2.0 & $(0.5)$ & 1.8 & $(0.4)$ \\
\hline
\end{tabular}


Table 4.4 (continued)- Raw scores (mean's and standard deviations) on cognitive measures

\begin{tabular}{llcccccccc}
\hline & & \multicolumn{2}{c}{ grade 1 } & \multicolumn{2}{c}{ Grade 2 } & \multicolumn{2}{c}{ Grade 3 } & \multicolumn{2}{c}{ grade 4 } \\
& & M & (SD) & M & (SD) & M & (SD) & M & (SD) \\
\hline Phon. Span & HUN & 41.1 & $(18.9)$ & 50.0 & $(18.7)$ & 59.7 & $(23.1)$ & 60.8 & $(21.3)$ \\
(\% cor) & NL & 53.7 & $(14.1)$ & 57.2 & $(12.1)$ & 58.9 & $(12.3)$ & 66.6 & $(10.9)$ \\
& PRT & 45.6 & $(12.7)$ & 50.7 & $(12.3)$ & 56.2 & $(13.3)$ & 58.6 & $(12.9)$ \\
\hline Syl. Span & HUN & 51.3 & $(18.4)$ & 54.8 & $(19.1)$ & 62.0 & $(19.7)$ & 65.1 & $(18.8)$ \\
(\% cor) & NL & 32.7 & $(12.0)$ & 36.7 & $(11.8)$ & 41.9 & $(12.5)$ & 47.9 & $(12.7)$ \\
& PRT & 31.7 & $(12.5)$ & 36.2 & $(13.5)$ & 42.9 & $(12.5)$ & 46.2 & $(11.9)$ \\
\hline Baseline RT & HUN & 1.0 & $(0.2)$ & 0.9 & $(0.2)$ & 0.8 & $(0.2)$ & 0.7 & $(0.2)$ \\
(sec/item) & NL & 1.1 & $(0.2)$ & 1.0 & $(0.2)$ & 0.9 & $(0.2)$ & 0.8 & $(0.1)$ \\
& PRT & 1.1 & $(0.2)$ & 1.1 & $(0.3)$ & 1.0 & $(0.2)$ & 0.8 & $(0.2)$ \\
\hline
\end{tabular}

Note: HUN=Hungary, NL=Netherlands, PRT=Portugal, phon del=phoneme deletion, LSS id=letter-sound identification, LSS disc =letter-sound discrimination, phon span= phoneme span, syl. Span=syllable span, acc=accuracy

\section{Creating latent variables}

To reduce the number of cognitive predictor variables, we created latent variables by running an exploratory factor analysis (principal components with oblimin rotation) on the cognitive variables that showed significant correlations with reading performance (PD accuracy, PD RT, RAN letters, digits and objects, Phoneme span, Syllable span, LSS-id acc, LSS-disc acc, LSS-id speed). We initially extracted 6 factors (Jolliffe's criterion was used, which allows Eigen values of .70 and higher; Jolliffe, 1972, 1986): a RAN factor, an LSS accuracy factor, a VWM factor, a LSS speed factor and a PA factor. However, PD accuracy loaded on more than one factor (PA and VWM) and factor loadings on the PA factor were relatively low (.51). More importantly it might be theoretically interesting to separate effects of phonological processing speed and phonological processing accuracy. Furthermore, LSS-id RT was the only task that loaded on the LSS-speed factor. Therefore, we decided to use the standardized T-scores on the PD accuracy, PD RT and LSS-id RT tasks in further analyses (from now on labelled PA-A, PA-RT and LSS-RT). We ran a new exploratory factor analysis on the three RAN tasks, the two LSS accuracy tasks, phoneme span and syllable span. Three factors were extracted, which were labelled as RAN, LSS-A, and VWM (Eigenvalues: resp. 2.58, 1.37 and .94; explained variance 70.0\%). The factor loadings and correlation matrix are presented in table 4.5 . 
Table 4.5 - Results of final exploratory factor analysis

\begin{tabular}{lcccc}
\hline & \multicolumn{5}{c}{ Factors } & Commu \\
& RAN & LSS-A & VWM & -nalities \\
\hline RAN letters & .85 & -.09 & .03 & .71 \\
RAN digits & .88 & -.05 & .02 & .76 \\
RAN objects & .70 & .17 & -.03 & .57 \\
LSS-id acc & .03 & .85 & .00 & .74 \\
LSS-disc acc & -.02 & .85 & .03 & .74 \\
Phoneme span & .05 & -.04 & .84 & .71 \\
Syllable span & -.04 & .06 & .82 & .69 \\
Eigen Values & 2.58 & 1.38 & .94 & \\
\hline Correlation matrix & & & & \\
\hline RAN & .24 & & & \\
LSS-A & .24 & .32 & & \\
VWM & & & & \\
\hline
\end{tabular}

Note: principal component analysis with oblimin rotation.

The effect of grade and entropy on the cognitive contributions to reading fluency

Linear mixed effect analyses (LMER procedure of R; Bates, 2008) were conducted. The predictor variables can be categorized into two types of factors: (a) intrachildren factors (cognitive variables; RAN (latent), LSS-A (latent), VWM (latent), PAA, PA-RT and LSS-RT) and (b) inter-children factors (entropy and grade as quantitative variables, no other inter-children variables were included). Therefore, three sets of multilevel regression analyses (with two levels; cognitive factors at the first level and grade and entropy at the second level) were conducted to investigate the modulating effect of entropy and grade on the cognitive predictor variables of reading fluency of respectively HF, LF and PW. 
Table 4.6- Beta coefficients of linear mixed effect analyses

\begin{tabular}{|c|c|c|c|}
\hline & $\begin{array}{c}\text { Model } 1 \\
\text { Y : HF fluency }\end{array}$ & $\begin{array}{c}\text { Model } 2 \\
\text { Y : LF fluency }\end{array}$ & $\begin{array}{c}\text { Model } 3 \\
\text { Y : PW fluency }\end{array}$ \\
\hline \multicolumn{4}{|l|}{ Level 1} \\
\hline Intercept & $30.27 * * * *$ & $26.43 * * * *$ & $24.45 * * * *$ \\
\hline$X_{1}: P A-A$ & $.17 * * * *$ & $.20 * * * *$ & $.23 * * * *$ \\
\hline $\mathrm{X}_{2}: \mathrm{PA}-\mathrm{RT}$ & $.16 * * * *$ & $.21 * * * *$ & $.21 * * * *$ \\
\hline $\mathrm{X}_{3}:$ RAN & $3.63 * * * *$ & $3.12 * * * *$ & $3.09 * * * *$ \\
\hline $\mathrm{X}_{4}:$ LSS-A & $1.25 * * * *$ & $1.50 * * * *$ & $1.16 * * * *$ \\
\hline $\mathrm{X}_{5}:$ LSS-RT & $.07 * * *$ & $.07 * * *$ & $.07 * * *$ \\
\hline $\mathrm{X}_{6}: \mathrm{VWM}$ & $.47 *$ & $.49 * *$ & $.40 *$ \\
\hline \multicolumn{4}{|l|}{ Level 2} \\
\hline \multicolumn{4}{|l|}{ 1. Entropy } \\
\hline PA-A $x$ entropy & $.77 * * * *$ & $.88 * * * *$ & $.79 * * * *$ \\
\hline PA-RT x entropy & $-.69 * * *$ & $-.73 * * * *$ & $-.69 * * * *$ \\
\hline LSS-A x entropy & ns & ns & $3.73 *$ \\
\hline LSS RT $x$ entropy & $.34 *$ & ns & ns \\
\hline \multicolumn{4}{|l|}{ 2. Grade } \\
\hline PA-A $x$ grade & $-.07 * * *$ & $-.07 * * * *$ & $-.04 *$ \\
\hline RAN $x$ grade & $.76 * * * *$ & $.55 * * *$ & $.38 *$ \\
\hline LSS-A $x$ grade & $-.49 * *$ & ns & $-.45 * *$ \\
\hline$Z_{1}$ : Entropy & $-21.18^{*}$ & -7.37 & -4.18 \\
\hline $\mathrm{Z}_{2}$ : Grade & $3.66 * * * *$ & $3.29 * * * *$ & .71 \\
\hline \multicolumn{4}{|l|}{ 1-level model } \\
\hline -2Log-Likelihood & -7678.7 & -7626.0 & -7625.9 \\
\hline AIC & 15375.3 & 15270.0 & 15269.8 \\
\hline Parameters & 9 & 9 & 9 \\
\hline \multicolumn{4}{|c|}{ Complete 2-level model } \\
\hline -2Log-Likelihood & -7641.4 & -7603.6 & -7591.5 \\
\hline AIC & 15330.9 & 15255.1 & 15229.1 \\
\hline Parameters & 24 & 24 & 24 \\
\hline \multicolumn{4}{|l|}{ Final model } \\
\hline -2Log-Likelihood & -7653.1 & -7616.8 & -7602.6 \\
\hline AIC & 15340.3 & 15261.7 & 15241.1 \\
\hline Parameters & 17 & 14 & 18 \\
\hline
\end{tabular}

Note: Level 1, Individuals; Level 2, Entropy and Grade. AIC, Akaike information criterion *p $\leq$ $.05 ; * * \mathrm{p} \leq .01 ; * * * \mathrm{p} \leq .001, * * * * \mathrm{p} \leq .0001, \mathrm{~ns}=$ non-significant 
The initial models included all possible relationships (see figure 4.1 for an example). Non-significant relationships were excluded from the model (least significant values first), and models were rerun until only significant relationships were left. The results of the final models for reading fluency of HF, LF and PW are presented in table 4.6.

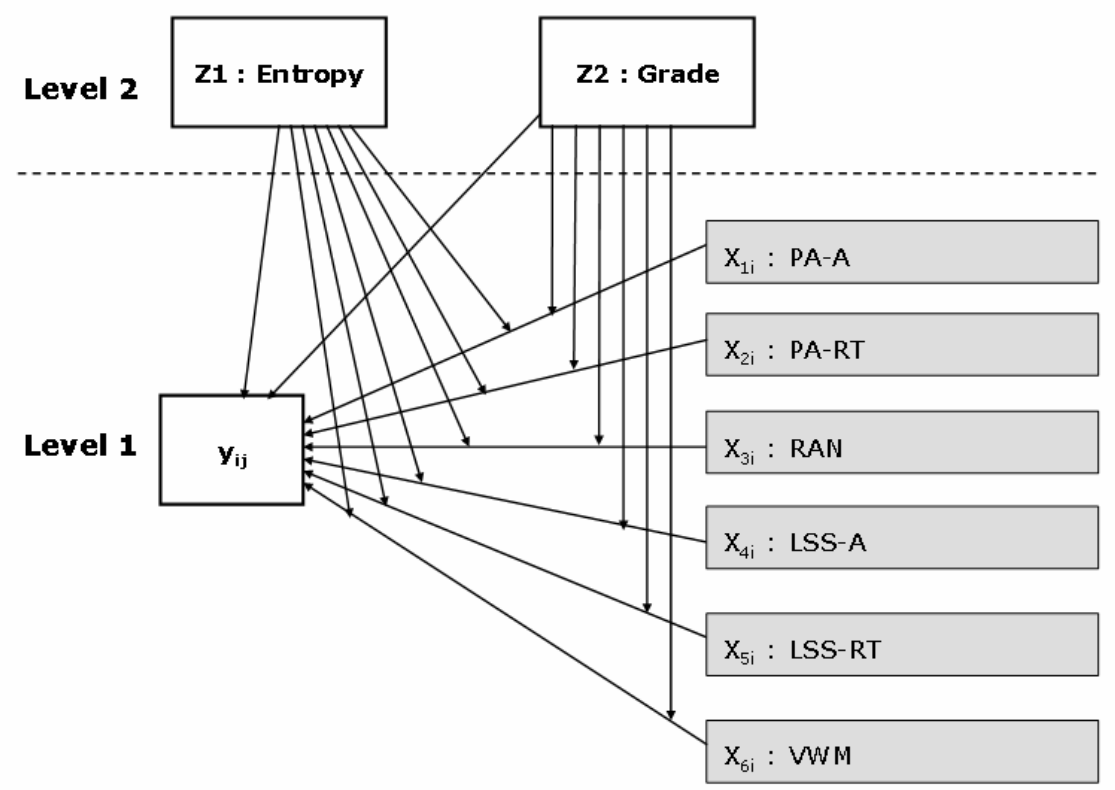

Figure 4.1: Example of initial linear mixed effect model

Grade effects: Grade modulated the relationship between PA-A and HF, LF and $P W$ reading fluency (the strength of the contribution of $P A$ accuracy decreased with Grade; HF reading fluency: unstand. $\beta=-.07, p<.001$; LF reading fluency: unstand. $\beta=$ - -.07, $p<.0001$; PW reading fluency, unstand. $\beta=-.04, p<.05)$. The contribution of LSS-A to HF and PW reading fluency also decreased as a function of Grade (HF reading fluency: unstand. $\beta=-.49, p<.01$; PW reading fluency: unstand. $\beta=-.45, p<.01)$. In contrast, the relationship between RAN and reading fluency of all word types increased as a function of Grade (HF reading fluency: unstand. $\beta=.76, p<.0001$; LF reading fluency: unstand. $\beta=.55, p<.001 ; \mathrm{PW}$ reading fluency, unstand. $\beta=.38$, $p<.05)$. The influence of PA-RT on reading fluency was equally strong in all grades 
(no interaction with grade). The relationships between VWM and reading fluency, and LSS-S and reading fluency were modest, and did not change as a function of Grade.

Entropy effects: Entropy modulated the effect of PA-A and PA-RT on HF, LF and PW fluency, but in different directions: while PA-A was more important in opaque orthographies (HF reading fluency: unstand. $\beta=.77, p<.0001$; LF reading fluency: unstand. $\beta=.88, p<.0001 ;$ PW reading fluency, unstand. $\beta=.79, p<.0001)$, PA-RT was more important in transparent orthographies (HF reading fluency: unstand. $\beta=-.69$, $p<.001$; LF reading fluency: unstand. $\beta=-.73, p<.0001 ;$ PW reading fluency, unstand. $\beta=-.69, p<.0001$ ). Entropy had a small effect on the strength of the contribution of LSS-RT to HF word reading fluency (unstand. $\beta=.34, p<.05$ ) and on the strength of the contribution of LSS-A to pseudoword reading fluency (unstand. $\beta=3.73, p<.05$ ). Entropy did not influence the strength of the contribution of RAN or VWM.

There was no three-way interaction between Grade, Entropy and the cognitive variables, indicating that the influence of Grade on the strength of the cognitive contributors does not differ between languages with varying orthographic consistency.

\section{Cognitive contributions per grade}

Since we were specifically interested in the influence of entropy on the contributions of cognitive variables at different levels of reading experience, separate analyses were conducted for each grade. We conducted hierarchical regression analyses with PA-A, PA-RT, RAN (latent), LSS-A (latent), LSS-RT and VWM (latent) and entropy value in the first step (all variables were centered) and interaction terms between entropy and cognitive variables in the second step, because this method provides standardized beta-coefficients, which are necessary to compare the strength of the modulating influence of entropy on the cognitive contributions to reading speed. Non-significant predictors were excluded from the model (least significant first), until all remaining relationships were significant. The results are presented in table 4.7 and visualized in figure $4.2,4.3$ and 4.4 to illustrate the developmental trend. 
Table 4.7 - Standardized Beta coefficients of regression models for each grade

\begin{tabular}{|c|c|c|c|c|}
\hline & \multicolumn{4}{|c|}{ HF word reading } \\
\hline & grade 1 & grade 2 & grade 3 & grade 4 \\
\hline \multicolumn{5}{|l|}{ Step I } \\
\hline PA-A & .25 & .27 & .19 & .05 \\
\hline PA-RT & .13 & .20 & .17 & .15 \\
\hline RAN & .22 & .28 & .41 & .46 \\
\hline LSS-A & .29 & .08 & .09 & .08 \\
\hline LSS-RT & .09 & .08 & .05 & .04 \\
\hline VWM & .00 & .06 & .01 & .07 \\
\hline \multicolumn{5}{|l|}{ Step II } \\
\hline PA-A x Entropy & .11 & .08 & ns & ns \\
\hline PA-RT x Entropy & -.12 & -.06 & ns & ns \\
\hline LSS-A x Entropy & ns & ns & .09 & ns \\
\hline Adjusted $\mathrm{R}^{2}$ step 1 & .490 & .437 & .468 & .397 \\
\hline \multirow[t]{3}{*}{ Adjusted $\mathrm{R}^{2}$ total } & .506 & .441 & .475 & .397 \\
\hline & \multicolumn{4}{|c|}{ LF word reading } \\
\hline & grade 1 & grade 2 & grade 3 & grade 4 \\
\hline \multicolumn{5}{|l|}{ Step I } \\
\hline PA-A & .25 & .26 & .21 & .10 \\
\hline PA-RT & .12 & .27 & .23 & .21 \\
\hline RAN & .23 & .23 & .32 & .40 \\
\hline LSS-A & .27 & .09 & .11 & .15 \\
\hline LSS-RT & .11 & .07 & .07 & .04 \\
\hline VWM & .01 & .08 & .01 & .04 \\
\hline \multicolumn{5}{|l|}{ Step II } \\
\hline PA-A x Entropy & .12 & ns & ns & ns \\
\hline PA-RT x Entropy & -.11 & ns & -.11 & ns \\
\hline LSS-A x Entropy & ns & ns & .12 & ns \\
\hline Adjusted $\mathrm{R}^{2}$ step 1 & .505 & .448 & .478 & .463 \\
\hline Adjusted $\mathrm{R}^{2}$ Total & .522 & .448 & .494 & .463 \\
\hline
\end{tabular}


Table 4.7 (continued) - Standardized Beta coefficients of regression models for each grade

\begin{tabular}{|c|c|c|c|c|}
\hline & \multicolumn{4}{|c|}{ PW reading } \\
\hline & grade 1 & grade 2 & grade 3 & Grade 4 \\
\hline \multicolumn{5}{|l|}{ Step I } \\
\hline PA-A & .26 & .24 & .27 & .14 \\
\hline PA-RT & .10 & .28 & .25 & .22 \\
\hline RAN & .27 & .25 & .29 & .38 \\
\hline LSS-A & .26 & .06 & .09 & .09 \\
\hline LSS-RT & .10 & .05 & .04 & .07 \\
\hline VWM & .03 & .09 & -.02 & .04 \\
\hline \multicolumn{5}{|l|}{ Step II } \\
\hline PA-A x Entropy & .11 & ns & ns & .07 \\
\hline PA-RT x Entropy & -.10 & ns & -.07 & ns \\
\hline LSS-A x Entropy & ns & ns & .13 & ns \\
\hline Adjusted $R^{2}$ step 1 & .522 & .450 & .473 & .468 \\
\hline Adjusted $R^{2}$ total & .535 & .450 & .487 & .472 \\
\hline
\end{tabular}

The results showed that the contributions of PA-A, PA-RT and RAN to reading fluency were substantial in all grades and for all word types, except for the contribution of PA-A to HF fluency in grade 4 . The involvement of LSS-A was strong in beginning readers ( $\beta$ between .26 and .29, $p<.0001$ ), but decreased in grade 2,3 and 4 ( $\beta$ between $.07, p<.05$ and $.16, p<.0001)$. RAN became increasingly involved in word reading fluency, and was the most important contributor to reading fluency of all word types in grade 3 and 4 ( $\beta$ between .29 and $.46, p<.0001$ ). The contribution of PA-RT was rather stable in grade 2 to 4 ( $\beta$ between .18 and $.29, p<.0001$ ). In grade 1 contributions were weaker ( $\beta$ between .10 and.13, $p<.01$ ). The contributions of LSSRT and VWM were not significant or very weak ( $\beta$ between .07 and.10, $p<.05$ ).

The main effect of entropy was not significant in any of the models (which is expected, because standardized scores for reading was calculated for each country separately). Entropy did however influence the strength of the contributions of PART and PA-A in some of the grades. In grade 1, entropy effects were strongest (PA-A $x$ entropy: $\beta$ between .11 and $.12, p<.01$; PA-RT $x$ entropy: $\beta$ between -.10 and -.12 , $p<.01)$. In grade 2 , only the contributions of PA-A and PA-RT to HF fluency, and not to LF or PW fluency, were significantly modulated by entropy (PA-A $x$ entropy: $\beta=.08, p<.05$, PA-RT $x$ entropy: $\beta=-.06, p<.05)$. In grade 3 , in contrast, entropy only modulated the contributions of PA-A and PA-RT to LF and PW fluency, and not to HF word reading fluency (PA-A $x$ entropy: $\beta=.09, p<.05$; PA-RT $x$ entropy: $\beta$ between .11 and $-.12, \mathrm{p}<.01)$. 
The contribution of LSS-A was only modulated by entropy in grade 3 ( $\beta$ between .08 and $-.09, p<.05)$, which might suggest that in beginning readers LSS-A contributions are equally strong across all countries, but remains important over a longer period of time in languages with an opaque orthography.

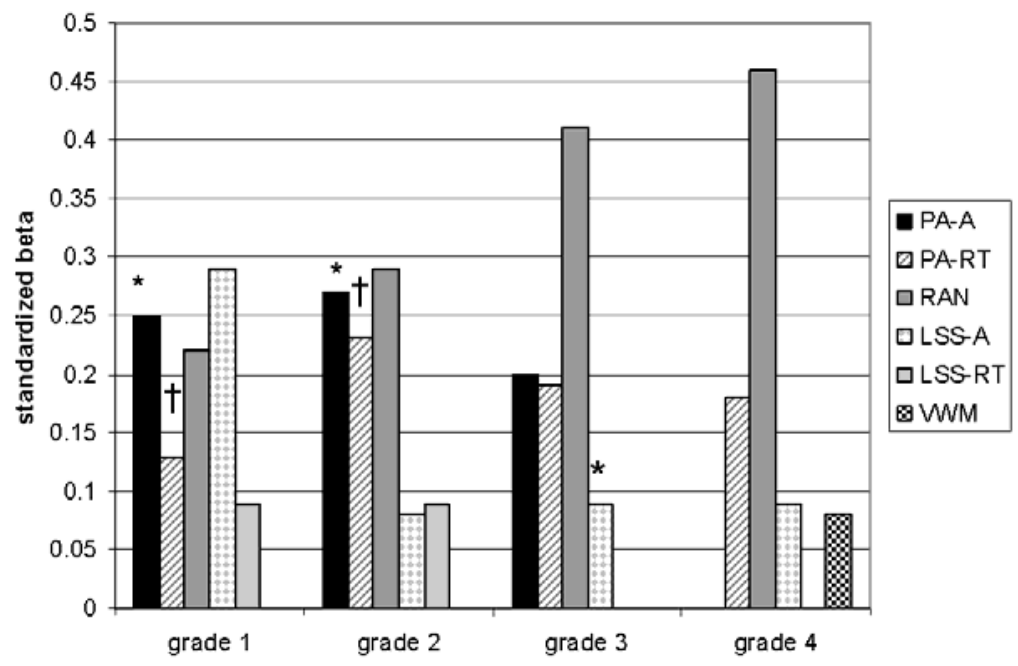

Figure 4.2 - Developmental pattern of cognitive contributions to HF word reading fluency. Modulations by orthographic consistency are indicated: *=stronger contribution in opaque orthography; $t=$ stronger contribution in transparent orthography 


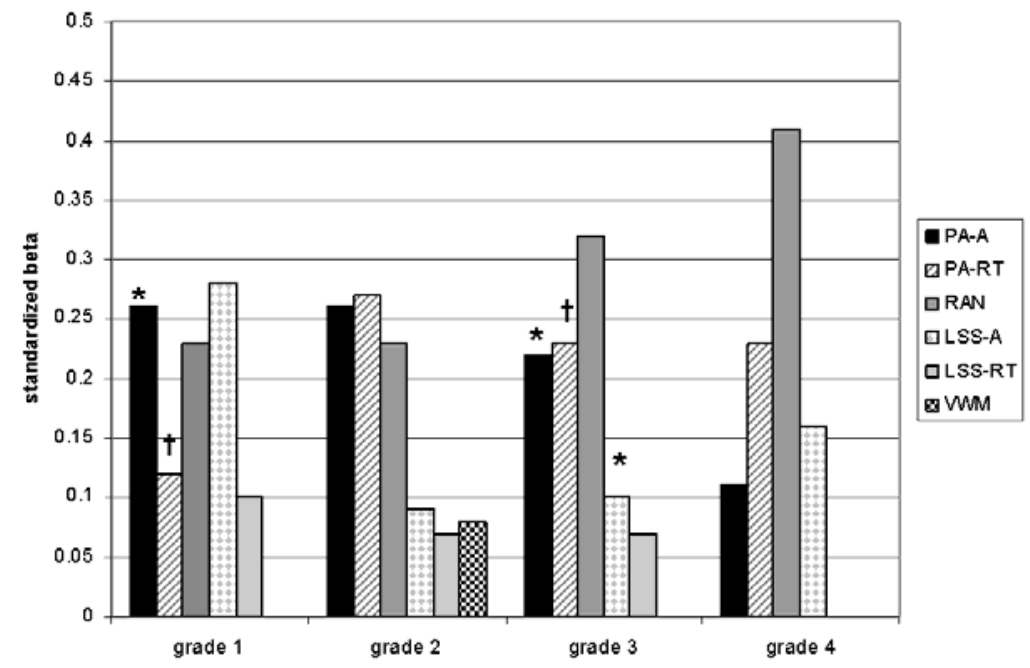

Figure 4.3 - Developmental pattern of cognitive contributions to LF word reading fluency. Modulations by orthographic consistency are indicated: *=stronger contribution in opaque orthography; $t=$ stronger contribution in transparent orthography

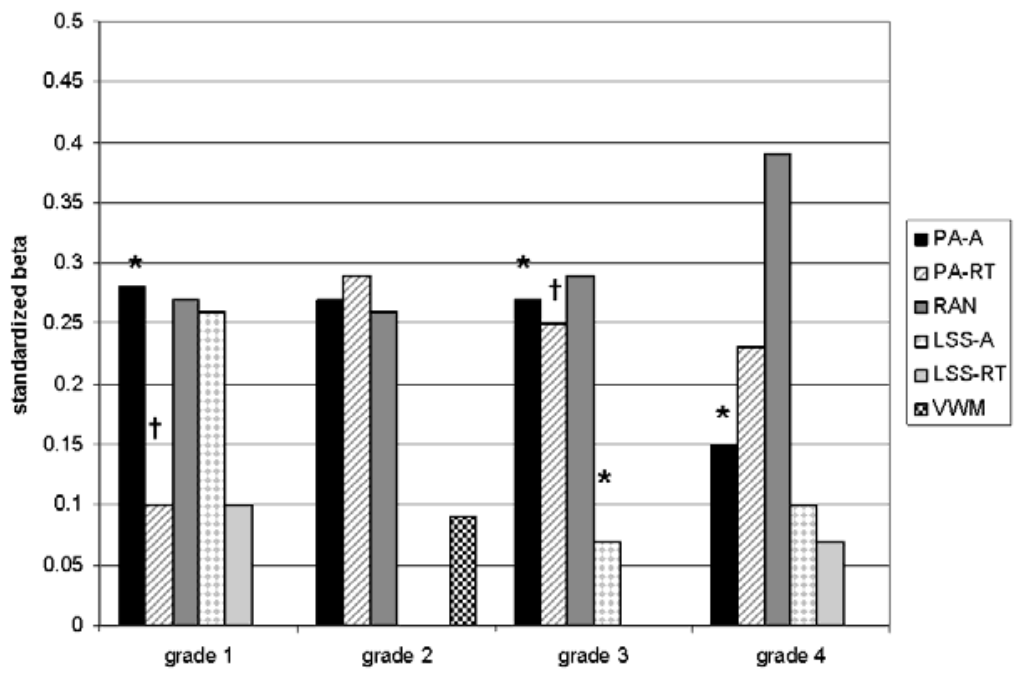

Figure 4.4 - Developmental pattern of cognitive contributions to PW word reading fluency. Modulations by orthographic consistency are indicated: *=stronger contribution in opaque orthography; $t=$ stronger contribution in transparent orthography 


\subsection{Discussion}

The present study investigated the developmental relationship between cognitive skills and reading fluency of different word types and the modulating influence of orthographic consistency on this relationship. The results showed that phonological awareness (PA) accuracy, PA speed, rapid naming (RAN) and letter-speech sound association (LSS) accuracy all substantially contributed to reading fluency, while the contributions of LSS speed and verbal working memory (VWM) were modest or non-significant. More importantly, the contributions of PA accuracy, RAN and LSS accuracy were modulated by grade; the contributions of PA accuracy and LSS accuracy declined with more reading experience, while RAN contributions to reading fluency of all word types increased in all three orthographies. The effects of grade on the cognitive contributions were most pronounced for high-frequency words and less pronounced for pseudowords (in line with the results of Vaessen \& Blomert, in revision).

This grade effect on the cognitive contributions to reading fluency was not modulated by entropy (no three-way interaction between grade, entropy and cognitive skills), indicating that the cognitive development of reading fluency follows a similar pattern across orthographies varying in consistency. Furthermore, entropy did not influence the contribution of RAN to reading fluency in any of the grades tested, indicating that the strength of the relationship between RAN and reading is equally strong in opaque and transparent orthographies. The gradually increasing relationship between RAN and reading fluency possibly reflects an increasing role of efficient matching of visual/orthographic and phonological information in fluent reading (Berninger, Abbott, Billingsley, \& Nagy, 2001; Bowers \& Ishaik, 2003; Vaessen, Gerretsen, \& Blomert, 2009) that occurs in all (alphabetic) languages, independent of the orthographic consistency.

The degree of entropy did however modulate the strength of the contributions of PA accuracy and PA speed to HF fluency in grade 1 and 2 and to LF and PW fluency in grade 1 and 3; PA accuracy contributed more strongly in opaque orthographies, while PA speed seems to be more important in transparent orthographies. Moreover, the contribution of LSS accuracy to reading fluency is equally strong in the different orthographies in first and second grade, but is stronger in opaque than in transparent orthographies in the third grade, probably implying that letterspeech sound association skills remain important for reading for a longer period in opaque orthographies than in transparent orthographies.

\section{The interplay between phonological accuracy and phonological speed}

It is worth noting that the effect of orthographic consistency on PA speed is opposite to the effect of entropy on PA accuracy; that is, PA speed is more important for 
reading in transparent orthographies while PA accuracy is more important in opaque orthographies. There might be several explanations for this discrepancy in the effect of PA speed and PA accuracy on reading. First it is possible that performance on the PA task reached ceiling levels faster in transparent than in opaque orthographies (for similar argumentation see Caravolas, Hulme, \& Snowling, 2001; Patel et al., 2004), thereby reducing the statistical power of PA accuracy favouring PA speed as the best discriminating variable. However, the performance on the phoneme deletion task in the present study did not reach ceiling in any of the languages, not even in grade 4. Moreover, if ceiling effects would be the reason for the stronger effect of orthographic consistency on PA speed, this effect should have been most obvious in grades in which the data were most skewed (grade 4). However, we found the opposite; the effect of orthographic consistency was largest in grade 1.

An alternative explanation could be that PA speed can not be reliably tested if PA accuracy is too low. Since many Portuguese first graders showed low performance on PA accuracy, the effect of PA speed on reading could be reduced in these children and this could explain the negative effect of entropy value in grade 1 .

A final possible explanation for the stronger involvement of PA speed in transparent orthographies might be that PA speed accrues importance when certain levels of reading expertise are reached. That is, it is possible that skills like efficiency of phonological decoding and fast retrieval of phonological information (which might be captured by speed on phonological awareness tasks) mainly assume importance when reading speed becomes a more salient characteristic of reading skill. In opaque orthographies, this phase of reading development might be reached at a later point in time than in transparent orthographies, explaining why the contribution of PA speed on reading was weaker in Portuguese mainly in the first grades.

\section{Implications for universal models of fluent reading development}

The fact that we found a similar pattern of results in all three orthographies, i.e., a strong influence of PA in beginning readers and a gradual shift in the relative importance of PA and RAN on reading fluency as a function of reading experience, indicates that cognitive contributions to reading development are relatively independent of orthographic depth. These results do not support claims that readers in transparent orthographies use cognitively different reading strategies than readers in opaque orthographies (as predicted by strong versions of the Orthographic Depth Hypothesis, Katz \& Frost, 1992). Moreover, a weak version of the ODH (i.e. readers in transparent orthographies rely relatively more heavily on phonological decoding strategies; Frost, 2005) is not supported by the current results either, since PA and LSS processing contributed as strong or even stronger in opaque orthographies 
compared to transparent orthographies (which is in line with previous reports; Georgiou, Parilla et al., 2008; Mann \& Wimmer, 2002; Ziegler et al., in press).

Rather, the current data suggest that fluent reading recruits the same cognitive processes in different orthographies, but the time course of the cognitive developmental pattern is influence by orthographic features such as transparency. That is, in opaque orthographies, it is more difficult to grasp the basic principle of the alphabetic structure of a language because letter-speech sound correspondences are ambiguous, and children learning to read in an opaque orthography probably have to develop more elaborate, complex phonological decoding strategies (as suggested by Ziegler \& Goswami, 2005). Consequently, it might take longer to form stable connections between orthographic (word-specific) patterns and phonological codes (i.e. moving to a consolidated alphabetic phase, Ehri, 1995, 2005), fluent reading develops at a slower rate in opaque orthographies (e.g. Frith, Wimmer, \& Landerl, 1998; Goswami, Gombert, \& De Barrera, 1998; Goswami, Ziegler, \& Richardson, 2005; Landerl, Wimmer, \& Frith, 1997; Seymour et al., 2003), and phonological processing and decoding skills are involved in reading for reading for a longer period of time. In other words, "phonemic awareness is likely to be equally important in consistent and inconsistent orthographies but at different phases in development" (Share, 2008, p.598).

\section{Generalisation to the English orthography}

As noted before, English has an outlier position regarding its orthographic consistency, and therefore 'universal' models of reading development might not be directly applicable to English (Share, 2008). However, Share also assumes that the beginning and end state of reading are universal for all alphabetic scripts: Phonological decoding is important for the initial acquisition of literacy skills in all (alphabetic) orthographies, while the quintessence of skilled reading is to automatically and effortlessly recognize words by sight. If the hypothesis that this shift is reflected in a concomitant shift in the relative importance of PA and RAN to word reading fluency (see also Vaessen \& Blomert, in revision) is correct, it seems reasonable to assume that this shift might eventually also occur in English readers, although PA might be important for a longer period of time when learning to read in English than is the case in other orthographies (Torgesen et al., 1997; Wagner et al., 1994). In line with this assumption, some English-language studies including a wide age-range also demonstrated a shift in the relative importance of PA and/or RAN for word reading (Badian, 2001; Kirby, Parrila, \& Pfeiffer, 2003).

\section{Potential limitations of this study}

There are some limitations of the current study that are worth mentioning. First of all, the present study only focused on one aspect of a language's orthography: or- 
thographic consistency defined in terms of word onsets. Obviously, the orthographic structure of a language is defined by more than only this type of orthographic consistency, and other linguistic aspects, such as syllabic complexity (Seymour et al., 2003), might also have had an impact on rate of reading development. However, the results of the current study do not indicate a strong influence of syllabic complexity on reading development, since children learning to read in Portuguese, which has a simple syllabic structure, showed a slower rate of reading development than children learning to read in Dutch, which has a complex syllabic structure. Nevertheless it remains, in principle, possible that other linguistic characteristics, such as syllabic stress patterns (Duncan, Cole, Seymour, \& Magnan, 2006) or semantic ambiguity (van Orden \& Kloos, 2005) have also influenced reading development in the three orthographies tested in this study.

Another limitation of the present study (and other cross-language investigations) is that there are systematic non-linguistic differences between countries, such as instructional methods (Rayner, Foorman, Perfetti, Pesetsky, \& Seidenberg, 2001; Ziegler \& Goswami, 2006), school support systems (Blomert, 2009), economic status of a country and parental education, which possibly affect the rate of reading development. For instance, the parental educational level of the Portuguese sample was lower than that of Dutch sample, which might have lead to their poorer reading performance. However, the Hungarian children also showed a lower parental educational level, but their reading levels were comparable to that of Dutch children, showing that parental education does not by itself lead to lower reading performance. Moreover, parental educational level did not correlate strongly with reading performance within one country (correlations between .07 and .20) suggesting that this factor might also not have had a large impact on between-country differences in reading performance. Still, other structural cross-country differences might have an influence on reading development.

A final factor that might influence the rate of reading development is age at which formal reading instruction starts. In Hungary, children enter school when they are 7 years old, while Portuguese and Dutch children are typically 6 years old. However, correlations between age and standardized reading scores were not significant, suggesting that age does not affect reading performance once the amount of formal reading education is taken into account. Moreover, the large-scale EU COST A8 study including 13 different orthographies showed that the age of school entrance did not affect reading performance (Seymour et al., 2003).

To close, it is worth mentioning that despite these linguistic and non-linguistic differences between the three countries (which might have contributed to differences in rate of reading development), the results regarding the developmental course of the cognitive skills associated with reading fluency were remarkably similar, supporting a fairly universal cognitive basis of fluent word reading development in alphabetic orthographies. 


\section{Conclusions}

The results of the present study indicate that cognitive development of fluent word reading (in alphabetic scripts) follows a similar pattern in orthographies varying in consistency of their letter-speech sound mappings. In all three included orthographies, the weight of the contributions of PA, LSS and RAN shifted as a function of reading expertise and word type/frequency, and orthographic consistency did not modulate this general effect. However, the contributions of PA and LSS to reading fluency were important for a longer period of time in opaque orthographies, suggesting that orthographic consistency does influence the rate at which the reading system develops. Because of the ambiguous letter-speech sound correspondences characteristic of opaque orthographies, children probably have to develop more elaborate decoding strategies and consequently phonological skills remain important for a longer period of time. Nevertheless, the results strongly indicate that the same cognitive components underlie the development of fluent reading skills in opaque and transparent orthographies.

\section{Acknowledgments}

The present study was supported by grant 2006-2798/001-001 SO2 61OBGE of the EU-SOCRATES program Action 6.1.2 \& 6.2 awarded to Leo Blomert. The Portuguese study was also partly funded by Fundação para a Ciência e Tecnologia PTDC/PSI/64920/2006 awarded to Alexandra Reis. 


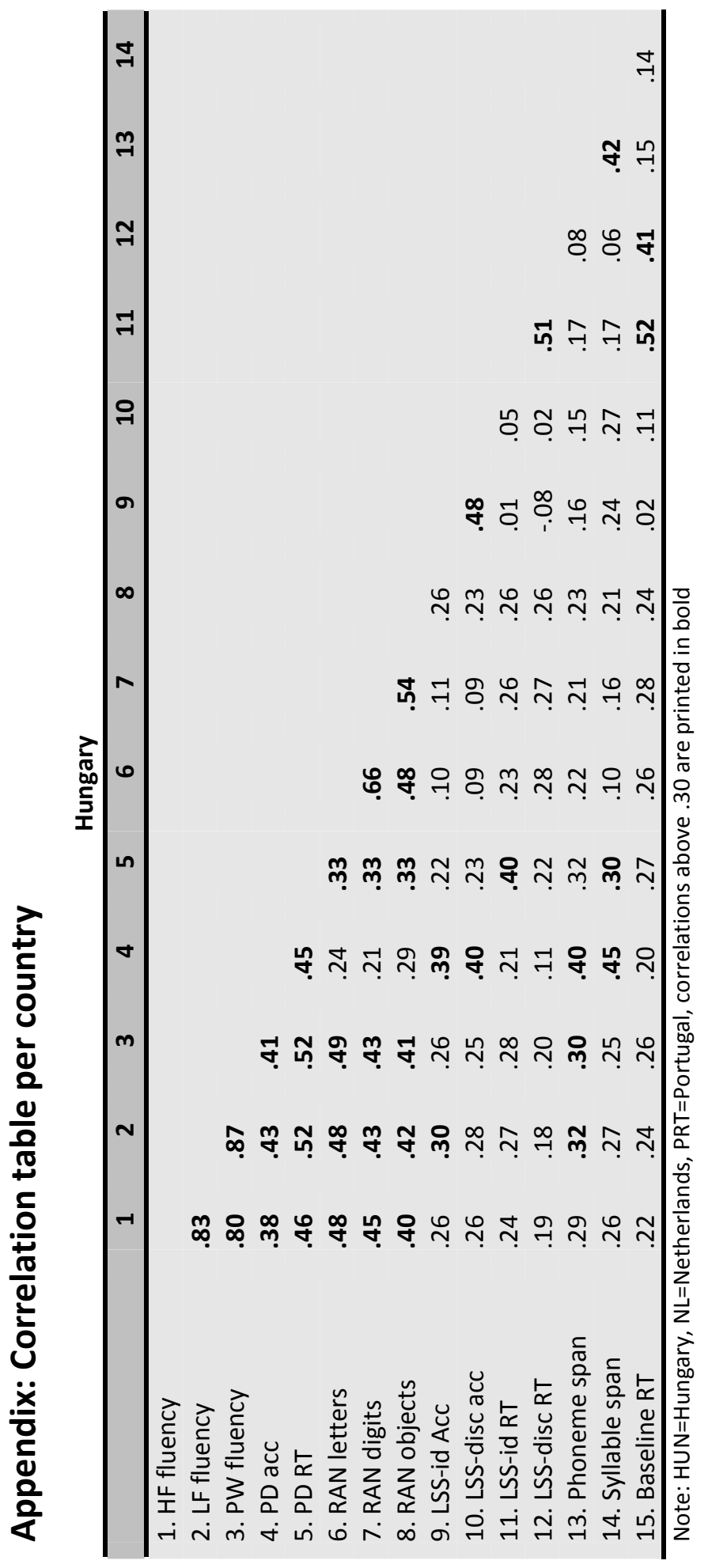




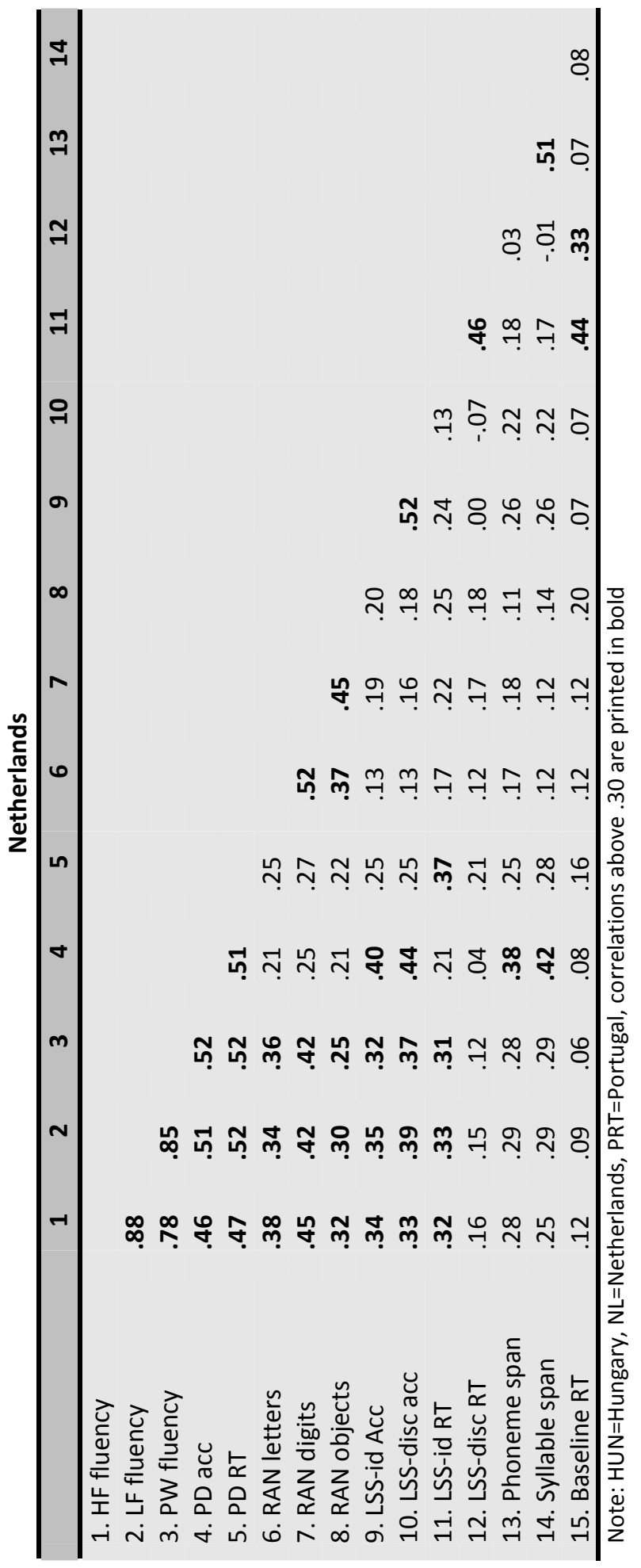




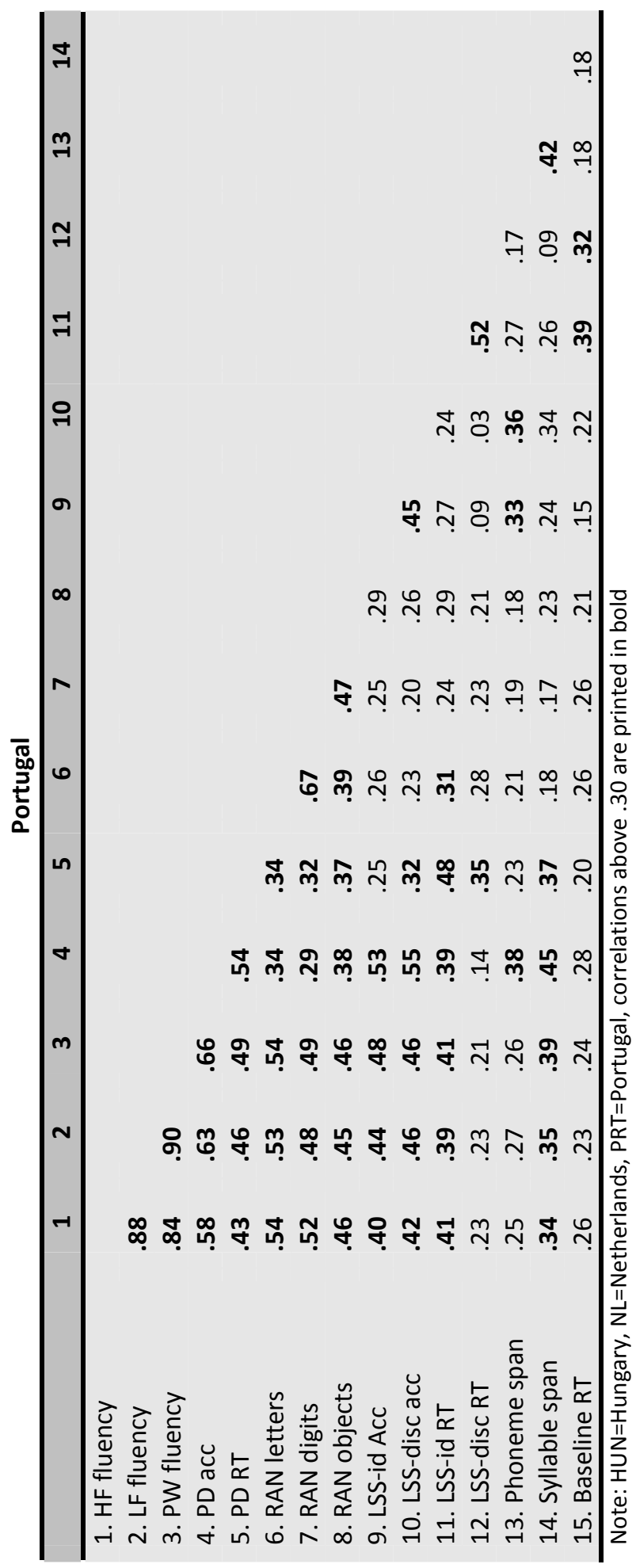




\section{References}

Baddeley, A. D. (1995). working memory. In M. S. gazzaniga (Ed.), The Cognitive Neurosciences. (pp. 755764). Cambridge MA, US: MIT: Press.

Badian, N. A. (2001). Phonological and orthographic processing: Their roles in reading prediction. Annals of Dyslexia, 51, 179-202.

Bates, D. (2008). from http://Ime4.r-forge.r-project.org/

Berninger, V. W., Abbott, R. D., Billingsley, F., \& Nagy, W. (2001). Processes underlying timing and fluency: efficiency, automaticity, coordination and morphological awareness. In M. Wolf (Ed.), Dyslexia, fluency and the brain (pp. 383-414). Timonium, MD: York Press.

Blomert, L. (2009). Cognitive and Educational Profiling of Reading and Poor Reader Support within the EU. Brussels: Final Report EU-PROREAD; project. nr. 2006-2798/001-001 SO2, 61OBGE. E.U.; D.G. Education and Culture: Research Program, SOCRATES Action 6.1 .2 and 6.2 http://ec.europa.eu/education/transversal-programme/doc950_en.htm.

Blomert, L., \& Vaessen, A. (2009). Differentiaal Diagnostiek van Dyslexie: Cognitieve analyse van lezen en spellen [Dyslexia Differential Diagnosis: Cognitive analysis of reading and spelling]. Amsterdam: Boom test publishers BV.

Borgwaldt, S. R., Hellwig, F. M., \& De Groot, A. M. B. (2005). Onset entropy matters - Letter-to-phoneme mappings in seven languages. Reading and Writing, 18, 211-229.

Bowers, P. G. (1993). Text reading and rereading: Determinants of fluency beyond word recognition. Journal of Reading Behavior, 25(2), 133-153.

Bowers, P. G., \& Ishaik, G. (2003). RAN's contribution to understanding reading disabilities. In S. Graham, H. Swanson \& K. R. Lee Harris (Eds.), Handbook of learning disabilities (pp. 140-157). New York, US: Guilford Press.

Caravolas, M., Hulme, C., \& Snowling, M. J. (2001). The foundations of spelling ability: Evidence from a 3year longitudinal study. Journal of Memory and Language, 45(4), 751-774.

Caravolas, M., Volin, J., \& Hulme, C. (2005). Phoneme awareness is a key component of alphabetic literacy skills in consistent and inconsistent orthographies: evidence from Czech and English children. Journal of Experimental Child Psychology, 92, 107-139.

Cirino, P., Israelian, M. K., Morris, M. K., \& Morris, R. D. (2005). Evaluation of the Double Deficit Hypothesis in college students referred for learning difficulties. Journal of Learning Disabilities, 38(1), 29-44.

de Jong, P. F., \& van der Leij, A. (1999). Specific contributions of phonological abilities to early reading acquisition: results from a Dutch latent variable longitudinal study. Journal of Educational Psychology, 91(3), 450-476.

de Jong, P. F., \& van der Leij, A. (2002). Effects of phonological abilities and linguistic comprehension on the development of reading. Scientific Studies of Reading, 6(1), 51-77.

Duncan, L. G., Cole, P., Seymour, P. H., \& Magnan, A. (2006). Differing sequences of metaphonological development in French and English. Journal of Child Language, 33(2), 369-399.

Ehri, L. C. (1995). Phases of development in learning to read words by sight. Journal of Research in Reading, 18, 116-125.

Ehri, L. C. (2005). Development of sight word reading: Phases and findings. In M. J. Snowling \& C. Hulme (Eds.), The Science of Reading: A Handbook (pp. 135-154). Oxford: Blackwell publishing. 
Frith, U. (1985). Beneath the surface of developmental dyslexia. . In K. E. Patterson, J. C. Marshhall \& M. Coltheart (Eds.), Surface Dyslexia (pp. 301-322). London: Erlbaum.

Frith, U., Wimmer, H., \& Landerl, K. (1998). Differences in phonological recoding in German- and Englishspeaking children. Scientific Studies of Reading, 2, 31-54.

Frost, R. (2005). Orthographic systems and skilled word recognition processes in reading. In M. J. Snowling \& C. Hulme (Eds.), The science of reading (pp. 272-295).

Froyen, D., van Atteveldt, N., Bonte, M., \& Blomert, L. (2008). Cross-modal enhancement of the MMN to speech-sounds indicates early and automatic integration of letters and speech-sounds. Neuroscience Letters, 430(1), 23-28.

Froyen, D. J., Bonte, M. L., van Atteveldt, N., \& Blomert, L. (2009). The long road to automation: neurocognitive development of letter-speech sound processing. Journal of Cognitive Neuroscience, 21(3), 567-580.

Georgiou, G. K., Das, J. P., \& Hayward, D. V. (2008). Comparing the contribution of two tests of working memory to reading in relation to phonological awareness and rapid naming speed. Journal of Research in Reading, 31(3), 302-318.

Georgiou, G. K., Parilla, R., \& Papadopoulos, T. C. (2008). Predictors of word decoding and reading fluency across languages varying in orthographic consistency. Journal of Educational Psychology, 100, 566-580.

Georgiou, G. K., Parrila, R., Kirby, J. R., \& Stephenson, K. (2008). Rapid naming components and their relationship with phonological awareness, orthographic knowledge, speed of processing, and different reading outcomes. Scientific Studies of Reading, 12(4), 325-350.

Goswami, U., Gombert, J. E., \& De Barrera, L. F. (1998). Children's orthographic representations and linguistic transparency: Nonsense word reading in English, French, and Spanish. Applied Psycholinguistics, 19, 19-52.

Goswami, U., Ziegler, J. C., \& Richardson, U. (2005). The effects of spelling consistency on phonological awareness: A comparison of English and German. Journal of Experimental Child Psychology, 92, 345365.

Hardy, M. H., Smythe, P. C., Stennet, R. G., \& Wilson, H. R. (1972). Developmental patterns in elemental reading skills: phoneme-grapheme and grapheme-phoneme correspondences. Journal of Educational Psychology, 63, 433-436.

Jolliffe, I. T. (1972). Discarding variables in a principle component analysis, I; artificial data. Applied Psycholinguistics, 21, 160-173.

Jolliffe, I. T. (1986). Principle component analysis. New York: Springer-Verlag.

Katz, L., \& Frost, R. (1992). The reading process is different for different orthographies: the orthographic depth hypothesis. In L. Katz \& R. Frost (Eds.), Orthography, phonology, morphology and meaning. Oxford, England:: North-Holland.

Kirby, J. R., Parrila, R. K., \& Pfeiffer, S. L. (2003). Naming speed and phonological awareness as predictors of reading development. Journal of Educational Psychology, 95(3), 453-464.

Landerl, K., \& Wimmer, H. (2008). Development of word reading fluency and spelling in a consistent orthography: an 8-year follow-up. Journal of Educational Psychology, 100(1), 150-161.

Landerl, K., Wimmer, H., \& Frith, U. (1997). The impact of orthographic consistency on dyslexia: a German-English comparison. Cognition, 63(3), 315-334. 
Leppanen, U., Niemi, P., Aunola, K., \& Nurmi, J. (2006). Development of Reading and Spelling Finnish From Preschool to Grade 1 and Grade 2. Scientific Studies of Reading, 10(1), 3-30.

Lervåg, A., Bråten, I., \& Hulme, C. (2009). The cognitive and linguistic foundations of early reading development: A Norwegian latent variable longitudinal study. Developmental Psychology, 45(3), 764.

Mann, V., \& Wimmer, H. (2002). Phoneme awareness and pathways into literacy: A comparison of German and American children. Reading and Writing: An Interdisciplinary Journal, 15, 653-682.

Manolitsis, G., Georgiou, G. K., Stephenson, K., \& Parrila, R. (in press). Beginning to read across languages varying in orthographic consistency: comparing the effects of non-cognitive and cognitive predictors. Learning and Instruction.

Marsh, G., Friedman, M., Welsh, V., \& Desberg, P. (1981). A cognitive developmental theory of reading acquisition. . In G. MacKinnon \& T. Walker (Eds.), Reading research: advances in theory and practice (pp. 199-211). New York: Academic Press.

McCallum, R. S., Bell, S. M., Wood, M. S., Below, J. L., Choate, S. M., \& McCane, S. J. (2006). What Is the Role of Working Memory in Reading Relative to the Big Three Processing Variables (Orthography, Phonology, and Rapid Naming)? Journal of Psychoeducational Assessment, 24(3), 243-259.

Mendonça, A., Inácio, F., Bramão, I., Araújo, S., Pacheco, A., Reis, A., et al. (2008). A influência do método de ensino da leitura e da escrita numa tarefa de leitura. Paper presented at the III Encontro Nacional da Associação Portuguesa de Psicologia Experimental, Universidade do Algarve, Faro.

Nikolopoulos, D., Goulandris, N., Hulme, C., \& Snowling, M. J. (2006). The cognitive bases of learning to read and spell in Greek: Evidence from a longitudinal study. Journal of Experimental Child Psychology, 94(1), 1-17.

Parrila, R., Kirby, J. R., \& McQuarrie, L. (2004). Articulation rate, naming speed, verbal short-term memory, and phonological awareness: longitudinal predictors of early reading development? Scientific Studies of Reading, 8(1), 3-26.

Patel, T. K., Snowling, M. J., \& de Jong, P. F. (2004). A cross-linguistic comparison of children learning to read in English and Dutch. Journal of Educational Psychology, 96(4), 785-797.

Perfetti, C. A. (1985). Reading ability. New York: Oxford City Press.

Perry, C., \& Ziegler, J. C. (2002). Cross-language computational investigation of the length effect in reading aloud. Journal of Experimental Psychology: Human Perception \& Performance, 28, 990-1001.

Powell, D., Stainthorp, R., Stuart, M., Garwood, H., \& Quinlan, P. (2007). An experimental comparison between rival theories of rapid automatized naming performance and its relation to reading. Journal of Experimental Child Psychology, 98, 46-68.

Puolakanaho, A., Ahonen, T., Aro, M., Leppanen, P. H. T., Tolvanen, A., Lyytinen, H., et al. (2007). Very early phonological and language skills: Estimating individual risk of reading disability. Journal of Child Psychology and Psychiatry, 48(9), 923-931.

Rayner, K., Foorman, B. R., Perfetti, C. A., Pesetsky, D., \& Seidenberg, M. S. (2001). How psychological science informs the teaching of reading. Psychological Science in the Public Interest, 2(2), 31-74.

Scarborough, H. S. (1990). Very early language deficits in dyslexic children. Child Development, 61(6), 1728-1743.

Schatschneider, C., Fletcher, J. M., Francis, D. J., Carlson, C. D., \& Foorman, B. R. (2004). Kindergarten Prediction of Reading skills: a longitudinal comparative analysis. Journal of Educational Psychology, 96(2), 265-282. 
Schneider, T. (2001). Analysis of incomplete climate data: Estimation of mean values and covariance matrices and imputation of missing values. Journal of Climate, 14, 853-871.

Schneider, T. (2008). Analysis of incomplete climate data: Matlab, from http://www.math.nyu.edu/tapio/imputation/.

Seymour, P., Aro, M., \& Erskine, J. (2003). Foundation literacy acquisition in European orthographies. British Journal of Psychology, 94(2), 143-174.

Share, D. L. (1995). Phonological recoding and self-teaching: sine qua non of reading acquisition. Cognition, 55, 151-218.

Share, D. L. (1999). Phonological recoding and orthographic learning: A direct test of the self-teaching hypothesis. Journal of Experimental Child Psychology, 72(2), 95-129.

Share, D. L. (2008). On the Anglocentricities of current reading research and practice: The perils of overreliance on an 'outlier' orthography. Psychological Bulletin, 134(4), 584-615.

Share, D. L., Jorm, A. F., Maclean, R., \& Matthews, R. (1984). Sources of individual differences in reading acquisition. Journal of Educational Psychology, 76(6), 1309-1324.

Swanson, H. L., Trainin, G., Necoechea, D. M., \& Hammil, D. D. (2003). Rapid naming, phonological awareness, and reading: a meta-analysis of the correlational evidence. Review of Educational Research, 73(4), 407-440.

Tijms, J. (2004). Verbal memory and phonological processing in dyslexia. Journal of Research in Reading, $27,300-310$.

Torgesen, J. K., Wagner, R. K., Rashotte, C. A., Burgess, S. R., \& Hecht, S. A. (1997). Contributions of phonological awareness and rapid automatic naming ability to the growth of word-reading skills in second- to fifth-grade children. Scientific Studies of Reading, 1(2), 161-185.

Treiman, R., Berch, D., Tincoff, R., \& Weatherson, S. (1993). Phonology and spelling: The case of syllabic consonants. Journal of Experimental Child Psychology, 56(3), 267-290.

Vaessen, A., \& Blomert, L. (in revision). Long term cognitive dynamics of fluent reading development.

Vaessen, A. A., Gerretsen, P., \& Blomert, L. (2009). Naming problems do not reflect a second, independent core deficit in dyslexia: 'Double deficits' explored. Journal of Experimental Child Psychology, 103, 202-221.

van Orden, G. C., \& Kloos, H. (2005). the question of phonology and reading. In M. J. Snowling \& C. Hulme (Eds.), The Science of Reading: A Handbook (pp. 61-78). Oxford: Blackwell publishing.

Wagner, R. K., Torgesen, J. K., \& Rashotte, C. A. (1994). Development of reading-related phonological processing abilities: New evidence of bidirectional causality from a latent variable longitudinal study. Developmental Psychology, 30(1), 73-87.

Wentink, H., \& Verhoeven, L. (2003). Protocol leesproblemen en dyslexie [protocol reading problems and dyslexia]. Nijmegen: Expertisecentrum Nederlands.

Wimmer, H., \& Hummer, P. (1990). How German-speaking first graders read and spell: Doubts on the importance of the logographic stage. Applied Psycholinguistics, 11, 349-368.

Ziegler, J., \& Goswami, U. (2006). Becoming literate in different languages: similar problems, different solutions. . Developmental Sciences, 9 (5), 429-453.

Ziegler, J. C., Bertrand, D., Toth, D., Csepe, V., Reis, A., Faisca, L., et al. (in press). Orthographic Depth and its impact on universal predictors of reading: a cross-language investigation. Psychological Science. 
Ziegler, J. C., \& Goswami, U. (2005). Reading acquisition, developmental dyslexia, and skilled reading across languages: a psycholinguistic grain size theory. Psychological Bulletin, 131(1), 3-29. 


\section{Chapter 5}

\section{Cognitive development of spelling skills}

This chapter is based on:

Vaessen, A., \& Blomert, L. (in revision). Cognitive dynamics of spelling development and its relationship with reading. Scientific studies of Reading 


\begin{abstract}
This study examined the cognitive dynamics of spelling development and its relationship with reading development in a large sample $(n=1284)$ covering all primary school grades. The results showed that phonological awareness (PA) as well as letter-speech sound association skills (LSS) consistently contributed to spelling performance up to grade 6, while RAN did not contribute to spelling performance in any grade. This pattern contrasts with cognitive reading development over the same grade range (Vaessen \& Blomert, 2010). Furthermore, the relationship between fluent reading and spelling declined over years, and was largely mediated by individual differences in PA and LSS. Together, the results indicate that spelling and reading only partly rely on common cognitive mechanisms (i.e. phonological processing), and children rely less on these common and more on unique cognitive mechanisms during reading and spelling when they become more experienced.
\end{abstract}




\subsection{Introduction}

In contrast to spoken language, written language is a relatively 'new' cultural invention ( 5500 years old, Rayner \& Pollatsek, 1989) which became a part of every one's daily life only recently. It is therefore unlikely that the human brain has developed a specialized literacy 'module'. Rather, during the acquisition of literacy skills, existing cognitive mechanisms in the visual and language domain will be recruited and specialized to serve as a network for reading and spelling. Many studies have therefore focused on the basic cognitive processes underlying the acquisition of literacy skills. Most of these studies have concentrated on the cognitive predictors of reading. For instance, successful acquisition of reading skills is predicted by adequate phonological processing skills (PA; e.g. Bradley \& Bryant, 1983; Torgesen, Wagner, \& Rashotte, 1994; Wagner \& Torgesen, 1987) and preschool knowledge of the mapping between letters and sounds (LSS; e.g. Puolakanaho et al., 2007; Scarborough, 1990; Share, Jorm, Maclean, \& Matthews, 1984; Wagner, Torgesen, \& Rashotte, 1994). Furthermore, rapid automatized naming of well-known visual items (RAN) is shown to be strongly and uniquely associated with fluent reading skills (e.g. Bowers, 1993; Manis, Seidenberg, \& Doi, 1999; Sunseth \& Bowers, 2002; Van den Bos, Zijlstra, \& lutje Spelberg, 2002; Wolf, Bally, \& Morris, 1986).

In comparison to the numerous studies on reading, the cognitive development of spelling skills is far less intensively investigated. This general tendency to 'overlook' spelling when examining the cognitive dynamics of literacy might be partly due to the fact that reading and spelling are often considered to be 'two sides of the same coin' (Ehri, 1997, 2000; Perfetti, 1997), suggesting that reading and spelling share many cognitive resources. However, other researchers have claimed that reading and spelling build upon unique as well as common cognitive mechanisms (Berninger, Cartwright, Yates, \& Swanson, 1994; Bradley \& Bryant, 1979; Bryant \& Bradley, 1980; Frith \& Frith, 1980; Nikolopoulos, Goulandris, Hulme, \& Snowling, 2006; Shanahan, 1984), implying that the cognitive predictors of reading might not be so closely related to spelling. It is therefore highly relevant to investigate the cognitive dynamics of spelling in the context of reading to get more insight into literacy development. Furthermore, since several models of literacy development assume that cognitive strategies used at beginning stages of literacy acquisitions differ qualitatively from strategies used at later stages (e.g. Ehri, 1992; Frith, 1980; Marsh, Friedman, Welch, \& Desberg, 1980; Templeton \& Bear, 1992), the relative importance of the cognitive skills underlying reading and spelling might change during development. Recent research has shown that the influence of PA and LSS on fluent word reading declined from grade 1 to grade 6 , while the relation[ between RAN and word reading fluency gradually increased over the years (Vaessen et al., accepted; Vaessen \& Blomert, 2010), implying that the weight of the cognitive contributions to reading shifts as a function of reading experience. The question is 
whether a similar shift in the relative importance of the cognitive predictors would occur during the acquisition of spelling skills.

\section{Cognitive development of spelling skills}

The ability to segment spoken words into their phonological counterparts and the capability to match each phoneme to a corresponding grapheme are crucial for the initial acquisition of spelling skills (e.g. Ehri, 1998). Cognitive skills like phonological awareness and the ability to efficiently associate letters and speech sounds can therefore be expected to show a large impact on initial spelling acquisition. In line with this expectation, several studies found that success in early spelling development could be predicted from (preschool) levels of phonological awareness (Caravolas, Hulme, \& Snowling, 2001; Cataldo \& Ellis, 1988; Juel, Griffith, \& Gough, 1986; Landerl \& Wimmer, 2008; Maki, Voeten, Vauras, \& Poskiparta, 2001; Strattman \& Hodson, 2005) and letter knowledge (Caravolas et al., 2001; Cardoso-Martins \& Pennington, 2004; Leppanen, Niemi, Aunola, \& Nurmi, 2006; Pennington, CardosoMartins, Green, \& Lefly, 2001; Wimmer \& Hummer, 1990).

Skilled spelling, in contrast, is thought to rely on more sophisticated strategies based on spelling rules, morphological knowledge or word-specific knowledge to spell words correctly (Ehri, 1992; Nunes, Bryant, \& Bindman, 1997; Perfetti, 1997; Rittle-Johnson \& Siegler, 1999; Treiman, Cassar, \& Zukowski, 1994). Several models of spelling development suggest a stage-like shift from a developmental phase characterized by the reliance on phonological strategies to a phase characterized by the predominant reliance on the orthographic and morphological regularities of words.(e.g. Ehri, 1992; Frith, 1980; Marsh et al., 1980; Templeton \& Bear, 1992). March and colleagues (1980) assumed that this shift takes place at around the fifth grade in English-language learners, but the results of a Dutch study of Notenboom \& Reitsma (2003) indicate that already after one year of spelling instruction Dutch children mainly rely on orthographic strategies. Stage-like models of spelling development indirectly seem to imply that phonological skills as well as cross-modal matching of letters and sounds are mainly important at initial 'phonological' stages and will have less impact at later 'orthographic' stages of spelling acquisition. This is in accordance with stage-models of reading that also suggest a shift from phonological processing to orthographic processing (for a overview see Ehri, 2005).

In contrast, more interactive views on spelling development claim that stagelike models do not fully capture the complexity of spelling acquisition, and suggest that spellers use a variety of spelling strategies from early stages of spelling acquisition on (e.g. Keuning \& Verhoeven, 2008; Snowling, 1994; Varnhagen, McCallum, \& Burstow, 1997). These interactive views on spelling accept that a gradual shift in the frequency of use of certain strategies might occur, but deny the existence of sharpbounded stages characterized by the use of one strategy and assume that all 
learned spelling strategies can be adaptively used for spelling once they are learned (Keuning \& Verhoeven, 2008).

Relatively few studies have investigated the contribution of PA to spelling performance in a developmental context. A study by Jongejan, Verhoeven and Siegel (2007) found support for a declining relationship between PA and spelling; PA only significantly contributed to spelling performance in grade 1-2 and not in grade 3-4 in English-language learners. However, other studies are more in line with a continuing relationship between PA and spelling. For instance, Maki et al. (2001) and Stage and Wagner (1992) showed that early PA performance predicts subsequent spelling performance at least until grade 3 in respectively Finnish and English language learners. Similarly, Stuart and Masterson (1992) found that PA performance in 4-year olds predicted spelling performance 6 years later, and Caravolas et al (2001) found strong concurrent and longitudinal correlations between PA performance in grade 1 and 2 and spelling performance in grade 1, 2 and 3 in Englishspeaking children. In an Austrian study of Landerl and Wimmer (2008), kindergarten PA was highly predictive of spelling performance even until grade 6 . This is in accordance with the observation that PA contributed to spelling performance even in high-school students (Shankweiler, Lundquist, Dreyer, \& Dickinson, 1996).

The influence of letter-speech sound association skills on spelling performance has rarely been investigated after the initial stages of spelling acquisition, probably because children are assumed to know the correspondences between letters and sounds after a relatively short period of education (Aarnoutse, van Leeuwe, \& Verhoeven, 2000; Hardy, Smythe, Stennet, \& Wilson, 1972; Siegel \& Faux, 1989; Snowling, 2000). However, recent electrophysiological studies have indicated that the automatic integration of letters and speech sounds takes years to develop, even though most children knew which letter belonged to which sound at the end of first grade (Froyen, Van Atteveldt, Bonte, \& Blomert, 2008; Froyen, Bonte, van Atteveldt, \& Blomert, 2009). Moreover, one developmental study that did include measures of letter name and letter sound knowledge (Caravolas et al., 2001) showed strong correlations between these skills and spelling performance at least until grade 3 . In addition, analyses of spelling errors indicate the use of letter-speech sound strategies in third graders (Waters, Waters, Bruck, \& Seidenberg, 1985) and in adults (Perry \& Ziegler, 2004), implying that the efficient associations of speech sounds to letters might affect spelling performance even in more experienced readers.

\section{The role of RAN in spelling acquisition}

In contrast to the clear-cut theoretical link between phonological processing, lettersound association skills and spelling, the theoretical link between RAN and spelling is less straightforward. The fact that RAN performance is closely related to reading tasks which require the recognition of orthographic word forms (e.g. Bowers \& 
Swanson, 1991; Clarke, Hulme, \& Snowling, 2005; Manis, Doi, \& Bhadha, 2000; Wile \& Borowsky, 2004) might imply that RAN taps the ability to store or retrieve wordspecific orthographic patterns (Wolf \& Bowers, 1999). In this case, RAN performance is expected to predict spelling as well as reading performance (Savage, Pillay, \& Melidona, 2008). However, if RAN taps the automaticity with which visual/orthographic information is matched to phonological codes (as is suggested by e.g. Berninger, Abbott, Billingsley, \& Nagy, 2001; Bowers \& Ishaik, 2003; Vaessen, Gerretsen, \& Blomert, 2009), there is little reason to expect that RAN is related to spelling performance. Studies focusing on the role of RAN in spelling acquisition show contrasting results. While some studies have found a (modest) influence of RAN on spelling performance (Plaza \& Cohen, 2004; Savage et al., 2008; Strattman \& Hodson, 2005), others have failed to find significant relationship between RAN performance and spelling skills in normal readers (Landerl \& Wimmer, 2008; Nikolopoulos et al., 2006) or dyslexic readers (Cornwall, 1992; Vaessen et al., 2009).

On factor that might prevent a clear-cut interpretation of the role of RAN in spelling is the fact that RAN is a speeded measure, while spelling performance is usually based on accuracy measures. This measurement-incompatibility might lead to an underestimation of the role of RAN in spelling acquisition. To illustrate, the contribution of RAN to reading is also strongest when tested with speeded measures (Bowers, 1995; Cirino, Israelian, Morris, \& Morris, 2005; Katzir et al., 2006; Savage \& Frederickson, 2005; Schatschneider, Fletcher, Francis, Carlson, \& Foorman, 2004; Vaessen et al., 2009). To investigate whether a weak contribution of RAN to spelling performance is a consequence of incompatible measurement parameters, we included measures of spelling accuracy as well as spelling speed in the current study. Since traditional spelling-to-dictation tasks involve a strong motor component, measuring speed of spelling on these traditional tasks might capture individual differences in handwriting speed, and not individual differences in spelling ability. We therefore used a speeded spelling paradigm that minimizes the influence of motor skill. (Kreiner, 1992) showed that measures of spelling speed are reliable and sensitive to individual differences in spelling performance.

\section{The cognitive basis of the relationship between spelling and reading}

As noted before, it has been assumed that spelling shares many cognitive resources with reading (Ehri, 1997, 2000; Perfetti, 1997). The fact that, at least in the beginning phases of literacy acquisition, PA and LSS knowledge (and possibly RAN) strongly contribute to the initial acquisition of reading as well as spelling skills (e.g. Landerl \& Wimmer, 2008; Strattman \& Hodson, 2005) seems to support this view. However, results of studies with older children have indicated that the cognitive skills underlying spelling are (partly) different from those found for reading. For instance, Landerl and Wimmer (2008) found kindergarten PA to be the most impor- 
tant predictor of spelling skills, while kindergarten RAN was the only significant predictor of reading skills in grade 4 and 6. Nikolopoulos et al (2006), working with Greek 7-10 years olds, found PA to be the only significant longitudinal predictor of spelling, while speech rate was the single significant longitudinal predictor of reading. Jongejan, Verhoeven and Siegel (2007), in contrast, found that PA was the best predictor of reading in grade 3-4, while spelling was predicted by performance on verbal working memory tasks. Similarly, Berninger et al (Berninger et al., 1994) showed that all measures of phonological coding used in their study (phonological memory, phoneme manipulation, phoneme articulation) contributed to reading performance, while only phonological memory contributed to spelling in grade 4-6. Orthographic coding measures contributed strongly to reading as well as spelling. These results, although rather mixed, all seem to indicate that the cognitive dynamics of reading differs from the cognitive dynamics of spelling, at least in more experienced readers/spellers.

A somewhat different approach to investigate the common cognitive basis of reading and spelling is offered by Stage \& Wagner (Stage \& Wagner, 1992). They investigated how much of the shared variance between reading accuracy and spelling could be accounted for by individual differences in PA and working memory at different levels of reading experience. The results showed that the relationship between reading and spelling in grade 1 was mainly phonologically mediated, while in grade 2 and 3 individual differences in phonological processing could only account for a small part of the shared variance between reading and spelling. These results indicate that the nature of the relationship between reading and spelling changes developmentally, and point to the importance to investigate spelling and its relationship with reading in a developmental context.

\section{Present study}

The present study aimed at investigating the cognitive development of spelling skills and its relationship to fluent reading development in a large unselected sample including children from grade 1 to 6 of primary school. First, we examined the developmental course of the relationship between three basic cognitive skills (PA, LSS and RAN) and spelling, and second, we used commonality analyses to explore how much variance in spelling performance is shared with word and pseudoword reading fluency at different levels of expertise, and in how far this shared variance could be accounted for by individual differences in cognitive skills. Commonality analysis is a method to partition the proportion of variance that is shared between two variables (i.e. reading-spelling) into a part that can be attributed to a common contribution with other variables (i.e. PA and LSS) and a part that is not mediated by the other variables in the equation (Kerlinger \& Pedhazur, 1973; Seibold \& McPhee, 
1979). We used accuracy and speed measures for all cognitive skills, including PA, LSS and spelling, to avoid possible speed-accuracy confounds.

As far as we are aware, this is one of the first studies investigating the cognitive dynamics of spelling development and its relationship with reading fluency in a sample covering all primary school grades, while using speeded measures for all variables.

\subsection{Methods}

\section{Participants}

1284 participants were recruited from 17 Dutch primary schools in 5 regions in the Netherlands (155 first graders, 237 second graders, 242 third graders, 248 fourth graders, 223 fifth graders and 179 sixth graders). The sample was unselected in the sense that all children within one classroom were tested regardless of their reading and spelling level (99\% of parents gave permission). Children from grade 1 were tested at the end of the year (May-June), while children from grade 2, 3 and 4 were tested in the middle of the year (January to March). Children from grade 5 en 6 were tested in March and May.

\section{Procedure}

Tasks were individually administered by a specially trained project coworker outside the classroom. All tasks (except the spelling-to-dictation task) were part of a computerized test battery (Dyslexia Differential Diagnosis, 3DM; Blomert \& Vaessen, 2009)), and administered with a specialized response-box to precisely measure response times in milliseconds The test battery was administered in either one or two sessions. The first and the second test session fell always within one week.

\section{Tasks}

Reading task - A list of respectively high-frequency words and pseudowords was presented on the screen (15 at one sheet). The child was instructed to read as many (pseudo)words correct as possible within the time limit ( $1 / 2$ minute for words and $1 / 2$ minute for pseudowords). The words of each level increased in number of syllables and syllabic complexity. Test-retest reliability coefficients were respectively .91 and .92 (reported in the test manual of 3DM).

Spelling-to-dictation - The spelling to dictation task (PI-dictee; Geelhoed \& Reitsma, 1999) contained 135 words which were either regularly spelled words, words containing spelling rules or exception words. Words were presented in blocks of 15 items, and the task was discontinued after 8 or more incorrect items within 
one block. The raw score was the percentage of correctly spelled words. The internal consistency of this standardized test is between .90 and .93 (reported in the test manual).

Computerized Spelling - A word was presented aurally (over the headphone) as well as visually (at the computer screen) presented. In the visually presented word, a letter (combination) was missing and the child was instructed to choose the missing part out of four visually presented options by pressing the corresponding button (e.g. auditory stimulus /boom/ (tree), visual stimulus 'b_m', options 'oo' 'o' ' $a$ ' 'aa'). Words were either phonetically spelled (18 items) or contained Dutch spelling rules (36 words). Word frequencies were systematically varied. Accuracy (\% correct) as well as response time (sec/item) was measured. Internal consistency was .80 for accuracy and .94 for speed (reported in the test manual of 3DM).

Phonological awareness (PA) - The phoneme deletion task contained 23 aurally presented pseudowords (CVC or CCVCC structure), from which either the first consonant, the last consonant or a consonant within a consonant cluster had to be deleted. The administrator pressed a button as soon as the participant gave an answer to indicate response time. Response time was time between stimulus offset and the button press. The task has an internal consistency of .85 for accuracy and .92 for speed (reported in the test manual of 3DM).

Rapid naming (RAN) - Sheets with 15 items (5 letters or digits repeated 3 times) were presented on the screen and the participant was instructed to name these items as fast and accurate as possible. Each set of 15 items was presented two times, with a different order of items. Response time was mean reaction time of the two presentations. The three subtasks have a split-half reliability of $.80, .83$ and .73 (reported in the test manual of 3DM).

Letter-sound association tasks (LSS) - Two tasks were used; a LSS identification task and a LSS discrimination task. In the LSS identification task, a child was instructed to match a auditory presented speech sound to one of four presented letter (combinations) by pressing the corresponding button (e.g. /b/ and ' $b$ ' ' $d$ ' ' $t$ ' ' $p$ '). Internal consistency of this task was .72 for accuracy and .90 for speed (reported in the test manual of 3DM). In the LSS discrimination task, a child had to judge whether a presented speech sound and letter are congruent or incongruent (e.g. /ui/ and 'oe'). Accuracy (\% correct) as well as response time (sec/item) was measured. Internal consistency of this task was .82 for accuracy and .96 for speed (reported in the test manual of 3DM).

Baseline response time (baseline RT) - To measure baseline response time, we used a simple non-verbal task, similar in design as the other tasks. The child had to respond as fast as possible when an animation figure appeared in one of four empty squares presented at the screen. Mean reaction time was calculated over 20 items. The task has an internal consistency of .93 (reported in the test manual of 3DM). 


\section{Data preparation}

For all analyses standardized T-scores instead of raw scores were used. This has two advantages: first, T-scores are normalized, thus reducing effects of outliers or nonnormally distributed data. Second, the standardization method is based on test period (number of months of formal reading instruction), so all analyses are automatically controlled for effects of test period.

Response times on the LSS tasks and the computerized spelling task were strongly correlated with response time on the baseline RT task ( $r$.35-.45), indicating a substantial influence of motor speed on these response time measures (see table 5.2). To control for effects of individual differences in motor response time, we first regressed the RT of the baseline response time task on the RT of the letter-sound processing tasks and the computerized spelling task. Subsequently, we computed the residuals, which were used as corrected scores. Since we did not find substantial correlations $(r<.20)$ between performance on the baseline response task and performance on RAN or phoneme deletion speed, we did not correct these measures for baseline RT.

\subsection{Results}

\section{Descriptives}

Descriptive statistics for each grade-category are shown in table 5.1. Accuracy scores are expressed in \% correct and speed scores in sec/items for all tasks.

Correlations between spelling speed and accuracy and reading fluency were modest to high (.36-.54). Phoneme deletion performance was strongly related to spelling performance (.37-.56). PA speed was relatively more strongly related to spelling speed and PA accuracy to spelling accuracy, but PA accuracy also showed substantial correlations with spelling speed and vise versa.

Accuracy scores on the LSS tasks showed moderate to high correlations with accuracy scores on the spelling task (.35-.48), while speed on LSS tasks (corrected and uncorrected) was most strongly related to spelling speed (.30-.65).

Correlations between PA accuracy and LSS accuracy were moderate (.33-.39) as were correlations between PA speed and LSS speed (.23-.42) and correlations between RAN and PA speed (.28). 
Table 5.1 - Descriptive statistics of all included measures and age

\begin{tabular}{lcccccc}
\hline & \multicolumn{2}{c}{ Grade 1-2 } & \multicolumn{2}{c}{ grade 3-4 } & \multicolumn{2}{c}{ grade 5-6 } \\
& Mean & SD & mean & SD & Mean & SD \\
\hline Age (in months) & 91.4 & 6.1 & 112.8 & 7.4 & 139.0 & 8.1 \\
Reading fluency (words/ 1 /2 min) & & & & & \\
Words & 33.3 & 10.0 & 47.7 & 8.2 & 44.7 & 11.7 \\
Pseudowords & 17.8 & 6.5 & 26.1 & 6.8 & 25.2 & 8.6 \\
& & & & & & \\
Accuracy (\% cor) & & & & & & \\
Spelling to dictation & 28.0 & 9.2 & 57.0 & 10.9 & 89.1 & 7.8 \\
Comp. Spelling & 60.3 & 14.1 & 81.8 & 11.9 & 86.8 & 8.5 \\
Phoneme Deletion & 59.7 & 19.5 & 75.7 & 18.5 & 82.6 & 13.8 \\
LSS identification & 93.0 & 6.3 & 95.2 & 4.6 & 94.9 & 4.4 \\
LSS discrimination & 85.8 & 10.1 & 90.4 & 6.7 & 91.2 & 5.6 \\
& & & & & & \\
Speed (sec/item) & & & & & & \\
Comp. Spelling & 4.5 & 0.9 & 3.3 & 0.7 & 2.3 & 0.4 \\
RAN letters & 0.7 & 0.2 & 0.6 & 0.1 & 0.5 & 0.1 \\
RAN digits & 0.6 & 0.1 & 0.5 & 0.1 & 0.4 & 0.1 \\
Phoneme Deletion & 5.7 & 2.3 & 3.5 & 1.7 & 2.1 & 1.0 \\
LSS identification & 2.6 & 0.5 & 2.0 & 0.4 & 1.7 & 0.3 \\
LSS discrimination & 2.0 & 0.5 & 1.5 & 0.4 & 1.2 & 0.3 \\
Baseline RT & 1.0 & 0.2 & 0.9 & 0.2 & 0.7 & 0.1 \\
\hline
\end{tabular}

Note: comp=computerized, LSS=letter-speech sound

Table 5.2 displays the correlations between standardized scores on all measures for each grade-category. Correlations above .10 were significant, but to increase interpretability of the correlation pattern, only modest to high correlations (above .30; Cohen, 1988, 1992) are printed in bold. 


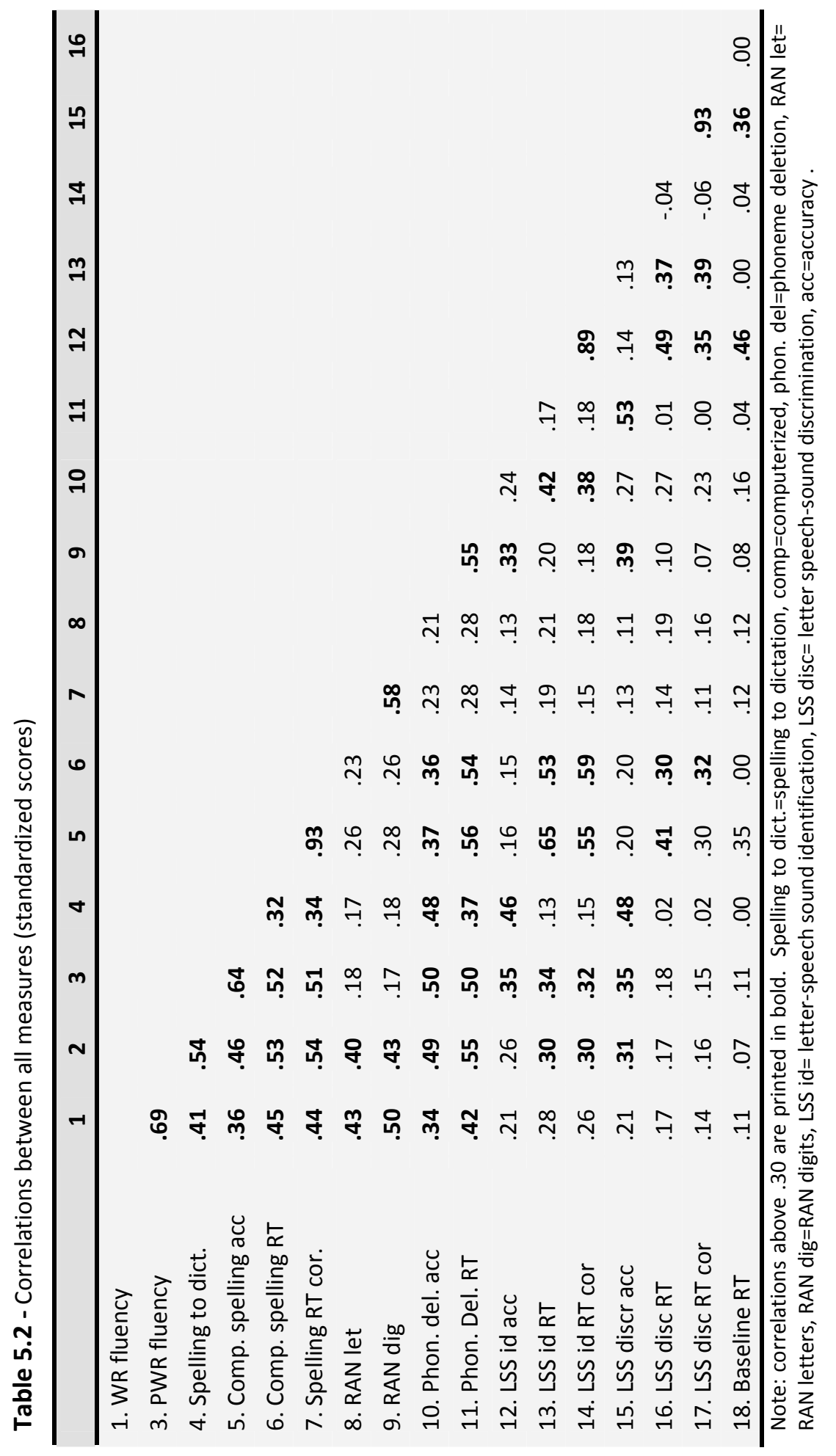




\section{Cognitive Contributions to spelling performance}

We first conducted an exploratory factor analysis (principal component with oblimin rotation) on the cognitive predictor variables (RAN letters and digits, phoneme deletion accuracy and speed, LSS discrimination accuracy and speed, LSS identification accuracy and speed) to create latent variables. In the first analyses, three factors were extracted with an Eigen value above 1 . However, communalities were rather low (5 values below .70), suggesting that a three-factor solution is not optimal. In a new analysis with 4 extracted factors, all communalities were above .70 . Eigen values of the four components were 2.78, 1.48, 1.17 and 0.80, which are all acceptable according to Jolliffe's criterion (Jolliffe, 1972). In table 5.3, factor loadings, communalities and the component correlation matrix are presented. Speed on LSS discrimination and identification loaded on factor 1 (which we will further refer to as 'LSS speed'), accuracy scores on LSS discrimination and identification loaded on factor 2 ('LSS accuracy'), RAN letters and digits loaded on factor 3 ('RAN') and phoneme deletion accuracy and speed loaded on factor 4 ('PA').

Table 5.3 - Results of exploratory factor analysis

\begin{tabular}{lccccc}
\hline \multicolumn{5}{c}{} & \multicolumn{5}{c}{ Components } & \\
\cline { 2 - 5 } & LSS & LSS & PA & communalities \\
\hline RAN letters & -0.04 & -0.01 & -0.89 & -0.02 & 0.79 \\
RAN digits & 0.03 & 0.00 & -0.88 & 0.02 & 0.79 \\
Phon del acc & -0.13 & -0.09 & 0.00 & -0.89 & 0.82 \\
Phon del RT & 0.21 & 0.07 & -0.05 & -0.82 & 0.79 \\
LSS id acc & 0.08 & -0.91 & -0.03 & 0.09 & 0.80 \\
LSS id RT & 0.82 & -0.13 & 0.01 & -0.08 & 0.75 \\
LSS discr acc & -0.06 & -0.81 & 0.02 & -0.13 & 0.74 \\
LSS discr RT & 0.87 & 0.08 & -0.02 & 0.04 & 0.76 \\
\hline Component correlation matrix & & & & \\
\hline LSS speed & $X$ & & & & \\
LSS acc & -0.04 & $X$ & & & \\
RAN & -0.23 & 0.15 & $X$ & & \\
PA & -0.25 & 0.38 & 0.29 & $X$ & \\
\hline
\end{tabular}

Note: Phon. Del.=phoneme deletion, LSS id=letter-speech sound identification, LSS disc=letter speech sound discrimination, acc=accuracy 
To examine the contributions of these cognitive factors to spelling performance in a developmental context, we conducted a set of hierarchical regression analyses for each spelling variable and additionally calculated the interactions between these cognitive contributions and grade. We included the cognitive factors (PA, RAN, LSS accuracy, LSS speed) in the first step and the interaction terms between the cognitive factors and grade in the second step. All variables were centered to avoid collinearity problems. The results are presented in table 5.4.

Table 5.4 - Contributions of cognitive predictors to spelling performance, with grade interactions (standardized $\beta$-values)

\begin{tabular}{lccc}
\hline & $\begin{array}{c}\text { spelling } \\
\text { to dict. }\end{array}$ & $\begin{array}{c}\text { Comp. spelling } \\
\text { acc }\end{array}$ & $\begin{array}{c}\text { Comp. } \\
\text { spelling RT }\end{array}$ \\
\hline PA & .44 & .33 & .37 \\
RAN & .00 & .04 & .08 \\
LSS acc & .23 & .40 & .03 \\
LSS speed & .15 & -.02 & .43 \\
& & & \\
PA x grade & -.01 & -.04 & .01 \\
RAN x grade & .03 & .03 & .01 \\
LSSacc x grade & -.06 & .01 & -.01 \\
LSSspeed x grade & -.04 & -.07 & -.02 \\
& & & .378 \\
\hline
\end{tabular}

Note: Comp=computerized, LSS=Letter-speech sound, PA=phonological awareness. Significant values printed in bold

The results show that the factors PA and LSS accuracy are the strongest predictors for accurate performance on the two spelling tasks. LSS speed additionally predicted a small amount of the variance in performance on the spelling to dictation task. RAN did not influence accurate spelling performance at all. Speed on the computerized spelling task was best predicted by the cognitive factors PA and LSS speed. In addition, RAN explained a small amount of the variance in spelling speed.

The cognitive predictors of spelling performance were not influenced by grade, indicating that the cognitive skills involved in early spelling skills remain important for skilled spelling. There were only two exceptions: the influence of LSS accuracy on performance on the spelling to dictation task declined as a function of grade, indicating that LSS accuracy was somewhat less important for spelling to dictation in higher grades. The influence of LSS speed on accurate performance on the comput- 
erized spelling task also significantly declined as a function of grade, but since the main effect of LSS speed was not significant, this interaction-effect is hard to interpret.

\section{The relationship between spelling and reading fluency}

To investigate the nature of the relationship between reading fluency and spelling, we conducted a set of commonality analyses (CA; Kerlinger \& Pedhazur, 1973; Seibold \& McPhee, 1979) to investigate which part of the variance in spelling speed and accuracy is shared with reading fluency, and in how far the relationship between these two skills can be accounted for by individual differences in cognitive skills. Because the interpretation of commonality analysis tables is complex when many predictor variables are entered (since all possible combinations of predictor variables have to be tested), we only included the predictor variables that were important for spelling (PA and LSS).

For each spelling variable and each grade-level, a commonality analysis was conducted with performance on the spelling task as dependent variable and LSS, PA and reading (word and pseudoword) as predictor variables. For spelling accuracy, LSS accuracy is used as predictor variable, while LSS speed is used as predictor variable for the analyses with spelling speed. In table 5.5 and 5.6, the results of the commonality analysis are presented.

The results show that spelling performance shared a relatively small part of its variance with word or pseudoword reading fluency (maximal 33\%). Furthermore, the results showed that a large proportion of the shared variance between reading fluency and spelling can be explained by individual differences in PA or LSS at all grade levels. For instance, in grade $1-2$, word reading explained $29 \%$ of the variance on the computerized spelling task, of which $6 \%$ was unique, $8 \%$ was shared with PA, $4 \%$ was shared with LSS, and $11 \%$ was shared with PA ánd LSS. Thus, $20 \%$ of the shared variance between reading and spelling is unique $(6 / 29 * 100)$, while $80 \%$ is mediated by performance on PA and/or LSS.

In higher grades, the proportion of the spelling variances that is shared with word reading fluency drops to $1-12 \%$ (dependent on the spelling task). The part of the variance that is explained by pseudoword reading fluency remains around $30 \%$ for spelling to dictation and spelling speed, and drops to $15 \%$ for the computerized spelling task. Similar to what was found in grade 1-2, the common variance between the three spelling measures and (pseudoword) reading was largely explained by individual differences in PA and LSS. Figure 5.1 visualizes the proportion of variance on the spelling measures that is shared with high frequency word and pseudoword reading fluency, and illustrates how much of this shared variance can be accounted for by individual differences in PA, LSS or both. 
Table 5.5 - Common and unique contributions of LSS processing, PA and word reading fluency to spelling performance

\begin{tabular}{|c|c|c|c|c|c|c|c|c|c|}
\hline \multirow[b]{3}{*}{ grade 1-2 } & \multicolumn{9}{|c|}{ Comp spelling } \\
\hline & \multicolumn{3}{|c|}{ Spelling to dict. } & \multicolumn{3}{|c|}{ acc } & \multicolumn{3}{|c|}{ Comp spelling RT } \\
\hline & LSS* & PA & WR & LSS* & PA & WR & LSS** & PA & WR \\
\hline unique LSS & .04 & & & .09 & & & .13 & & \\
\hline unique $\mathrm{PA}$ & & .04 & & & .03 & & & .02 & \\
\hline unique WR & & & .09 & & & .06 & & & .08 \\
\hline Common LSS \& PA & .03 & .03 & & .03 & .03 & & .01 & .01 & \\
\hline Common LSS \& WR & .03 & & .03 & .04 & & .04 & .06 & & .06 \\
\hline Common PA \& WR & & .10 & .10 & & .08 & .08 & & .08 & .08 \\
\hline Common & & & & & & & & & \\
\hline LSS,PA\&WR & .10 & .10 & .10 & .11 & .11 & .11 & .09 & .09 & .09 \\
\hline Total & .20 & .27 & .33 & .27 & .25 & .29 & .29 & .21 & .31 \\
\hline grade $3-4$ & LSS* & PA & WR & LSS* & PA & WR & LSS** & PA & WR \\
\hline unique LSS & .02 & & & .12 & & & .21 & & \\
\hline unique $\mathrm{PA}$ & & .15 & & & .07 & & & .09 & \\
\hline unique WR & & & .03 & & & .03 & & & .03 \\
\hline Common LSS \& PA & .05 & .05 & & .07 & .07 & & .02 & .02 & \\
\hline Common LSS \& WR & .01 & & .01 & .02 & & .02 & .02 & & .02 \\
\hline Common PA \& WR & & .10 & .10 & & .06 & .06 & & .09 & .09 \\
\hline Common & & & & & & & & & \\
\hline LSS,PA\&WR & .07 & .07 & .07 & .08 & .08 & .08 & .04 & .04 & .04 \\
\hline Total & .15 & .37 & .20 & .29 & .28 & .18 & .30 & .24 & .18 \\
\hline grade 5-6 & LSS* & PA & WR & LSS* & PA & WR & LSS** & PA & WR \\
\hline unique LSS & .05 & & & .16 & & & .11 & & \\
\hline unique $\mathrm{PA}$ & & .19 & & & .05 & & & .14 & \\
\hline unique WR & & & .01 & & & .00 & & & .02 \\
\hline Common LSS \& PA & .12 & .12 & & .11 & .11 & & .08 & .08 & \\
\hline Common LSS \& WR & .00 & & .00 & .00 & & .00 & .02 & & .02 \\
\hline Common PA \& WR & & .05 & .05 & & .01 & .01 & & .03 & .03 \\
\hline Common & & & & & & & & & \\
\hline LSS,PA\&WR & .01 & .01 & .01 & .01 & .01 & .01 & .04 & .04 & .04 \\
\hline Total & .19 & .37 & .07 & .27 & .17 & .01 & .25 & .30 & .12 \\
\hline
\end{tabular}

Note: Comp=computerized, LSS*=letter-speech sound accuracy, LSS**=letter-speech sound speed, $\mathrm{PA}=$ phonological awareness, WR=word reading fluency 
Table 5.6 - Common and unique contributions of LSS, PA and pseudoword reading fluency to spelling performance

\begin{tabular}{|c|c|c|c|c|c|c|c|c|c|}
\hline \multirow[b]{3}{*}{ grade 1-2 } & \multicolumn{9}{|c|}{ Comp spelling } \\
\hline & \multicolumn{3}{|c|}{ spelling to dict. } & \multicolumn{3}{|c|}{ acc } & \multicolumn{3}{|c|}{ Comp spelling RT } \\
\hline & LSS* & PA & PWR & LSS* & PA & PWR & LSS** & PA & PWR \\
\hline unique LSS & .04 & & & .09 & & & .14 & & \\
\hline unique PA & & .04 & & & .04 & & & .01 & \\
\hline unique PWR & & & .07 & & & .04 & & & .09 \\
\hline common LSS \& PA & .03 & .03 & & .04 & .04 & & .01 & .01 & \\
\hline common LSS \& PWR & .03 & & .03 & .03 & & .03 & .05 & & .05 \\
\hline common PA \& PWR & & .10 & .10 & & .07 & .07 & & .09 & .09 \\
\hline Common & & & & & & & & & \\
\hline LSS,PA\&WR & .10 & .10 & .10 & .11 & .11 & .11 & .09 & .09 & .09 \\
\hline Total & .20 & .27 & .30 & .27 & .25 & .25 & .29 & .21 & .32 \\
\hline grade $3-4$ & LSS* & PA & PWR & LSS* & PA & PWR & LSS** & PA & PWR \\
\hline unique LSS & .02 & & & .12 & & & .19 & & \\
\hline unique PA & & .09 & & & .04 & & & .05 & \\
\hline unique PWR & & & .05 & & & .03 & & & .05 \\
\hline common LSS \& PA & .04 & .04 & & .05 & .05 & & .00 & .00 & \\
\hline common LSS \& PWR & .01 & & .01 & .01 & & .01 & .04 & & .04 \\
\hline $\begin{array}{l}\text { common PA \& PWR } \\
\text { Common }\end{array}$ & & .16 & .16 & & .08 & .08 & & .13 & .13 \\
\hline LSS,PA\&WR & .09 & .09 & .09 & .10 & .10 & .10 & .06 & .06 & .06 \\
\hline Total & .15 & .37 & .30 & .29 & .28 & .23 & .30 & .24 & .28 \\
\hline grade 5-6 & LSS* & PA & PWR & LSS* & PA & PWR & LSS** & PA & PWR \\
\hline unique LSS & .04 & & & .15 & & & .11 & & \\
\hline unique PA & & .08 & & & .01 & & & .05 & \\
\hline unique PWR & & & .06 & & & .02 & & & .05 \\
\hline common LSS \& PA & .04 & .04 & & .04 & .04 & & .03 & .03 & \\
\hline common LSS \& PWR & .01 & & .01 & .01 & & .01 & .02 & & .02 \\
\hline common PA \& PWR & & .16 & .16 & & .04 & .04 & & .12 & .12 \\
\hline Common & & & & & & & & & \\
\hline LSS,PA\&WR & .10 & .10 & .10 & .08 & .08 & .08 & .09 & .09 & .09 \\
\hline Total & .19 & .37 & .32 & .27 & .17 & .15 & .25 & .30 & .28 \\
\hline
\end{tabular}

Note: Comp=computerized, LSS*=letter-speech sound accuracy, LSS**=letter-speech sound speed, $\mathrm{PA}=$ phonological awareness, $\mathrm{PWR}=$ pseudoword reading fluency 
variance shared between RWR and spelling to dictation

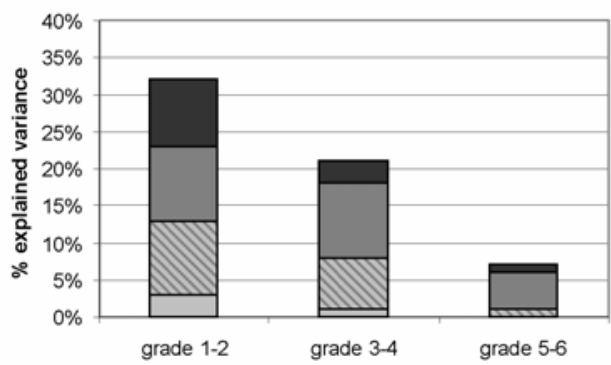

variance shared between RWR and comp spelling acc

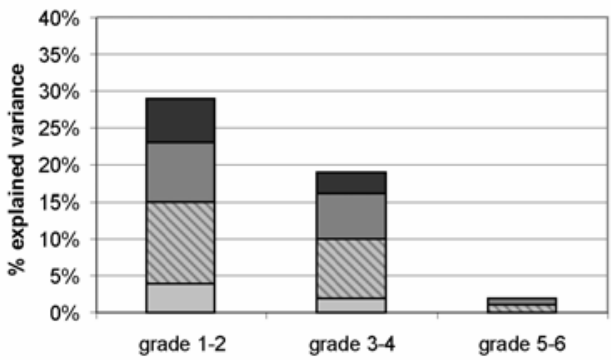

variance shared between RWR and spelling speed

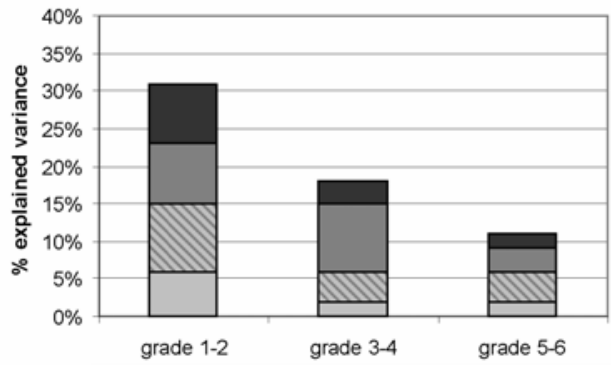

variance shared between PWR and spelling to dictation

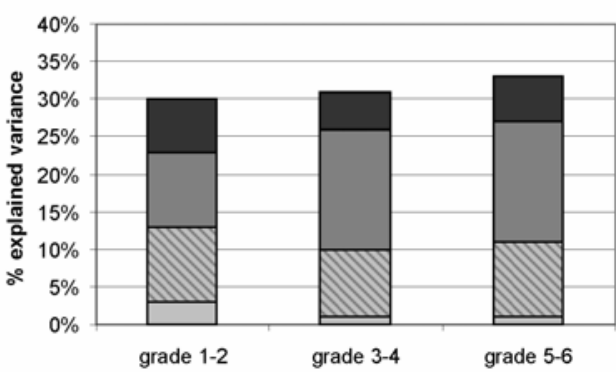

variance shared between PWR and comp spelling acc

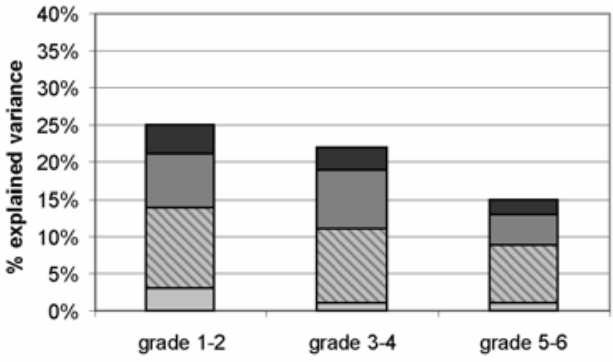

variance shared between PWR and spelling speed

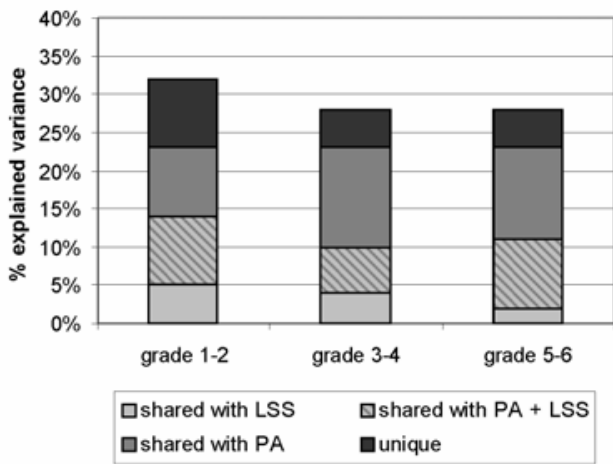

Figure 5.1 - Proportion of shared variance between reading and spelling which is accounted for by individual differences in PA, LSS or both. 


\subsection{Discussion}

The present study set out to investigate the cognitive development of spelling and its relationship with reading development, first by investigating the developmental course of the relationship between three basic cognitive skills (phonological awareness (PA) and letter-speech sound associations (LSS) and RAN) and different measures of spelling, and second by examining how much variance in spelling performance was shared with word and pseudoword reading fluency, and in how far this shared variance was mediated by individual differences in basic cognitive skills.

The results showed that PA and LSS accuracy strongly contributed to accurate performance on the spelling-to-dictation task and the computerized spelling task. Spelling speed was predicted by PA performance and LSS speed. The contribution of RAN to spelling accuracy was not significant and the contribution of RAN to spelling speed very small. Furthermore, contributions of PA and LSS to spelling performance maintained their strength over years, in contrast to what was previously found for word reading fluency (Vaessen et al., accepted; Vaessen \& Blomert, 2010). The only exception was the contribution of LSS to spelling-to-dictation, which influence gradually decreased over years.

The results of the commonality analysis showed that the strength of the relationship between word reading fluency and spelling declined as a function of literacy expertise, while the relationship between pseudoword reading fluency and spelling remained stable. In addition, the common variance between spelling and word as well as pseudoword reading fluency was for a large part (70-85\%) mediated by individual differences in phonological and/or letter-speech sound association skills in beginning as well as experienced spellers.

\section{Implications for models of spelling development}

As introduced before, stage-like models on spelling generally assume a shift from a phonological stage, in which children mainly rely on phonological recoding strategies, to an orthographic stage, in which children mainly rely on morphological or word-specific orthographic knowledge (e.g. Ehri, 1992; Frith, 1980; Marsh et al., 1980; Templeton \& Bear, 1992). If spelling development does involve a switch between qualitatively different stages, it seems reasonable to assume that cognitive skills that are important for phonological recoding (i.e. PA and LSS) will be more closely related to spelling skills in beginning spellers than in more experienced spellers (similar to what was found for reading fluency; Vaessen \& Blomert, 2010). However, the current results showed consistently strong contributions not only of PA but also of LSS to spelling performance up to grade 6 . What are the implications of these results for stage-like models of spelling? 
First of all, it is important to notice that the strong relationship between PA and LSS and spelling performance in skilled spellers does not necessarily imply that skilled spellers do not use orthographic word-specific knowledge or morphological knowledge when spelling a word. On the contrary, even relatively transparent orthographies like Dutch with relatively consistent letter-to-phoneme mappings are rather inconsistent in their phoneme-to-letter relations (Bosman \& Van Orden, 1997). Consequently, many words cannot be spelled correctly purely based on phonological recoding. Application of spelling rules and morphological or orthographic knowledge thus seem an essential part of skilled spelling. However, the stable influence of PA and LSS on spelling performance does indicate that phonological recoding skills remain important for spelling at all levels of expertise. This might be more in line with models claiming that spellers adaptively use a range of spelling strategies (including phonological recoding) throughout development (Keuning \& Verhoeven, 2008; Snowling, 1994; Varnhagen et al., 1997) than with models claiming a stagelike development of spelling.

It might be argued that the strong phonology-spelling relationship reported in this study is not a manifestation of a causal influence of phonological skills on spelling development, but might be due to the fact that orthographic spelling knowledge guides performance on phonological awareness tasks (Landerl, Frith, \& Wimmer, 1996). Since the present study employed a cross-sectional design, interpretations of the causality of the relationship are speculative. However, a longitudinal study of Landerl and Wimmer (2008) has shown that pre-literacy PA levels predicted subsequent spelling performance even until grade 6 , suggesting that the close relationship between PA and spelling reported in the current study at least partly reflects a genuine influence of phonological processing skills on the development of adequate spelling skills.

In contrast to PA and LSS, RAN was not related to spelling performance. The fact that the contribution of RAN to spelling speed was also negligible illustrates that the weak relationship between RAN and spelling is not simply a consequence of a measurement-incompatibility between RAN and spelling. The weak RANspelling relationship is hard to integrate with claims that RAN reflects the ability to establish or use orthographic representations (Savage et al., 2008; Wolf \& Bowers, 1999). Rather, it seems to imply that RAN taps cognitive processes which are uniquely involved in fluent word reading, such as the automaticity to recognize visual/orthographic information and match it onto its phonological counterparts (Berninger et al., 2001; Bowers \& Ishaik, 2003; Vaessen et al., 2009). Recently Lervåg and Hulme (in press) have suggested that RAN taps the integrity of neural circuits for object recognition and naming that are progressively recruited for visual word recognition during the acquisition of reading skills, which would explain the unique, growing relationship between RAN and reading fluency (Vaessen \& Blomert, 2010), and the weak relationship between RAN and spelling. 


\section{Arguments for the relative independence of reading fluency and spelling}

The present data indicate that spelling and reading development build upon common as well as on unique cognitive mechanisms (for similar suggestions see e.g. Berninger et al., 1994; Nikolopoulos et al., 2006; Shanahan, 1984), and that the contributions of these common and unique cognitive mechanisms to word reading and spelling change with increasing literacy experience and/or expertise.

More concretely, in initial stages of literacy acquisition, both spelling and fluent reading seem to rely heavily on the ability to segment words into its phonological counterparts and to efficiently match letters to their speech sounds. This is in line with results of previous studies that reported a strong contribution of PA and/or letter knowledge to both reading and spelling in the initial phases of literacy acquisition (e.g.Juel et al., 1986; Landerl \& Wimmer, 2008; Strattman \& Hodson, 2005; Wimmer \& Hummer, 1990), and suggests that phonological processing and letterspeech sound association skills serve as a common cognitive mechanism for reading and spelling. This is further corroborated by the fact that most of the shared variance between reading fluency and spelling was found to be mediated by individual differences in PA and/or LSS skills.

Whereas phonological processing skills and the ability to efficiently match letters onto speech sounds maintain their importance for adequate spelling performance, these skills gradually loose their impact on fluent word reading. Instead, fluent word reading is thought to increasingly rely on efficient recognition of visual word forms and the matching of visual/orthographic information to its phonological and semantic counterparts (probably reflected in an increased involvement of RAN in fluent word reading, Vaessen et al., accepted; Vaessen \& Blomert, 2010). Thus, fluent word reading and spelling increasingly depend on unique cognitive mechanisms in experienced spellers. Consequently, the relationship between word reading fluency and spelling diminishes over years. In contrast, phonological decoding skills remain important for pseudoword reading, which is probably the reason for the stable relationship between pseudoword reading fluency and spelling over years.

It should be noted that spelling as well as reading probably build upon a wide variety of basic and higher-order cognitive skills, and that the cognitive variables included in this study only cover part of these skills (the proportion of variance in spelling performance explained by LSS, PA and RAN never exceeded 43\%). However, the fact that the shared variance between spelling and fluent reading could for a large part be accounted for by individual differences in PA and LSS at all grade-levels indicates that the major common cognitive mechanism underlying reading and spelling is phonological processing, and not for instance orthographic processing. Thus, even though it is likely that word-specific orthographic representations are used for skilled reading as well as for skilled spelling (e.g. Conrad \& Conrad, 2008; 
Holmes \& Carruthers, 1998), the cognitive mechanisms underlying the recognition of these orthographic presentations might be different from the cognitive mechanisms involved in the reproduction of these orthographic representations (see also Frith \& Frith, 1980).

The declining spelling-word reading relationship reported in the present study contradicts what is reported in several previous studies. Most studies found a rather strong relationship between reading and spelling, even in experienced readers (Berninger et al., 1994; Ehri, 1997; Greenberg, Ehri, \& Perin, 1997; Zutell, 1992; Zutell \& Rasinski, 1989). We can only speculate about the reasons for this dissociation. A first possible explanation is that we used a measure of reading fluency, while some other studies used measures of reading accuracy. Since phonological processing seems to influence reading accuracy more strongly than reading fluency (e.g. Bowers, 1993; Savage \& Frederickson, 2005), relations between reading accuracy and spelling might be stronger than relationships between reading fluency and spelling. However, studies that investigated the relationship between spelling accuracy and reading speed found correlations that were comparable with those found between spelling accuracy and reading accuracy (Zutell, 1992; Zutell \& Rasinski, 1989), rendering this explanation unlikely. Moreover, in the present study the correlations between word reading fluency and spelling speed showed the same pattern as the correlations between word reading fluency and spelling accuracy, indicating that a speed-accuracy confound did not cause the low correlations between spelling and reading found in the present study.

A second explanation might be that the present study is conducted with Dutch children, while most contrasting studies are conducted with English-speaking children. The English orthography is much more complex and inconsistent (Share, 2008), and learning to read and spell takes much longer in English than in more transparent orthographies (Goswami, Gombert, \& De Barrera, 1998; Landerl, Wimmer, \& Frith, 1997; Seymour, Aro, \& Erskine, 2003). It is possible that phonological processing is more important for reading in English and for a longer period of time because of the complex phonological-orthographic structure of English (see Georgiou, Parilla, \& Papadopoulos, 2008; Share, 2008; Vaessen et al., accepted). If phonological processing remains strongly involved in reading in English-speaking children for a longer period of time, and if phonological processing mediates the relationship between reading and spelling, it is not surprising that reading and spelling are more strongly correlated in English language studies.

\section{Conclusions}

The results of the present study suggest that phonological processing skills and letter-speech sound association skills continue to affect spelling performance at least until the end of primary school. Overall the results support the view that spell- 
ers adaptively use a range of spelling strategies (including phonological recoding) throughout development. Moreover, the major common cognitive mechanism mediating the relationship between word reading fluency and spelling skills seems to be phonological processing, and since the contribution of phonological processing to word reading fluency declines as a function of reading experience, the proportion of variance in spelling performance that is shared with word reading fluency also declines. In contrast, RAN seems to reflect a cognitive process that is uniquely involved in fluent reading. Spelling and reading thus only partly rely on common cognitive mechanisms (i.e. phonological processing), and children rely less on these common and more on unique cognitive mechanisms during reading and spelling when they become more experienced.

\section{Acknowledgements}

The present study was partly supported by a grant (608/001/2005) of the Dutch National Board of Health Care Insurance to L. Blomert. We thank the pupils, schools and parents for their participation. 


\section{References}

Aarnoutse, C., van Leeuwe, J., \& Verhoeven, L. (2000). Ontwikkeling van beginnende geletterdheid [development of beginning literacy]. Pedagogische Studiën, 77, 307 - 325.

Berninger, V. W., Abbott, R. D., Billingsley, F., \& Nagy, W. (2001). Processes underlying timing and fluency: efficiency, automaticity, coordination and morphological awareness. In M. Wolf (Ed.), Dyslexia, fluency and the brain (pp. 383-414). Timonium, MD: York Press.

Berninger, V. W., Cartwright, A. C., Yates, C. M., \& Swanson, H. L. (1994). Developmental skills related to writing and reading acquisition in the intermediate grades: Shared and unique functional systems. Reading and Writing, 6(2), 161-196.

Blomert, L., \& Vaessen, A. (2009). Differentiaal Diagnostiek van Dyslexie; Cognitieve analyse van lezen en spellen [Dyslexia Differential Diagnosis; cognitive analysis of reading and spelling]. Amsterdam: Boom B.V. publishers.

Bosman, A. M. T., \& Van Orden, G. C. (1997). Why spelling is more difficult than reading. In C. A. Perfetti, L. Rieben \& M. Fayol (Eds.), Learning to spell: Research, theory, and practice across languages. (pp. 173-194). Mahwah, NJ, US: Lawrence Erlbaum Associates Publishers.

Bowers, P. G. (1993). Text reading and rereading: Determinants of fluency beyond word recognition. Journal of Reading Behavior, 25(2), 133-153.

Bowers, P. G. (1995). Tracing symbol naming speed's unique contributions to reading disabilities over time. Reading and Writing: An Interdisciplinary Journal, 7, 189-216.

Bowers, P. G., \& Ishaik, G. (2003). RAN's contribution to understanding reading disabilities. In S. Graham, H. Swanson \& K. R. Lee Harris (Eds.), Handbook of learning disabilities (pp. 140-157). New York, US: Guilford Press.

Bowers, P. G., \& Swanson, L. B. (1991). Naming speed deficits in reading disability: Multiple measures of a singular process. Journal of Experimental Child Psychology, 51(2), 195-219.

Bradley, L., \& Bryant, P. E. (1979). Independence of reading and spelling in backward and normal readers. Developmental Medicine and Child Neurology, 21, 504-514.

Bradley, L., \& Bryant, P. E. (1983). Categorizing sounds and learning to read: A causal connection. Nature, 301(5899), 419-421.

Bryant, P. E., \& Bradley, L. (1980). Why children sometimes write words which they do not read. In U. Frith (Ed.), Cognitive processes in spelling. London: Academic Press.

Caravolas, M., Hulme, C., \& Snowling, M. J. (2001). The foundations of spelling ability: Evidence from a 3year longitudinal study. Journal of Memory and Language, 45(4), 751-774.

Cardoso-Martins, C., \& Pennington, B. F. (2004). The relationship between phoneme awareness and rapid serial naming skills and literacy acquisition: The role of developmental period and reading ability. Scientific Studies of Reading, 8(1), 27-52.

Cataldo, S., \& Ellis, N. C. (1988). Interactions in the development of spelling, reading and phonological skills. Journal of Research in Reading, 11(2), 86-109.

Cirino, P., Israelian, M. K., Morris, M. K., \& Morris, R. D. (2005). Evaluation of the Double Deficit Hypothesis in College Students Referred for Learning Difficulties. Journal of Learning Disabilities, 38(1), 29-44.

Clarke, P., Hulme, C., \& Snowling, M. (2005). Individual differences in RAN and reading: A response timing analysis. Journal of Research in Reading, 28(2), 73-86. 
Cohen, J. (1988). statistical power analysis for the bahavioral sciences (2nd ed.). New York: Academic Press.

Cohen, J. (1992). A power primer. Psychological Bulletin, 112(1), 155-159.

Conrad, N. J., \& Conrad, N. J. (2008). From reading to spelling and spelling to reading: Transfer goes both ways. Journal of Educational Psychology, 100(4), 869.

Cornwall, A. (1992). The relationship of phonological awareness, rapid naming, and verbal memory to severe reading and spelling disability. Journal of Learning Disabilities, 25(8), 532-538.

Ehri, L. C. (1992). Review and commentary: Stages of spelling development. In S. Templeton \& D. Bear (Eds.), Development of Orthographic Knowledge and the Foundations of Literacy: A Memorial Festschrift for Edmund H. Henderson (pp. 307-332). Hillsdale, N.J.: Erlbaum.

Ehri, L. C. (1997). Learning to read and learning to spell are one and the same, almost. In C. A. Perfetti, L. Rieben \& M. Fayol (Eds.), Learning to spell: research, theory, and practice across languages (pp. 237269). Mahwah, NJ, US: Lawrence Erlbaum Associates Publishers.

Ehri, L. C. (1998). Grapheme-phoneme knowledge is essential to learning to read words in English. In J. L. Metsala \& L. C. Ehri (Eds.), Word recognition in beginning literacy (pp. 3-40). Mahwah, NJ, US: Lawrence Erlbaum Associates Publishers.

Ehri, L. C. (2000). Learning to read and learning to spell: Two sides of a coin. Topics in Language Disorders, 20 (3)(19-36).

Ehri, L. C. (2005). Development of sight word reading: Phases and findings. In M. J. Snowling \& C. Hulme (Eds.), The Science of Reading: A Handbook (pp. 135-154). Oxford: Blackwell publishing.

Frith, U. (1980). Unexpected spelling problems. In U. Frith (Ed.), Cognitive Processes in Spelling (pp. 495515). London: Academic Press.

Frith, U., \& Frith, C. (1980). Relationships between reading and spelling. In J. F. Kavanagh \& R. L. Venesky (Eds.), Orthography, reading and dyslexia (pp. 287-295). Baltimore: University Park Press.

Froyen, D., Van Atteveldt, N., Bonte, M., \& Blomert, L. (2008). Cross-modal enhancement of the MMN to speech-sounds indicates early and automatic integration of letters and speech-sounds. Neuroscience Letters, 430(1), 23-28.

Froyen, D. J., Bonte, M. L., van Atteveldt, N., \& Blomert, L. (2009). The long road to automation: neurocognitive development of letter-speech sound processing. Journal of Cognitive Neuroscience, 21(3), 567-580.

Geelhoed, J., \& Reitsma, P. (1999). Pi-dictee. Lisse: Swets \& Zeitlinger.

Georgiou, G. K., Parilla, R., \& Papadopoulos, T. C. (2008). Predictors of word decoding and reading fluency across languages varying in orthographic consistency. Journal of Educational Psychology, 100, 566-580.

Goswami, U., Gombert, J. E., \& De Barrera, L. F. (1998). Children's orthographic representations and linguistic transparency: Nonsense word reading in English, French, and Spanish. Applied Psycholinguistics, 19, 19-52.

Greenberg, D., Ehri, L. C., \& Perin, D. (1997). Are word-reading processes the same or different in adult literacy students and third-fifth graders matched for reading level? Journal of Educational Psychology, 89(2), 262-275. 
Hardy, M. H., Smythe, P. C., Stennet, R. G., \& Wilson, H. R. (1972). Developmental patterns in elemental reading skills: phoneme-grapheme and grapheme-phoneme correspondences. Journal of Educational Psychology, 63, 433-436.

Holmes, V. M., \& Carruthers, J. (1998). The relation between reading and spelling is skilled adult readers. Journal of Memory and Language, 39(2), 264-289.

Jolliffe, I. T. (1972). Discarding variables in a principle componetn analysis, I; artificial data. Applied Psycholinguistics, 21, 160-173.

Jongejan, W., Verhoeven, L., \& Siegel, L. S. (2007). Predictors of reading and spelling abilities in first- and second-language learners. Journal of Educational Psychology, 99(4), 835-851.

Juel, C., Griffith, P. L., \& Gough, P. B. (1986). Acquisition of literacy: A longitudinal study of children in first and second grade. Journal of Educational Psychology, 78(4), 243-255.

Katzir, T., Youngsuk, K., Wolf, M., O'Brien, B., Kennedy, B., Lovett, M., et al. (2006). Reading fluency: the whole is more than the parts. Annals of Dyslexia, 56(1), 51-82.

Kerlinger, F. N., \& Pedhazur, E. J. (1973). Multiple regression in behavioral research. New York: Holt, Rinehart, \& Winston.

Keuning, J., \& Verhoeven, L. (2008). Spelling development throughout the elementary grades: The Dutch case. Learning and Individual Differences, 18(4), 459-470.

Kreiner, D. S. (1992). Reaction time measures of spelling: Testing a two-strategy model of skilled spelling. Journal of Experimental Psychology: Learning, Memory, and Cognition, 18(4), 765.

Landerl, K., Frith, U., \& Wimmer, H. (1996). Intrusion of orthographic knowledge on phoneme awareness: Strong in normal readers, weak in dyslexic readers. Applied Psycholinguistics, 17(1), 1-14.

Landerl, K., \& Wimmer, H. (2008). Development of word reading fluency and spelling in a consistent orthography: an 8-year follow-up. Journal of Educational Psychology, 100(1), 150-161.

Landerl, K., Wimmer, H., \& Frith, U. (1997). The impact of orthographic consistency on dyslexia: a German-English comparison. Cognition, 63(3), 315-334.

Leppanen, U., Niemi, P., Aunola, K., \& Nurmi, J. (2006). Development of Reading and Spelling Finnish From Preschool to Grade 1 and Grade 2. Scientific Studies of Reading, 10(1), 3-30.

Lervåg, A., \& Hulme, C. (in press). Rapid Automatized Naming (RAn) taps a mechanisms that places constraints on the development of early reading fluency. Psychological Science.

Maki, H. S., Voeten, M. J. M., Vauras, M. M. S., \& Poskiparta, E. H. (2001). Predicting writing skill development with word recognition and preschool readiness skills. Reading and Writing, 14(7), 643-672.

Manis, F. R., Doi, L. M., \& Bhadha, B. (2000). Naming speed, phonological awareness, and orthographic knowledge in second graders. Journal of Learning Disabilities, 33(4), 325-333, 374.

Manis, F. R., Seidenberg, M. S., \& Doi, L. M. (1999). See Dick RAN: Rapid naming and the longitudinal prediction of reading subskills in first and second graders. Scientific Studies of Reading, 3(2), 129157.

Marsh, G., Friedman, M., Welch, V., \& Desberg, P. (1980). The development of strategies in spelling. In U. Frith (Ed.), Cognitive processes in spelling (pp. 339-353). London: Academic Press.

Nikolopoulos, D., Goulandris, N., Hulme, C., \& Snowling, M. J. (2006). The cognitive bases of learning to read and spell in Greek: Evidence from a longitudinal study. Journal of Experimental Child Psychology, 94(1), 1-17. 
Notenboom, A., \& Reitsma, P. (2003). Investigating the dimensions of spelling ability. Educational and Psychological Measurement, 63(6), 1039-1059.

Nunes, T., Bryant, P. E., \& Bindman, M. (1997). Morphological spelling strategies: Developmental stages and processes. Developmental Psychology, 33(4), 637-649.

Pennington, B. F., Cardoso-Martins, C., Green, P. A., \& Lefly, D. L. (2001). Comparing the phonological and double deficit hypotheses for developmental dyslexia. Reading and Writing: An Interdisciplinary Journal, 14(7-8), 707-755.

Perfetti, C. A. (1997). The psycholinguistics of spelling and reading. In C. A. Perfetti, L. Rieben \& M. Fayol (Eds.), Learning to spell: Research, theory, and practice across languages. (pp. 21-38). Mahwah, NJ, US: Lawrence Erlbaum Associates Publishers.

Perry, C., \& Ziegler, J. C. (2004). Beyond the two-strategy model of skilled spelling: Effects of consistency, grain size, and orthographic redundancy. The Quarterly Journal of Experimental Psychology A: Human Experimental Psychology, 57(2), 325-356.

Plaza, M., \& Cohen, H. (2004). Predictive influence of phonological processing, morphological/syntactic skill, and naming speed on spelling performance. Brain and Cognition, 55(2), 368-373.

Puolakanaho, A., Ahonen, T., Aro, M., Leppanen, P. H. T., Tolvanen, A., Lyytinen, H., et al. (2007). Very early phonological and language skills: Estimating individual risk of reading disability. Journal of Child Psychology and Psychiatry, 48(9), 923-931.

Rayner, K., \& Pollatsek, A. (1989). The Psychology of Reading. New Jersey: Prentice-Hall.

Rittle-Johnson, B., \& Siegler, R. S. (1999). Learning to spell: Variability, choice, and change in children's strategy use. Child Development, 70(2), 332-348.

Savage, R., \& Frederickson, N. (2005). Evidence of a highly specific relationship between rapid automatic naming of digits and text-reading speed. Brain and language, 93(2), 152-159.

Savage, R., Pillay, V., \& Melidona, S. (2008). Rapid serial naming is a unique predictor of spelling in children. Journal of Learning Disabilities, 41(3), 235-250.

Scarborough, H. S. (1990). Very early language deficits in dyslexic children. Child Dev, 61(6), 1728-1743.

Schatschneider, C., Fletcher, J. M., Francis, D. J., Carlson, C. D., \& Foorman, B. R. (2004). Kindergarten Prediction of Reading skills: a longitudinal comparative analysis. Journal of Educational Psychology, 96(2), 265-282.

Seibold, D. R., \& McPhee, R. D. (1979). Commonality Analysis: a method for decomposing explained variance in multiple regression analyses. Human Communication Research, 5(4), 355-365.

Seymour, P., Aro, M., \& Erskine, J. (2003). Foundation literacy acquisition in European orthographies. British Journal of Psychology, 94(2), 143-174.

Shanahan, T. (1984). Nature of the reading-writing relation: An exploratory multivariate analysis. Journal of Educational Psychology, 76(3), 466-477.

Shankweiler, D., Lundquist, E., Dreyer, L. G., \& Dickinson, C. C. (1996). Reading and spelling difficulties in high school students: Causes and consequences. Reading and Writing, 8(3), 267-294.

Share, D. L. (2008). On the Anglocentricities of current reading research and practice: The perils of overreliance on an 'outlier' orthography. Psychological Bulletin, 134(4), 584-615.

Share, D. L., Jorm, A. F., Maclean, R., \& Matthews, R. (1984). Sources of individual differences in reading acquisition. Journal of Educational Psychology, 76(6), 1309-1324. 
Siegel, L. S., \& Faux, D. (1989). Aquisition of certain grapheme-phoneme correspondences in normally achieving and diabled readers. Reading and Writing, an interdisciplinary journal, 1, 37-52.

Snowling, M. (2000). Dyslexia. Oxford: Blackwell Publishers.

Snowling, M. J. (1994). Towards a model of spelling acquisition: the development of some component skills. In G. D. A. Brown \& N. C. Ellis (Eds.), Handbook of spelling: Theory, Process and Intervention. Chichester: John Wiley \& Sons Ltd.

Stage, S. A., \& Wagner, R. K. (1992). Development of young children's phonological and orthographic knowledge as revealed by their spellings. Developmental Psychology, 28(2), 287-296.

Strattman, K., \& Hodson, B. W. (2005). Variables that influence decoding and spelling in beginning readers. Child Language Teaching \& Therapy, 21(2), 165-190.

Stuart, M., \& Masterson, J. (1992). Patterns of reading and spelling in 10-year-old children related to prereading phonological abilities. Journal of Experimental Child Psychology, 54(2), 168-187.

Sunseth, K., \& Bowers, P. G. (2002). Rapid naming and phonemic awareness: Contributions to reading, spelling, and orthographic knowledge. Scientific Studies of Reading, 6(4), 401-429.

Templeton, S., \& Bear, D. R. (1992). Development of orthographic knowledge and the foundations of literacy: A memorial festschrift for Edmund H. Henderson. Hillsdale: NJ: Erlbaum.

Torgesen, J. K., Wagner, R. K., \& Rashotte, C. A. (1994). Longitudinal studies of phonological processing and reading. Journal of Learning Disabilities, 27(5), 276-286; discussion 287-291.

Treiman, R., Cassar, M., \& Zukowski, A. (1994). What types of linguistic information do children use in spelling? The case of flaps. Child Development, 65, 1310-1329.

Vaessen, A., Bertrand, D., Tóth, D., Csépe, V., Faísca, L., Reis, A., et al. (accepted). Cognitive ingredients of developing reading networks do not differ between transparent and opaque orthographies. Journal of Educational Psychology.

Vaessen, A., \& Blomert, L. (2010). Long term cognitive dynamics of fluent reading development. Journal of Experimental Child Psychology, 105, 213-231.

Vaessen, A. A., Gerretsen, P., \& Blomert, L. (2009). Naming problems do not reflect a second, independent core deficit in dyslexia: 'Double deficits' explored. Journal of Experimental Child Psychology, 103, 202-221.

Van den Bos, K. P., Zijlstra, B. J. H., \& lutje Spelberg, H. C. (2002). Life-span data on continuous-naming speeds of numbers, letters, colors, and pictured objects, and word-reading speed. Scientific Studies of Reading, 6(1), 25-49.

Varnhagen, C. K., McCallum, M., \& Burstow, M. (1997). Is children's spelling naturally stage-like? Reading and Writing, 9(5), 451-481.

Wagner, R. K., \& Torgesen, J. K. (1987). The nature of phonological processing and its causal role in the acquisition of reading skills. Psychological Bulletin, 101(2), 192-212.

Wagner, R. K., Torgesen, J. K., \& Rashotte, C. A. (1994). Development of reading-related phonological processing abilities: New evidence of bidirectional causality from a latent variable longitudinal study. Developmental Psychology, 30(1), 73-87.

Waters, G. S., Waters, G. S., Bruck, M., \& Seidenberg, M. (1985). Do children use similar processes to read and spell words? Journal of Experimental Child Psychology, 39(3), 511. 
Wile, L. T., \& Borowsky, R. (2004). What does rapid automatized naming measure? A new RAN task compared to naming and lexical decision. Brain and Language, 90, 47-62.

Wimmer, H., \& Hummer, P. (1990). How German-speaking first graders read and spell: Doubts on the importance of the logographic stage. Applied Psycholinguistics, 11, 349-368.

Wolf, M., Bally, H., \& Morris, R. (1986). Automaticity, retrieval processes, and reading: a longitudinal study in average and impaired readers. Child Development, 57(4), 988-1000.

Wolf, M., \& Bowers, P. G. (1999). The double-deficit hypothesis for the developmental dyslexias. Journal of Educational Psychology, 91(3), 415-438.

Zutell, J. (1992). An integrated view of word knowledge: Correlational studies of the relationships among spelling, reading, and conceptual development. In S. Templeton \& D. R. Bear (Eds.), Development of orthographic knowledge and the foundations of literacy: A Memorial Festschrift for Edmund H. Henderson (pp. 213-230). Hillsdale, NJ, England: Lawrence Erlbaum Associates, Inc.

Zutell, J., \& Rasinski, T. (1989). reading and spelling connections in third and fifth grade students. Reading Psychology, 10(2), 137-155. 



\section{Chapter 6}

\section{Cognitive deficits underlying dyslexia: The double deficit hypothesis}

This chapter is based on:

Vaessen, A., Gerretsen, P., \& Blomert, L. (2009). Naming problems do not represent a second independent core deficit in dyslexia: double deficits explored. Journal of Experimental Child Psychology, 103, 202-221. 


\begin{abstract}
The double deficit hypothesis (Bowers \& Wolf, 1993) states that naming speed problems represent a second core deficit in dyslexia independent from a phonological deficit. The current study investigated the main assumptions of this hypothesis in a large sample of well-diagnosed dyslexics. The three main findings were that (a) naming speed was consistently related only to reading speed; (b) phonological processing speed and naming speed loaded on the same factor, and this factor contributed strongly to reading speed and (c) although general processing speed was involved in speeded naming of visual items, it does not explain the relationship between naming speed and reading speed. The results do not provide support for the existence of a second independent core naming deficit in dyslexia and indicate that speeded naming tasks are mainly phonological processing speed tasks with an important addition: fast cross-modal matching of visual symbols and phonological codes.
\end{abstract}




\subsection{Introduction}

Dyslexic children show severe difficulties with reading and spelling that are not a consequence of sensory impairments, low intelligence, or a lack of educational opportunities (Lyon, Shaywitz, \& Shaywitz, 2003). It is widely accepted that the core deficit underlying dyslexia is a phonological deficit, and evidence in favor of such a deficit is substantial (for a review, see Vellutino, Fletcher, Snowling, \& Scanlon, 2004).

However, impaired phonological processing does not seem to be the only problem in dyslexia; many dyslexics also show problems with speeded naming of visual items. The first demonstration of naming speed problems in dyslexics was given by Denckla and Rudel (1976a, 1976b). They found that dyslexic readers are slower in naming a restricted set of well-known visual items than are normal reading controls and nondyslexic poor readers. Since these first investigations, many researchers have reported that dyslexics were slower when asked to rapidly name visual items (for an overview, see Wolf, Bowers, \& Biddle, 2000). To explain the persistent finding of naming speed problems in dyslexics, Wolf and Bowers developed the double deficit hypothesis (Bowers \& Wolf, 1993; Wolf, 1997; Wolf \& Bowers, 1999). The double deficit hypothesis acknowledges the existence of a phonological deficit but postulates that some dyslexics show a second independent naming speed deficit that is assumed to be equally important in causing reading problems. The claim that naming speed problems represent a second independent core deficit in dyslexia assumes that naming speed contributes uniquely to reading and spelling performance and that there should exist a subgroup of dyslexics showing naming speed problems in the absence of phonological problems. Moreover, it is assumed that dyslexics with a double deficit will show more severe literacy problems than will dyslexics with a single naming or single phonological deficit because the two problems are independent and additive.

As the current study aims to test the main assumptions of the double deficit hypothesis in a large clinical sample of dyslexics, we summarize the evidence for each of these assumptions (for a review, see Bowers \& Ishaik, 2003; Vukovic \& Siegel, 2006).

\section{Main assumptions of the double deficit hypothesis}

The first main assumption claims the unique contribution of naming speed skills to literacy performance. Although several cross-sectional and longitudinal studies have reported that naming speed contributed uniquely to the variance in reading ability (Bowers \& Swanson, 1991; Eleveld, 2005; Felton \& Brown, 1990; Hulslander et al., 2004; Manis, Doi, \& Bhadha, 2000; Van den Bos, 1998; Van den Bos, Zijlstra, \& Van den Broeck, 2003; Wolf, 1986; Wolf, Bally, \& Morris, 1986), other studies have 
found only a modest contribution of naming speed to literacy performance when compared with the contribution of phonological awareness (Cardoso-Martins \& Pennington, 2004; Pennington, Cardoso-Martins, Green, \& Lefly, 2001; Plaza \& Cohen, 2004). Some studies have even failed to find any unique contribution of naming speed to reading or spelling performance (Patel, Snowling, \& De Jong, 2004; Torgesen, Wagner, \& Rashotte, 1994). In reviewing the predictive value of naming speed, Allor (2002) concluded that although all studies have found a unique contribution of phonological awareness to literacy performance, the evidence for a unique contribution of naming speed is less convincing.

In addition, naming speed seems to have a stronger and more consistent relationship with reading speed than with other literacy measures (e.g., Cornwall, 1992; Sunseth \& Bowers, 2002; Vukovic, Wilson, \& Nash, 2004; Wolf et al., 2000), although some studies have found unique contributions to spelling (Pennington et al., 2001; Savage, Pillay, \& Melidona, 2008) or reading accuracy (Cornwall, 1992; Savage et al., 2008; Wolf et al., 1986).

The second assumption of the double deficit hypothesis states that naming speed and phonological awareness deficits are independent and thus relatively unrelated. The correlation between naming speed and phonological awareness indeed seems to be rather modest. Swanson, Trainin, Necoechea, and Hammil (2003) found a correlation of .38 in their meta-analysis of studies reporting correlations between naming speed and phonological awareness performance. In addition, Neuhaus and Swank (2002) showed that variance in rapid naming performance could not be accounted for entirely by variance in phonological processing, suggesting that naming speed cannot be interpreted as a purely phonological variable. However, some studies have suggested that the shared variance of phonological awareness and naming speed predicts at least as much of the variance in reading performance as does the unique variance of the separate variables (Schatschneider, Carlson, Francis, Foorman, \& Fletcher, 2002). Chiappe, Stringer, Siegel, and Stanovich (2002) showed that only $25 \%$ of the variance in reading that is explained by naming speed is unique, with the other $75 \%$ being shared with phonological awareness. In other words, although the modest correlation between phonological awareness and naming speed suggests that speeded naming tasks incorporate only a relatively small phonological component, it seems to be just this phonological component in speeded naming tasks that predicts reading performance the best.

The third main assumption of the double deficit hypothesis predicts the existence of a subgroup of dyslexics suffering from naming speed deficits in the absence of phonological deficits (single naming speed deficit). Wolf et al. (2000) reported several studies revealing a substantial percentage of dyslexics exhibiting such a single naming speed deficit. Moreover, Morris et al. (1998) identified one subtype that was characterized by only naming speed problems when using a cluster analysis method. It should be noted, however, that the naming speed problems in this 
subgroup were relatively mild. Other studies did not find strong evidence for the existence of a single naming deficit subtype. Pennington et al. (2001) included several phonological processing tasks to investigate the phonological performance of 71 dyslexics and found only one child who showed a naming deficit in the absence of phonological processing problems, suggesting that classification of subtypes depends greatly on the measures and cutoff points used for classification. Moreover, Spector (2005) showed that classification of subtypes is unstable because only half of the sample was reclassified to the same subtype a year after testing. In other words, the evidence for the existence of a single naming speed deficit subgroup is at least mixed.

The fourth assumption predicts that children with a double deficit should be more impaired in reading and spelling than are children with a single deficit because both deficits contribute independently to literacy problems and thus should be additive (Hulslander et al., 2004; Wolf et al., 2000). In addition, if naming speed and phonological awareness are related to different components of the reading process, the single naming speed deficit subtype should show a different performance pattern than the single phonological deficit subtype. Some studies (e.g., Lovett, Steinbach, \& Frijters, 2000; Manis et al., 2000) have found support for the claim that double deficit children are more impaired than single deficit children. Others have not found any differences in reading and spelling between children with a double deficit and those with a single deficit (e.g., Ackerman, Holloway, Youngdahl, \& Dykman, 2001). Wimmer, Mayringer, and Landerl (2000) showed that mainly reading speed, and not reading accuracy or spelling, was more impaired in children with a double deficit than in children with a single phonological deficit. However, because reading accuracy was high for all subtypes, results regarding word reading accuracy should be interpreted with caution. Schatschneider et al. (2002) and Vellutino et al. (2004) suggested that differences in reading ability between double deficit groups and single deficit groups may be a statistical artifact. Because naming speed and phonological processing are interrelated, children with a double deficit may have more pronounced phonological difficulties and thus more severe reading problems. On the other hand, Sunseth and Bowers (2002) and Wimmer et al. (2000) tested the severity of phonological processing problems in the double deficit subtypes and could not find evidence for the claim that double deficit children have more pronounced phonological difficulties.

To summarize, the results of studies investigating one or more double deficit assumptions are inconsistent and the evidence for the double deficit hypothesis is equivocal. The large variation in sample sizes, selection procedures for participants, and selected behavioral tasks may account at least partly for the inconsistent results (Vukovic \& Siegel, 2006). An additional factor that might complicate the interpretation of the evidence for the double deficit hypothesis is the dynamic nature of the reading process and its related cognitive processes during literacy development. 
Therefore, the strength and nature of the relation between naming speed and literacy may depend on the age and reading expertise of the sample under study. Some studies have found evidence that the influence of naming speed and phonological awareness on reading performance changes with more reading experience, although not always in the same direction (e.g., Kirby, Parrila, \& Pfeiffer, 2003; Landerl \& Wimmer, 2008; Vaessen \& Blomert, 2008, 2009; Van den Bos, Zijlstra, \& lutje Spelberg, 2002; Wagner et al., 1997).

A final issue potentially complicating a straightforward interpretation of the evidence in the double deficit debate resides in the differences in orthographic transparency of the test language used in the different studies. In general, in opaque orthographies such as English, the evidence for the role of phonological awareness in reading development is strong if compared with the evidence for naming speed problems (e.g., Allor, 2002; Torgesen, Wagner, Rashotte, Burgess, \& Hecht, 1997; Wagner, Torgesen, \& Rashotte, 1994). However, studies in relatively transparent orthographies have reported a rather modest, and over time decreasing, contribution of phonological awareness to reading, whereas naming speed contributions were strong and consistent (e.g., De Jong \& Van der Leij, 1999; Landerl \& Wimmer, 2008). Also in nonalphabetic languages such as Chinese, naming speed was consistently related with reading speed over time (Liao, Georgiou, \& Parrila, 2008).

There might be several reasons for the observed differences between studies in opaque and more orthographically transparent languages. The orthographic structure of the language itself may influence reading development and thus the cognitive processes involved in reading (see, e.g., the orthographic depth hypothesis [Katz \& Frost, 1992] or the psycholinguistic grain size theory [Ziegler \& Goswami, 2005]). In addition, methodological issues may have influenced the contrastive results reported for transparent and nontransparent languages. First, in transparent orthographies, performance on phonological awareness measures is often high and consequently the performance range is restricted, thereby potentially attenuating the estimated contributions of phonological awareness to reading in transparent languages. Including a sensitive measure for phonological awareness might help to avoid this problem, as does including a speeded measure for phonological awareness. For instance, Patel et al. (2004) showed that the contribution of phonological awareness to reading performance was strong in English as well as Dutch students when measured with a sensitive phonological measure including a speed component. A second methodological issue is that most English language studies have used reading accuracy to index reading ability, whereas most studies in transparent orthographies have used reading speed measures because word accuracy levels reach ceilings early in reading development (Wimmer \& Hummer, 1990). A recent study suggested that the contrasting results between opaque and transparent languages regarding the contribution of phonological awareness and naming speed to 
reading may result because of a confound between the degree of transparency of a language and the habit of comparing accuracy measures in the one type of language with speed measures in the other type of language (Vaessen \& Blomert, 2009). Therefore, accuracy and speed measures for both phonological awareness and reading were included in the current study.

\section{Nature of naming problems}

Independent of the question as to whether naming speed problems represent a second core deficit, it is important to discuss what the nature of naming speed problems is. Some authors have claimed that naming speed problems reflect a general processing speed deficit (Kail \& Hall, 1994), potentially causing a disruption of the temporal integration of visual and phonological information but also timingrelated deficits outside of the language domain (Bowers, Sunseth, \& Golden, 1999; Bowers \& Wolf, 1993; Farmer \& Klein, 1995; Wolf, 1991). However, several studies have failed to find any disruptions in general speed or timing for nonlanguage tasks (Chiappe et al., 2002; De Jong \& Van der Leij, 2003), suggesting that the nature of the naming deficit is language specific. Several studies have reported that naming speed is most strongly related to literacy tasks that rely on the recognition of wordspecific orthographic patterns such as the recognition of exception words (Bowers \& Ishaik, 2003; Manis et al., 2000; Wile \& Borowsky, 2004; Wolf, 1997; Wolf \& Bowers, 1999), leading to the hypothesis that naming speed reflects a process that is involved in orthographic skill. However, the exact nature of this underlying process is still unclear; speeded naming has been associated with visual letter recognition speed (e.g., Bowers \& Wolf, 1993), learning new orthographic patterns (e.g., Levy, Bourassa, \& Horn, 1999), learning arbitrary associations (Manis et al., 2000), and the efficiency of integrating orthographic and phonological information (Berninger, Abbott, Billingsley, \& Nagy, 2001; Bowers \& Ishaik, 2003), among others.

Several opponents of the double deficit hypothesis have suggested that naming speed problems do not represent an independent core deficit but rather merely reflect problems in phonological processing; naming visual items is thought to depend on the fast retrieval of phonological codes, which in turn might be influenced by phonological problems in dyslexia (Chiappe et al., 2002; Clarke, Hulme, \& Snowling, 2005; Katz \& Shankweiler, 1985; Pennington et al., 2001; Torgesen et al., 1994, 1997; Vukovic \& Siegel, 2006; Wagner \& Torgesen, 1987; Wagner, Torgesen, Laughon, Simmons, \& Rashotte, 1993). The fact that naming speed is not highly correlated with phonological awareness seems to contradict a purely phonological explanation of naming speed problems. However, since traditional phonological awareness tasks usually do not measure speed, potential relationships between speed of phonological decoding/processing and naming speed might be concealed. There- 
fore, in the current study, we included a speed measure in a traditional phonological awareness task.

In conclusion, the evidence for the double deficit hypothesis is mixed, and the nature of the naming deficit remains elusive. Therefore, Vukovic and Siegel (2006) recommended that the assumptions of the double deficit hypothesis be tested within participants in a large group of well-diagnosed dyslexics.

\section{The current study}

We investigated the four main assumptions of the double deficit hypothesis within the same group of well-diagnosed Dutch dyslexic children. We conducted an archive study using diagnostic data of 162 dyslexic children who were tested at specialized dyslexia institutes in The Netherlands. Nationally standardized measures for reading speed, reading accuracy, and spelling were available, making it possible to investigate the relationship between naming speed and different literacy measures. Furthermore, the phonological awareness task includes a measure for phonological processing speed. In addition, a visual matching speed measure was included to investigate whether naming speed problems in dyslexia are a result of more general processing speed problems. The dyslexic sample had a wide grade and age range (Grades 1-6, ages 80-153 months). This wide range created the opportunity to investigate whether the influence of naming speed and phonological awareness on literacy performance differs between younger and older dyslexics. In closing, it should be pointed out that Dutch is a language with a fairly transparent orthography, comparable to German (Borgwaldt, Hellwig, \& De Groot, 2005), and is more consistent in the grapheme-to-phoneme direction than in the phoneme-tographeme direction. 


\subsection{Method}

\section{Participants and procedure}

We used diagnostic data that were collected from the archives of a specialized dyslexia institute, the Regional Institute for Dyslexia, situated in four different regions in The Netherlands. We collected a sample of consecutive cases who had been diagnosed as dyslexic on the basis of a psychometric evaluation of their performance on a cognitive reading and spelling test battery. For all but one of the tests, Dutch national norms were available. These tests were standardized on large representative samples of the Dutch school population; this is possible because of the relatively homogeneous educational system for reading and spelling in The Netherlands. These normative data made it possible to compare the performance of the dyslexic sample with that of a large unselected school population.

At the institute, children are diagnosed as dyslexic when having severe reading and/or spelling problems in the absence of sensory, neurological, or attention problems. Children with clinically manifest comorbidity possibly related to the reading and spelling problems are not diagnosed as dyslexic and were not included in the study. Severe reading and/or spelling problems were defined as having a percentile score of 10 or less on a Dutch standardized word reading test (One-Minute Test [Brus \& Voeten, 1973]) and/or having a percentile score of 10 or less on a standardized spelling to dictation test (PI-dictee [Geelhoed \& Reitsma, 1999]). All included children at least had performance scores for reading and spelling, phoneme deletion, rapid naming speed, and an assessment of their IQ (Weschler Intelligence Scale for Children-Revised , 1986]). The final sample consisted of 162 primary school children who at the time of testing ranged between 80 and 153 months of age ( $M=$ 114.6 months, SD = 17.7).

\section{Tasks}

Speed and accuracy of reading - The standardized word reading task, the OneMinute Test (OMT) (Brus \& Voeten, 1973), contains 116 words that vary from one to four syllables presented in four columns of 29 words. The list includes highfrequency words as well as low-frequency words. Reading speed was defined as the total amount of words read in $1 \mathrm{~min}$, whereas reading accuracy was defined as the percentage of correctly read words (number of correctly read words/total number of words read in $1 \mathrm{~min} \times 100$ ). Dutch norms are available for children from Grade 1 to the first class of secondary school (Van den Bos, lutje Spelberg, Scheepstra, \& de Vries, 1994).

Speed and accuracy of pseudoword reading - In the standardized pseudoword reading task, the Klepel (Van den Bos et al., 1994), the syllabic structure and length of the pseudowords are similar to the words of the OMT. Most pseudowords dif- 
fered in more than one letter from the words of the OMT. Reading speed was defined as the total amount of pseudowords read in 2 min, whereas reading accuracy was defined as the percentage of correctly read pseudowords (number of correctly read pseudowords/ total number of pseudowords read in $2 \mathrm{~min} \times 100$ ). Dutch norms are available for children from Grade 1 to the first class of secondary school.

Accuracy of spelling - The standardized word spelling to dictation task, PI-dictee (Geelhoed \& Reitsma, 1999), consists of 135 words of increasing difficulty and syllabic complexity. The total amount of correctly spelled words was scored. Dutch norms are available for children from Grade 1 to Grade 6.

Speed and accuracy of phonological awareness - A phoneme deletion task developed by the Regional Institute for Dyslexia was used. Accuracy was defined as the total number of correct items. Mean response time was calculated by averaging the response latencies between the presentation of the word and the answer. Although the phoneme deletion task has no national norms, the data of 162 normal reading children from Grades 1 to 5 were used as the control norm group.

Naming speed - An adapted version of the Denckla and Rudel task was used to measure naming speed of letters, digits, and objects. The reaction time is time per 50 items. Dutch norms are available for children from kindergarten to secondary school (Van den Bos, 2003).

General intelligence - For verbal, nonverbal, and full-scale IQ scores (WISC-R, 1986), two subtasks, Coding and Digit Span, were used as measures for visual matching speed and verbal working memory, respectively. The Dutch version of the WISC-R has norms for children between 6 and 16 years of age. 


\subsection{Results}

The assumptions of the double deficit hypothesis were tested using statistical procedures that assume normal distribution of the data and equal variances between groups. Not all tasks revealed a normal distribution. Therefore, we used logtransformed scores for phoneme deletion and naming speed tasks and square roottransformed scores for reading and spelling measures. The scores on WISC-digit span and WISC-coding were normally distributed and did not need transformation. After transformations, all scores were normally distributed except for word reading speed (scores showed a negative kurtosis value) and phoneme deletion accuracy (scores were somewhat positively skewed).

Another methodological issue that should be taken into consideration is that a population of dyslexics might show a restricted performance range on reading and reading-related measures, especially when they are selected for low performance on a reading measure. A restricted range might attenuate the correlations and other analyses based on correlations within this population. However, a comparison of the variance in the dyslexic population and the variance in the normative samples of the tasks showed that the standard deviation (SD) in the dyslexic population was equal to or even larger than that in the normative samples, although mean scores were much lower than in the normative sample. The only exceptions were the word reading speed and pseudoword reading speed measures. For these tasks, the size of the correlations and amount of explained variance might be attenuated, and these values should be interpreted with caution.

\section{Performance on literacy tasks, cognitive tasks, and IQ measures}

Means and SDs on literacy tasks, IQ, and cognitive tasks are presented in Table 6.1. In addition, the mean standardized scores on the tasks (if available) are shown (all standardized scores are expressed in standard scores with a mean of 10 and an SD of 3), and the percentage of children showing a standardized score of 6 (percentile 10 ) or less is presented. In addition to poor performance on the reading and spelling tasks, the dyslexic sample showed poor performance on phoneme deletion, pseudoword reading speed, and naming speed. Working memory seemed to be less affected; only $19 \%$ scored below the 10th percentile. The mean score on WISCcoding fell within the normal range, and only $9 \%$ of the sample performed below the 10th percentile, showing that the dyslexic sample did not exhibit major visual matching speed problems. 
Table 6.1 - Performance on literacy tasks, cognitive tasks and IQ-measures

\begin{tabular}{|c|c|c|c|c|c|}
\hline & \multicolumn{2}{|c|}{ raw score } & \multicolumn{2}{|c|}{$\begin{array}{c}\text { standardized } \\
\text { score* }\end{array}$} & \multirow{2}{*}{$\begin{array}{c}\% \text { children } \\
\text { with } \\
\text { sS<=6 or } \\
\text { IQ }<80 \\
\%\end{array}$} \\
\hline & mean & SD & mean & SD & \\
\hline IQ Full-scale (WISC) & n.a. & n.a. & 102.6 & 11.0 & 1.9 \\
\hline IQ Verbal (WISC) & n.a. & n.a. & 102.9 & 12.2 & 1.9 \\
\hline IQ Non-verbal (WISC) & n.a. & n.a. & 101.8 & 12.3 & 3.9 \\
\hline RWR (cor. words/min)** & 33.1 & 16.0 & 4.7 & 2.3 & 83.3 \\
\hline RWR speed (words/min) & 36.5 & 15.3 & n.a. & n.a. & n.a. \\
\hline RWR acc (\% correct) & 87.7 & 12.8 & 5.8 & 4.0 & 58.1 \\
\hline PWR (cor. words/2min)** & 22.9 & 13.2 & 5.4 & 2.1 & 74.1 \\
\hline PWR speed (words/2min) & 38.7 & 15.5 & n.a. & n.a. & n.a. \\
\hline PWR acc (\% correct) & 57.5 & 17.0 & 6.4 & 2.9 & 56.1 \\
\hline Spelling (score; $\max =135$ ) & 49.8 & 27.6 & 3.1 & 2.4 & 86.4 \\
\hline PA speed (sec/ item) & 5.0 & 2.4 & n.a. & n.a. & n.a. \\
\hline PA acc (score; Max=28) & 19.3 & 6.7 & 4.1 & 4.0 & 72.2 \\
\hline RAN letters (sec/50 items) & 38.1 & 11.3 & 6.1 & 3.6 & 50.6 \\
\hline RAN digits (sec/50 items) & 34.3 & 9.9 & 7.0 & 3.8 & 45.7 \\
\hline RAN objects (sec/50 items) & 59.1 & 16.2 & 7.3 & 3.4 & 40.7 \\
\hline WISC-digit span (score; Max=30) & 9.7 & 2.6 & 9.0 & 2.8 & 19.2 \\
\hline WISC-coding (score; Max=93) & 39.5 & 9.5 & 9.7 & 2.7 & 9.0 \\
\hline
\end{tabular}

Note. WISC, Wechsler Intelligence Scale for Children; RWR, real word reading; PWR, pseudoword reading; PA, phonological awareness; RAN, rapid automatized naming. n.a. not available.

* Standardized scores: IQ expressed in IQ scores (mean $=100, \mathrm{SD}=15$ ); performance on other tasks expressed in standardized scores (mean $=10, S D=3$ ). Standardized z scores for naming tasks and reading accuracy tasks were transformed into standardized scores to improve comparability of performance levels between tasks.

** Raw scores on the reading tasks embody both reading speed and reading accuracy. In further analyses, we use only reading speed and reading accuracy scores. 


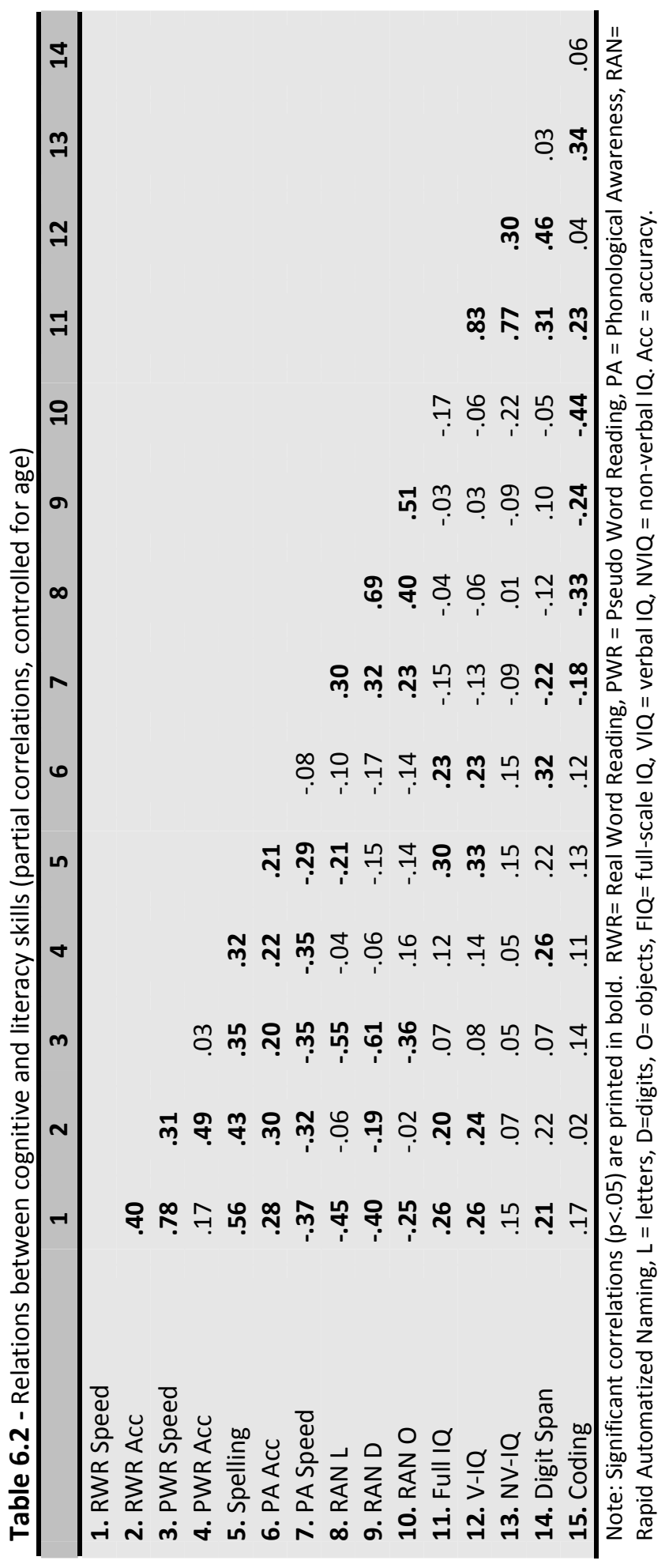




\section{Naming speed and phonological awareness in relation to literacy measures}

To get a first insight into the overall relationship between tasks, partial correlations (controlled for age) were calculated (Table 6.2). The results showed that phoneme deletion scores (accuracy and speed) were related to reading accuracy as well as reading speed. In contrast, naming speed was substantially correlated only with real word and pseudoword reading speed and not with reading accuracy. Furthermore, verbal and full-scale IQ scores were correlated with real word reading accuracy and speed, spelling, and phoneme deletion accuracy but not with naming speed or phonological processing speed.

WISC-digit span was modestly but significantly correlated with all reading and spelling measures except pseudoword reading speed. Also, digit span scores were related to performance on the phoneme deletion task (accuracy and speed). Performance on WISC-coding, was correlated only with naming speed and not with phonological awareness accuracy or speed, reading speed, reading accuracy, or spelling performance.

\section{Testing the assumptions of the double deficit hypothesis}

1. Unique contributions of naming speed to reading and spelling performance: To investigate whether naming speed contributed uniquely to reading and spelling performance, hierarchical regression analyses were performed. WISC-coding was not included in analyses because this task was not correlated with any of the reading or spelling measures. In the initial analyses, WISC-digit span was entered in the model directly after verbal IQ. However, WISC-digit span did not contribute to any of the literacy measures after controlling for verbal IQ. Therefore, new analyses were performed without WISC-digit span. Age was entered in the first step in the regression equation, and verbal IQ was entered in the second step. In the first model, phonological awareness (PA) accuracy and speed were entered in the third and fourth steps, respectively, and a combined measure of rapid automatized naming (RAN) letters and digits was entered last. In the second model, RAN was entered before PA accuracy and speed. The results of the hierarchical regressions (R2 and R2 change of each subsequent model) are presented in Table 6.3.

The composite score of naming speed of RAN letters and digits predicted a significant amount of variance of word and pseudoword reading speed ( 5 and 17\%, respectively) even after controlling for phonological awareness speed and accuracy. In contrast, naming speed did not predict any variance in reading accuracy and spelling. Phonological awareness accuracy contributed modestly to all aspects of literacy (2-4\%) when entered into the equation before RAN. After controlling for RAN, this variable contributed significantly to word and pseudoword reading accuracy and to real word reading speed (1-3\%). Phonological awareness speed con- 
tributed significantly to all aspects of literacy (2-9\%) even after controlling for RAN performance.

Table 6.3 - Contributions of naming speed and phonological awareness to reading and spelling performance (hierarchical regression analyses)

\begin{tabular}{|c|c|c|c|c|c|c|c|c|c|c|}
\hline & \multicolumn{2}{|c|}{ RWR speed } & \multicolumn{2}{|c|}{ RWR acc } & \multicolumn{2}{|c|}{ PWR speed } & \multicolumn{2}{|c|}{ PWR acc } & \multicolumn{2}{|c|}{ Spelling } \\
\hline & $\mathrm{R}^{2}$ & $\Delta \mathrm{R}^{2}$ & $\mathrm{R}^{2}$ & $\Delta \mathrm{R}^{2}$ & $R^{2}$ & $\Delta R^{2}$ & $\mathrm{R}^{2}$ & $\Delta \mathrm{R}^{2}$ & $\mathrm{R}^{2}$ & $\Delta R^{2}$ \\
\hline \multicolumn{11}{|l|}{ Step } \\
\hline 1. Age & .52 & $.52 * *$ & .20 & $.20 * *$ & .32 & $.32 * *$ & .21 & $.21 * *$ & .49 & $.49 * *$ \\
\hline 2. VIQ & .56 & $.04 * *$ & .26 & $.05^{* *}$ & .33 & .01 & .24 & $.03^{*}$ & .57 & $.08 * *$ \\
\hline 3. PA Acc & .59 & $.03 * *$ & .30 & $.04 * *$ & .35 & $.02 *$ & .27 & $.04^{*}$ & .59 & $.02 *$ \\
\hline 4.PA RT & .66 & $.06 * *$ & .35 & $.05 * *$ & .43 & $.08 * *$ & .35 & $.08^{* *}$ & .63 & $.04 * *$ \\
\hline 5.RANI\&d & .71 & $.05 * *$ & .35 & .00 & .60 & $.17^{* *}$ & .36 & .01 & .63 & .00 \\
\hline 3.RANI\&d & .67 & $.11^{* *}$ & .27 & .01 & .58 & $.25^{* *}$ & .24 & .00 & .59 & $.02 *$ \\
\hline 4. $P A A C C$ & .69 & $.01^{*}$ & .30 & $.04 * *$ & .58 & .00 & .27 & $.03 *$ & .60 & .01 \\
\hline 5.PA RT & .71 & $.02 *$ & .35 & $.05^{* *}$ & .60 & $.02 *$ & .36 & $.09 * *$ & .63 & $.03^{* *}$ \\
\hline Adj. $R^{2}$ & \multicolumn{2}{|c|}{$.70 * *$} & \multicolumn{2}{|c|}{$.32 * *$} & \multicolumn{2}{|c|}{$.58 * *$} & \multicolumn{2}{|c|}{$.34 * *$} & \multicolumn{2}{|c|}{$.62 * *$} \\
\hline
\end{tabular}

Note. RWR, real word reading; PWR, pseudoword reading; PA, phonological awareness. RAN letters and digits is a composite score of rapid automatized naming letters and digits.

$* p<.05$.

$* * p<.01$.

2. Validity of subtypes: The double deficit hypothesis assumes that a subgroup of dyslexics shows naming speed problems in the absence of phonological problems. To test this assumption, the sample was divided in four groups: children with a single phonological deficit, children with a single naming speed deficit, children with a double deficit and children with no deficit in phonological awareness or naming speed.

Definitions for a naming deficit and a phonological deficit were as follows: performing at least 1 SD below the average of the relevant norm group on a composite score on RAN letters and digits and performing at least 1 SD below the average on phoneme deletion accuracy, respectively. In our sample, 17 children (10.5\%) showed a single naming deficit (ND), 66 children (40.7\%) showed a double deficit (DD), 51 children (31.5\%) showed a single phonological deficit (PD), and 28 children (17.3\%) did not show problems on phoneme deletion or RAN. 
To check whether the single naming speed subtype indeed did not show phonological problems of any type, we investigated performance on verbal working memory and phonological awareness speed. Within the sample of 17 children with a single ND subtype, 5 performed below the normal range (standardized score $<8$ ) on verbal working memory (digit span), and, 3 ND children showed very slow response times on the phoneme deletion task (mean reaction time $>7 \mathrm{~s}$, which is more than 1 SD above the mean of all dyslexics). In other words, only 9 children in our sample of 162 children (5.5\%) showed a single naming deficit in the absence of phonological problems of any kind.

3. Independence of phonological processing and naming speed: The third assumption that was tested concerns the independence of naming speed and phonological processing. Correlations (presented in Table 6.2) showed that naming speed and phoneme deletion performance were not significantly related (correlation coefficients with RAN letters, digits, and objects varied between .10 and .17, p > .05) and that the correlation between naming speed and digit span performance was not reliable ( $r$ between .05 and $.12, p>.05$ ). However, naming speed and phoneme deletion speed were significantly correlated (RAN letters $r=.30$, RAN digits $r=.32$, RAN objects, $r=.23$, all $p s<.05)$.

4. Severity of reading and spelling problems in DD subtype: The double deficit hypothesis assumes that the DD subtype is more impaired in reading and/or spelling than the single ND subtype because both deficits contribute independently to their reading and spelling problems. In addition, the single ND subtype is assumed to show a literacy performance pattern different from that of the single PD subtype.

Analyses of covariance (ANCOVAs), controlled for age, were used to investigate the effect of deficit subtype on literacy performance. Post hoc analyses (with Bonferroni correction) were used to compare the three double deficit subtypes (the nodeficit subgroup was excluded from analysis). Reading and spelling abilities of the three subtypes are presented in Figure 6.1.

A significant main effect of deficit subtype was found for pseudoword reading speed, $F(2,128)=9.153, p<.0001, r=.35$, but not for real word reading speed, $F(2$, $128)=2.275, p>.05, r=.18$. Post-hoc comparisons revealed that the DD subtype was slower than the PD subtype on pseudoword reading $(p<.001)$. The single ND subtype did not differ from the DD subtype or the PD subtype $(p>.05)$. 
Table 6.4 - Means and standard deviations on the literacy tasks for the deficit subtypes (with pure ND subtype)

\begin{tabular}{lrrrrrr}
\hline & \multicolumn{3}{c}{ DD } & \multicolumn{2}{c}{ pure ND } & \multicolumn{2}{c}{ PD } \\
\cline { 2 - 7 } & mean & SD & mean & SD & mean & SD \\
\hline RWR speed & & & & & & \\
(words/min) & 34.6 & 14.5 & 38.9 & 18.2 & 39.1 & 17.1 \\
RWR acc (\% correct) & 88.9 & 10.2 & 49.9 & 4.6 & 83.4 & 16.0 \\
PWR speed & & & & & & \\
(words/2 min) & 34.5 & 12.1 & 35.1 & 14.8 & 43.7 & 17.0 \\
PWR acc (\% correct) & 57.7 & 15.8 & 68.6 & 8.3 & 55.7 & 19.1 \\
Spelling & & & & & & \\
(\# correct, max 135) & 51.0 & 26.1 & 57.1 & 36.2 & 49.1 & 30.0 \\
\hline
\end{tabular}

Note: $\mathrm{DD}=$ double deficit subtype, pure $\mathrm{ND}=$ pure single naming deficit subtype (children with verbal working memory problems or phonological processing speed problems excluded), $P D=$ single phonological deficit subtype. RWR=real word reading, PWR= pseudo word reading.

Furthermore, a significant main effect of deficit subtype was found for real word reading accuracy, $F(2,128)=3.004, p<.05, r=.22$. Children with an ND made significantly fewer errors than did children with a PD $(p<.05)$. The DD subtype did not differ from the single deficit subtypes ( $p>.05)$.

No significant main effect of subtype was found for pseudoword reading accuracy, $F(2,128)=1.150, p>.05, r=.13$, or spelling, $F(2,128)=0.735, p>.05, r=.10$. Because some children who were classified as having a single naming deficit actually showed problems with verbal working memory or phoneme deletion speed, it is possible that the results of the single ND subtype are influenced by these phonological problems. Therefore, the performance of the 9 "pure" ND children was investigated (see Table 6.4). The performance of this pure ND group was somewhat better than that of the original ND group on all reading and spelling measures. However, the difference between the pure ND group and the single PD group was significant only for real word reading accuracy, main effect of subtype, $F(2,123)=$ 4.064, $p<.05, r=.25$, post hoc comparisons between PD and pure ND, $p<.05$. Thus, the exclusion of children with verbal working memory or phonological processing speed problems from the ND group led to a generally less severely affected group of children but did not lead to different outcome patterns. 


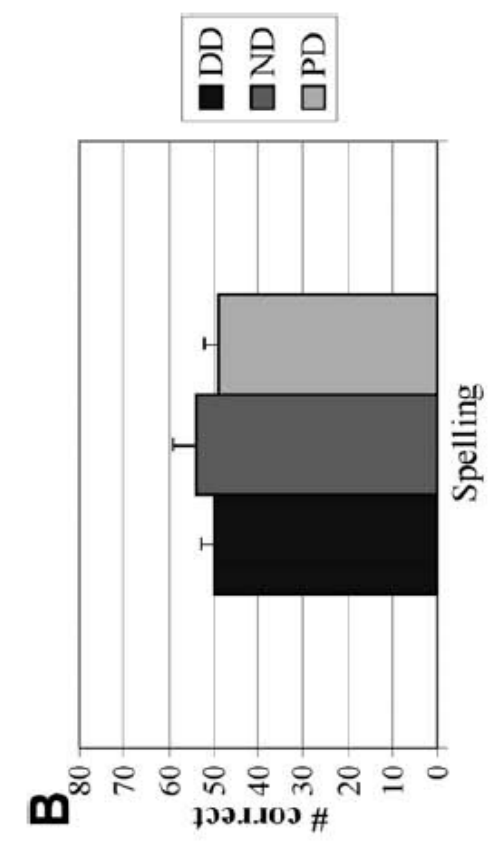

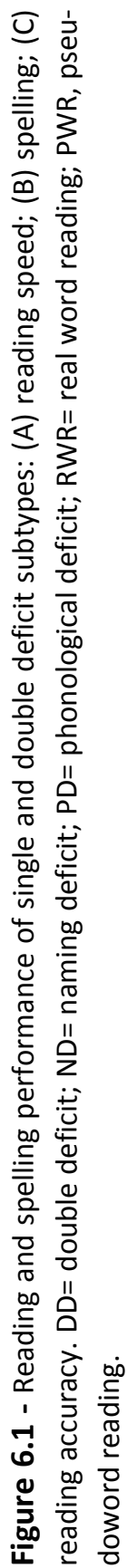
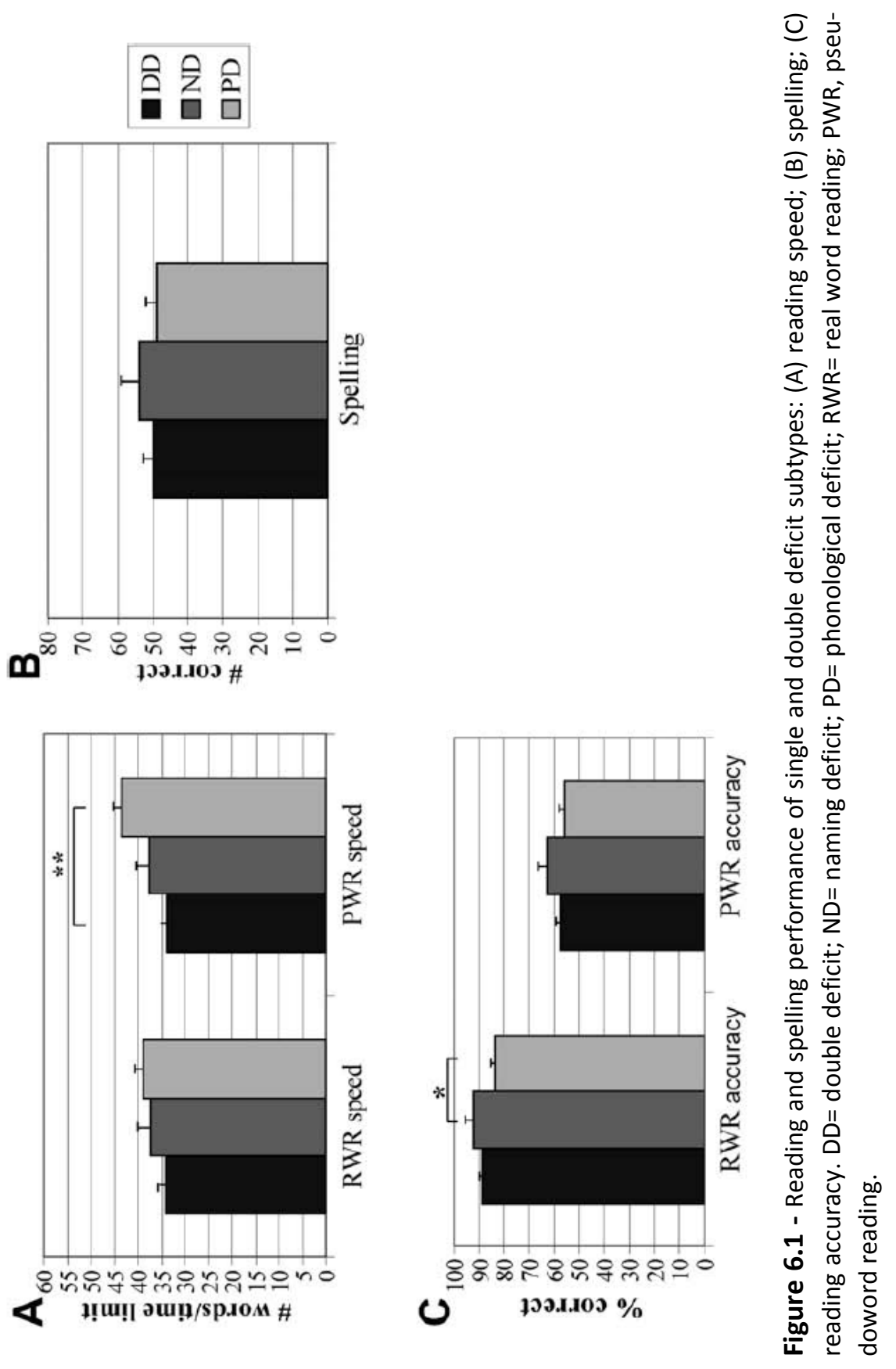
Development of relationship among naming speed, phonological awareness, and literacy performance

The relationship among phonological awareness, naming speed, and literacy performance may change when children grow older and have more reading experience. To investigate the effect of age, the sample was divided into two age groups based on the median age of the sample (113 months). There were several children whose age was 113 months; therefore, the sizes of the two subsamples were not completely equal (see Table 6.5).

Table 6.5 - Means and standard deviations on literacy tasks, IQ and cognitive tasks for the two age-groups

\begin{tabular}{lllll}
\hline & \multicolumn{2}{c}{$\begin{array}{c}\text { young dyslexics } \\
\text { (age<113 }\end{array}$} & \multicolumn{2}{c}{$\begin{array}{c}\text { old dyslexics } \\
\text { (age>=113 }\end{array}$} \\
\cline { 2 - 5 } & \multicolumn{1}{c}{ months) } \\
\hline IQ Full-scale (WISC) & 104.5 & 11.3 & 100.7 & 10.5 \\
IQ Verbal (WISC) & 104.6 & 11.6 & 101.3 & 12.6 \\
IQ Non-verbal (WISC) & 103.5 & 13.3 & 100.1 & 11.0 \\
RWR speed (words/min) & 27.0 & 11.0 & 45.6 & 13.3 \\
RWR acc (\% correct) & 84.2 & 14.4 & 91.0 & 10.1 \\
PWR speed (words/2min) & 31.5 & 12.3 & 45.5 & 15.1 \\
PWR acc (\% correct) & 52.2 & 14.8 & 62.4 & 17.5 \\
Spelling (\# correct; max=135) & 34.8 & 17.4 & 64.2 & 28.0 \\
PA speed (sec/ item) & 5.7 & 2.3 & 4.3 & 2.3 \\
PA acc (\# correct; Max=28) & 16.7 & 6.6 & 21.8 & 5.9 \\
RAN letters (sec/15 items) & 43.5 & 11.2 & 33.0 & 8.8 \\
RAN digits (sec/ 50 items) & 37.8 & 9.5 & 31.0 & 9.1 \\
RAN objects (sec/ 50 items) & 65.3 & 16.5 & 53.2 & 13.7 \\
WISC-digit span (score. Max=30) & 9.0 & 1.9 & 10.4 & 2.9 \\
WISC-coding (score. Max=93) & 37.7 & 10.2 & 41.3 & 8.5 \\
\hline
\end{tabular}

Note: RWR $=$ Real Word Reading, PWR $=$ Pseudo Word Reading, PA = Phonological Awareness, RAN= Rapid Automatized Naming, Acc = accuracy.

Hierarchical regression analyses were performed for each age group (young dyslexics $n=79$, older dyslexics $n=83$ ) with (pseudo)word reading speed, reading accuracy, and spelling as independent variables. Age was entered first in the regression equation, followed by verbal IQ. In the first model, phoneme deletion accuracy and phoneme deletion speed were entered as the third and fourth steps, respectively, followed by a composite score of RAN letters and digits. In the second model, RAN letters and digits was entered as the third step, followed by phoneme deletion accuracy and phoneme deletion speed as the fourth and fifth steps, respectively. 
Means and standard deviations on the cognitive and literacy tasks of the two age groups are shown in Table 6.5. In Table 6.6, the results of the regression analyses are presented.

Table 6.6 - Contributions of RAN and PA to reading and spelling performance (hierarchical regression analyses) for the two age-groups

\begin{tabular}{|c|c|c|c|c|c|c|c|c|c|c|}
\hline \multirow[t]{2}{*}{ Age $<113$} & \multicolumn{2}{|c|}{ RWR speed } & \multicolumn{2}{|c|}{ RWR acc } & \multicolumn{2}{|c|}{ PWR speed } & \multicolumn{2}{|c|}{ PWR acc } & \multicolumn{2}{|c|}{ Spelling } \\
\hline & $\mathbf{R}^{2}$ & $\Delta \mathbf{R}^{2}$ & $\mathbf{R}^{2}$ & $\Delta R^{2}$ & $\mathbf{R}^{2}$ & $\Delta \mathbf{R}^{2}$ & $\mathbf{R}^{2}$ & $\Delta \mathbf{R}^{2}$ & $\mathbf{R}^{2}$ & $\Delta \mathbf{R}^{2}$ \\
\hline 1. Age & .37 & $.37 * *$ & .34 & $.34 * *$ & .27 & $.27^{* *}$ & .05 & $.05^{*}$ & .25 & $.25 * *$ \\
\hline 2. VIQ & .38 & .02 & .40 & $.06 * *$ & .27 & .00 & .05 & .00 & .33 & $.08^{* *}$ \\
\hline 3. PA Acc & .38 & .00 & .41 & .01 & .27 & .00 & .06 & .01 & .33 & .00 \\
\hline 4. PA RT & .42 & .03 & .44 & .03 & .31 & $.05^{*}$ & .15 & $.09 * *$ & .38 & $.05 *$ \\
\hline 5.RANI\&d & .57 & $.15^{* *}$ & .47 & .03 & .59 & $.28 * *$ & .19 & .04 & .40 & .02 \\
\hline 3.RANI\&d & .56 & $.17^{* *}$ & .42 & .02 & .57 & $.31 * *$ & .07 & .02 & .36 & .03 \\
\hline 4. PA Acc & .56 & .00 & .43 & .01 & .58 & .00 & .08 & .01 & .36 & .00 \\
\hline 5.PA RT & .57 & .01 & .47 & $.04 *$ & .59 & .02 & .19 & $.11^{* *}$ & .40 & $.04 *$ \\
\hline Adj. $R^{2}$ & & & & $* *$ & & & & & & \\
\hline \multirow[t]{2}{*}{ Age $>=113$} & \multicolumn{2}{|c|}{ RWR speed } & \multicolumn{2}{|c|}{ RWR acc } & \multicolumn{2}{|c|}{ PWR speed } & \multicolumn{2}{|c|}{ PWR acc } & \multicolumn{2}{|c|}{ Spelling } \\
\hline & $\mathbf{R}^{2}$ & $\Delta \mathbf{R}^{2}$ & $\mathbf{R}^{2}$ & $\Delta \mathbf{R}^{2}$ & $\mathbf{R}^{2}$ & $\Delta \mathbf{R}^{2}$ & $\mathbf{R}^{2}$ & $\Delta R^{2}$ & $R^{2}$ & $\Delta \mathbf{R}^{2}$ \\
\hline 1. Age & .16 & $.16^{* *}$ & .10 & $.10 * *$ & .07 & $.07 * *$ & .21 & .21 & .28 & $.28 * *$ \\
\hline 2. VIQ & .30 & $.15^{* *}$ & .18 & $.09 * *$ & .10 & .03 & .29 & .08 & .44 & $.16^{* *}$ \\
\hline 3. PA Acc & .48 & $.18^{* *}$ & .27 & $.08 * *$ & .19 & $.10^{* *}$ & .37 & .07 & .51 & $.07^{* *}$ \\
\hline 4. PA RT & .59 & $.11^{* *}$ & .37 & $.10 * *$ & .35 & $.16^{* *}$ & .44 & .07 & .55 & $.04 *$ \\
\hline 5.RANI\&d & .64 & $.06 * *$ & .37 & .01 & .54 & $.20 * *$ & .44 & .00 & .55 & .00 \\
\hline 3.RANI\&d & .53 & $.23 * *$ & .27 & $.09 * *$ & .51 & $.42 * *$ & .32 & .03 & .46 & .02 \\
\hline 4. PA Acc & .61 & $.07 * *$ & .31 & $.04 *$ & .52 & .01 & .37 & $.05^{*}$ & .51 & $.05^{*}$ \\
\hline 5. PA RT & .64 & $.03 *$ & .37 & $.06 * *$ & .54 & .02 & .44 & $.07 * *$ & .55 & $.04 *$ \\
\hline Adj. $R^{2}$ & \multicolumn{2}{|c|}{$.61^{* *}$} & \multicolumn{2}{|c|}{$.33^{* *}$} & \multicolumn{2}{|c|}{$.51 * *$} & \multicolumn{2}{|c|}{$.40 * *$} & \multicolumn{2}{|c|}{$.51^{* *}$} \\
\hline
\end{tabular}

Note: RWR $=$ Real Word Reading, PWR = Pseudo Word Reading, PA = Phonological Awareness, RANI\&d= Rapid Automatized Naming letters \& digits, VIQ = verbal IQ, Acc = accuracy.

In general, the results show that the influence of naming speed and phonological awareness was stronger in older dyslexics than in younger dyslexics. Phonological awareness showed an unexpectedly low contribution in the youngest group. It is possible that correlations between phonological awareness and literacy are somewhat attenuated because the scores are not entirely normally distributed even after transformation. Moreover, the youngest group showed less variance on pseudo 
word reading speed and spelling, which might also have attenuated correlations between the performance on these tasks and performance on the cognitive tasks.

However, the most important finding in the light of this study is that in both age groups naming speed contributed significantly only to reading speed and not to reading accuracy or spelling. Although naming speed did account for a small amount of the variance in real word reading accuracy in the older dyslexics when entered first in the regression equation, this effect disappeared when analyses were controlled for phonological awareness.

\section{Nature of naming speed problems}

It has been hypothesized that the general processing speed underlies the relationship between reading speed and naming speed. If naming speed reflects general processing speed, performance on naming speed tasks should be related to other tasks that measure speed such as a task that measures visual matching speed. Indeed, the correlation between speed of matching two visual symbols (measured by performance on WISC-coding) and naming speed was significant ( $r=-.33$ with RAN letters, $r=-.24$ with RAN digits, and $r=-.44$ with RAN objects, $p<.05$, see Table $6.2)$, although the correlation between WISC-coding and phonological processing speed was not significant ( $r=-.18$ )

However, the fact that naming speed tasks seems to have a general speed component does not necessarily imply that this general speed component is the main connection between naming speed and reading speed. To get more insight into the nature of the naming speed deficit and its relation to visual matching speed and phonological processing, we performed an exploratory factor analysis on phoneme deletion accuracy, phoneme deletion speed, RAN letters and digits naming speed, object naming speed, WISC-coding, and WISC-digit span. In the initial analysis, only factors that had an Eigenvalue >= 1 were extracted (Kaiser's, 1960 criterion). Two factors were extracted (Eigenvalues of 2.714 and 1.071). However, the communalities of PA speed, RAN objects, and WISC-coding were rather low $(<.60)$. This suggests that the two-factor solution is not optimal. Therefore, we decided to use Jolliffe's $(1972,1986)$ criterion, which accepts all factors with eigenvalues $>=.70$. Three factors were extracted (see Table 6.7). In this three-factor solution, all communalities were above .70, and the Eigenvalue of the third factor was .716 (the proportion of explained variance was $75.8 \%$ ). Factor loadings, communalities, and component correlations are presented in Table 6.7.

RAN objects and WISC-coding loaded most strongly on the first factor. The factor loadings are in the expected direction; RAN objects loaded positively and WISCcoding loaded negatively due to the fact that RAN objects is expressed in response time (a longer response time is associated with lower performance), whereas WISCcoding is expressed in number of items within a time limit (a higher score is associ- 
ated with better performance). Phoneme deletion accuracy and WISC-digit span loaded on the second factor. Phoneme deletion speed loaded most strongly on the third factor, and RAN letters and digits loaded on both the first and third factors. Although interpretation of the three factors is never fully unbiased, for the purposes of this study, we refer to the three factors as a nonalphabetic processing speed factor, a phonological accuracy factor, and a phonological decoding speed factor.

Table 6.7 - Relation between phonological awareness, naming, digit span and coding (PCA with oblimin rotation: factor loadings, communalities and component correlations)

\begin{tabular}{lcccc}
\hline & \multicolumn{3}{c}{ Factors } & \begin{tabular}{c} 
Communality \\
\cline { 2 - 4 }
\end{tabular} \\
\cline { 2 - 4 } & $\mathbf{1}$ & $\mathbf{2}$ & $\mathbf{3}$ & .72 \\
\hline PA acc & & .79 & & .86 \\
PA speed & & & .94 & .72 \\
RAN objects & .66 & & & .74 \\
RAN letters \& digits & .43 & & .60 & .77 \\
WISC-digit span & & .87 & & .74 \\
WISC-coding & -.88 & & & \\
\hline Component correlations & $\mathbf{1}$ & $\mathbf{2}$ & $\mathbf{3}$ & \\
\hline Factor 1 & $\mathrm{X}$ & & & \\
Factor 2 & -.21 & $\mathrm{x}$ & & \\
Factor 3 & .31 & -.31 & $\mathrm{x}$ & \\
\hline
\end{tabular}

Note: Factor loadings $<.40$ not presented. $\mathrm{PA}=$ phonological awareness, RAN= rapid automatic naming. Acc=accuracy.

The fact that the naming speed tasks loaded on two different factors underlines the common assumption that speeded naming tasks involve multiple cognitive processes. Not all of these cognitive components will be equally predictive for reading; therefore, investigating which components account for variance in reading performance may help to get more insight into the specific nature of the relationship between naming speed and reading. To examine which of the naming components is most predictive for reading, hierarchical regression analyses were performed with the three extracted factors as predictors and reading and spelling performance as dependent variables. If both the phonological decoding speed factor and the nonalphabetic processing speed factor explain a reasonable amount of variance in reading or spelling, this would indicate that both components of naming play a role in reading and/or spelling performance and would support the claim that naming speed tasks capture a nonphonological cognitive process that is associated with reading performance. However, if only the phonological decoding speed factor is a 
significant predictor, it seems more likely that the phonological component of the speeded naming tasks accounts for most of the variance in reading.

The order of entry into the regression equation was as follows: age, verbal IQ, phonological accuracy factor, phonological decoding speed factor, and nonalphabetic processing speed factor. Using this order of entry, we were able to investigate whether the nonalphabetic processing speed factor contributed significantly to reading when controlling for all of the other factors.

Table 6.8 - Contributions of extracted factors to literacy performance (hierarchical regression analyses)

\begin{tabular}{|c|c|c|c|c|c|c|c|c|c|c|}
\hline & \multicolumn{2}{|c|}{$\begin{array}{l}\text { RWR } \\
\text { speed }\end{array}$} & \multicolumn{2}{|c|}{ RWR acc } & \multicolumn{2}{|c|}{$\begin{array}{c}\text { PWR } \\
\text { speed }\end{array}$} & \multicolumn{2}{|c|}{ PWR acc } & \multicolumn{2}{|c|}{ spelling } \\
\hline & $\mathbf{R}^{2}$ & $\Delta \mathbf{R}^{2}$ & $\mathbf{R}^{2}$ & $\Delta \mathbf{R}^{2}$ & $\mathbf{R}^{2}$ & $\Delta \mathbf{R}^{2}$ & $\mathbf{R}^{2}$ & $\Delta \mathbf{R}^{2}$ & $\mathbf{R}^{2}$ & $\Delta \mathbf{R}^{2}$ \\
\hline 1. Age & .53 & $.53 * *$ & .24 & $.24 * *$ & .34 & $.34 * *$ & .21 & $.21^{* *}$ & .50 & $.50 * *$ \\
\hline 2. VIQ & .57 & $.04 * *$ & .29 & $.04 * *$ & .34 & .01 & .23 & .02 & .56 & $.07 * *$ \\
\hline 3.Phon.Acc. & .59 & $.02 *$ & .33 & $.05 * *$ & .36 & .01 & .28 & $.05 * *$ & .58 & $.02 *$ \\
\hline 4.Phon.Speed & .68 & $.09 * *$ & .38 & $.05^{* *}$ & .55 & $.19 * *$ & .32 & $.04 * *$ & .62 & $.04 * *$ \\
\hline 5. NA.Speed & .69 & .01 & .39 & .01 & .59 & $.04 * *$ & .32 & .00 & .63 & .01 \\
\hline Adjusted $\mathrm{R}^{2}$ & \multicolumn{2}{|c|}{$.68 * *$} & \multicolumn{2}{|c|}{$.36 * *$} & \multicolumn{2}{|c|}{$.57 * *$} & \multicolumn{2}{|c|}{$.29 * *$} & \multicolumn{2}{|c|}{$.61^{* *}$} \\
\hline
\end{tabular}

Note. RWR, real word reading; PWR, pseudoword reading. Phon. Acc $=$ phonological accuracy factor, Phon. Speed = phonological decoding speed factor, NA speed=non-alphabetic processing speed, acc $=$ accuracy. ${ }^{*} \mathrm{p}<.05 .{ }^{* *} \mathrm{p}<.01$.

Results are shown in Table 6.8. The phonological decoding speed factor was a significant predictor for all literacy measures, but especially for pseudoword reading speed, even after accounting for phonological accuracy (17\% of the variance of pseudoword reading speed was explained uniquely by the phonological decoding speed factor). The nonalphabetic processing speed factor contributed uniquely to pseudoword reading speed ( $4 \%$ of the variance was explained), but this contribution was weak compared with the contribution of phonological decoding speed.

\subsection{Discussion}

The current archive study tested four main assumptions of the double deficit hypothesis (Bowers \& Wolf, 1993; Wolf \& Bowers, 1999) within participants in a large clinical sample of well-diagnosed dyslexics and found a unique but highly specific contribution of naming speed to literacy performance, a significant relation be- 
tween naming speed performance and phonological awareness speed, and no convincing evidence for a single naming deficit subtype, and that double deficit children did not differ in severity from single deficit children on most literacy measures. Therefore, we could not confirm the four main assumptions of the double deficit hypothesis.

More particular, the central assumption of the double deficit hypothesis postulates the independence of speeded naming and phonological deficits in dyslexia. In younger dyslexics as well as older dyslexics, we found a unique contribution of naming speed to reading speed but not to reading accuracy or spelling. Second, although we did not find a significant relation between naming speed performance and phonological awareness if expressed in accuracy of performance, we did find a relation if expressed in speed of phonological processing. In addition, the double deficit hypothesis predicts that if naming speed problems constitute a second core deficit, a substantial subgroup of dyslexics should have naming deficit problems in the absence of phonological problems. In our sample, only $5 \%$ of the participants showed naming speed problems in the absence of any phonological problems. Finally, on the basis of the assumed independence and additivity of the deficits, the double deficit hypothesis also predicts that the different subtypes will show differentiating literacy performance patterns and that the double deficit subtype shows more severe reading problems than does the single deficit subtype.

However, the double deficit children did not differ from single deficit children in real word reading speed, reading accuracy, or spelling, and they revealed poorer performance only on pseudoword reading speed, whereas the two single deficit subtypes differed only in real word reading accuracy. In other words, the main assumptions of the double deficit hypothesis could not be confirmed.

How far do the current results resonate with other studies in transparent languages? In line with the current results, RAN has been found to be a consistent predictor of reading speed in younger children as well as older children (Aarnoutse, Van Leeuwe, \& Verhoeven, 2005; De Jong \& Van der Leij, 1999; Landerl \& Wimmer, 2008; Van den Bos et al., 2002). However, in contrast to the present study three of these studies reported the absence of phonological contributions to reading after Grade 1 (Van den Bos et al., 2002 did not measure phonological awareness). One explanation for this difference might be that we tested dyslexic children, whereas the other studies focused on normal reading children. Another explanation might be that these studies investigated the predictive value of kindergarten phonological awareness to later reading performance, whereas we tested the influence of phonological awareness performance on concurrent reading performance. De Jong and Van der Leij (1999) showed that Grade 1 phonological abilities are a better predictor for reading than are kindergarten phonological abilities, possibly indicating that kindergarten measures of phonological processing skills might not be a good predictor for phonological awareness performance in later grades (Kirby et al., 2003). In 
addition, predicting reading performance from tests that were administered several years earlier might attenuate potential correlations (Vaessen \& Blomert, 2009).

Another difference between the current study and some other studies with poor readers in transparent orthographies (Landerl, Wimmer, \& Frith, 1997; Wimmer, 1996; Wimmer et al., 2000; Yap \& Van der Leij, 1993) is that these studies found relatively high accuracy levels on reading tasks. Wimmer et al. (2000) stated, "in consistent orthographies, the typical dyslexic child exhibits accurate word decoding skills but poor reading fluency" (p. 669). In contrast, in the current study, error percentages on pseudoword reading exceeded $30 \%$ in younger dyslexics as well as older dyslexics even though they were selected on reading speed. This finding is not unique; another Dutch study (Van den Bos, 1998) found even higher error percentages in its sample of poor readers. Because reading accuracy levels are measured using timed reading tasks, some errors may be made in attempting to "save time and effort" (Wimmer et al., 2000, p. 668). However, there is no evidence for a speed-accuracy trade-off in the correlation pattern between reading speed and accuracy (in this case, a positive correlation between percentage of errors and number of words read would be expected). Therefore, our results indicate that dyslexic children in transparent orthographies do show problems with word decoding next to problems with reading fluency.

One could argue that the current study provides some support for the double deficit hypothesis. First, naming speed did predict a unique proportion of the variance in reading speed in dyslexic participants. The finding that reading accuracy and spelling were not predicted by naming speed does not necessarily contradict the double deficit hypothesis given that speeded naming might reflect a deficit that is affecting mainly reading speed. Moreover, the rather modest relationship between naming speed and phonological processing speed might suggest that the performance on those tasks is at least partly independent. In addition, we did find a small group of children with single naming speed deficits.

However, the fact that we found a rather small group with single naming speed problems loses impact when one considers the fact that the large majority of the children with naming speed problems $(90 \%)$ did show phonological problems. How can such a large overlap be explained if naming speed problems and phonological problems represent two largely independent deficits? In addition, the small differences in literacy performance among the three deficit subtypes do not provide sufficient evidence for the claim that the two presumably independent deficits are additive or that children with a single naming speed deficit show a performance pattern different from that of children with a phonological deficit. Moreover, the creation of deficit subtypes based on cutoffs defined on continuous variables may create statistical problems (Compton, DeFries, \& Olson, 2001). Adjusting cutoff criteria and tasks may substantially influence the group size of the deficit subtypes. In addition, creating subtypes based on two measures that are correlated to reading 
and spelling results in less regression toward the mean in the double deficit subtype, and this might cause differences between single and double deficit subtypes that are due to a statistical artifact. Therefore, even if differences can be found among subtypes, these should be interpreted carefully. Finally, although the modest correlation between naming speed and phonological processing speed seems to be an indication of relative independence, a modest correlation does not necessarily imply that naming speed problems reflect an independent deficit. The process of speeded visual naming recruits cognitive processes over and above phonological processing that very likely differ from the extra cognitive processes recruited in traditional phonological awareness tasks over and above phonological processes. Therefore, high correlations between performance on naming tasks and traditional phonological awareness tasks cannot, and should not, be expected. The more relevant question is which characteristic of the naming task accounts for the variance in reading speed and whether this characteristic can be seen as independent from phonological processing. The fact that phonological processing speed and alphanumeric naming speed loaded on the same factor, which was highly predictive for reading performance, suggests that it is the phonological part of the naming process that makes the task particularly predictive for reading speed. Savage, Pillay, and Melidona (2007) came to similar conclusions; they extracted three naming components - a phonological decoding factor, an additional alphanumeric naming factor, and a more general naming factor-but only the phonological decoding component (which included naming speed of digits and letters and phonological decoding) was a substantial predictor of literacy. Altogether, the most parsimonious interpretation of the results leads inevitably to the conclusion that there is no evidence for the existence of a second core non-phonological naming deficit.

The only consistent finding is that naming speed contributes uniquely to reading speed. However, this unique contribution of naming speed to reading speed does not necessarily indicate that naming represents a second core deficit in dyslexia; it may simply imply that speeded naming tasks tap an aspect of phonological processing that is not captured by traditional phonological awareness tasks. This leads to the question: What exactly defines the relationship between naming speed and reading speed?

The finding that naming speed contributed only to reading speed, together with the finding that naming speed correlated with phonological processing speed, could point to a general speed interpretation of the naming speed deficit given that speed of processing clearly poses as the shared central element in the deficit pattern (phonological awareness, naming, and reading). General processing speed has indeed been suggested as the common basis for naming and reading speed deficits (Catts, Gillispie, Leonard, Kail, \& Miller, 2002; Kail \& Hall, 1994). However, our results do not confirm this hypothesis. First, there is no indication that visual matching speed was impaired in our dyslexic sample (the mean standardized score was ap- 
proximately 10 , and only $9 \%$ of the sample performed below the 10 th percentile on WISC-coding).

Furthermore, although rapid naming speed loaded on a non-alphabetic processing speed factor as well as on a phonological decoding speed factor, the phonological decoding speed factor is the one that was highly predictive of reading speed, whereas the non-alphabetic processing speed factor accounted for only a small proportion of the variance in reading speed. In agreement with Wimmer and Mayringer (2001), our results do not support a general speed deficit that causes reading speed problems as well as naming speed problems in dyslexia. A recent literature review on general processing speed deficits in dyslexia advanced a similar conclusion (Savage, 2004).

To explain the finding that naming speed contributes uniquely to reading speed, even when controlling for phonological awareness speed, we suggest taking a closer look at the task used to measure rapid naming. There is an essential difference between phonological awareness tasks and speeded naming tasks phonological awareness tasks are essentially uni-modal in nature and are confined to the domain of spoken language, whereas naming tasks are always cross-modal in nature. Fast cross-modal matching of visual/orthographic units to phonological codes is an important aspect of fluent reading. Wimmer and Mayringer (2002) proposed that in regular orthographies the main problem in dyslexics is the progress from slow sequential grapheme-phoneme decoding into fast parallel phonological/orthographic processing. The fact that speeded naming tasks also require fast matching of visual units to phonological codes may explain why reading speed and naming speed share a part of the variance and why naming problems are associated with slow reading in dyslexics. It might also explain why naming speed and speed on phonological awareness tasks are related. Several studies have suggested that orthographic information is automatically activated during the phonological process (Perre \& Ziegler, 2008; Ziegler \& Muneaux, 2007) and that this orthographic information may influence performance on phonological awareness tasks (Landerl, Frith, \& Wimmer, 1996). Therefore, speed on phonological awareness tasks might also partly reflect the efficiency of the integration of phonological and orthographic information, as do speeded naming tasks.

The concept of naming speed reflecting the ability to quickly and automatically recode visual/orthographic information was advanced by the authors of the double deficit hypothesis themselves (see Bowers \& Wolf, 1993). Initially, they interpreted this as a visual problem and not a phonological problem, possibly related to deficits in the magnocellular system (e.g., Wolf \& Bowers, 1999), although an extensive previous review already had indicated that non-language auditory-visual transfer deficits in dyslexia are unlikely (Vellutino, 1979). However, our results revealed that phonological processing speed and naming speed did load on the same factor that turned out to be the strongest predictor for reading speed, suggesting that the 
problem is very likely more phonological in nature. Wimmer et al. (2000) also proposed that the deficit is not purely visual but that the formation of graphemephoneme associations or the association of written words with their phonological presentation probably forms the basis of the reading deficit and is consequently reflected by the naming problems. In a more recent article, Bowers and Ishaik (2003) hypothesized that "RAN reflects the efficient integration of verbal and visual information" (p. 153). This is in agreement with the claim of Berninger et al. (2001) that RAN is a measure for the efficiency and automaticity of integration of orthographic and phonological information. According to Wimmer, Mayringer, and Landerl (1998), the crucial problem in learning to read is the difficulty in forming memory representations of letter sequences. They assumed that the critical step in the formation of new orthographic representations is the formation of the corresponding phonological forms, suggesting that phonological processing is deeply involved in orthographic processing.

In summary, we suggest that the reason why a speeded naming task is uniquely predictive for reading speed resides in the finding that it is a phonological processing speed task with an important addition that is absent in traditional phonological awareness tasks; naming tasks require fast matching or integration of visual to phonological codes. The underlying mechanisms of this integration process are not yet understood at this time, but we speculate that phonological processing contributes heavily to this cross-modal integration and that impaired performance on phonological awareness and naming tasks likely reflect phonological processing problems as well as less automatic integration of visual and phonological codes.

When interpreting the results of the current study, it is important to keep in mind that the research sample included only dyslexic children. The correlation pattern in a normal reading population might be different (McBride-Chang \& Manis, 1996). Moreover, the scores on the reading speed measures suffered from a restricted range compared with the scores in a population with a full range of reading abilities. As a consequence, correlations between reading speed measures and cognitive skills might be attenuated, and so the amount of explained variance might be lower than that found in a normal population. Therefore, the strength of the contributions should be interpreted with caution. However, the relative weights of the different cognitive contributions to reading performance, and thus the interpretation of the results, would not be different if correlations between reading speed and the cognitive measures were stronger. Yet it remains important to investigate the cognitive contributions to literacy performance in an unselected school sample with a large range of reading abilities to examine how far the results of the current study with dyslexics can be generalized to other populations. In a recent study investigating the unique effects of naming speed and phonological awareness on reading and spelling performance in a large unselected school sample, we found a pattern similar to that in the current study; naming speed was related only to read- 
ing speed, whereas phonological awareness showed a consistent and unique relation to reading speed, reading accuracy, and spelling (Vaessen \& Blomert, 2008, 2009). The contributions of phonological awareness performance to reading and spelling were even higher in the unselected school sample than in the current dyslexic sample, strengthening our conclusions about the importance of phonological awareness in reading.

Another point that should be kept in mind is that the current study was conducted in a rather transparent orthography. The results should be replicated in other languages with varying orthographic transparencies to investigate whether the results can be generalized.

Although the current work is an archive evaluation study, limiting the choice of cognitive tasks to those available, we believe that the selected measures represent the measures used in the relevant literature fairly well. Furthermore, we believe that this potential weakness of the study was well compensated by the strengths over previous studies; we tested all assumptions within participants in a large set of well-diagnosed dyslexics (in reference to Vukovic \& Siegel, 2006), included several measures of literacy (in reference to Wolf et al., 2000), and (most important) included a phonological processing speed factor that enabled us to reveal the intricate relation between phonological speed and naming speed.

\section{Conclusions}

The current study tested the main assumptions of the double deficit hypothesis in a large group of well-diagnosed dyslexics. The results do not support that naming speed problems represent a second independent core deficit in dyslexia. Naming speed and phonological processing speed show an intricate relation that is probably reflective of a common underlying factor for which general speed does not account. The unique contribution of naming speed to reading speed is probably attributable to the fact that speeded naming tasks, like speeded reading tasks but unlike standard phonological awareness tasks, require the fast cross-modal matching of visual/orthographic units to phonological codes. Therefore, the intricate relation between deficits in naming and phonological processing speed may reflect two sides of the same coin: the processes involved in establishing integrated written and spoken speech associations (for similar suggestions, see Bowers \& Ishaik, 2003; Wimmer et al., 1998, 2000). Recent brain imaging evidence shows that the detection of congruency between letters and speech sounds is predicted by the activation for isolated speech sounds (Blau, Atteveldt, Ekkebus, Goebel, \& Blomert, in press), directly supporting the role of phonological processes in the cross-modal basis of reading.

The results of the current study indicate that the search for independent naming deficits might not easily result in theoretical advances. The findings suggest that 
a direct investigation of the cross-modal nature of the reading process in deviant and normal readers may present better chances to reveal why naming essentially reflects the speed aspects of the manifold relations between phonological processing and reading, thereby opening new theoretical perspectives on the cognitive dynamics of reading development.

\section{Acknowledgements}

The present study was partly supported by a grant (608/001/2005) of the National Board of Health Care Insurance to L. Blomert. We are grateful to the Dutch Regional institutes of Dyslexia (RID) for opening up their diagnostic data archives to us for this study. We also thank three anonymous reviewers for their valuable comments. 


\section{References}

Aarnoutse, C., Van Leeuwe, J., \& Verhoeven, L. (2005). Early literacy from a longitudinal perspective. Educational Research and Evaluation, 11, 253-275.

Ackerman, P. T., Holloway, C. A., Youngdahl, P. L., \& Dykman, R. A. (2001). The double-deficit theory of reading disability does not fit all. Learning Disabilities Research \& Practice, 16, 152-160.

Allor, J. H. (2002). The relationships of phonemic awareness and rapid naming to reading development. Learning Disability Quarterly, 25, 47-57.

Berninger, V. W., Abbott, R. D., Billingsley, F., \& Nagy, W. (2001). Processes underlying timing and fluency: Efficiency, automaticity, coordination, and morphological awareness. In M. Wolf (Ed.), Dyslexia, fluency, and the brain (pp. 383-414). Timonium, MD: York.

Blau, V., Attenveldt, N., Ekkebus, M., Goebel, R., \& Blowert, L. (in press). Reduced neural integration of letters and speech sounds links phonological and reading deficits in adult dyslexia. Current Biology.

Borgwaldt, S. R., Hellwig, F. M., \& De Groot, A. M. B. (2005). Onset entropy matters: Letter-to-phoneme mappings in seven languages. Reading and Writing: An Interdisciplinary Journal, 18, 211-229.

Bowers, P. G., \& Ishaik, G. (2003). RAN's contribution to understanding reading disabilities. In S. Graham, H. Swanson, \& K. R. Lee Harris (Eds.), Handbook of learning disabilities (pp. 140-157). New York: Guilford.

Bowers, P. G., Sunseth, K., \& Golden, J. (1999). The route between rapid naming and reading progress. Scientific Studies of Reading, 3, 31-53.

Bowers, P. G., \& Swanson, L. B. (1991). Naming speed deficits in reading disability: Multiple measures of a singular process. Journal of Experimental Child Psychology, 51, 195-219.

Bowers, P. G., \& Wolf, M. (1993). Theoretical links among naming speed, precise timing mechanisms, and orthographic skill in dyslexia. Reading and Writing: An Interdisciplinary Journal, 5, 69-85.

Brus, B. T., \& Voeten, M. J. M. (1973). Een-minuut test, vorm A en B [One-Minute Test, Versions A and B]. Nijmegen, The Netherlands: Berkhout.

Cardoso-Martins, C., \& Pennington, B. F. (2004). The relationship between phoneme awareness and rapid serial naming skills and literacy acquisition: The role of developmental period and reading ability. Scientific Studies of Reading, 8, 27-52.

Catts, H. W., Gillispie, M., Leonard, L. B., Kail, R. V., \& Miller, C. A. (2002). The role of speed of processing, rapid naming, and phonological awareness in reading achievement. Journal of Learning Disabilities, 35, 510-525.

Chiappe, P., Stringer, R., Siegel, L. S., \& Stanovich, K. E. (2002). Why the timing deficit hypothesis does not explain reading disability in adults. Reading and Writing: An Interdisciplinary Journal, 15, 73-107.

Clarke, P., Hulme, C., \& Snowling, M. (2005). Individual differences in RAN and reading: A response timing analysis. Journal of Research in Reading, 28, 73-86.

Compton, D. L., DeFries, J. C., \& Olson, R. K. (2001). Are RAN- and phonological awareness-deficits additive in children with reading disabilities? Dyslexia, 7, 125-149.

Cornwall, A. (1992). The relationship of phonological awareness, rapid naming, and verbal memory to severe reading and spelling disability. Journal of Learning Disabilities, 25, 532-538. 
De Jong, P. F., \& Van der Leij, A. (1999). Specific contributions of phonological abilities to early reading acquisition: Results from a Dutch latent variable longitudinal study. Journal of Educational Psychology, 91, 450-476.

De Jong, P. F., \& Van der Leij, A. (2003). Developmental changes in the manifestation of a phonological deficit in dyslexic children learning to read a regular orthography. Journal of Educational Psychology, $95,22-40$.

Denckla, M. B., \& Rudel, R. G. (1976a). Naming of object-drawings by dyslexic and other learning disabled children. Brain and Language, 3, 1-15.

Denckla, M. B., \& Rudel, R. G. (1976b). Rapid “automatized” naming (RAN): Dyslexia differentiated from other learning disabilities. Neuropsychologia, 14, 471-479.

Eleveld, M. (2005). At risk for dyslexia: The role of phonological abilities, letter knowledge, and speed of serial naming in early intervention and diagnosis. Unpublished manuscript, Rijksuniversiteit Groningen.

Farmer, M. E., \& Klein, R. M. (1995). The evidence for a temporal processing deficit linked to dyslexia: A review. Psychonomic Bulletin and Review, 2, 460-493.

Felton, R. H., \& Brown, I. S. (1990). Phonological processes as predictors of specific reading skills in children at risk for reading failure. Reading and Writing: An Interdisciplinary Journal, 2, 39-59.

Geelhoed, J., \& Reitsma, P. (1999). PI-dictee. Lisse, Switzerland: Swets \& Zeitlinger.

Hulslander, J., Talcott, J., Witton, C., DeFries, J., Pennington, B., Wadsworth, S., et al (2004). Sensory processing, reading, IQ, and attention. Journal of Experimental Child Psychology, 88, 274-295.

Jolliffe, I. T. (1972). Discarding variables in a principal component analysis: I. Artificial data. Applied Statistics, 21, 160-173.

Jolliffe, I. T. (1986). Principal component analysis. New York: Springer-Verlag.

Kail, R., \& Hall, L. K. (1994). Processing speed, naming speed, and reading. Developmental Psychology, 30, 949-954.

Kaiser, H. F. (1960). The application of electronic computers to factor analysis. Educational and Psychological Measurement, 20, 141-151.

Katz, L., \& Frost, R. (1992). The reading process is different for different orthographies: The orthographic depth hypothesis. In L. Katz \& R. Frost (Eds.), Orthography, phonology, morphology, and meaning. Oxford, UK: North-Holland.

Katz, L., \& Shankweiler, D. (1985). Repetitive naming and the detection of word retrieval deficits in the beginning reader. Cortex, 21, 617-625.

Kirby, J. R., Parrila, R. K., \& Pfeiffer, S. L. (2003). Naming speed and phonological awareness as predictors of reading development. Journal of Educational Psychology, 95, 453-464.

Landerl, K., Frith, U., \& Wimmer, H. (1996). Intrusion of orthographic knowledge on phoneme awareness: Strong in normal readers, weak in dyslexic readers. Applied Psycholinguistics, 17, 1-14.

Landerl, K., \& Wimmer, H. (2008). Development of word reading fluency and spelling in a consistent orthography: An 8-year follow-up. Journal of Educational Psychology, 100, 150-161.

Landerl, K., Wimmer, H., \& Frith, U. (1997). The impact of orthographic consistency on dyslexia: A German-English comparison. Cognition, 63, 315-334. 
Levy, B. A., Bourassa, D. C., \& Horn, C. (1999). Fast and slow namers: Benefits of segmentation and whole word training. Journal of Experimental Child Psychology, 73, 115-138.

Liao, C.-H., Georgiou, G. K., \& Parrila, R. (2008). Rapid naming speed and Chinese character recognition. Reading and Writing: An Interdisciplinary Journal, 21, 231-253.

Lovett, M. W., Steinbach, K. A., \& Frijters, J. C. (2000). Remediating the core deficits of developmental reading disability: A double-deficit perspective. Journal of Learning Disabilities, 33, 334-358.

Lyon, G. R., Shaywitz, S. E., \& Shaywitz, B. A. (2003). A definition of dyslexia. Annals of Dyslexia, 53, 1-14.

Manis, F. R., Doi, L. M., \& Bhadha, B. (2000). Naming speed, phonological awareness, and orthographic knowledge in second graders. Journal of Learning Disabilities, 33, 325-333. 374.

McBride-Chang, C., \& Manis, F. R. (1996). Structural invariance in the associations of naming speed, phonological awareness, and verbal reasoning in good and poor readers: A test of the double deficit hypothesis. Reading and Writing: An Interdisciplinary Journal, 8, 323-339.

Morris, R. D., Stuebing, K. K., Fletcher, J. M., Shaywitz, S. E., Lyon, G. R., Shankweiler, D. P., et al (1998). Subtypes of reading disability: Variability around a phonological core. Journal of Educational Psychology, 90, 347-373.

Neuhaus, G. F., \& Swank, P. R. (2002). Understanding the relations between RAN letter subtest components and word reading in first-grade students. Journal of Learning Disabilities, 35, 158-174.

Patel, T. K., Snowling, M. J., \& De Jong, P. F. (2004). A cross-linguistic comparison of children learning to read in English and Dutch. Journal of Educational Psychology, 96, 785-797.

Pennington, B. F., Cardoso-Martins, C., Green, P. A., \& Lefly, D. L. (2001). Comparing the phonological and double deficit hypotheses for developmental dyslexia. Reading and Writing: An Interdisciplinary Journal, 14, 707-755.

Perre, L., \& Ziegler, J. C. (2008). On-line activation of orthography in spoken word recognition. Brain Research, 1188, 132-138.

Plaza, M., \& Cohen, H. (2004). Predictive influence of phonological processing, morphological/ syntactic skill, and naming speed on spelling performance. Brain and Cognition, 55, 368-373.

Savage, R. (2004). Motor skills, automaticity, and developmental dyslexia: A review of the research literature. Reading and Writing: An Interdisciplinary Journal, 17, 301-324.

Savage, R., Pillay, V., \& Melidona, S. (2007). Deconstructing rapid automatized naming: Component processes and the prediction of reading difficulties. Learning and Individual Differences, 17, 129146.

Savage, R., Pillay, V., \& Melidona, S. (2008). Rapid serial naming is a unique predictor of spelling in children. Journal of Learning Disabilities, 41, 235-250.

Schatschneider, C., Carlson, C. D., Francis, D. J., Foorman, B. R., \& Fletcher, J. M. (2002). Relationship of rapid automatized naming and phonological awareness in early reading development: Implications for the double-deficit hypothesis. Journal of Learning Disabilities, 35, 245-256.

Spector, J. E. (2005). Instability of double-deficit subtypes among at-risk first grade readers. Reading Psychology, 26, 285-312.

Sunseth, K., \& Bowers, P. G. (2002). Rapid naming and phonemic awareness: Contributions to reading, spelling, and orthographic knowledge. Scientific Studies of Reading, 6, 401-429. 
Swanson, H. L., Trainin, G., Necoechea, D. M., \& Hammil, D. D. (2003). Rapid naming, phonological awareness, and reading: A meta-analysis of the correlational evidence. Review of Educational Research, 73, 407-440.

Torgesen, J. K., Wagner, R. K., \& Rashotte, C. A. (1994). Longitudinal studies of phonological processing and reading. Journal of Learning Disabilities, 27, 276-286.

Torgesen, J. K., Wagner, R. K., Rashotte, C. A., Burgess, S. R., \& Hecht, S. A. (1997). Contributions of phonological awareness and rapid automatic naming ability to the growth of word-reading skills in second- to fifth-grade children. Scientific Studies of Reading, 1, 161-185.

Vaessen, A.A., \& Blomert, L. (2008). Naming speed co-varies with development of automatic word recognition. Paper presented at the annual meeting of the Cognitive Neuroscience Society, San Francisco.

Vaessen, A. A., \& Blomert, L. (2009). Cognitive dynamics of the development of fluent word reading. In revision.

Van den Bos, K. P. (1998). IQ, phonological awareness, and continuous naming speed related to poor decoding children's performance on two word identification tests. Dyslexia, 4, 73-89.

Van den Bos, K. P. (2003). Snel Serieel Benoemen (SSB) [Rapid Serial Naming. Unpublished experimental version]. Groningen, The Netherlands: Rijksuniversiteit Groningen.

Van den Bos, K. P., Lutje Spelberg, H. C., Scheepstra, A. J. M., \& de Vries, J. (1994). De Klepel. Vorm A en B. Een test voor de leesvaardigheid van pseudowoorden. [The 'clapper'. Form A and B. A test of pseudo-word reading ability]. Nijmegen, The Netherlands: Berkhout.

Van den Bos, K. P., Zijlstra, B. J. H., \& lutje Spelberg, H. C. (2002). Life-span data on continuous-naming speeds of numbers, letters, colors, and pictured objects, and word-reading speed. Scientific Studies of Reading, 6, 25-49.

Van den Bos, K. P., Zijlstra, B. J. H., \& Van den Broeck, W. (2003). Specific relations between alphanumeric-naming speed and reading speeds of monosyllabic and multisyllabic words. Applied Psycholinguistics, 24, 407-430.

Vellutino, F. R. (1979). Dyslexia: Theory and research. Cambridge, MA: MIT Press.

Vellutino, F. R., Fletcher, J. M., Snowling, M. J., \& Scanlon, D. M. (2004). Specific reading disability (dyslexia): What have we learned in the past four decades? Journal of Child Psychology and Psychiatry, $45,2-40$.

Vukovic, R. K., \& Siegel, L. S. (2006). The double-deficit hypothesis: A comprehensive analysis of the evidence. Journal of Learning Disabilities, 39, 25-47.

Vukovic, R. K., Wilson, A. M., \& Nash, K. K. (2004). Naming speed deficits in adults with reading disabilities: A test of the double deficit hypothesis. Journal of Learning Disabilities, 37, 440-450.

Wagner, R. K., \& Torgesen, J. K. (1987). The nature of phonological processing and its causal role in the acquisition of reading skills. Psychological Bulletin, 101, 192-212.

Wagner, R. K., Torgesen, J. K., Laughon, P., Simmons, K., \& Rashotte, C. A. (1993). Development of young readers' phonological processing abilities. Journal of Educational Psychology, 85, 83-103.

Wagner, R. K., Torgesen, J. K., \& Rashotte, C. A. (1994). Development of reading-related phonological processing abilities: New evidence of bidirectional causality from a latent variable longitudinal study. Developmental Psychology, 30, 73-87. 
Wagner, R. K., Torgesen, J. K., Rashotte, C. A., Hecht, S. A., Barker, T. A., Burgess, S. R., et al (1997). Changing relations between phonological processing abilities and word-level reading as children develop from beginning to skilled readers: A 5-year longitudinal study. Developmental Psychology, 33, 468-479.

Wile, L. T., \& Borowsky, R. (2004). What does rapid automatized naming measure? A new RAN task compared to naming and lexical decision. Brain and Language, 90, 47-62.

Wimmer, H. (1996). The nonword reading deficit in developmental dyslexia: Evidence from children learning to read German. Journal of Experimental Child Psychology, 61, 80-90.

Wimmer, H., \& Hummer, P. (1990). How German-speaking first graders read and spell: Doubts on the importance of the logographic stage. Applied Psycholinguistics, 11, 349-368.

Wimmer, H., \& Mayringer, H. (2001). Is the reading-rate problem of German dyslexic children caused by slow visual processes? In M. Wolf (Ed.), Dyslexia, fluency, and the brain (pp. 93-102). Timonium, MD: York.

Wimmer, H., \& Mayringer, H. (2002). Dysfluent reading in the absence of spelling difficulties: A specific disability in regular orthographies. Journal of Educational Psychology, 94, 272-277.

Wimmer, H., Mayringer, H., \& Landerl, K. (1998). Poor reading: A deficit in skill-automatization or a phonological deficit? Scientific Studies of Reading, 2, 321-340.

Wimmer, H., Mayringer, H., \& Landerl, K. (2000). The double-deficit hypothesis and difficulties in learning to read a regular orthography. Journal of Educational Psychology, 92, 668-680.

WISC-R, Project Group (1986). Wechsler Intelligence Scale for Children-Revised. Lisse, The Netherlands (in Dutch).

Wolf, M. (1986). Rapid alternating stimulus naming in the developmental dyslexias. Brain and Language, 27, 360-379.

Wolf, M. (1991). The word-retrieval deficit hypothesis and developmental dyslexia. Learning and Individual Differences, 3, 205-223.

Wolf, M. (1997). A provisional, integrative account of phonological and naming-speed deficits in dyslexia: Implications for diagnosis and intervention. In B. A. Blachman \& A. Benita (Eds.), Foundations of reading acquisition and dyslexia: Implications for early intervention (pp. 67-92). Mahwah, NJ: Lawrence Erlbaum.

Wolf, M., Bally, H., \& Morris, R. (1986). Automaticity, retrieval processes, and reading: A longitudinal study in average and impaired readers. Child Development, 57, 988-1000.

Wolf, M., \& Bowers, P. G. (1999). The double-deficit hypothesis for the developmental dyslexias. Journal of Educational Psychology, 91, 415-438.

Wolf, M., Bowers, P. G., \& Biddle, K. (2000). Naming-speed processes, timing, and reading: A conceptual review. Journal of Learning Disabilities, 33, 387-407.

Yap, R., \& Van der Leij, A. (1993). Word processing in dyslexics: An automatic decoding deficit? Reading and Writing: An Interdisciplinary Journal, 5, 261-279.

Ziegler, J. C., \& Goswami, U. (2005). Reading acquisition, developmental dyslexia, and skilled reading across languages: A psycholinguistic grain size theory. Psychological Bulletin, 131, 3-29.

Ziegler, J. C., \& Muneaux, M. (2007). Orthographic facilitation and phonological inhibition in spoken word recognition: A developmental study. Psychonomic Bulletin Review, 14, 75-80. 

Chapter 7

Summary and Discussion 


\subsection{Summary of the main findings}

This thesis set out to investigate the cognitive dynamics of reading and spelling development. First, we examined the cognitive development of fluent reading in a large school sample from grade 1 to 6 (chapter 2). Most models of reading development assume a shift from slow, sequential phonological decoding to fast, automatic word recognition (e.g. Ehri, 1995; Frith, 1985; Marsh, Friedman, Welsh, \& Desberg, 1981; Share, 1995) with increasing reading proficiency. Since phonological awareness (PA) seems to be more closely related to phonological decoding and rapid automatized naming (RAN) more closely related to automatic word recognition (e.g. Clarke, Hulme, \& Snowling, 2005; Manis, Doi, \& Bhadha, 2000; Manis, Seidenberg, \& Doi, 1999; Wile \& Borowsky, 2004), we hypothesized that the shift in reading strategy implies a concomitant shift in the relative importance of these skills. In line with our expectations, the results showed that the relative weight of the cognitive contributions of PA and RAN to word reading fluency changed over time, although both skills substantially contributed to fluent reading performance in all grades. More specifically, the contribution of PA to word reading fluency was strong in beginning readers, but diminished with increasing reading experience. On the other hand, the contribution of RAN to word reading fluency was modest in beginning readers but gradually increased over time. This cognitive shift was more pronounced for high-frequency (HF) words than for low-frequency (LF) words; RAN was the most important contributor to HF word reading fluency from the third grade on, but its contribution to LF word reading fluency only dominated that of PA in grade 5. PA remained the most important contributor to pseudoword reading fluency, although RAN also explained a substantial part of the variance in pseudoword reading fluency. In sum, the results imply that the relative weight of the cognitive skills underlying fluent reading depends both on level of reading expertise and of word familiarity.

In chapter 3 and 4 , we investigated whether the relative importance of the cognitive predictors of (fluent) word reading was modulated by orthographic consistency of a language. In chapter 3 the cognitive predictors of reading were studied in second graders from five European writing systems lying on a continuum from transparent to relatively opaque (Finnish, Hungarian, Dutch, Portuguese, and French). The results showed that PA was the most important predictor in all countries (except Finnish, were the contribution of vocabulary was equally strong). Interestingly, the strength of the contribution of PA was modulated by orthographic consistency; PA was more important for reading in opaque orthographies than it was in transparent orthographies.

In chapter 4 we more closely examined the influence of orthographic consistency on the cognitive dynamics of reading development from grade 1 to 4 in three languages (Hungarian, Dutch, and Portuguese). We were especially interested in the 
question whether the cognitive shift observed in Dutch readers (see chapter 2) could also be observed in other orthographies. The results suggest that the overall pattern of results did not differ between countries: the contributions of PA diminished over years, while the contributions of RAN increased in all orthographies. Thus, the cognitive shift observed in Dutch readers seemed to be rather universal. Moreover, the impact of letter-speech sound (LSS) knowledge also decreased over years in all orthographies. However, in concordance with what was found in chapter 3, PA accuracy and LSS processing played a more important and protracted role in opaque orthographies. In contrast, PA speed was more important in transparent orthographies.

In chapter 5, we investigated in how far spelling and reading share the same underlying cognitive mechanisms. The results indicate that reading and spelling only partly rely on common cognitive processes; while reading and spelling both were influenced by PA and LSS knowledge (at least in beginning readers), only reading and not spelling performance was influenced by RAN. Furthermore, the shared variance between reading and spelling was for a large part mediated by individual differences in PA and LSS, suggesting that the major common cognitive source for reading and spelling is phonological analysis and decoding. Since the influence of these phonological skills on fluent word reading seems to diminish over years (see chapter 2 and 4), the proportion of variance shared between spelling and word reading fluency also declined.

Finally, in chapter 6 we examined the impact of cognitive deficits on the development of reading and spelling skills in children with developmental dyslexia from grade 1 to 6 . Since PA and RAN seem to be related to different aspects of reading (PA seems to be most strongly related to phonological decoding, while RAN is strongly related to automatic word recognition), it has been hypothesized that weak performance on RAN tasks reflect a underlying deficit that is relatively independent from a phonological deficit (the double deficit hypothesis of Wolf \& Bowers, 1993, 1999). This would imply that dyslexic children with naming problems have a qualitatively different underlying deficit than children with phonological problems, and hence might even require different kind of therapies. However, the results did not support the hypothesis that RAN reflects a second, independent core deficit in dyslexia. $90 \%$ of the children with RAN problems also showed phonological problems of some kind, and those children that did show RAN problems in the absence of phonological problems did not show a qualitatively different pattern of reading and spelling difficulties than children with phonological problems. Moreover, the children with RAN and PA problems did not show more severe reading and spelling problems than children with a only RAN or only PA difficulties, which would be expected if deficits were independent and effects were additive. Finally, the results of the factor analysis suggested that although the RAN task had a phonological speed component as well as a general speed component, it was just the phonological 
speed component that predicted reading performance the best. It was concluded that RAN is a phonological speed task with an important addition that is not captured by traditional phonological tasks; fast, efficient matching of visual/orthographic information to its phonological codes. Phonological as well as RAN problems are probably different manifestations of the same underlying core deficit; phonological processing.

\subsection{Implications for universal models of reading development}

The fact that PA and LSS are strong predictors of reading fluency of all word types in the first grades in all tested languages (chapter 2-4) is in accordance with claims that phonological decoding is the basis of learning to read in all alphabetic scripts (e.g. Caravolas, 2005; Ehri et al., 2001; Share, 2008). However, with increasing reading expertise, children are able to recognize more and more words by sight, and consequently individual differences in PA and LSS knowledge have less impact on word reading (chapter 2 and 4 ). It is important to notice that the declining impact of PA and LSS does not necessarily imply that fluent reading in experienced readers does not involve phonological processing. On the contrary, numerous studies with adolescents and adults have indicated that even during silent reading tasks phonological information is automatically activated (e.g. Lukatela, Eaton, Lee, \& Turvey, 2001; Lukatela \& Turvey, 1991, 1994; Van Orden, Johnston, \& Hale, 1988). Moreover, orthography and phonology even get more closely integrated with increasing reading proficiency (Booth, Perfetti, \& MacWhinney, 1999). The declining influence of PA and LSS on word reading fluency does however indicate that the type of phonological processing picked up by these tasks (e.g. fine-grained phonological analysis and decoding) have less impact on word reading fluency in experienced readers.

In contrast, other (phonological) cognitive processes, like fast automatic recognition of orthographic patterns and matching of visual-orthographic information to phonological codes, showed an increasing influence on fluent word reading, which seems to be reflected by the growing relationship between RAN and word reading fluency (see also Berninger, Abbott, Billingsley, \& Nagy, 2001; Bowers \& Ishaik, 2003; Wimmer, Mayringer, \& Landerl, 1998). The fact that the shift in the relative importance of PA and RAN occurred earlier in time for HF words than for LF words is in line with Shares' claim that the transition from phonological decoding to fastautomatic word recognition is item-based rather than stage-based (see introduction). Since most words will be virtually unfamiliar to beginner readers, most words have to be deciphered phonologically, which is in line with the strong influence of PA on reading fluency of all word types in beginner readers. However, frequent 
exposure to words forms the opportunity to build up word-specific orthographic representations (Share, 1995; 1999). HF words will therefore be recognized by sight a relatively early phases of reading development, and consequently the need for fine-grained phonological analysis for HF word reading will reduce rather quickly. Children will be less often exposed to words with a low frequency of occurrence, and consequently they will have to rely for a longer period of time on phonological decoding skills when reading LF words. In experienced readers, phonological decoding will predominantly be used for reading very rare words or pseudowords, probably reflected by the stable contribution of PA to pseudoword reading fluency until grade 6 (chapter 2). The fact that RAN also strongly contributed to pseudoword reading fluency seems to be in line with Ehri's view on sight word learning; she proposes that advanced readers are not only able to match whole words to their phonological counterpart, but also other multi-graphemic units such as morphemes, onset, rhymes and syllables (Ehri, 2005).

The results of chapter 4 showed that PA and LSS knowledge were relatively more involved in reading fluency and for a longer period of time in opaque orthographies compared to transparent orthographies. However, eventually the contributions of these phonological decoding skills on word reading fluency decreased in all three orthographies (Hungarian, Dutch and Portuguese), while the influence of RAN on word reading fluency systematically increased. Moreover, in higher grades, the impact of orthographic consistency on the strength of the contributions of PA and LSS diminished, possibly suggesting that skilled reading relies on rather similar cognitive processes in opaque and transparent orthographies. The results seem to imply that orthographic consistency does not so much affect the architecture of the reading network (as for instance is suggested by the strong version of the orthographic depth hypothesis, Katz \& Frost, 1992), but rather the rate at which the reading system develops. The beginning and end state of the process of learning to read are probably universal for all alphabetic scripts (Share, 2008). Phonological decoding is a universal element for the initial acquisition of literacy skills, while the quintessence of skilled reading in all orthographies is to automatically and effortlessly recognize word by sight. If our hypothesis that the shift in the importance of PA and RAN reflects this transition from phonological decoding to fast, automatic word recognition is correct, it is expected that this cognitive shift can be observed even in an extremely opaque orthography like English (although the time window might be much wider). In line with this assumption, some English-language studies including a wide age-range also demonstrated a shift in the relative importance of PA and/or RAN to word reading (Badian, 2001; Kirby, Parrila, \& Pfeiffer, 2003), and several studies with adult readers showed a strong influence of RAN to word reading fluency (e.g. Cirino, Israelian, Morris, \& Morris, 2005; Wile \& Borowsky, 2004).

The stronger and more long-lasting involvement of PA in reading in opaque orthographies observed in chapter 3 and 4 can probably be explained by the fact that 
reading develops at a slower rate in orthographically opaque languages (e.g. Seymour, Aro, \& Erskine, 2003). That is, the ambiguous letter-speech sound correspondences make it more difficult to understand the alphabetic structure of a language, and children are forced to rely on more elaborate, complex decoding strategies (Goswami and Ziegler, 2005). Therefore, it costs more time and effort to acquire fluent reading skills, and consequently fine-grained phonological analysis and decoding remains important for a longer period of time. It is important to notice that this explanation implies that orthographic consistency does not impact the overall importance of the cognitive skills underlying fluent reading development, but rather the rate at which the reading system develops. This would also explain why the impact of orthographic consistency was stronger in grade 1 and 2 than in later grades (chapter 4); in earlier grades the difference in reading level between the three languages was rather strong, and consequently differences in relative importance of PA for reading fluency will be relatively large. In contrast, in higher grades children from all three orthographies probably strongly rely on automatic recognition of word forms during word reading, and differences between orthographies will be reduced. As Share (2008) argues: "phonological awareness is likely to be equally important in consistent and inconsistent orthographies but at different phases in development" (page 598).

To make a final note, orthographic consistency is just one factor that might influence the rate of reading development; other linguistic features of a language (rhythmic aspects of syllables; Duncan, Cole, Seymour, \& Magnan, 2006; syllabic complexity; Seymour et al., 2003), as well as non-linguistic factors such as a countries' instructional method (Rayner, Foorman, Perfetti, Pesetsky, \& Seidenberg, 2001; Ziegler \& Goswami, 2006), school support system (Ise et al., submitted), ecomonic status and level of parental education might also affect the rate of reading development, and consequently developmental course of the relationship between PA, LSS knowledge, RAN and reading fluency. However, it should be noticed that despite large differences in linguistic and non-linguistic factors between countries, the overall developmental pattern of the cognitive contributions to reading fluency is remarkably similar in languages differing in orthographic consistency, pointing to a universal cognitive development of reading.

\subsection{Link to brain models of reading development}

Although it would be beyond the scope of this thesis to give a full overview of the brain areas involved in reading, it is worth mentioning that some electrophysiological and brain imaging studies provided evidence for the gradually increasing involvement of visual word recognition skills in reading. The most relevant brain imaging findings concern the so-called "Visual Word Form Area" (VWFA). The VWFA is an 
area in the left occipitotemporal region centered on the mid-fusiform gyrus (see e.g. McCandliss, Cohen, \& Dehaene, 2003), which responds more strongly to visual words compared to other complex unfamiliar stimuli, and even more strongly words than to pseudowords (Kronbichler et al., 2007; Kronbichler et al., 2004). According to Schlaggar and McCandliss (2007), the primary function of the VWFA during reading is "to support a form of perceptual expertise for visual word recognition that enables rapid perception of visual words in one's own language". During the acquisition of reading skills, the VWFA is thought to show a progressive specialization for visual word forms (McCandliss et al., 2003). In line with this claim, two developmental fMRI-studies (Sandak et al., 2004; Shaywitz et al., 2004) demonstrated an increased activity of the VWFA as a function of reading proficiency.

More evidence for the increasing involvement of visual word recognition skills comes from electrophysiological studies showing that the N170-component (which is thought to reflect perceptual specialization for visual word forms) gradually became more sensitive to visual word forms with increasing reading experience (Mauer, Brem, Bucher, \& Brandeis, 2005; Posner \& McCandliss, 1999) and this N170 components even continued to develop into adulthood (Brem et al., 2006).

Although linking these brain data to the behavioral data in the present thesis is of course speculative, there seem to be some clear parallels between the functional specialization of the neural mechanisms subserving visual word recognition and our results regarding the changing role of RAN in reading fluency. First, we found a gradual increase in the importance of RAN to word reading over the whole primary school which seems to be in line with the increasing specialization of the VWFA for reading fluency reported above. Second, the fact that the strength of the relationship between RAN and word reading partly depended on word familiarity seems to be in accordance with the finding that 10-years old only show an adult-like N200 response to high-frequency words but not to pseudowords (Posner \& McCandliss, $1999)$ and with the results of Kronbichler et al $(2007 ; 2004)$ showing that word frequency modulated activation in the VWFA in adults. These results indicate a close link between cognitive processes reflected by RAN performance and the automatic recognition of visual word forms by left-hemisphere areas including the midfusiform area.

\subsection{The (in)dependence of RAN and PA}

The results of chapter 2 and 4 indicate that RAN and PA are related to different aspects of reading (RAN was more strongly related to automatic visual word recognition, and PA was more strongly related to phonological decoding). This might indicate that RAN and PA represent two relatively independent cognitive processes that can be independently impaired in dyslexic children (as claimed by the double 
deficit hypothesis Wolf, 1991; Wolf \& Bowers, 1999). However, the results of chapter 6 do not seem to support the existence of a second, core, naming deficit that is independent from a phonological deficit. Many dyslexics with naming problems also showed phonological problems and the pattern of reading and spelling problems did not qualitatively differ between different deficit subtypes. Moreover, alphanumeric RAN and phonological speed loaded on one factor in the factor analysis, and this factor was highly predictive for reading performance. Although RAN also loaded on a general non-phonological speed factor, this factor was not strongly related to reading skills. This result seems in line with a language-specific perspective (e.g. Savage, 2004; Wimmer \& Mayringer, 2001) rather than a general speed perspective on the RAN-reading relationship (Catts, Gillispie, Leonard, Kail, \& Miller, 2002; Kail \& Hall, 1994). Thus, RAN does not seem to tap an independent cognitive process which can be selectively impaired in dyslexics. But why then does RAN contribute uniquely to reading fluency (chapter 2, 4 and 6) and why does it seem to relate to different components of reading than phonological awareness (chapter 2 and 4)?

First of all, it should be noticed that PA tasks and RAN tasks require rather different cognitive skills. PA tasks for instance involve the segmentation of words into their phonological units, a skill that is particularly important when words have to be decoded letter-by-letter. RAN tasks in contrast require the fast recognition of wellknown visual symbols, the efficient cross-modal matching of visual and phonological information, and retrieval of phonological codes from memory, skills that are particularly important for skilled, fluent word reading. Therefore it is not surprising that these tasks relate to different aspects of reading. Nevertheless, a deficit in phonological processing might affect performance on rapid naming tasks as well as phonological awareness tasks; that is, a phonological deficit might impair both the ability to manipulate the sound structure of a word as well as the ability to quickly match visual information to their phonological counterparts or to retrieve phonological codes from memory. Thus, problems on RAN and PA may be different manifestations of the same underlying phonological deficit (Clarke et al., 2005; Katz \& Shankweiler, 1985; Torgesen, Wagner, \& Rashotte, 1994; Wagner, Torgesen, Laughon, Simmons, \& Rashotte, 1993).

Moreover, cognitive models as well as brain models of reading development suggest that phonological decoding is crucial for the development of visual word recognition skills (i.e. the functional specialization of the VWFA), and difficulties with phonological decoding might have a cascading effect on the development of visual word recognition skills (McCandliss \& Noble, 2003). The different components of the reading network are thus strongly connected and interdependent, as might be the cognitive skills underlying these components. Furthermore, performance on PA tasks as well RAN tasks might be reciprocally related to the development of reading and spelling skills (for RAN see Bowey \& Miller, 2007; for PA see Perfetti, Beck, Bell, \& Hughes, 1987; Wagner \& Torgesen, 1987; Wimmer, Landerl, Linortner, 
\& Hummer, 1991; Ziegler \& Goswami, 2005), making it particularly difficult to distinguish cause from consequence. Thus, the unique contributions of RAN and PA to different aspects of reading does not necessarily imply that these tasks tap from independent sources, and impaired performance on RAN tasks does not automatically point to an underlying cognitive deficit that is independent from phonological processing.

To summarize the main conclusions of this thesis; the results point to the existence of one interactive reading network over the course of development, in which type of preferred processing (i.e. fine-grained phonological decoding or mapping of orthographic word patterns to phonological codes) as well as processing load depends on reading expertise and word familiarity. Orthographic consistency affects the rate of reading development, and thus the time window in which certain cognitive skills are important for fluent word reading. That is, the ambiguous letter-sound correspondences in orthographically opaque languages might be a stumbling block for the basic understanding of the alphabetic principle of a language, and might ask for more complex, elaborate decoding strategies (Ziegler \& Goswami, 2005). Therefore, learning to read fluently and accurately costs more time and effort, and consequently fine-grained phonological analysis and decoding of words might be important for word reading for a longer period of time. However, we suggest that eventually the cognitive development of reading will follow a similar pattern in all alphabetic orthographies, and that the cognitive ingredients of the reading network are fairly universal. 


\section{References}

Badian, N. A. (2001). Phonological and orthographic processing: Their roles in reading prediction. Annals of Dyslexia, 51, 179-202.

Berninger, V. W., Abbott, R. D., Billingsley, F., \& Nagy, W. (2001). Processes underlying timing and fluency: efficiency, automaticity, coordination and morphological awareness. In M. Wolf (Ed.), Dyslexia, fluency and the brain (pp. 383-414). Timonium, MD: York Press.

Booth, J. R., Perfetti, C. A., \& MacWhinney, B. (1999). Quick, automatic, and general activation of orthographic and phonological representations in young readers. Developmental Psychology, 35(1), 3-19.

Bowers, P. G., \& Ishaik, G. (2003). RAN's contribution to understanding reading disabilities. In S. Graham, H. Swanson \& K. R. Lee Harris (Eds.), Handbook of learning disabilities (pp. 140-157). New York, US: Guilford Press.

Bowey, J. A., \& Miller, R. (2007). correlates of orthographic learning in third-grade children's silent reading. Journal of Research in Reading, 30(2), 115-128.

Brem, S., Bucher, K., Halder, P., Summers, P., Dietrich, T., Martin, E., et al. (2006). Evidence for developmental changes in the visual word processing network beyond adolencence. Neuroimage, 29(3), 822-837.

Catts, H. W., Gillispie, M., Leonard, L. B., Kail, R. V., \& Miller, C. A. (2002). The role of speed of processing, rapid naming, and phonological awareness in reading achievement. Journal of Learning Disabilities, 35(6), 510-525.

Cirino, P., Israelian, M. K., Morris, M. K., \& Morris, R. D. (2005). Evaluation of the Double Deficit Hypothesis in College Students Referred for Learning Difficulties. Journal of Learning Disabilities, 38(1), 29-44.

Clarke, P., Hulme, C., \& Snowling, M. (2005). Individual differences in RAN and reading: A response timing analysis. Journal of Research in Reading, 28(2), 73-86.

Duncan, L. G., Cole, P., Seymour, P. H., \& Magnan, A. (2006). Differing sequences of metaphonological development in French and English. Journal of Child Language, 33(2), 369-399.

Ehri, L. C. (1995). Phases of development in learning to read words by sight. Journal of Research in Reading, $18,116-125$.

Ehri, L. C. (2005). Development of sight word reading: Phases and findings. In M. J. Snowling \& C. Hulme (Eds.), The Science of Reading: A Handbook (pp. 135-154). Oxford: Blackwell publishing.

Frith, U. (1985). Beneath the surface of developmental dyslexia. . In K. E. Patterson, J. C. Marshhall \& M. Coltheart (Eds.), Surface Dyslexia (pp. 301-322). London: Erlbaum.

Georgiou, G. K., Parilla, R., \& Papadopoulos, T. C. (2008). Predictors of word decoding and reading fluency across languages varying in orthographic consistency. Journal of Educational Psychology, 100, 566-580.

Ise, E., Blomert, L., Bertrand, D., Faísca, L., Puolakanaho, A., Saine, N., et al. (submitted). Profiling poor reader support systems - empirical data from six EU-member states.

Kail, R., \& Hall, L. K. (1994). Processing speed, naming speed, and reading. Developmental Psychology, 30(6), 949-954.

Katz, L., \& Frost, R. (1992). The reading process is different for different orthographies: the orthographic depth hypothesis. In L. Katz \& R. Frost (Eds.), Orthography, phonology, morphology and meaning. Oxford, England:: North-Holland. 
Katz, L., \& Shankweiler, D. (1985). Repetitive naming and the detection of word retrieval deficits in the beginning reader. Cortex, 21(4), 617-625.

Kirby, J. R., Parrila, R. K., \& Pfeiffer, S. L. (2003). Naming speed and phonological awareness as predictors of reading development. Journal of Educational Psychology, 95(3), 453-464.

Kronbichler, M., Bergmann, J., Hutzler, F., Staffen, W., Mair, A., Ladurner, G., et al. (2007). Taxi vs. taksi: on orthographic word recognition in the left ventral occipitotemporal cortex. Journal of cognitive neuroscience, 19(10), 1584-1594.

Kronbichler, M., Hutzler, F., Wimmer, H., Mair, A., Staffen, W., \& Ladurner, G. (2004). The visual word form area and the frequency with which words are encountered: evidence from a parametric $f M R I$ study. Neuroimage, 21(3), 946-953.

Lukatela, G., Eaton, T., Lee, C., \& Turvey, M. T. (2001). Does visual word identification involve a subphonemic level? Cognition, 78(3), B41-B52.

Lukatela, G., \& Turvey, M. T. (1991). Phonological access of the lexicon: evidence from associative priming with homophones. Journal of Experimental Psychology: Human Perception and Performance, 17(4), 951-966.

Lukatela, G., \& Turvey, M. T. (1994). Visual lexical access is initially phonological: 1. evidence from associative priming by words, homophones, and pseudohomophones. Journal of Experimental Psychology: General, 123(2), 107-128.

Manis, F. R., Doi, L. M., \& Bhadha, B. (2000). Naming speed, phonological awareness, and orthographic knowledge in second graders. Journal of Learning Disabilities, 33(4), 325-333, 374.

Manis, F. R., Seidenberg, M. S., \& Doi, L. M. (1999). See Dick RAN: Rapid naming and the longitudinal prediction of reading subskills in first and second graders. Scientific Studies of Reading, 3(2), 129157.

Marsh, G., Friedman, M., Welsh, V., \& Desberg, P. (1981). A cognitive developmental theory of reading acquisition. . In G. MacKinnon \& T. Walker (Eds.), Reading research: advances in theory and practice (pp. 199-211). New York: Academic Press.

Mauer, U., Brem, S., Bucher, K., \& Brandeis, D. (2005). emerging neurophysiological specialization for letter strings. Journal of Cognitive Neuroscience, 17, 1532-1552.

McCandliss, B. D., Cohen, L., \& Dehaene, S. (2003). The visual word form area: Expertise for reading in the fusiform gyrus. Trends in Cognitive Sciences, 7(7), 293-299.

McCandliss, B. D., \& Noble, K. G. (2003). The development of reading impairment: a cognitive neuroscience model. Mental Retardation and Developmental Disabilities Research Review, 9(3), 196-204.

Perfetti, C. A., Beck, I., Bell, L. C., \& Hughes, C. (1987). phonemic knowledge and learning to read are reciprocal: a longitudinal study of first grade children. Merill-Palmer Quarterly, 33(3), 283-319.

Posner, M., \& McCandliss, B. D. (1999). brain circuity during reading. In R. M. Klein \& P. A. McMullen (Eds.), Converging Methods for Understanding Reading and Dyslexia (pp. 305-337): MIT Press.

Rayner, K., Foorman, B. R., Perfetti, C. A., Pesetsky, D., \& Seidenberg, M. S. (2001). How psychological science informs the teaching of reading. Psychological science in the public interest, 2(2), 31-74.

Sandak, R., Mencl, W. E., Frost, S. J., Rueckl, J. G., Katz, L., Moore, D. L., et al. (2004). The neurobiology of adaptive learning in reading: a contrast of different training conditions. Cognitive Affective Behavioral Neuroscience, 4(1), 67-88. 
Savage, R. (2004). Motor skills, automaticity and developmental dyslexia: A review of the research literature. Reading and Writing: An Interdisciplinary Journal, 17, 301-324.

Schlaggar, B. L., \& McCandliss, B. D. (2007). Development of neural systems for reading. Annual Review of Neuroscience, $30,475-503$.

Seymour, P., Aro, M., \& Erskine, J. (2003). Foundation literacy acquisition in European orthographies. British Journal of Psychology, 94(2), 143-174.

Share, D. L. (1995). Phonological recoding and self-teaching: sine qua non of reading acquisition. Cognition, 55, 151-218.

Share, D. L. (2008). On the Anglocentricities of current reading research and practice: The perils of overreliance on an 'outlier' orthography. Psychological Bulletin, 134(4), 584-615.

Shaywitz, B. A., Shaywitz, S. E., Blachman, B. A., Pugh, K. R., Fulbright, R. K., Skudlarski, P., et al. (2004). Development of left occipitotemporal systems for skilled reading in children after a phonologicallybased intervention. Biological Psychiatry, 55(9), 926-933.

Torgesen, J. K., Wagner, R. K., \& Rashotte, C. A. (1994). Longitudinal studies of phonological processing and reading. Journal of Learning Disabilities, 27(5), 276-291.

Van Orden, G. C., Johnston, J. C., \& Hale, B. L. (1988). Word identification in reading proceeds from spelling to sound to meaning. Journal of Experimental Psychology: Learning, Memory, and Cognition, 14(3), 371-386.

Wagner, R. K., \& Torgesen, J. K. (1987). The nature of phonological processing and its causal role in the acquisition of reading skills. Psychological Bulletin, 101(2), 192-212.

Wagner, R. K., Torgesen, J. K., Laughon, P., Simmons, K., \& Rashotte, C. A. (1993). Development of young readers' phonological processing abilities. Journal of Educational Psychology, 85(1), 83-103.

Wile, L. T., \& Borowsky, R. (2004). What does rapid automatized naming measure? A new RAN task compared to naming and lexical decision. Brain and Language, 90, 47-62.

Wimmer, H., Landerl, K., Linortner, R., \& Hummer, P. (1991). The relationship of phonemic awareness to reading acquisition: more consequence than precondition but still important. Cognition, 40(3), 219249.

Wimmer, H., \& Mayringer, H. (2001). Is the reading-rate problem of German dyslexic children caused by slow visual processes? In M. Wolf (Ed.), Dyslexia, fluency, and the brain. (pp. 93-102). Timonium, MD: York Press.

Wimmer, H., Mayringer, H., \& Landerl, K. (1998). Poor reading:b a deficit in skill-automatization or a phonological deficit? Scientific Studies of Reading, 2, 321-340.

Wolf, M. (1991). The word-retrieval deficit hypothesis and developmental dyslexia. Learning and Individual Differences, 3(3), 205-223.

Wolf, M., \& Bowers, P. G. (1999). The double-deficit hypothesis for the developmental dyslexias. Journal of Educational Psychology, 91(3), 415-438.

Ziegler, J., \& Goswami, U. (2006). Becoming literate in different languages: similar problems, different solutions. . Developmental Sciences, 9 (5), 429-453.

Ziegler, J. C., \& Goswami, U. (2005). Reading acquisition, developmental dyslexia, and skilled reading across languages: a psycholinguistic grain size theory. Psychological Bulletin, 131(1), 3-29. 


\section{Nederlandse samenvatting}

In onze moderne samenleving is vloeiend leren lezen en spellen van cruciaal belang voor een goede economische en sociale toekomst. Mensen met lees- en spellingsproblemen ondervinden vaak ernstige beperkingen tijdens hun opleiding en hun werksituatie, en komen vaak uiteindelijk op een lager opleidingsniveau of werkniveau terecht dan op basis van hun intelligentie en sociale capaciteiten verwacht mag worden. Daarom is het van groot belang te onderzoeken hoe lezen en spellen zich ontwikkelen, en waar het bij dyslectische lezers mis gaat.

Hoewel lezen en spellen voor beginnende lezers en dyslectische lezers een langzaam, moeizaam proces is, kunnen normaallezende volwassenen binnen $250 \mathrm{~ms}$ woorden herkennen, en kunnen ze de schrijfwijze van duizenden woorden correct reproduceren. Dit duidt op het bestaan van een hoog geautomatiseerd lees- en spellingssysteem in onze hersenen. Toch zijn lezen en spellen in evolutionair opzicht 'nieuwe' vaardigheden; het eerste schrift is pas zo'n 5500 jaar geleden ontstaan, en pas recent zijn lezen en spellen een vast onderdeel van ons dagelijks leven. Daarom is het zeer onwaarschijnlijk dat wij een gespecialiseerde cognitieve 'module' voor lezen en spellen hebben in onze hersenen. In plaats daarvan wordt gedacht dat tijdens de leesontwikkeling bepaalde aangeboren visuele en auditieve processen gerekruteerd en voor lezen en spellen gespecialiseerd worden. Om te begrijpen hoe lees-en spellingsvaardigheden zich ontwikkelen is het daarom van groot belang de onderliggende cognitieve processen van lezen en spellen te onderzoeken. Het doel van dit proefschrift is daarom ook om de cognitieve ontwikkeling van het lezen en spellen in kaart te brengen, en te onderzoeken welke onderliggende processen bij dyslexie verstoord zijn.

De eerste studie in deze thesis (hoofdstuk 2 ) bestudeert de cognitieve ontwikkeling van het lezen. Men gaat er vanuit dat er bij normale lezers tijdens de ontwikkeling een 'shift' plaatsvindt van langzaam letter-voor-letter (fonologisch) decoderen van woorden naar het snel herkennen van hele woordvormen. Hoe en wanneer deze shift plaatsvindt is echter nog niet helemaal duidelijk. Eén manier om deze shift in leesstrategieën te onderzoeken is om te kijken naar de onderliggende cognitieve processen bij lezen. Twee belangrijke cognitieve vaardigheden die sterk met lezen samenhangen zijn fonologische verwerking (PA) en snel benoemen (RAN). PA taken meten de vaardigheid om spraakklanken binnen een woord te kunnen herkennen, segmenteren en manipuleren van deze klanken, en de prestatie op deze taken lijkt sterk samen te hangen met het fonologisch decoderen van woorden. Bij RAN taken moeten kinderen zo snel mogelijk bekende visuele informatie benoemen (bv. plaatjes, letters, cijfers), en de prestatie op deze taken hangt sterk samen met automatische woordherkenning. Als er tijdens de leesontwikkeling inderdaad een verandering plaatsvindt in gebruik van leesstrategie, valt te verwachten dat het 
belang van deze onderliggende processen voor lezen ook verandert. Daarom is in hoofdstuk twee de ontwikkeling van de relatie tussen PA, RAN en lezen onderzocht in normaal-lezende Nederlandse leerlingen van groep 3 tot groep 8. Uit de resultaten blijkt dat de verwachte shift in leesstrategieën inderdaad gereflecteerd wordt in een graduele verandering in de sterkte van de samenhang tussen deze twee cognitieve vaardigheden en leesprestatie: terwijl fonologische vaardigheden vooral een belangrijke rol spelen bij lezen in beginnende lezers, hangt RAN voornamelijk sterk samen met woord lezen in meer ervaren lezers. Deze cognitieve shift is echter niet stapsgewijs maar gradueel: beide vaardigheden spelen een rol bij lezen op alle geteste tijdstippen, maar de sterkte van de samenhang verandert over tijd. Bovendien wordt deze cognitieve shift beïnvloed door de frequentie van de te lezen woorden. Het lezen van hoogfrequente (bekende) woorden vertoont al vanaf groep 5 een sterkere samenhang met RAN dan met PA, terwijl het lezen van laagfrequente woorden of pseudowoorden veel langer met PA blijft samenhangen. De resultaten duiden sterk op het bestaan van een interactief netwerk voor lezen, waarbij de sterkte van de bijdrage van de specifieke processen binnen dit netwerk afhangt van zowel leeservaring als bekendheid met een woord.

Hoewel de resultaten van hoofdstuk 2 veelbelovend zijn, is kennis over de generaliseerbaarheid van de resultaten naar andere talen beperkt omdat bij dit onderzoek alleen Nederlandse kinderen deelnamen. Daarom is in de studies uit hoofdstuk $\mathbf{3}$ en $\mathbf{4}$ onderzocht in hoeverre de cognitieve ontwikkeling van lezen en spellen wordt beïnvloed voor door de orthografische consistentie van een taal. Verschillende talen hebben namelijk een verschillende mate van consistentie in hun letterspraakklank relaties. Het Fins bijvoorbeeld, heeft een zeer hoge orthografische consistentie; een letter wordt altijd door één spraakklank gerepresenteerd en andersom. Het Engels, daarentegen, heeft zeer inconsistente letterspraakklank relaties en een letter kan op meerdere manieren uitgesproken worden, afhankelijk van de woordcontext. Andere Europese talen vallen wat betreft orthografische consistentie ergens tussen Fins en Engels in. De vraag is nu in hoeverre de orthografische consistentie (oftewel de transparantie van een taal) invloed heeft op de cognitieve ontwikkeling van het leessysteem. Sommige theorieën gaan ervan uit dat bij het lezen van een taal met een lage orthografische consistentie (niet-transparante talen) voornamelijk gebruik wordt gemaakt van hele woordherkenning (omdat het decoderen van deze woorden vaak tot een niet-correcte uitspraak leidt), terwijl in transparante talen lezers probleemloos gebruik kunnen blijven maken van fonologisch decoderen. Met andere woorden, de karakteristieken van een taal zou dus medebepalend kunnen zijn voor de ontwikkeling van het leessysteem. In hoofdstuk $\mathbf{3}$ is bij beginnende lezers afkomstig uit 5 Europese landen (Finland, Hongarije, Nederland, Portugal en Frankrijk) onderzocht in hoeverre orthografische consistentie de sterkte van de samenhang tussen onderliggende cognitieve processen en lezen beïnvloedt. Hieruit blijkt dat fonologische verwerking (PA) een grotere rol speelt bij 
lezen in niet-transparante talen (zoals Frans) dan in transparante talen (zoals Fins). Echter, het is van belang op te merken dat PA een samenhang met lezen vertoont in álle talen, onafhankelijk van de orthografische consistentie. In hoofdstuk $\mathbf{4}$ is de invloed van orthografische consistentie van een taal op de cognitieve ontwikkeling van het lezen onderzocht in Hongaarse, Nederlandse en Portugese kinderen van groep 3 tot 6 . De hoofdvraag was of de cognitieve 'shift' die gevonden werd in $\mathrm{Ne}$ derlandse leerlingen in hoofdstuk 2 ook geobserveerd kan worden in talen met een andere orthografische opbouw. Uit de resultaten bleek dat in alle onderzochte talen de shift in de relatieve samenhang van PA en RAN plaatsvond. Daarnaast bleek dat de tijdslijn van deze shift beïnvloedt wordt door de orthografische consistentie van een taal. Dat wil zeggen, in minder transparante talen vond deze verschuiving later plaats dan in transparante talen (PA bleef langer een rol spelen in niet-transparante talen). De resultaten van hoofdstuk 3 en 4 suggereren dat het cognitieve leessysteem zich op dezelfde manier ontwikkelt in verschillende talen, maar dat de snelheid van de ontwikkeling beïnvloedt wordt door de transparantie van een taal.

In hoofdstuk $\mathbf{5}$ is de cognitieve ontwikkeling van het spellen onderzocht. Vanwege de vrij sterke samenhang tussen de prestatie op lezen en spellen wordt er vaak van uit gegaan dat spellen en lezen twee kanten van dezelfde munt zijn, implicerend dat deze twee vaardigheden grotendeels een gezamenlijke cognitieve basis hebben. Echter, de resultaten van eerder onderzoek duiden erop dat spellen en lezen zowel van gezamenlijke als unieke cognitieve processen gebruik maken. In hoofdstuk 5 is daarom onderzocht in hoeverre drie cognitieve processen die een rol spelen bij de leesontwikkeling (PA, RAN en letterspraakklank integratie) ook een rol spelen bij de spellingsontwikkeling. Uit de resultaten blijkt dat in beginnende lezers/spellers PA en letterspraakklank integratie sterk samenhangen met zowel lezen als spellen, en deze twee vaardigheden vormen samen de gemeenschappelijke cognitieve basis voor lezen en spellen. In oudere kinderen neemt het belang van deze fonologische vaardigheden voor lezen af, maar voor spellen blijven ze een belangrijke rol spelen. RAN daarentegen hangt alleen met lezen en niet spellen samen, ook niet met de snelheid van spellen. Deze resultaten duiden er op dat lezen en spellen slechts gedeeltelijk een gezamenlijke cognitieve basis hebben (voor beiden is in het beginstadium een goede fonologische verwerking en een goede letter-klank integratie nodig). Naarmate kinderen meer ervaren lezers en spellers zijn neemt het belang van gezamelijke cognitieve factoren af en worden cognitieve processen die uniek zijn voor lezen of spellen van groter belang (bv. snelle automatische herkenning van woorden bij lezen).

Tenslotte is in de studie uit hoofdstuk 6 onderzocht welke cognitieve processen verstoord zijn bij kinderen met dyslexie. De fonologische-deficiet hypothese gaat ervan uit dat dyslectische lezers een fonologisch tekort hebben (onder andere merkbaar door hun slechte prestatie op PA taken) dat hun lees-en spellingsproblemen veroorzaakt. Echter, veel dyslectische lezers presteren ook slecht op RAN ta- 
ken. Dit zou kunnen betekenen dat benoemproblemen een tweede, onafhankelijk deficiet representeren. Het is echter ook mogelijk dat één onderliggende stoornis (i.e.. een fonologische deficiet) de prestatie op beide taken beïnvloedt. Als er sprake is van twee onafhankelijke stoornissen, dan zou men verwachten dat RAN en PA beiden een onafhankelijke bijdrage leveren aan de lees-en spellingsprestatie, en dat de prestatie op RAN en PA taken onderling weinig samenhangt. Daarnaast zou men verwachten dat RAN en PA problemen onafhankelijk van elkaar voorkomen (dus dat een groep kinderen alléén op een taak uitvalt maar niet op de ander). Bovendien zouden kinderen met alleen RAN problematiek een ander lees-en spellingspatroon moeten vertonen dan kinderen met alleen PA problemen, en kinderen met uitval op beide taken de meest ernstige problematiek zouden de meest ernstige uitval hebben omdat zij twee stoornissen hebben die beiden een onafhankelijke invloed hebben op hun lees- en spellingsproblemen. Uit de resultaten van de studie in hoofdstuk 6 bleek dat voor de meerderheid van deze assumpties geen ondersteuning gevonden werd: hoewel RAN en PA beiden inderdaad een onafhankelijke bijdrage leverden aan de leessnelheid van dyslectici, bleek het lees- en spellingspatroon van kinderen met alleen RAN problematiek of alleen PA problematiek niet sterk te verschillen. Bovendien waren de problemen van kinderen met RAN en PA problematiek niet veel ernstiger dan die van kinderen met PA óf RAN problemen. Verder bleek het overgrote gedeelte van de kinderen met RAN problemen ook PA problemen te hebben (90\%). Tenslotte bleek dat RAN een sterke fonologische snelheidscomponent heeft, en dat deze component een sterke samenhang met lezen vertoond. Geconcludeerd werd dan ook dat bij dyslexie één onderliggende stoornis (i.e. een fonologisch deficiet) de problemen op zowel PA als RAN kan verklaren.

Ter conclusie: de resultaten van dit proefschrift duiden op het bestaan van een interactief netwerk voor lezen, waarbij het type van verwerking (fonologisch decoderen of automatische herkenning van hele woorden) afhankelijk is van zowel leeservaring als de bekendheid met een woord. Sommige processen spelen (bijvoorbeeld het fonologisch decoderen) spelen vooral een belangrijke rol bij beginnende lezers en onbekende woorden. Andere processen (het snel kunnen koppelen van visuele woordvormen aan hun fonologische code) worden vooral gebruikt door ervaren lezers en bij bekende woorden. Verder beïnvloedt de mate van orthografische consistentie van een taal de snelheid waarmee het leessysteem zich ontwikkeld, maar niet noodzakelijk de architectuur van het leessysteem. Waarschijnlijk zijn de inconsistente letter-klank relaties in niet-transparante talen een struikelblok voor het begrijpen van de fonologische structuur van een taal, en zijn meer uitgebreide fonologische decoderingsstrategieën nodig voor het leren lezen in een niettransparante taal. Echter, de ontwikkeling van lezen volgt eenzelfde patroon in talen met verschillende transparantie en de uiteindelijke architectuur van het leessysteem lijkt universeel. 


\section{Dankwoord}

De periode waarin ik als $\mathrm{PhD}$ aan de Universiteit van Maastricht verbonden ben geweest kan ik oprecht beschouwen als een zeer belangrijke periode in mijn leven, niet alleen op het gebied van werkervaring, maar ook op het gebied van persoonlijke ontwikkeling en vriendschappen. De totstandkoming van mijn proefschrift is uiteraard niet vanzelf gegaan en heeft een hoop tijd en inzet gekost, niet alleen van mijzelf maar ook van anderen om mij heen. Daarom wil ik graag degenen bedanken die direct of indirect hebben bijgedragen aan de totstandkoming van dit proefschrift.

Ten eerste wil ik mijn promotor, Leo Blomert, bedanken voor de mooie kans om op dit project te werken en er mijn proefschrift over te schrijven. Je wist hoe belangrijk het voor me is om een maatschappelijk relevante invalshoek bij een onderzoek te hebben, en met dit onderwerp is duidelijk aan die eis voldaan. Je begeleiding bij het opzetten van dit grootschaalse onderzoek met tientallen testmedewerkers, evenzoveel scholen en dyslexie instituten en honderden kinderen was onontbeerlijk, evenals je begeleiding bij het schrijven van de artikelen.

Verder wil ik graag alle mensen bedanken die een rol hebben gespeeld in het goede verloop van dit project. Gonny, Kim, Dries, Lilian, Hanne, en Nadia, jullie waren al in het beginstadium bij het project betrokken en hebben immens geholpen bij het ontwikkelen van de taken, het testen van kinderen en/of het analyseren van een deel van de data. Zonder jullie had ik hier waarschijnlijk nu niet gezeten!

Barbra, Tamara, Jolanda, Hilde, Tessa, Natalie, Liesbeth, Inez, Carine, Tijmen, Damaris, Saskia, Ceacile, Loes, Janneke, Manon, Malu, Nienke, Marije en Miriam (hopelijk ben ik niemand vergeten), jullie hebben een onvergetelijke bijdrage geleverd door enorm grote groepen kinderen te testen op scholen door heel het land!

Daarnaast wil ik de medewerkers van alle RID's in Nederland bedanken voor hun bijdrage aan het inzamelen van data van dyslectische kinderen en het diagnosticeren van de kinderen die door ons werden doorverwezen. Vooral Patty en Michel hebben onvermoeibaar meegewerkt om te zorgen dat het project op rolletjes liep binnen het RID. Ook wil ik alle participerende scholen en ouders bedanken voor hun medewerking en steun aan het onderzoek.

During the second period as a PhD student, I worked together with several excellent European research groups from Marseille (France), Budapest (Hungary), Faro (Portugal), Munchen (Germany) and Jyväskylä (Finland). This cooperation was an unforgettable learning experience and served as a great opportunity to travel to beautiful 
places and meet interesting people. Denes, Valeria, Alexandra, Luis, Jo, Daisy, Gerd, Elena and Heikki, thank you for the great collaboration, the outstanding research papers that were a result of this collabaration, you hospitality, and your willingness to share information and knowledge! Denes and Daisy, thanks for your statistical and methodological guidance and help.

Ik wil Annemie en Riny van het secretariaat bedanken voor hun hulp tijdens mijn $\mathrm{PhD}$ studentschap. Annemie, bedankt voor je geduld en flexibele houding als ik weer eens vergeten was hoe een bepaalde procedure werkt of als ik te laat was met het inleveren met mijn declaraties, en bedankt voor de prettige gesprekken op persoonlijk vlak! Jacco en Johan, bedankt voor jullie technische ondersteuning, en Joost en Michiel bedankt voor het programmeren van enkele van de computertaken.

I would like to thank my $\mathrm{CN}$ collegues for the nice atmosphere at work as well as outside. I very much enjoyed all the diners, parties, and special events!

Een aantal van mijn collega's zijn veel meer dan alleen collega's geworden, en die wil ik daarom extra bedanken. Ten eerste natuurlijk mijn paranimfen, Petra en Gonny. Gonny, jij bent heel lang mijn kamergenote geweest, en wat mis ik nu onze gesprekken (zowel over werk als persoonlijke zaken), onze lunch- en koffiepauzes en het gevoel altijd een vriendin direct naast je te hebben! Gelukkig is wel gebleken dat onze vriendschap ook met iets meer afstand even sterk blijft. Petra, bedankt voor je luisterend oor, je steun en je vriendschap de afgelopen jaren. Meiden, ik hoop dat we als we oud en rimpelig zijn nog steeds gezellig met z'n drieën kunnen kletsen!

Daarnaast wil ik ook mijn andere lunch/klets/stap/reismaatjes bedanken voor de broodnodige afleiding van het werken aan mijn proefschrift in de vorm van gezellige lunches, etentjes, vakanties en feestjes. Dries, Noel en Vera, de California trip samen met Petra en Gonny was onvergetelijk. Dries, jij was de onbetwiste leider van het gezelschap, en altijd de eerste tot wie wij ons wendden in geval van nood (Dries!! De camper piept!!). Vera, we hebben een hoop fijne gesprekken gehad, en ik weet nu officieel wie ik uit kies als ik nog eens samen met iemand een hotelkamer moet delen! Noel, met jou hoef je je nooit te vervelen 's avonds bij het kampvuur. Jeannette, bedankt voor alle gezelligheid tijdens de lunches en pauzes, en onze gesprekken (af en toe zijn we echt niet af te remmen he!). Teresa, bedankt voor alle gezellige lunches en fijn dat ik bij jou met al mijn aanstaande-moeder vragen terecht kan. Federico, thanks for you friendship and thanks for organizing all the nice barbecues, parties, picnics etc. I miss our movie dates! Anke, you're great company, and always brighten up our social events. Lars $\mathrm{H}$. and Roberta, thanks for being such nice and friendly roommates. 
Ook buiten het Universitaire wereldje zijn er een aantal mensen die ik wil bedanken. Tessa, jij was altijd een luisterend oor op de momenten dat ik het even niet meer zag zitten, en onze ontelbare etentjes en stapavonden waren een heerlijke afwisseling van het werkend leven. Meriam en Jessy, ondanks dat we nu allemaal in een andere hoek van het land wonen hebben we het toch voor elkaar gekregen onze vriendschap die begon in onze studententijd voort te zetten, en daar ben ik heel blij om! Marijke, jij woont zelfs nog verder weg, maar als we elkaar spreken over de telefoon lijkt het alsof we elkaar nog elke dag zien. Bedankt voor alle fijne gesprekken en de steun afgelopen jaren! Saskia, ik heb na mijn eigen promotie nog meer bewondering voor het feit dat jij met twee zwangerschappen toch je promotie binnen de tijd hebt afgerond. Hoe heb je het voor elkaar gekregen!

Pap en mam, wat ben ik blij met jullie als ouders. Het is een onbeschrijflijk gevoel te weten dat ik altijd op jullie onvoorwaardelijke steun kan rekenen. Jullie hebben mij gestimuleerd om hard te werken en het vertrouwen gegeven dat ik kan bereiken wat ik maar wil. Tegelijkertijd hebben jullie me echter nooit het gevoel gegeven te moeten presteren, en ik wist altijd dat jullie hoe dan ook trots op me zijn en voor me klaar staan. Dat heeft een sterke basis gelegd voor mijn karakter en leven! Bram, Maarten en Thijs, mijn drie broertjes, bedankt voor alle warmte en gezelligheid die jullie in ons gezinsleven hebben gebracht. Hopelijk gaan er nog heel veel leuke familievakanties komen!

Er is nog een belangrijk persoon over die ik nog niet heb bedankt. Paul, mijn lieve maatje, bedankt dat je altijd geduldig naar mijn verhalen en frustraties over het werk hebt geluisterd, dat je voor me zorgde en kookte als ik na een lange dag uitgeput thuis kwam, en dat je me hielp relativeren en afstand nemen van het werk. Bedankt voor alle mooie momenten die we samen hebben gedeeld de afgelopen 10 jaar. 



\section{Curriculum Vitae}

Anniek Vaessen was born September $30^{\text {th }} 1979$ in Hoensbroek, The Netherlands. She attended Sintermeerten College in Heerlen and obtained her VWO diploma in June 1997. In September 1997, she started studying psychology at the University of Maastricht. From 1999 to 2001, she was a teaching assistant in several first and second year Psychology courses. In 2001, she started her internship at the University of Konstanz, Germany. She investigated brain activation patterns during (anti)saccadic eye-movements in schizophrenic patients under supervision of Drs. J. Kissler and Dr. Prof. B. Rockstroh (external supervisors) and Dr. Leo Blomert (internal supervisor). Back in Maastricht (in September 2001) she started working as a student research assistant for Dr. Blomert meanwhile writing her master thesis. In 2002 , she graduated with a specialisation in neuropsychology. Directly after graduation, she was employed at the Regional Institute for Dyslexia (RID) Maastricht. Next to her work as a diagnostician and therapist she conducted several research tasks. During this period, she investigated the effectiveness of the treatment for dyslexia provided at the RID. In 2004, she started working as a research assistant at the University of Maastricht. In the beginning of this period, she went to Jyväskylä for a Marie-Curie Host Fellowship for 6 weeks. There, she worked on the development of new online diagnostic tests for dyslexia and adapted an existing training program for phoneme-grapheme correspondences to the Dutch language. When she got back in August 2004, she started working on the evaluation of existing diagnostic tasks for dyslexia. In 2005, she started as a PhD student at the department of Cognitive Neuroscience. During her PhD studentship she conducted the studies described in this thesis under supervision of Prof. Dr. Blomert. Her thesis was approved in September 2009. Anniek will continue to work at the department of Cognitive Neuroscience as a post-doc researcher. 